\title{
REVISION DER WÜRMTERRASSEN \\ IM RHEINTAL \\ ZWISCHEN DIESSENHOFEN UND KOBLENZ
}

Albert Leemann

\section{A. EINLEITUNG}

\section{Das Arbeitsgebiet}

Auf Anregung von Herrn Prof. Dr. H. Boesch, Direktor des Geographischen Institutes der Universität Zürich, begann ich im Sommer 1954 mit den quartärmorphologischen Untersuchungen in meinem Arbeitsgebiet, das sich vorerst längs des Rheines von Schaffhausen bis nach Kaiserstuhl erstreckte und dort an das von Bugmann bearbeitete Gebiet des nordöstlichen Teiles des Kantons Aargau grenzt. Nachdem ich vor allem in den Gebieten der Siegfriedblätter 24 (Hüntwangen), 26 (Kaiserstuhl), 27 (Eglisau), 40 (Steinmaur) und 41 (Bülach) kartiert hatte, wandte sich mein Interesse einzelnen Spezialfragen im Gebiete von Weiach-Kaiserstuhl zu. Im Einverständnis mit Herrn Prof. Dr. H. Boesch arbeitete ich eingehend an diesen Detailstudien im zürcherisch-aargauischen Grenzgebiet des Rheines, im bewußten Gegensatz zu den bis anhin großräumig geführten Untersuchungen anderer Autoren stehend. In einem erweiterten Untersuchungsgebiet - rheinaufwärts bis Dießenhofen, rheinabwärts bis Koblenz - wurden die gewonnenen Ergebnisse geprüft und angewandt; dies führte zu einer Revision der Würmterrassen im Hochrheingebiet.

\section{Problemstellung}

Die vorliegende Arbeit beschäftigt sich mit geomorphologischen Untersuchungen im Rheintal zwischen Dießenhofen und Koblenz. Besprochen werden vor allem Oberflächenformen, die auf die Würmeiszeit und die nachfolgende Zeit zurückzuführen sind. Mein Untersuchungsgebiet ist schon mehrfach in großräumige Arbeiten einbezogen worden; ich erinnere an die Werke von Du PasQuier 1891 (60), Penck 1901 (61), Penck und BrǘcKner 1901-1909 (62), Hug 1907 (36) und 1909 (37), Göhringer 1915 (109), Heim 1919 (31), Erb 1936 (17), Zink 1940 (98), Suter 1944 (79), Huber 1956 (34). Nebst diesen Autoren haben in benachbarten Gebieten gearbeitet: WeBer 1928 (87) und 1934 (88), Stein 1948 (76), Bugmann 1954 (12) und 1956 (13). Bisher sind mit Ausnahme der Arbeiten Bugmanns keine Resultate aus diesem Gebiete bekannt, die sich auf die Ergebnisse der neueren Periglazialforschung stützen.

Ein Teil der geomorphologischen Gletschervorfeld-Untersuchungen befaßt sich mit den verschiedenen Akkumulations- und Erosionsformen des Pleistozäns; daraus versucht man rückschließend, sich über die verschiedenen formbildenden Kräfte ins Bild zu setzen. Von deutschen Autoren vor allem (Büdel, Poser, Schäfer, Troll) werden Kastentäler, asymmetrische Täler, Dellen usw. beschrieben, Formen, die wir auch im schweizerischen würmextramoränischen Gebiet häufig antreffen können. Nebst diesen «klassischen» Periglazialbildungen finden sich tief in die Terrassenhänge eingeschnittene Gräben, bis jetzt vor allem im untersten Aaretal (BugMANN, 13) und längs des Rheines festgestellt. In der folgenden Arbeit sei versucht, diese wenig beachteten Formen in die Untersuchung miteinzubeziehen.

Meine Untersuchung gliedert sich in folgende Abschnitte:

1. einen methodischen Teil, in dem zugleich das Tatsachenmaterial gesammelt wird. Auf Grund eingehender Detailuntersuchungen im Raume von Weiach- 
Kaiserstuhl, Windlach und des Rafzerfeldes soll gezeigt werden, wie man

a) die Natur der Formschaffung,

b) den Zeitpunkt der Schaffung einzelner Formelemente nach neuen Arbeitsmethoden bestimmen kann.

2. einen den Interpretationen gewidmeten Teil.

a) Die bisherigen Auffassungen werden kurz besprochen und korreliert.

b) Wie modifizieren meine Ansichten, gewonnen auf Grund der Detailstudien, das bisherige Bild der Genese, das weitgehend auf großräumigen Untersu. chungen beruht?

Im ersten Abschnitt sollen folgende Teilprobleme erarbeitet werden:

Dellen und Gräben in der Umgebung von Weiach und ihre Beziehung zur Talgeschichte. Dabei ergeben sich Fragen nach:

- den genauen geologischen Verhältnissen bei Weiach-Kaiserstuhl, vor allem der Schotterauflagerungsfläche.

- der Akkumulationsperiode der Würmschotter.

- der Unterscheidung von Akkumulations- und Erosionsterrassen.

- der Unterteilung der Würmeiszeit.

- der Erweiterung der Gräben; der Förderung von Erosion und Denudation.*

Die Periglazialtälchen südlich von Wil.

- Art ihrer Entstehung und Altersbestimmung.

- Wie lange fand sich ein Dauerfrostboden vor?

Die auf das Rütifeld (nördlich von Windlach) ausmündenden Periglazialtälchen.

- Ihre Entstehung und Datierung.

Der zweite Abschnitt ist der Genese gewidmet. Die gesammelten Tatsachen und Teillösungen der Detailstudien werden in einen erweiterten Rahmen gestellt. Die Untersuchungen führen dabei zu einer Revision der Würmablagerungs- und -erosionsverhältnisse im Rheingebiet, die sich durch Bugmanns Untersuchungen im untersten Aaretal aufgedrängt hat. Es wird versucht, folgende Fragen zu beantworten:

Woher rührt der Wechsel von ausgeprägter Seitenerosion zu einer intensiven Tiefenerosion im Rafzerfeld während der Würmeiszeit?

Die Unterteilung der Talentstehung in Phasen.

Kann diese Mehrphasigkeit rheinaufwärts und -abwärts verfolgt werden, oder ist die Entwicklung in den verschiedenen Abschnitten eigenständig?

Bei den Untersuchungen wird das Augenmerk ferner kurz auf folgende Probleme gerichtet, die im Rahmen meiner Dissertation nicht erarbeitet werden können und noch der Lösung harren:

- die Mittelterrasse im Rheingebiet.

- der praewürmische Rheinverlauf.

- der Rheincañon zwischen Rüdlingen und Tössegg und seine Entstehung.

- die den «Würmendmoränen» vorgelagerten Wälle auf der Akkumulationsfläche des Windlacherfeldes.

\section{Geologische Grundlagen}

Die «Geologische Karte des Kantons Zürich und der Nachbargebiete» (Suter 1939) und die «Geologische Generalkarte der Schweiz», Blatt 3 (1950) geben einen

* Unter der Denudation verstehe ich den flächenhaften Abtrag. 
Überblick über mein Arbeitsgebiet; in ihnen sind die Resultate verschiedener Forscher zusammengefaßt. (Mösch, 1867: Aargauer Jura und nördliche Gebiete des Kantons Zürich; Hug, 1905: Kaiserstuhl, Andelfingen, Rheinfall; GöHringer, 1915: Lienheim; Schalch und Göhringer, 1921: Jestetten-Schaffhausen; Schalch, 1922: Grießen; Weber, 1928: Tößtal, Unteres Glattal; Heim und Hübscher, 1931: Rheinfall.)

Detaillierte Angaben finden sich ferner im «Exkursionsführer in der Umgebung von Zürich », 1946: Suter, Exkursion 20: Wehntal-Kaiserstuhl ; Weber, Exkursion 21 : Seebach-Glattbrugg-Kloten-Bülach - Eglisau - Rüdlingen - Irchel - Winterthur ; Peyer, Exkursion 22: Kohlfirst; HüBscher, Exkursion 23: Klettgau-Randen.

Der Dissertation von Stein (76) ist eine zusammenfassende geologische Karte des Glattales beigelegt. vON BRAUN hat 1953 die Resultate seiner geologischen und sedimentpetrographischen Untersuchungen im Hochrheingebiet zwischen Zurzach und Eglisau veröffentlicht (5). Bugmanss Diplomarbeit (12) enthält eine geologische Karte des untersten Aaretales.

Das Untersuchungsgebiet liegt im Bereich mehrerer geologischer Einheiten (voN BraUn, 5, p. 145):

1. Im Schlüchtal nördlich Waldshut tritt das Kristallin des Schwarzwaldmassivs zutage.

2. Tafeljura; der Nordrand mit der Steilstufe gegen das Klettgau kann als südwestliche Fortsetzung der Schwäbischen Alb aufgefaßt werden.

3. Von Südosten greift das Molassebecken herein.

4. Zwischen 2 und 3 liegt eine Zwitterbildung von Tafel- und Kettenjura: eine in ziemlich flache Antiklinalen und Synklinalen gegliederte Mesozoikum-TertiärSerie.

Es sind vorwiegend glaziale und fluvioglaziale Vorgänge des Quartärs, die das Bild meines Arbeitsgebietes geprägt haben; Ablagerungen der Eiszeiten verhüllen weitgehend die Untergrundsverhältnisse.

Weber (87, p. 4-6) beschreibt die Tektonik der Molasseschichten, gestützt auf den Befund früherer Autoren, als sehr einfach;

«Im oberen Tößtal sind es die nach NW einsinkenden tortonischen Nagelfluhmassen, im Tößunterlauf die zum Jurarand aufsteigenden Sandstein- und Mergelschichten der unteren, marinen und oberen Molasse, die zeigerı, daß die Molasse eine große, ungefähr $50 \mathrm{~km}$ weit gespannte Mulde bildet. Ein flaches, kleines Gewölbe mit WSW-ENE-Streichen ist von C. MösCH und L. BENDEL beschrieben worden.»

Demgegenüber stellt vON BRAUN (5, p. 153-155) bei seinen Untersuchungen eine recht bedeutende Struktuierung fest:

a) Eine vermutlich praeeozäne Kippachse; Hebung im NW und N.

b) Die untere Süßwassermolasse transgredierte diskordant über ein tektonisch bedingtes Malmrelief hinweg. Malmkulmination ohne klare Antiklinalstruktur. Flexur der Malmunterlage zwischen Rheinsfelden und Weiach. Die praeaquitanen Flexuren werden später zu Antiklinalen aufgefaltet.

c) Prae- und Intravindobon: Wechsel von Transgressions- und Regressionsperioden. Heraushebung des nordwestlichen Hinterlandes. Eventuell bereits Abzeichnung späterer schwacher Depressionen und Kulminationen als Vorläufer späterer Mulden und Antiklinalen.

d) Postvindobon: Bildung von Synklinalen und Antiklinalen im Zusammenhang mit der Juraauffaltung: Lienheimer Mulde, Siglistorfer Antiklinale, Windlacher Mulde, Irchel Antiklinale. Der Südschenkel der Siglistorfer Antiklinale bildet gleichzeitig den Nordschenkel der Lengnauer Mulde. Aus der prae- 
aquitan angelegten Endinger Flexur entwickelt sich die Siglistorfer Antiklinale, die Windlacher Mulde aus der Weiacher Depression.

Im Gegensatz zu anderen Autoren lehnt von BraUn das Vorhandensein intradiluvialer Störungen ab.

Im Norden von Schaffhausen tritt der Randen als Endglied des Tafeljuras auf. Stratigraphisch stimmt er mit dem Schwäbischen Jura überein. Vom Bodensee ist der Randen durch die abgesunkene Hegauscholle getrennt, die mit miozänen Ablagerungen und vulkanischen Bildungen angefüllt ist (Ḧ̈вSCHER, 35, p. 145).

Die starke geologische Gliederung, verbunden mit dem Wechsel petrographischer Verhältnisse, wirkt sich auch auf die Morphologie der Landschaft aus. Klar ausgeprägte, scharfe Formen können sich im Kalk, in der Nagelfluh, in hartem Sandstein und im Schotter bilden. In Mergeln und lehmigen Sanden angelegte Hänge sind meistens unausgeglichener, aber sanfter gestaltet. Das Verlagern des Flußbettes von weichem auf härteres Gestein führt zur Bildung von Schwellen, die als lokale Erosionsbasen wirken und so die Erosionsintensität oberhalb dieser Stellen zu beeinflussen vermögen. In den nachfolgenden Untersuchungen wird den verschiedenen formbestimmenden Faktoren eingehende Beachtung geschenkt werden.

\section{B. UN'TERSUCHUNG \\ UND LÖSUNG VON DETAILPROBLEMEN IM KERNGEBIET \\ I. Dellen und Gräben in der Umgebung von Weiach und ihre Beziehung zur Talgeschichte}

\section{Vorkommen}

Die Rheingräben und Dellen können ihrer Lage gemäß in 2 Kategorien eingeteilt werden: Höher gelegene Gräben und Dellen, tiefer gelegene Gräben.

Auf dem Blatt 26 des Topographischen Atlas der Schweiz (Kaiserstuhl) sowie auf der Landeskarte der Schweiz 1:25000 (Eglisau, Blatt 1051) sind diese Formen verzeichnet. Die höher gelegenen Gräben und Dellen liegen am Nordabhang des Sanzenberges; als Hangbezeichnungen finden sich: Wingert, Frankenhalde, Saxenholz, Siechenbuck (Koordinatengerade $673200 / 268400$ bis $674500 / 267500$ ). Die tiefer gelegenen Gräben sind in der Rheinhalde angelegt; zum Teil sind sie mit Namen bezeichnet: Griesgraben, Sädel, Kaibengraben (letzterer auch Stubengraben genannt). Weitere kleine unbenannte Grabenanrisse liegen in der Rheinhalde (Koordinatengerade $674500 / 268625$ bis $676000 / 269125$ ).

Die in meiner Arbeit erwähnten Höhenkoten beziehen sich durchwegs auf den neuen Ausgangshorizont von 373,60 m. Um zur Übereinstimmung mit den Höhenangaben der Siegfriedblätter zu gelangen, addiere man zu'meinen Angaben 3,26 m. Die Koordinaten beziehen sich auf die Landeskarte der Schweiz.

\section{Untersuchung der Gräben und Dellen}

\section{a) Höher gelegene Gräben und Dellen}

Sämtliche höher gelegenen Gräben und Dellen sind in älterem Material als NTSchotter angelegt; sie reißen ein typisch leicht gewelltes HT-Plateau zwischen einer Höhe von $425 \mathrm{~m}$ und $435 \mathrm{~m}$ an und durchbrechen dann mehr oder weniger intensiv den HT-Terrassenhang. Die Hauptdelle (Fig. 1, 1) mündet im Terrassenhang, $6 \mathrm{~m}$ oberhalb der obersten NT-Terrassenfläche aus, während die Gräben und das Frankenhaldetal auf die Terrasssenfläche auslaufen, dabei Schuttkegel aufschüttend. In beiliegender Skizze (Fig. 1) sind Lage und Namen der einzelnen Erscheinungen aufgeführt. (Über das Gebiet der Gemeinde Weiach existiert ein Plan 1:5000, angefer- 


\section{Höher gelegene Gräben und Dellen}

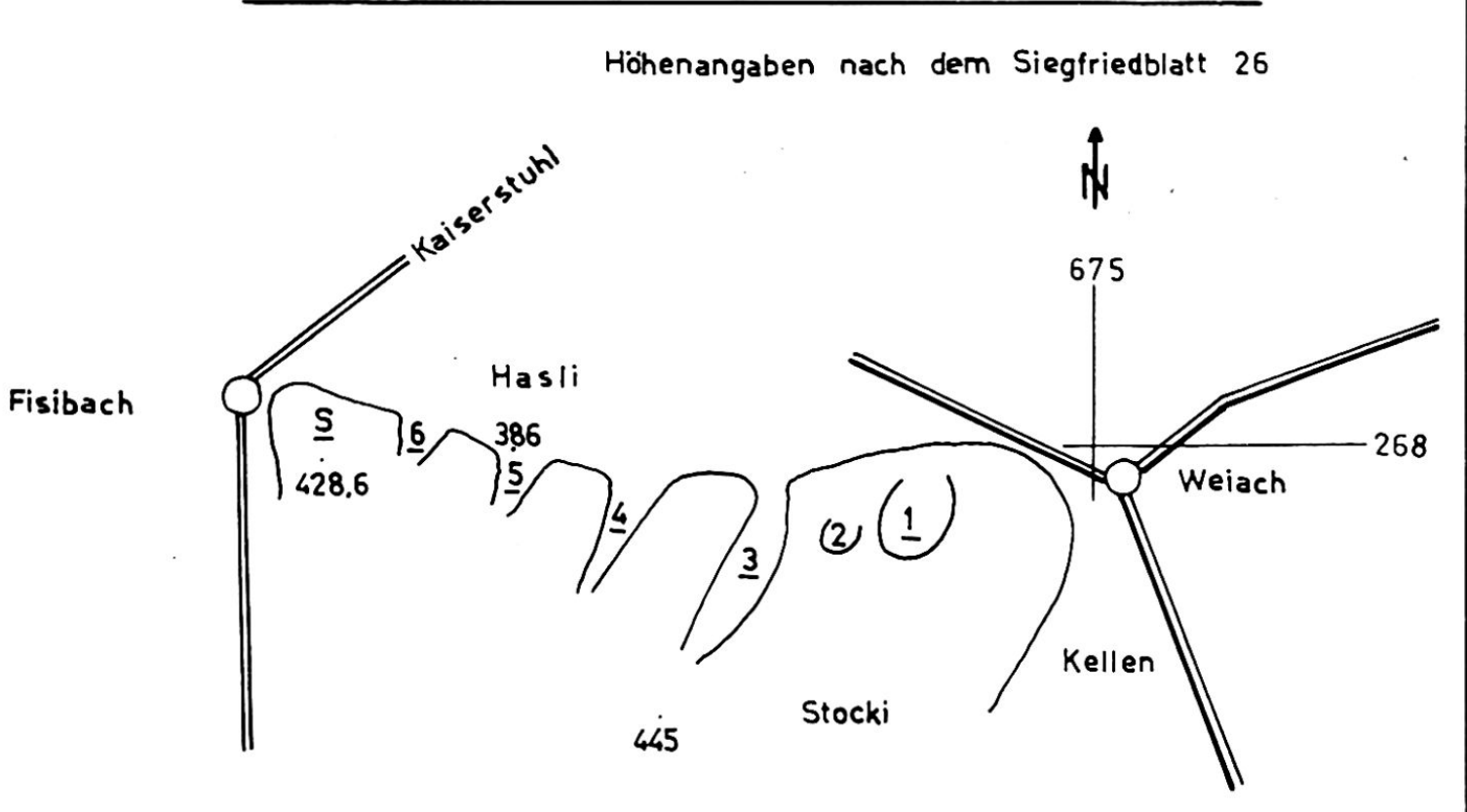

1 Wingert-Hangdelle 1

5 Hasliraingraben I

2 Wingert-Hangdelle II

6 Hasliraingraben II

3 Frankenhaldetal

S Siechenbuck

4 Saxenholzgraben

Fig. 1

tigt im Jahre 1955; die Gemeinden Kaiserstuhl und Fisibach sind noch nicht vermessen.)

\section{a1) Wingert-Hangdelle I}

\section{a) Einzeluntersuchung}

Unter einer Hangdelle verstehe ich eine muldenartige Ausräumungsform in einem Hang, geschaffen zur Fließerdezeit, währenddem man als Delle ein langgezogenes, trockenes Muldentälchen mit geringem Gefälle, ebenfalls in der Solifluktionszeit angelegt, bezeichnet.

Dem Wanderer auf der Hauptstraße von Weiach nach Kaiserstuhl fällt sicher die Wingert-Hangdelle I zu seiner Linken auf: Eine mächtige, symmetrisch geformte Mulde schmiegt sich in den Wingerthang östlich des Waldrandes ein (Abb. 1).

Die Hangdelle setzt auf $425 \mathrm{~m}$ ein und entsteht durch Vereinigung von 2 kleineren, seitlichen Hangdellen. Folgende Ausmaße kennzeichnen die Hauptform: Länge $115 \mathrm{~m}$, Breite $100 \mathrm{~m}-120 \mathrm{~m}$, Höhe $31 \mathrm{~m}$. Die Hangdelle mündet auf $394 \mathrm{~m}$ im Steilhang aus, d.h. $6 \mathrm{~m}$ oberhalb des Übergangsstückes zur Hasli-Terrassenfläche (mittlere Höhe angenähert $380 \mathrm{~m}-381 \mathrm{~m}$ ). Es finden sich nicht die geringsten An- 


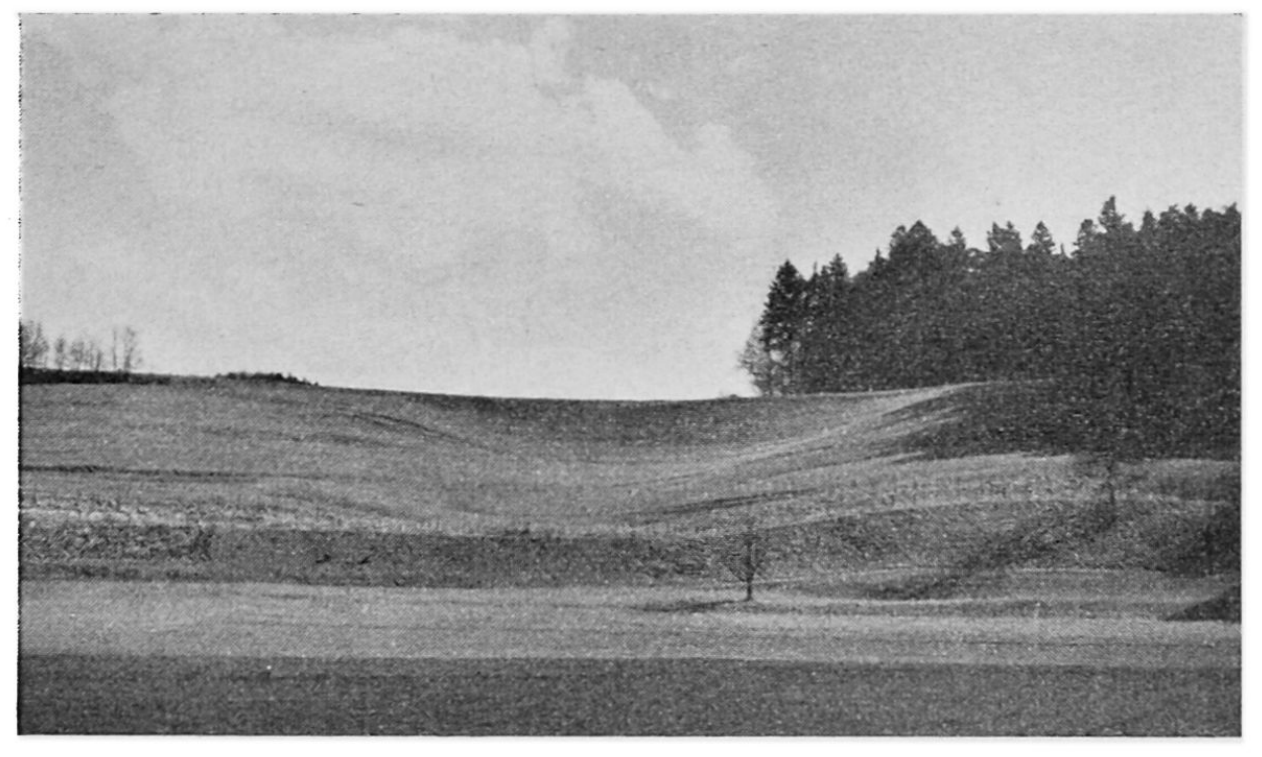

Abb. 1

Wingert-

Hangdelle I

zeichen eines Schuttkegels auf der N'T-Terrassenfläche: Der Steilhang $394 \mathrm{~m}-388 \mathrm{~m}$ setzt mit scharfer Kante an die Hangdelle an; ebenso ausgeprägt ist der Knick zwischen Steilhang und dem leicht geneigten Übergangsstück zum Hasli (Fig. 2). Die leicht versteilte Verbindung Terrassenfläche-Steilhang darf nicht als Schuttkegelrest der Delle aufgefaßt werden. Gründe, die dagegen sprechen, sind:

1. Scharfe Kante zwischen Hangdelle und Steilhang.

2. Auch andernorts kann beobachtet werden, daß die Terrassenflächen nicht topfeben an den Steilhang stoßen, sondern gegen den Hang hin sanft ansteigen.

\section{a2) Wingert-Hangdelle II}

$50 \mathrm{~m}$ westlich des Westrandes der großen Wingert-Hangdelle I setzt eine zweite, kleinere dellenförmige Mulde ein. Diese Wingert-Hangdelle II liegt südöstlich des Weiacher Scheibenstandes im Wald versteckt. Sie setzt ebenfalls mit deutlicher Kante auf $425 \mathrm{~m}$ ein; in der Breite erreicht sie $50 \mathrm{~m}$. Nach unten ist die Form der Beobachtung schlecht zugänglich; Stacheldrahtverhaue und Dorngestrüpp erschweren die Untersuchung. Die Ausmündungsstelle ist nicht exakt bestimmbar wie bei Hangdelle I; ich verwende für die weiteren Schlüsse daher immer die sicheren Beobachtungen der östlichen Wingert-Hangdelle. Folgende Punkte lassen sich aber auch bei der Form II eindeutig feststellen:

1. Die Ausmündungsstelle der Mulde liegt deutlich höher als die Haslifläche.

2. Es existiert kein Schuttkegel auf der obersten vorhandenen NT-Terrassenfläche.

Mit Bezug auf die Haslifläche heißt das folgendes: Während der Anlage der Haslifläche (d. h. zur Zeit der Unterschneidung, der Prallhangzurückversetzung zum heutigen Steilhang $394 \mathrm{~m}-388 \mathrm{~m}$ ) hörte die Wingert-Hangdelle I zu funktionieren auf. Die Haslifläche ist also jüngerer Entstehung als die Hangdelle; die höhere Ausmündungsstelle der Hangdelle und das Fehlen eines Schuttkegels sind Belegstücke dafür. Auf Grund späterer Untersuchungen ergibt sich, daß die Haslifläche bereits ein Erosionsniveau darstellt (Abschnitt «Die Würmterrassen in den verschiedenen Abschnitten des Rheintales, Abschnitt Tössegg-Kaiserstuhl») ; sie liegt innerhalb des ersten Erosionsniveaus. Aus den Verhältnissen bei Wil (Rafzerfeld) können wir ersehen, daß die Tieferlegung der Akkumulationsfläche auf das erste Erosionsniveau Ende Hochglazial - Anfang Spätglazial erfolgt ist. Die Hangdelle ist älter als diese Tieferlegung und muß auf Grund dieser Befunde dem Würm-Hochglazial, ev. schon dem Würm-Frühglazial zugeordnet werden. 


\section{PROFIL WINGERT - HAUPT-NT-FL ̈̈̈CHE}

$\mathrm{N}$

S

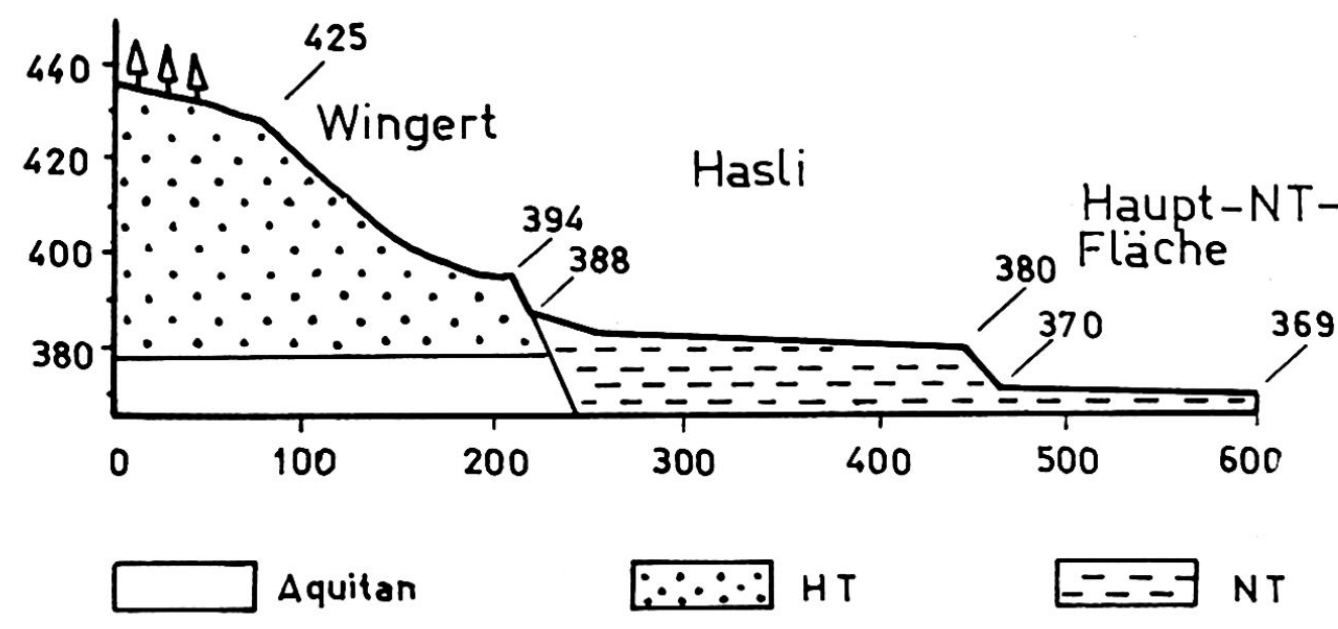

Fig. $2425 \mathrm{~m}-394 \mathrm{~m}$ : Hangdelle, $394 \mathrm{~m}-388 \mathrm{~m}$ : Steilhang, $388 \mathrm{~m}-380 \mathrm{~m}$ : Terrassenfläche Hasli mit leicht versteiltem Übergangsstück, $380 \mathrm{~m}-370 \mathrm{~m}$ : Terrassenhang, $370 \mathrm{~m}-369 \mathrm{~m}$ : Weiacher Hauptterrassenfläche

Dellen müssen in einem Klima angelegt worden sein, das flächenhafte Abtragungserscheinungen begünstigt hat. Zur Zeit des Permafrostbodens sind solche Bedingungen gegeben: In der wärmeren Jahreszeit tauen die obersten Erdschichten auf; die feuchtigkeitsdurchtränkten Massen gleiten auf dem dauernd gefrorenen Untergrund $a b$ und ergießen sich dabei auf die in Bildung begriffene oder bereits gebildete NT-Akkumulationsfläche. Die Hangdellen sind zur Würm-Solifluktionszeit entstanden. In eine frühere Eiszeit reichen sie nicht zurück; die praewürmisch entstandenen Solifluktionsformen sind zur jüngsten Fließerdezeit wieder verwischt worden. Nach BüDEL (9) sind Fließerdeerscheinungen dem feuchten, sommerkühlen Frühglazial zuzurechnen. Auf diesen Zeitabschnitt mit ozeanischem Klimacharakter sei das kontinental ausgeprägte, trockene Hochglazial gefolgt. Man kann sich vorstellen, daß die Rutschungen, vor allem an Hängen, auch noch im Hochglazial angedauert haben. Wenn diese Zeit auch als niederschlagsärmer als das Frühglazial charakterisiert wird, so schmilzt der Schnee und taut die Bodenoberfläche umso rascher, so daß eine genügende Feuchtigkeitsmenge zur Verfügung steht. Mit Beginn des Spätglazials verschwindet der Dauerfrostboden; somit endet auch die Dellenbildung.

Das weiter westwärts gelegene Frankenhaldetal war noch länger aktiv; es stellt keine reine Solifluktionsform wie die Hangdellen dar, die nur während der Dauerfrostbodenzeit wirksam sein können, sondern hat auch nach der Permafrostzeit gelegentlich Wasserzuschüsse erhalten (vgl. $\alpha 3$ ).

Das Akkumulationsniveau muß bei Weiach höher gelegen sein als die Haslifläche, vermutlich wenig tiefer als die Ausmündungsstelle der Hangdelle (mittlere Höhe der Akkumulationsfläche angenähert $388 \mathrm{~m}$ ). Im Abschnitt «Zur Entstehung der Würmterrassen im Rheingebiet, 3. Die Akkumulation der Niederterrassenschotter » wird die Aufschotterung während der Vorstoßphase des Gletschers belegt. 


\section{Frankenhalde - Tal}
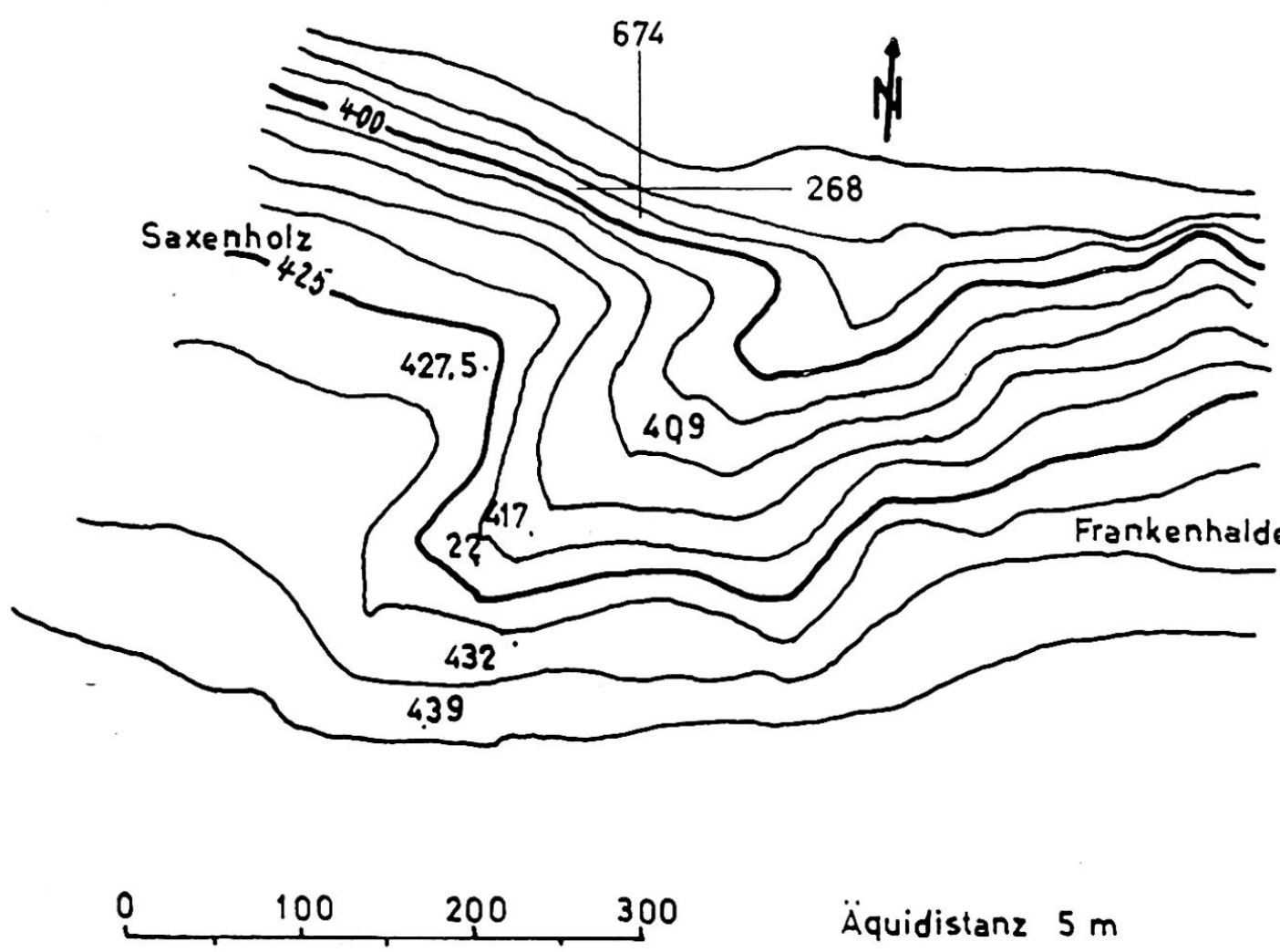

Äquidistanz $5 \mathrm{~m}$

Fig. 3

\section{a3) Frankenhaldetal $*$}

Marschieren wir vom Scheibenstand Weiach $150 \mathrm{~m}$ in westlicher Richtung, so gelangen wir zur Ausmündung eines Tales, das die Frankenhalde durchbricht (Fig. 3 ). Das Tälchen setzt kastenförmig auf einem leicht nach $W$ geneigten, welligen HTPlateau auf einer Höhe von $430 \mathrm{~m}$ ein. Auf $425 \mathrm{~m}$ ist die Sohle $50 \mathrm{~m}$ breit. In der Höhenlage zwischen $410 \mathrm{~m}$ und $420 \mathrm{~m}$ verschmälert sich die Talsohle und wird gleichzeitig asymmetrisch: Der NW-Hang ist gegenüber dem SE-Hang versteilt. Im untersten Teil verengert sich das Tal weiter auf $20 \mathrm{~m}$ und nimmt wieder Kastenform an. Kleinere Mulden führen von der Frankenhalde gegen das Tälchen zu. Das Frankenhaldetal mündet, den Ende Hochglazial/Anfang Spätglazial geschaffenen Terrassenhang durchbrechend und einen kleinen Schuttkegel aufschüttend, auf die Hasli-Terrassenfläche. Das Tal weist eine Länge von $400 \mathrm{~m}$ auf.

Aus diesen Beobachtungen kann auf die formbildenden Kräfte geschlossen werden. Mulden und Rutschnischen weisen auf eine denudative Tätigkeit, das Vorhandensein einer Sohle auf die erosiv-korrasiven Kräfte hin. Das Frankenhaldetal ist kein Graben, sondern macht mit seiner breiten, vor allem im obersten und untersten Teil

* Das Frankenhaldetal wird auf der Landeskarte 1:25000 als Saxengraben bezeichnet. 
ebenen Sohle, den Anschein eines Korrasionstales: Es fehlen dem Tal die Zeichen reiner, kräftiger Tiefenerosion, wie sie den V-förmig ausgeprägten Gräben eigen sind.

Für die zeitliche Eingliederung lassen sich folgende Tatsachen verwenden: Der auf die Haslifläche geworfene Schuttkegel beweist, daß das Frankenhaldetal im Spätwürm noch wirksam gewesen ist, zur Zeit als die oberste NT-Erosionsfläche bereits gebildet war. Schwierig ist es, den Beginn dieser Talbildung zu bestimmen. Sicher ist die Form älter als die westlich gelegenen Gräben. Das Frankenhaldetal erinnert in seinem Habitus an die hauptsächlich korrasiv geschaffenen Periglazialtälchen im Bereich des Haslibodens (siehe Kap. III). Diese Art der Talbildung wird zur Zeit des Dauerfrostbodens mit starker Feuchtigkeitsdurchtränkung der obersten Bodenschicht ermöglicht. Eine solche Durchfeuchtung findet sich im Frühglazial, bedingt durch die vermehrten Niederschläge, und im Hochglazial, bedingt durch die intensiven Temperaturwechsel des kontinentalen Klimatypus. Eiszeitlicher Solifluktionsschutt ist die Frankenhalde hinuntergeflossen. Im Gebiet des heutigen Frankenhaldetales haben sich verschiedene Ströme gesammelt, sind auf breiter Sohle korradierend nach unten gezogen und haben sich dort mit dem NT-Schotter vermengt. Der Beginn der Frankenhaldebildung mag bis zum Würm-Frühglazial zurückreichen. Das Tal hat also schon vor der Bildung der Haslifläche existiert und hat wie die WingertHangdelle I auf das Akkumulationsniveau des Niederterrassenschotters ausgemündet. Darauf hat eine erste Eintiefung in den aufgeschütteten Schotter stattgefunden: Die heutige Haslifläche ist freigelegt worden. Damit ist eine Stufe zwischen Talmündung und Terrassenfläche entstanden. Vielleicht ist diese Übertiefung nur theoretisch zu verstehen; denn es kann ganz gut sein, daß die Tieferlegung des Talausganges mit der Erodierung der Akkumulationsplatte Schritt gehalten hat. Auf alle Fälle aber hat das Frankenhaldetal noch als Wasserableiter gedient, als die oberste NT-Erosionsfläche bereits Bestand hatte; davon zeugt der aufgeschüttete Schuttkegel. Die Mächtigkeit dieser Schuttaufhäufung scheint aber schlecht mit der Gesamtheit der erodierten und denudierten Talfüllung übereinzustimmen. Wenn wir aber in Rechnung ziehen, daß der bedeutendere Teil des ausgeräumten Materiales früh- bis hochglazial auf die Akkumulationsfläche abgelagert wurde, können wir verstehen, daß nur noch Restteile, z. B. das Mündungsstufenmaterial und das durch Gefällsausgleichung weggeräumte Material auf der Haslifäche liegen. Daß die Denudations- und Erosionstätigkeit bedeutend abgenommen hat, kann am Talausgang beobachtet werden: Die Kraft hat bei der Eliminierung des Höhenunterschiedes zwischen hochglazialem Talausgang und dem obersten Erosionsniveau nicht mehr ausgereicht, die gleiche Talbreite wie im oberen Teil zu schaffen. Wohl der wichtigste Grund in der Abnahme der Denudationstätigkeit liegt im Verschwinden des Dauerfrostbodens. Ein Teil des Wassers versickert im leicht verlehmten HT-Schotter. Bessere Versickerung bedeutet eine geringere Durchnässung der oberen Schichten; zudem fehlt der Gleithorizont, über den ein Wasser-Erde-Gemisch abgleiten könnte. Eine gewisse Denudationstätigkeit hat allerdings auch noch im vorerst vegetationsarmen Spätglazial und später stattgefunden. Die früh- bis hochglaziale, immerhin $400 \mathrm{~m}$ lange Rinne hat teilweise als Wasserfänger gedient, weniger bei Regen (der Schotter vermag dieses Wasser zu schlucken; zudem fängt der Stockiwald einen Teil des Niederschlages auf) als bei plötzlichen Schneeschmelzen. Die Schmelzwasser haben sich nicht regelmäßig über das HT-Plateau ergossen, sondern sind teilweise durch das Frankenhaldetal aufgefangen worden. Auf das gerichtete Fließen deuten vor allem die Mulden hin, die vom E-Hang her in das Frankenhaldetal einmünden. Die Schmelzwasser sind nur zum Teil auf dem leicht lehmigen, noch halbwegs gefrorenen Untergrund versickert und haben die obersten Schichten durchfeuchtet. Ein Gefällsausgleich ist so noch möglich gewesen. Das Überwinden der schmalen Ausmündungsstufe kann auf diese Art erklärt werden, ebenso die welligen Wülste im mittleren Talabschnitt. Diese Unebenheiten sind Zeichen einer stark abflauenden Denudationstätigkeit. 


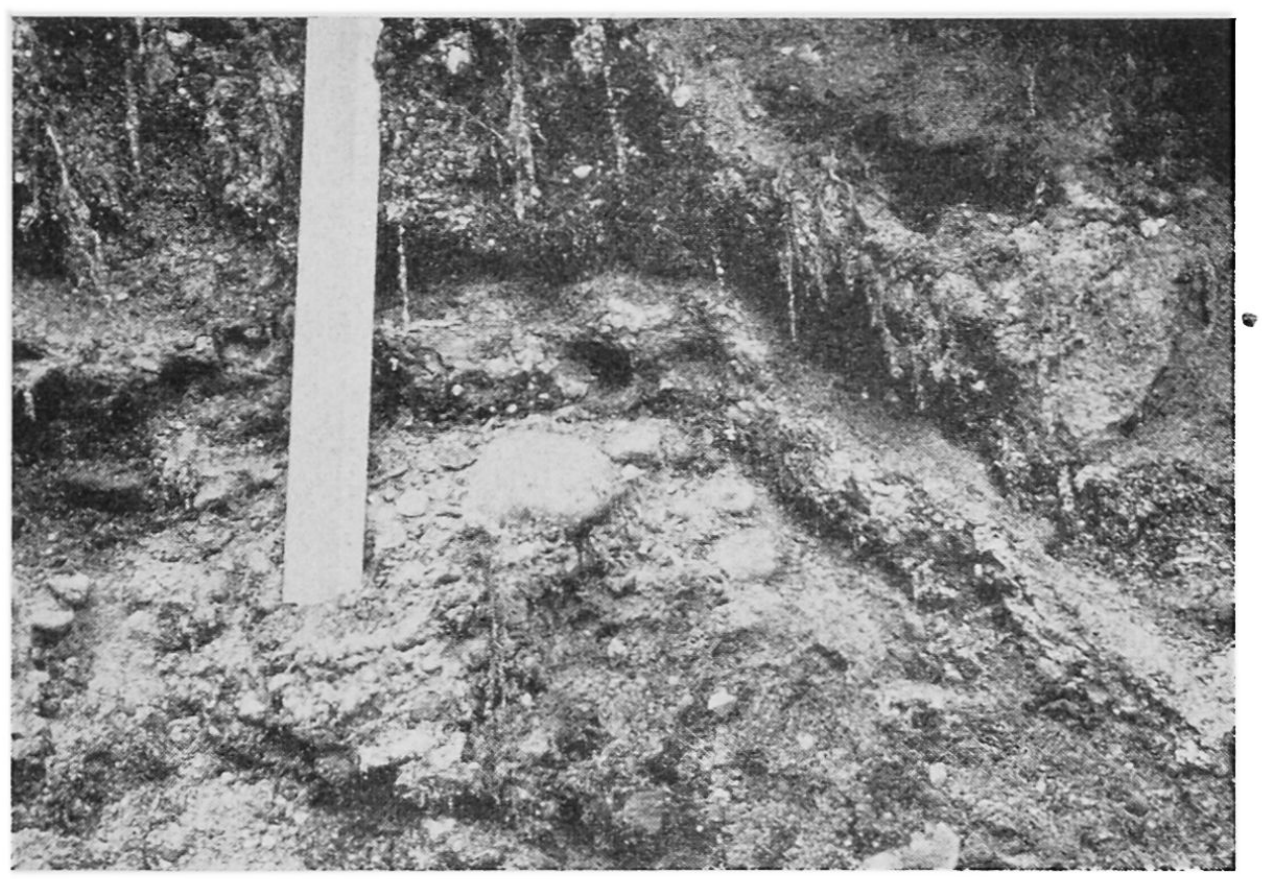

Abb. 2

Hakenschlagen eines Lehmbändchens im HT-Steilhang

Im HT-Steilhang kommen gelegentlich heute noch Rutschungen vor; das beweisen verschiedene schöne Aufschlüsse, so vor allem die Siechenbuck-Grube (673 275/ 268400 ) und die Kiesgrube, die etwas weiter östlich an der auf das HT-Plateau führenden Straße liegt $(673425 / 268175)$. In der Siechenbuck-Grube liegen abgeglittene Bäume und abgesackte Schotterpakete; in der nachfolgend genannten Kiesgrube zeigt ein helles $3-5 \mathrm{~cm}$ mächtiges Lehmbändchen ein deutliches Hakenschlagen. Das Lehmband liegt in $1 \mathrm{~m}$ Tiefe und verläuft \pm parallel zur Hangneigung. Tiefer gelegene Schichten sind von der Bewegung nicht erfaßt worden (Abb. 2).

\section{a4) Saxenholzgraben}

Mehrere muldenartige Vertiefungen im HT-Plateau setzen auf einer Höhe zwischen $435 \mathrm{~m}$ und $440 \mathrm{~m}$ ein (Fig. 4). Diese sanft geneigten, ausgeglichenen Formen versteilen sich nach dem Anreißen des Hanges ganz bedeutend; die obersten Grabenteile haben zum Teil sogar ein konvexes Gefälle. Die gewunden verlaufenden, östlichen Seitenarme a und b weisen vom Beginn des Steilhanges bis zu ihrer Vereinigung auf einer Länge von $70 \mathrm{~m}$ ein Gefälle von $20 \mathrm{~m}$ auf; dies entspricht einem mittleren Gefälle von nahezu 29\%. Der westliche Seitenarm c verläuft ausgeglichener; das Sohlengefälle bis zur Vereinigung mit a und b beträgt $22 \%$. Die gemeinsame Sohle der drei vereinigten Arme fällt bis zum Scheibenstand auf $150 \mathrm{~m}$ noch $13 \mathrm{~m}$ (= $82 / 3 \%)$.

Der Talausgang der Gräben wird gestört durch den Kaiserstuhler Schießwall; nordnordwestlich davon wölbt sich ein großer Schuttkegel auf die Haslifläche (Abb. 4). Im Gegensatz zum Frankenhaldetal sind die Rinnen V-förmig angelegt; schmale Sohlen und steile Seitenhänge kennzeichnen den Saxenholzgraben (Abb. 3).

Sohlenbreite a: $2 \mathrm{~m}$; b: Kerbe schmaler als $0,5 \mathrm{~m}$; c: $1 \mathrm{~m}-3 \mathrm{~m}$.

bei Vereinigung von a mit b: $8 \mathrm{~m}$, dann sich auf $2 \mathrm{~m}-3 \mathrm{~m}$ verschmälernd.

nach Vereinigung von $\mathrm{a}, \mathrm{b}$ und $\mathrm{c}: 7 \mathrm{~m}$, nach unten sich auf $3 \mathrm{~m}$ verengernd.

Die Grabenarme b und c weisen Spuren rezenter Erosion auf.

Die Gräben sind erosiver Entstehung; die Denudation hat nur eine untergeordnete Rolle gespielt. Die Formen sind nicht durch kontinuierliches Wasserfließen ent- 
Fig. 4

a : östlicher Arm

$\mathrm{b}$ : mittlerer Arm

c: westlicher Arm

d: blindes Hänge-

tal (östlich der vereinigten Sohle)

\section{Saxenholz-Graben}

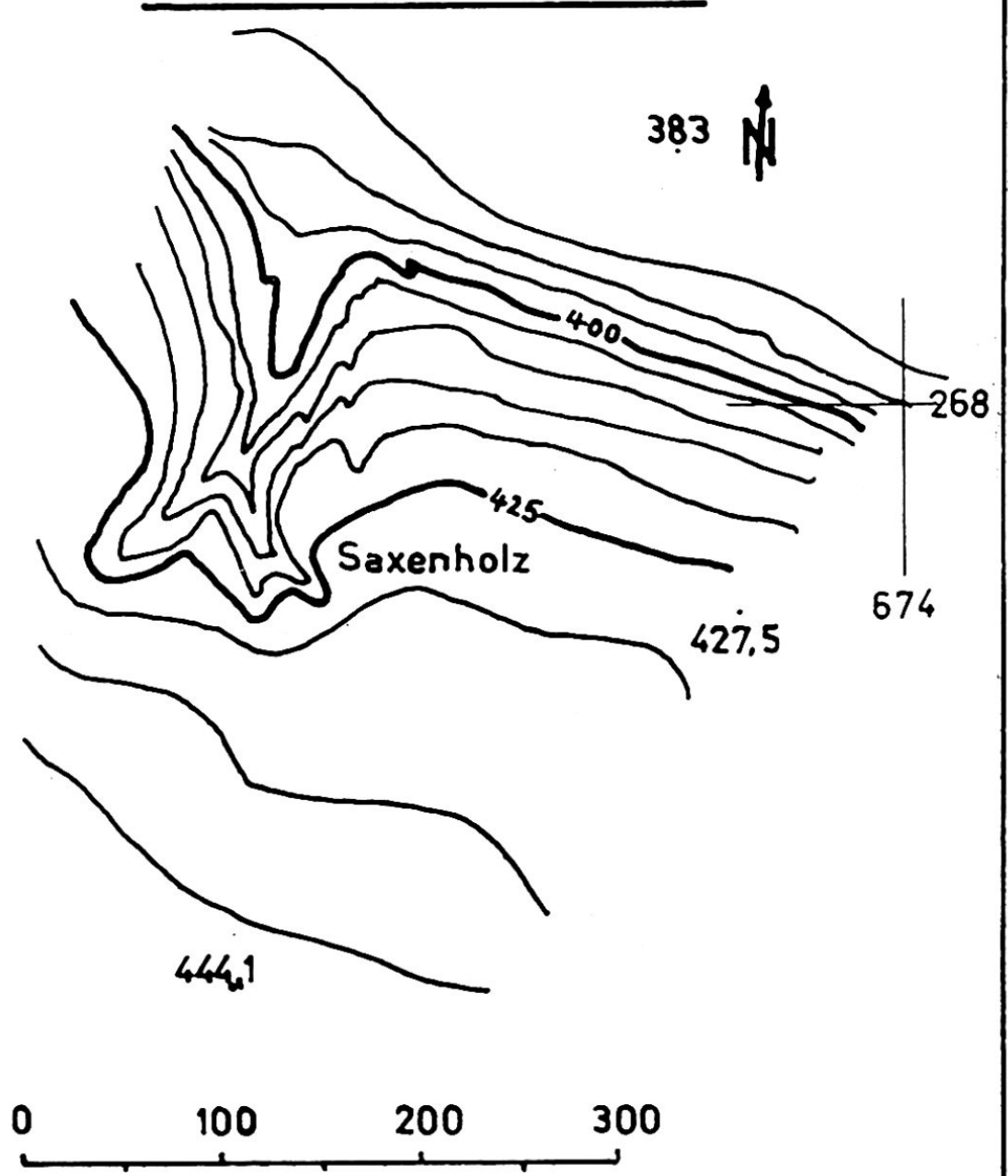

Äquidistanz $5 \mathrm{~m}$

standen. Nirgends auf dem HT-Plateau finden sich Spuren eines Bachbettes, das zu den oberen Gräben führen würde. $Z$ wischen vielleicht recht seltenen, wildbachartigen Wasserführungen sind die Gräben während längerer Zeit ohne eigentliche Wasserführung geblieben. Eine länger dauernde, gleichmäßige Erosion müßte ein der Erosionsterminante genähertes Sohlengefälle geschaffen haben.

Interessant ist der Verlauf eines im Hang liegenden, blind beginnenden und blind endenden Seitenarmes d, der ungefähr $100 \mathrm{~m}$ vor der Mündung des Haupttales endet. Das Tälchen setzt kurz nach der Vereinigung von a und b im Osthang, $10 \mathrm{~m}$ oberhalb der heutigen Talsohle, ein. Seine Längsachse fällt mit derjenigen des Armes b zusammen. Das Tälchen d muß als Ableiter des Grabenwassers des Seitenarmes b gedient haben. Dann ist die kräftige Eintiefung des Teilstückes a erfolgt; die Erosion im Seitenarm a ist dabei so kräftig gewesen, daß sie das Tälchen d vom Wasserliefe- 


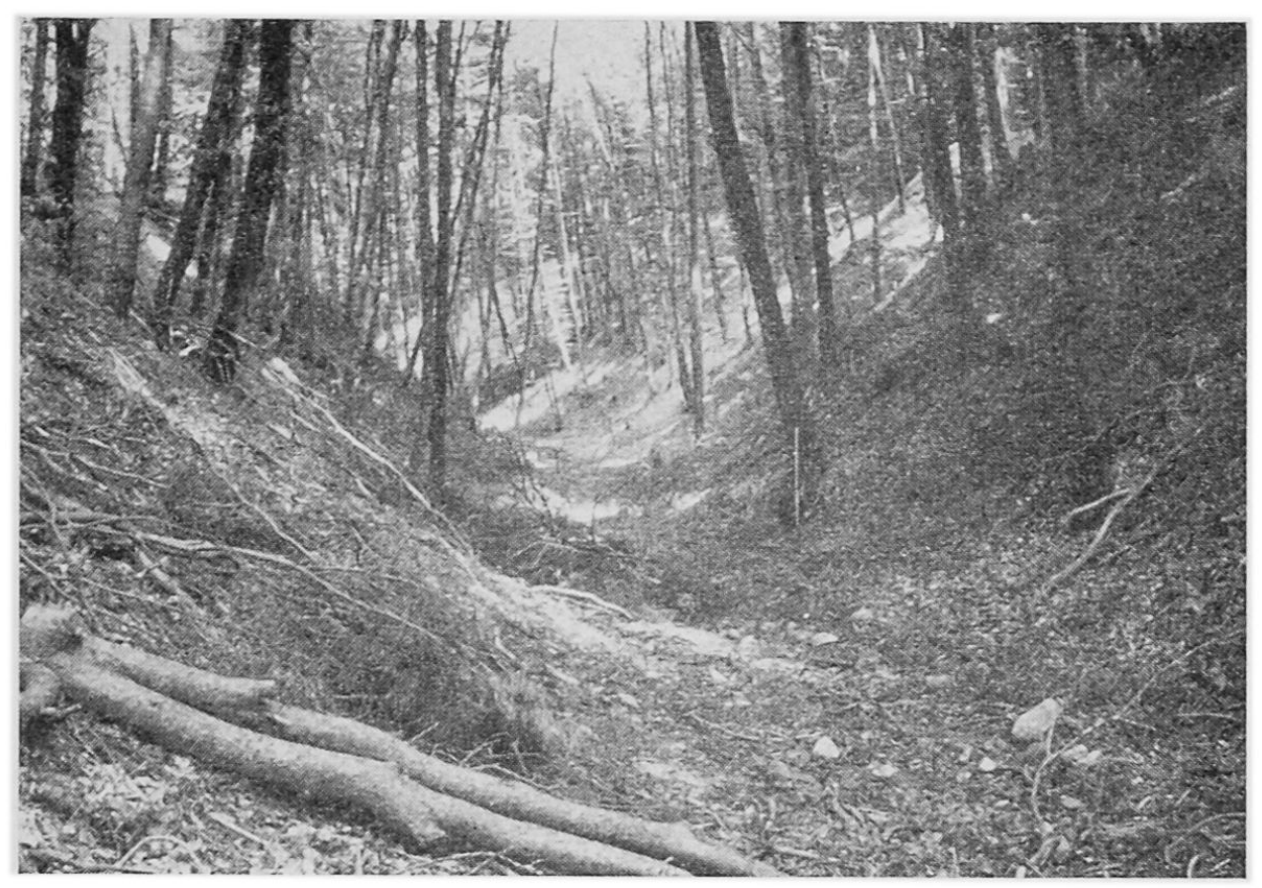

Abb. 3

Westlicher Arm c des Saxenholzgrabens

ranten $b$ zu trennen vermocht hat; $d$ ist dadurch zu einem blinden Hängetal degradiert worden.

Für die Altersbestimmung des Grabens ist der mächtige aufgeschüttete Schuttkegel ein Kriterium: Der Graben hat sicher noch nach der Formung des obersten Würm-Erosionsniveaus funktioniert; die Hangwände machen einen ausgesprochen frischen Eindruck. Rezente Vertiefungen weisen auf die heute noch - allerdings nur sporadischen - Erosionseinwirkungen hin. Würde der Graben im gleichen Niveau wie die Rheinhalde-Einschnitte liegen, müßte er der Form nach als gleichaltrig bezeichnet werden. Die Lage in den verschiedenen Höhenstufen darf kein Grund dazu sein, den Grabenbildungsprozeß der oberen Gräben als früher beendigt zu erklären. Auch die relative Mächtigkeit des Schuttkegels sagt nichts über die Dauer der Erosionstätigkeit aus: Kurze, intensive Hochwasser vermögen wohl zu ebenso bedeutenden Aufschüttungen zu führen. - Sicher sind die ersten Spuren des Saxenholzgrabens erst nach der Schaffung des HT-Terrassenhanges entstanden. Nun stellt sich die Frage, ob die Wingert-Hangdellen, das Frankenhaldetal sowie der Saxenholzgraben in ihrer ersten Anlage gleichaltrig seien, d. h. ihre erste Ausbildung zur Würm-Fließerdezeit erhalten haben. Man könnte sich vorstellen, daß im Früh- bis Hochglazial oberflächliche Rutsche auf dem Dauerfrostboden mehrere Hangdellen geschaffen hätten, die jeweils als Sammler für das Schmelzwasser dienten. Da jedoch der Dauerfrostboden einer wirksamen Erosion entgegenstand, dürften die erosiven Wirkungen klein gewesen sein. Dagegen ist der Weg für in die Breite gerichtetes, denudatives Abfließen der obersten Bodenschichten frei. Die V-förmigen Gräben in der Umgebung von Weiach-Kaiserstuhl sind nicht zur Zeit des Dauerfrostbodens entstanden, sondern später, unter Klimabedingungen, die der Tiefenerosion förderlich sind. Die schmalen Formen lassen sich nicht als erosiv umgestaltete Hangdellen deuten.

Der Saxenholzgraben ist spätglazialer und postglazialer Entstehung und hat noch gleichzeitig mit den unteren Rheingräben funktioniert. Es ist nicht einzusehen, daß zur Zeit der Anlage der unteren Gräben nur gerade in jenem Niveau ausgeprägte Erosionstätigkeit geherrscht haben soll, währenddem die oberen Gräben ohne Wasserführung ungenützt dagelegen hätten. Wie ich bei der Entstehung der unteren Gräben genauer erörtern werde, führe ich die Haupteintiefung der Rheinhaldegräben auf plötzlich anschwellende Wasser des Mühlebaches und des Sägebaches bei Gewitter- 


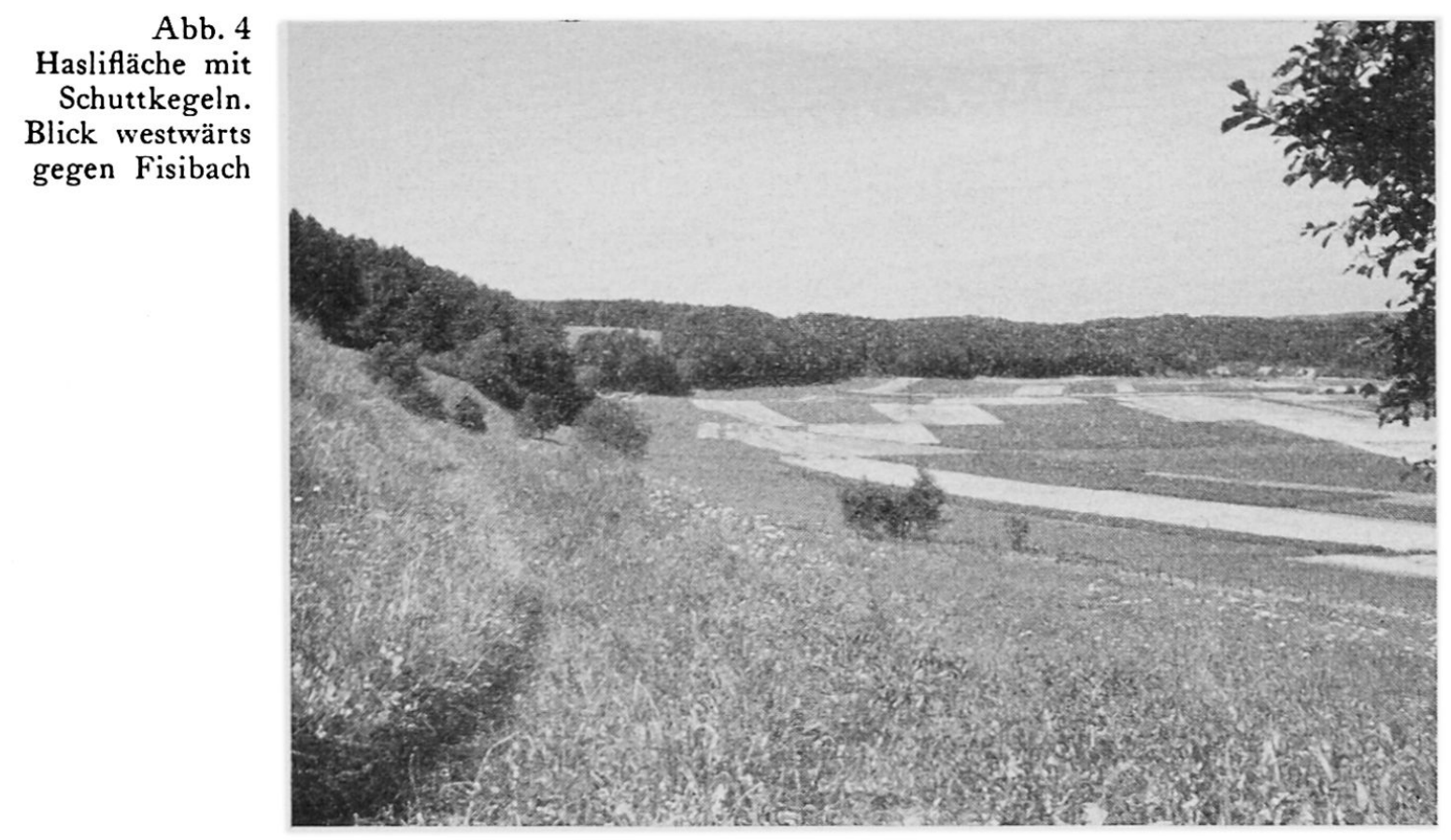

güssen und vor allem bei Schneeschmelzen zurück (siehe auch Kap. «Erweiterung der Gräben; Förderung von Erosion und Denudation»). Der erhöhte Wasseranfall muß sich gleichzeitig auch auf dem HT-Plateau bemerkbar machen. Wohl fließt auf der HT-Terrassenfläche kein permanentes Gewässer; doch ist die lehmige Brunnhalde dem HT-Terrassenhang nah. Beim Saxenholzgraben beträgt das zwischengeschaltete Schotterstück - das ebenfalls leicht verlehmt ist - nicht einmal $200 \mathrm{~m}$.

\section{a 5) Hasliraingraben $I$}

Prinzipiell gleich wie der Saxenholzgraben ist der Hasliraingraben I ausgebildet; er weist zwei Vertiefungen auf, wobei der westliche Arm die Haupterosionsrinne darstellt. Typisch ist auch hier wieder der sanfte, nischenförmige Beginn kurz vor dem Steilhang. Der milde Grabenanfang geht dann im Wald unvermittelt in ein sehr steiles Gefälle über. Gegen den Grabenausgang verflacht sich die Sohle. Im mittleren Abschnitt liegt ein losgerissener, mehrere $\mathrm{m}^{3}$ großer Nagelfluhblock. Der Hasliraingraben endet mit einem deutlichen Schuttkegel (Abb. 4). Für die Natur der Formentstehung und die Datierung können die gleichen Argumente wie beim Saxenholzgraben herangezogen werden. Die Formen sind homolog. Die nischenartigen Beginne der Gräben lassen sich folgendermaßen erklären: Durch rückwärtsschreitende Erosion wird der Graben weiter in die Hochterrassenfläche zurückverlegt. Bei starker Durchfeuchtung des Schotters rutschen einzelne Teile auf dem versteilten Gefälle in die Erosionsrinne ab. Vor dem eigentlichen Grabenanfang finden sich daher auch denudativ bedingte Formen.

\section{a6) Hasliraingraben II}

Die Straße, die von Fisibach her den Haslirain hinauf gegen den Alten Zürichweg führt, durchquert den Hasliraingraben II, den kleinsten noch als Graben zu bezeichnenden Einschnitt innerhalb der Halde. Dieser Graben ist sehr steil, die Sohle nur wenig eingeschnitten. Die Straße schneidet den Graben in zwei Teile; der untere Grabenteil wird aufgefüllt. Ein Schuttkegel liegt in der Grabenverlängerung auf dem Haslifeld (Abb. 4). 


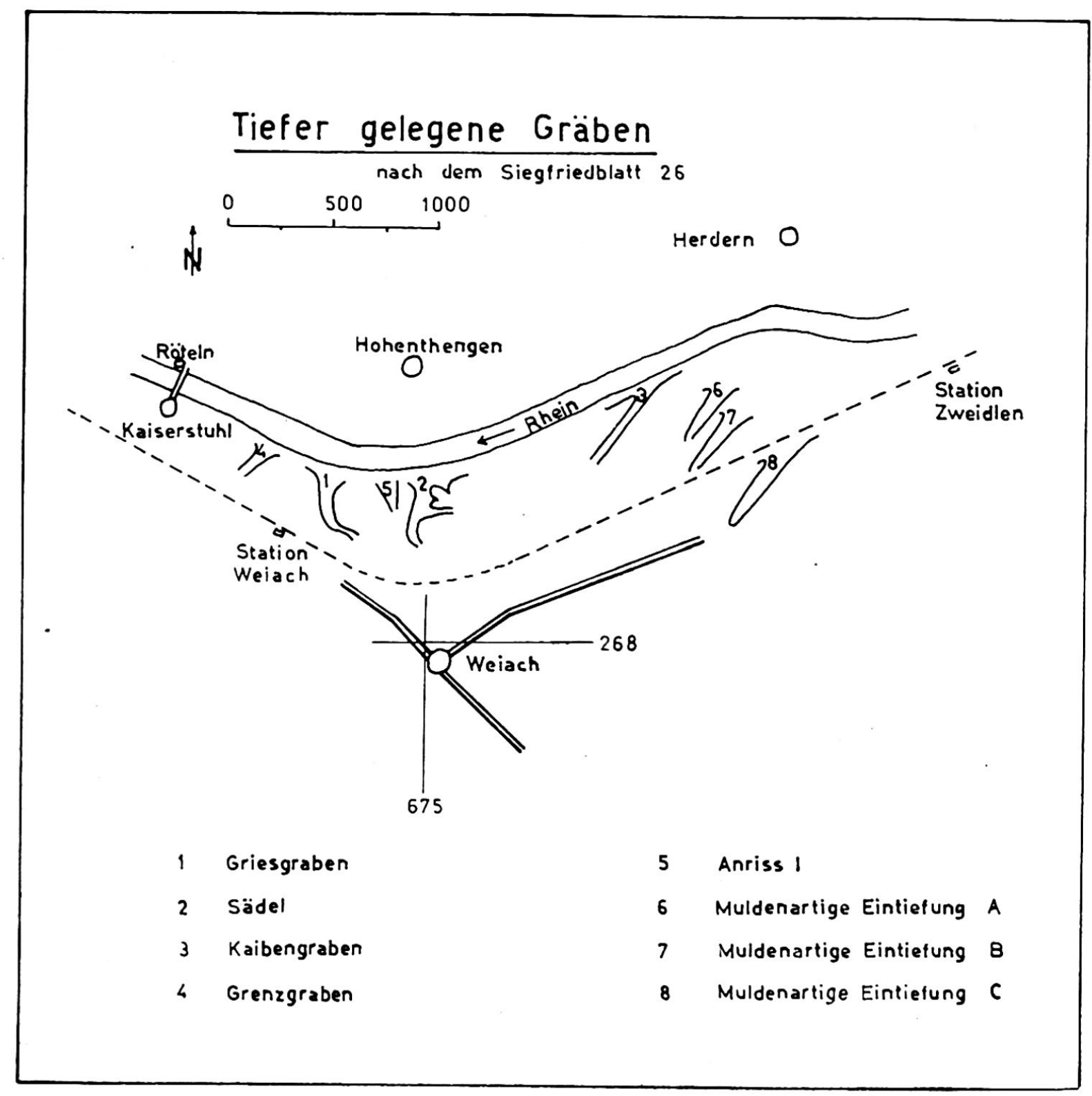

Fig. 5

\section{B) Allgemeines über die oberen Gräben}

Auffallend bei der Betrachtung der Formen ist die Abnahme ihrer Größe von SE nach NW: Am bedeutendsten ist der Saxenholzgraben; der kleinste der Gräben, der Hasliraingraben II. Noch weiter gegen Fisibach zu finden sich nur noch Rutscherscheinungen im Hang. Woher rührt nun diese deutliche Abnahme der Erosionsintensität?

Um eine große Erosionswirkung zu erzielen, sind bedeutende, wenn auch nur periodisch fließende Wassermengen, ein großes Gefälle und ein Untergrund nötig, der der angreifenden Kraft keinen großen Widerstand entgegenzusetzen vermag. Gehen wir diese Kriterien einzeln durch: Der Untergrund ist am ganzen Hang derselbe; er spielt für die verschiedene Ausprägung der Gräben demzufolge keine Rolle. Die Steilheit innerhalb der Halde vom Saxenholzgraben Richtung NW ist ursprünglich mehr oder weniger ausgeglichen gewesen (Prallhang). Bleibt als intensitätsbestimmender Faktor die Wasserführung übrig. Das Wasser, das den Ausschlag zur Grabenbildung gegeben hat, stammt einerseits vom N- und NW-Hang des Sanzenberges, anderseits von der HT-Terrassenfläche selbst. Das Plateau des Sanzenberges 


\section{Griesgraben}

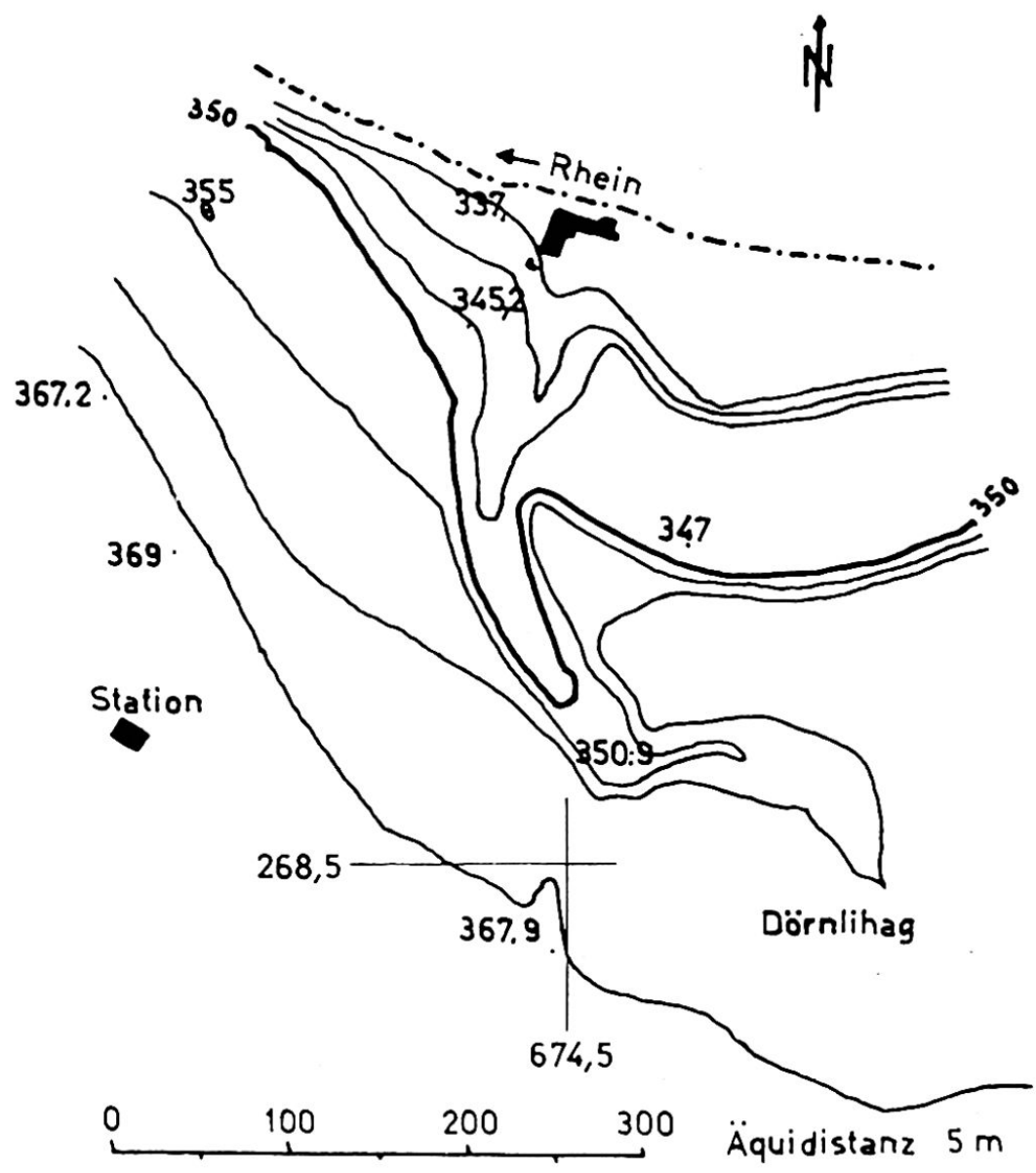

Fig. 6

wird aus jüngerem Deckenschotter gebildet, der einem Molassesockel aufsitzt. Der $\mathrm{N}$-Abhang ist von Gehängeschutt überzogen. Auf dem Schotterplateau versickert der Regen, während der Gehängeschutt weniger wasseraufnahmefähig ist. Im Stocki drückt das Wasser teilweise aus dem Schutt heraus und führt zu Sumpferscheinungen. Stark erodierende Bäche sind nicht geflossen. Nirgends am Sanzenberg finden sich tobelartige Eintiefungen. Zu Zeiten rascher Schneeschmelzen allerdings vermag sich das Wasser, wenigstens teilweise, flächenhaft gegen das HT-Plateau zu ergießen, um sich mit dem dort anfallenden Schmelzwasser zu vereinigen. Die Chance für das herabfließende Wasser, den Hochterrassenhang zu erreichen, ist dort am größten, wo das zwischengeschaltete Schotterstück in der kürzesten, direkten Gefällslinie mit dem Gehängeschuttsteilhang liegt. Dies ist beim Saxenholzgraben der Fall: Weniger als $200 \mathrm{~m}$ trennen ihn vom Kirchholzhang. Dieser Graben hat den größten Wasserzuschuß erhalten, und die Einkerbung, verbunden mit rückwärtsschreitender Erosion, ist hier am stärksten erfolgt. Je weiter wir nach NW schreiten, umso weiter ent- 


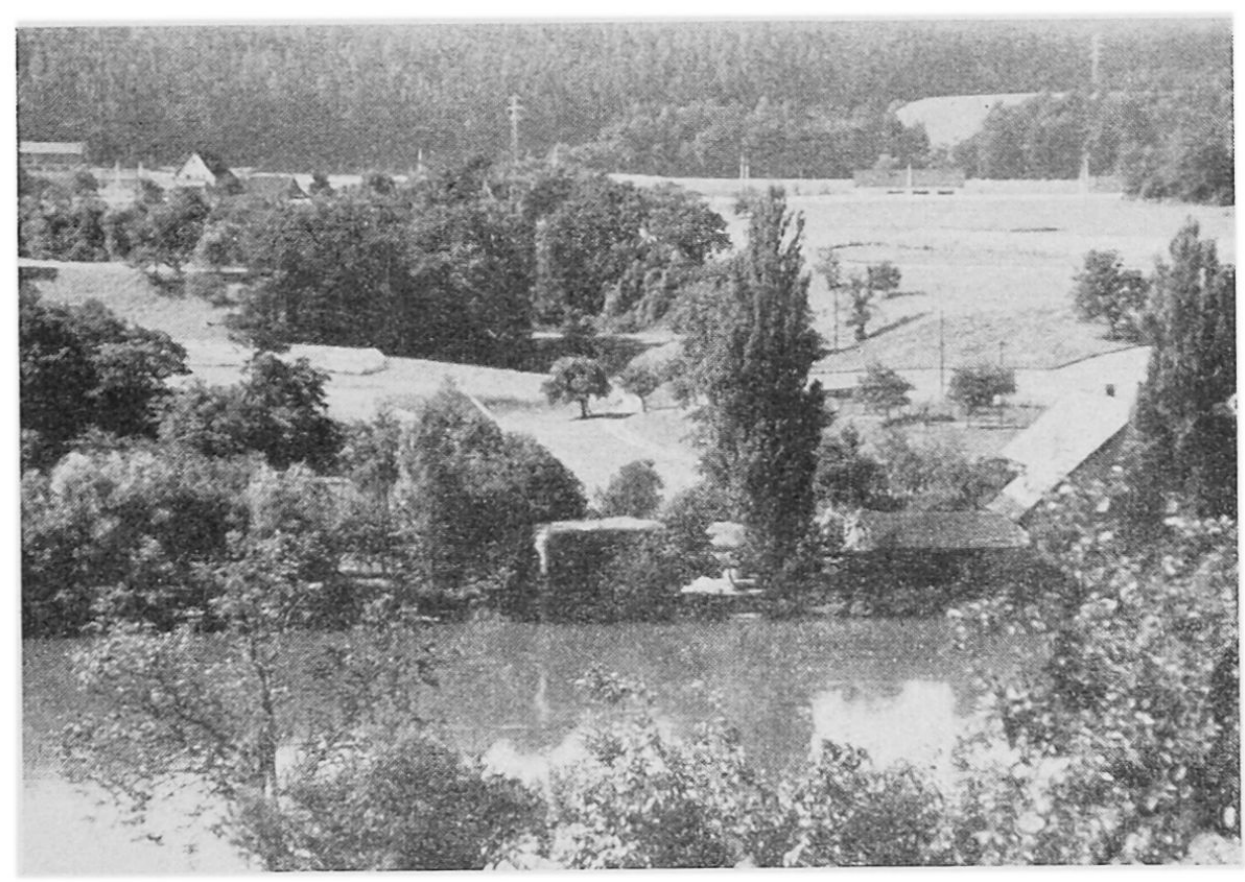

Abb. 5

Griesgrabenausmündung; vom deutschen Rheinufer aus fotografiert

fernen wir uns vom Gehängeschutthang, umso größer wird die zwischengeschaltete HT-Schotterzone. Der Siechenbuck liegt $700 \mathrm{~m}$ vom Kirchholzhang entfernt. Nichtversickertes Schmelzwasser des HT-Plateaus, aber nicht mehr das Sanzenbergwasser, spielt die entscheidende Rolle für die Denudation und Erosion am Siechenbuck. Bei bestimmten Voraussetzungen kann nun die Überbrückung der HT-Zone erleichtert werden: Wenn zur Zeit einer plötzlichen Schneeschmelze die Auftauung des Bodens etwas nachhinkt. Dann vermag das Wasser das $Z$ wischenstück von $H$ ang zu Hang leicht zu überbrücken und innert kurzer Zeit bedeutend zu erodieren.

\section{b) Tiefer gelegene Gräben}

Die tiefer gelegenen Gräben sind in der Rheinhalde angelegt. Die Anrisse der drei Hauptgräben setzen auf der Hauptniederterrassenfläche in einer Höhenlage von $360 \mathrm{~m}$ bis $365 \mathrm{~m}$ ein; sie durchschneiden die Rheinhalde ganz. Griesgraben und Kaibengraben (beide ohne Wasserlauf) münden auf $334 \mathrm{~m}, 2 \mathrm{~m}-3 \mathrm{~m}$ über dem heutigen Rheinpegel. Der Sädelbach hat auch die letzte Stufe durchschnitten und ergießt sich in den Rhein. Anriß I, Grenzgraben und Nebenanrisse des Sädels vermögen nicht den ganzen Steilhang zu durchbrechen, sondern sind lediglich Einkerbungen im ziemlich ausgeglichenen Gefälle der Rheinhalde. Gegen den Hardwald zu finden sich dreı muldenförmige Vertiefungen, die ungefähr parallel zum Kaibengraben verlaufen. Im Gegensatz zum Graben laufen aber diese Mulden auf der Hauptterrassenfläche im Hardwald aus, ohne überhaupt den Steilhang zu erreichen (Fig. 5). Die Kartenskizzen sind dem Plan von Weiach, 1:5000 entnommen.

\section{a1) Griesgraben}

\section{a) Einzeluntersuchung}

Der Griesgraben ist im westlichen Teil der Rheinhalde angelegt. Er beginnt muldenartig auf $360 \mathrm{~m}$, biegt rechtwinklig ab und tieft sich auf $150 \mathrm{~m}$ Länge um $9 \mathrm{~m}$ ein (Fig. 6).

Von Punkt $350,9 \mathrm{~m}$ an ist die Längsachse wieder nordnordwestwärts gerichtet. Auf diesem letzten Teilstück von $335 \mathrm{~m}$ Länge überwindet die Sohle in regelmäßigem Gefälle eine Höhendifferenz von $17 \mathrm{~m}$ und mündet dann breit auf die unterste Ver- 
ebnung von $334 \mathrm{~m}$ aus. An der Mündungsstelle befinden sich der Griesgrabenhof und ein Bunker (Abb.5).

Östlich des Talausganges liegt oberer Malmkalk aufgeschlossen. 1948 ist bei Schottergrabungen ein eingeschwemmter, $3,30 \mathrm{~m}$ langer Mammutzahn gefunden worden (Abb. 6).

Der Graben ist erosiv entstanden; bei der Schaffung der Talsohle hat die Korrasion mitgewirkt (Abb. 7). Die Sohlenbreite beträgt im mittleren Abschnitt 15m-20 m.

Die Durchbrechung von Terrassenkomplexen weist darauf hin, daß die Grabenanlage jünger ist als die betreffenden Terrassen. Der Graben ist gegen Ende Spätwürm/Beginn Holozän angelegt worden. Über die exaktere Bestimmung der Entstehung und der Ausweitung verweise ich auf die nachfolgenden Kapitel.

\section{a2) Sädel}

Der Sädel ist der komplizierteste Graben. Er wird aus drei Hauptarmen geformt: Der westlichste setzt auf einem Niveau von $360 \mathrm{~m}$ ein, der östliche auf $365 \mathrm{~m}$. Der mittlere Grabenarm formt sich nach der Vereini-

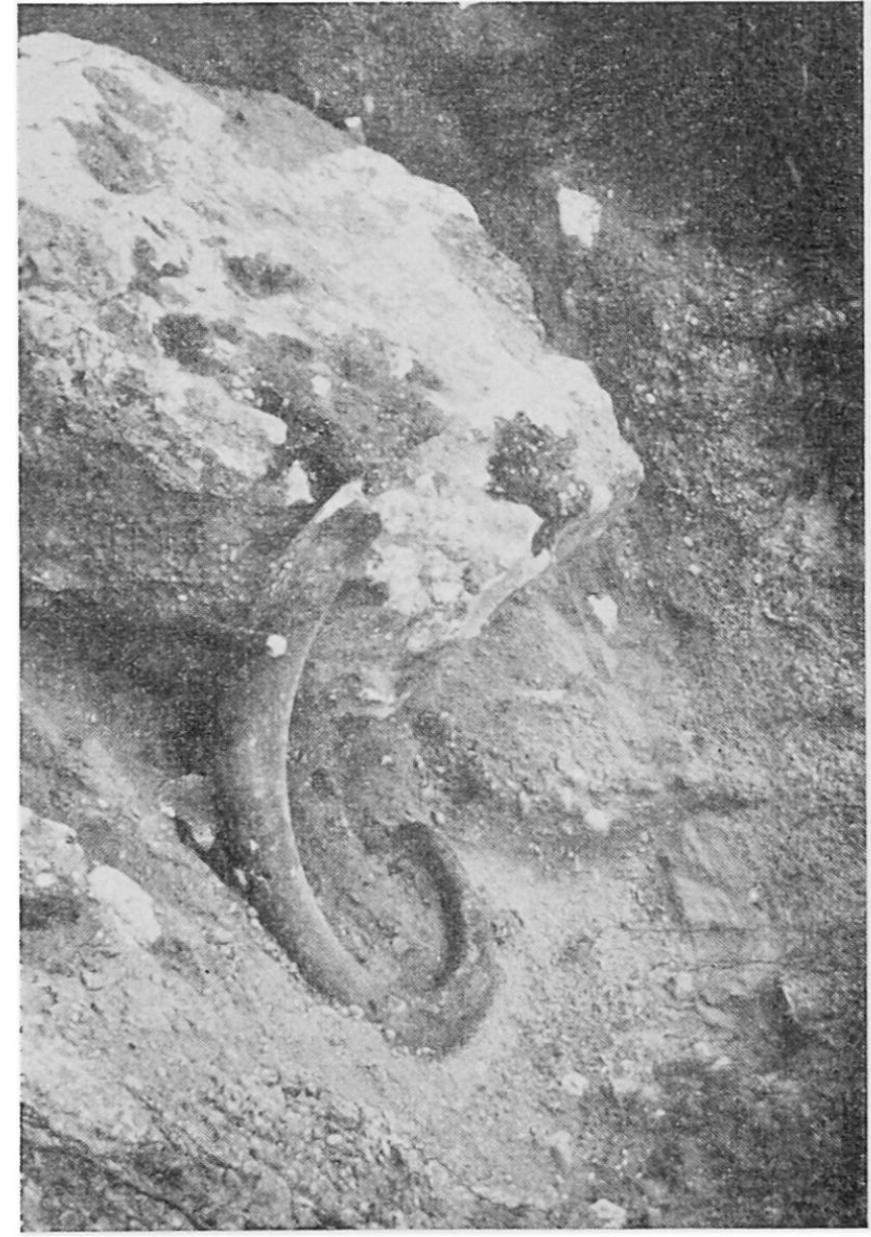

Abb. 6 Zahn eines Manmuts (Elephas primigenius Blumenbach). Foto Zollinger. Der Zahn ist im Zoologischen Museum der Universität Zürich ausgestellt gung von drei bedeutenden Muldentälchen, wobei die östlichste Mulde wieder zweiteilig ist. Die Weiacher Hauptniederterrassenfläche wird auf diese Weise stark an-

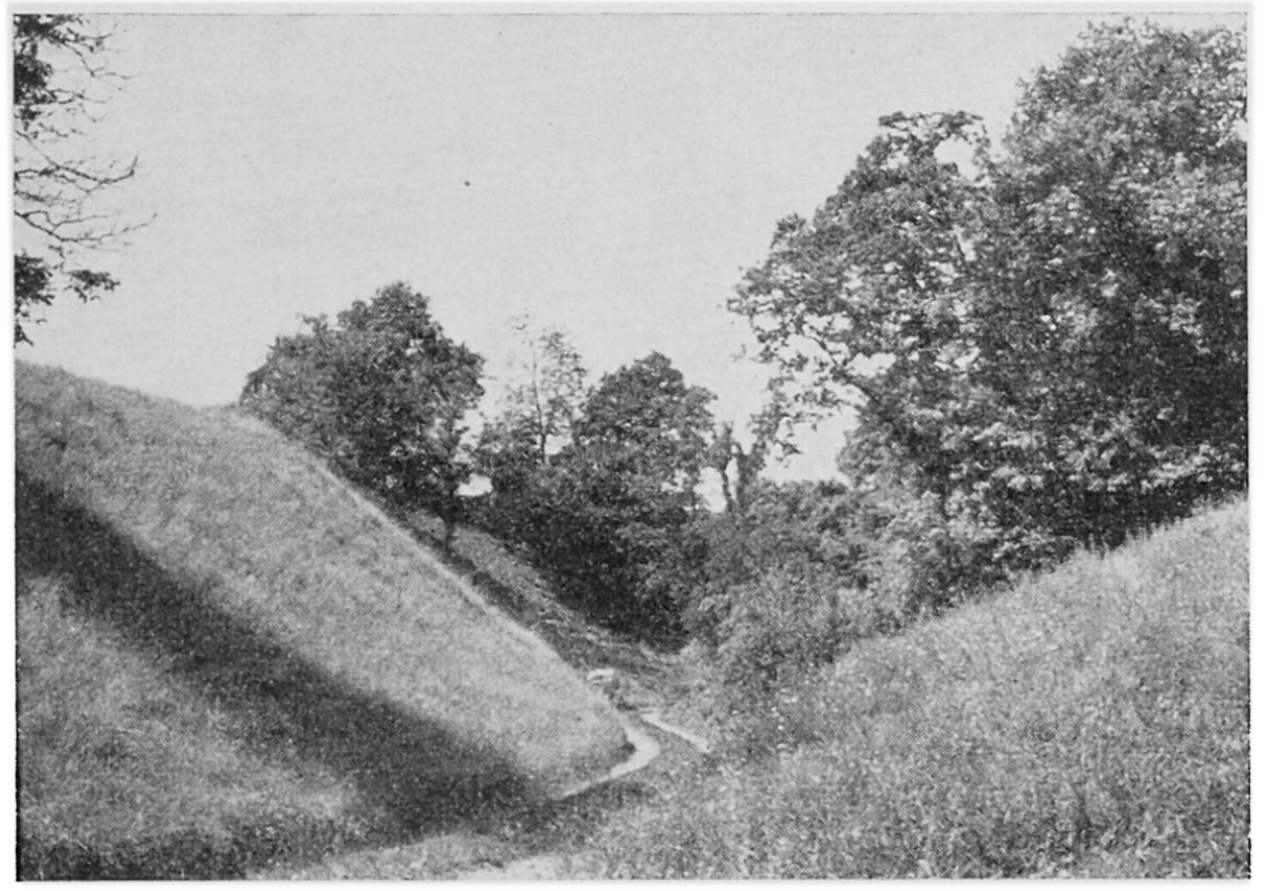

Abb. 7

E-W verlaufendes

Teilstück des

Griesgrabens 


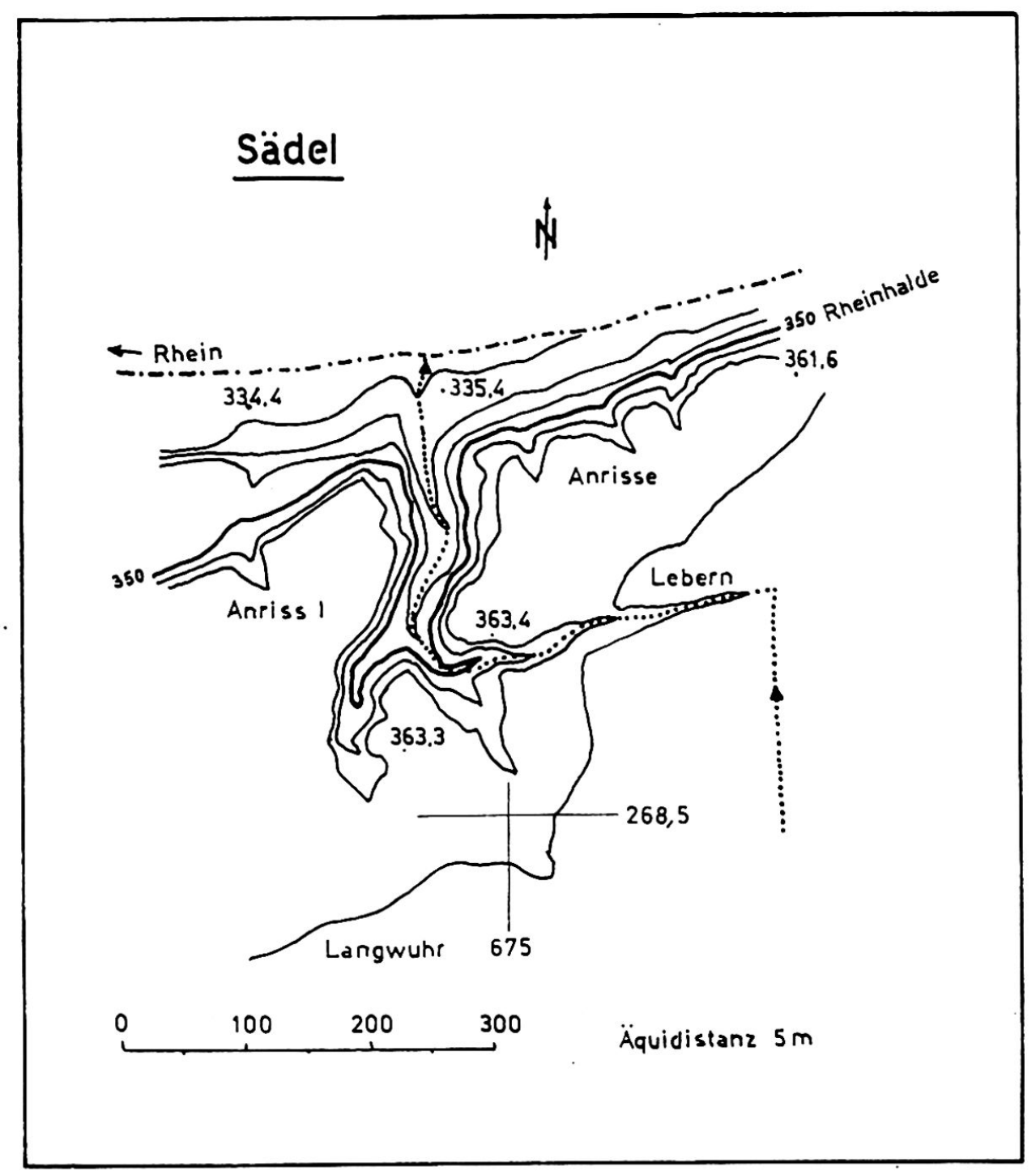

Fig. 7

geschnitten und über $100 \mathrm{~m}$ zurückverlegt (Fig. 7). Auf einem Niveau von $345 \mathrm{~m}$ vereinigen sich die Arme. Die Gefällsverhältnisse bis zur Vereinigung des mittleren und östlichen Armes sind folgende:

$\begin{array}{lll}\text { Mittlerer Arm } & \text { Länge } 140 \mathrm{~m} & \text { Gefälle } 10 \mathrm{~m} \\ \text { Östlicher Arm } & \text { Länge } 115 \mathrm{~m} & \text { Gefälle } 10 \mathrm{~m}\end{array}$

Die Sohle des westlichen Armes fällt bis zur Vereinigung mit den beiden andern auf einer Länge von $145 \mathrm{~m}$ um $15 \mathrm{~m}$. Auf dem gemeinsamen letzten Teilstück wird auf $220 \mathrm{~m}$ Länge noch eine Höhendifferenz von $11 \mathrm{~m}$ überwunden.

Der Sädelbach erodiert kräftig. Prallhangunterspülungen und zerstörte Bachverbauungen lassen die Wucht dieses so harmlos scheinenden Gewässers erkennen. Der 1921/22 in den östlichen Arm eingeleitete Bach hat sein Bett gegenüber dem früheren mittleren Lauf bereits um 1,20 m tiefer gelegt (Abb. 8).

Daß die Erosion die formschaffende Kraft dieser Gräben ist, wird durch das Beispiel des Sädels demonstriert.

Der Bach ist ursprünglich von Weiach her gegen die Dürrwies geflossen und hat sich dort in einer Sumpfzone verloren. Aus dem Ried heraus hat ein Bächlein das Wasser gesammelt und es gegen die ursprüngliche Sädeleinmündungsstelle geleitet (vgl. Wild-Karte, IX, Weiach). Die Sumpfbildungen auf einem Schotterfeld weisen darauf hin, daß in sehr geringer Tiefe unter dem wasserdurchlässigen, trockenen NTSchotter eine wasserundurchlässige Schicht durchzieht. Dieser Wasserstauer muß sich 
vor Erreichen des Rheinhalde bedeutend absenken; er ist am Steilabfall des Rheinufers nicht aufgeschlossen.

Die östlich des Sädels gelegenen grabenartigen Rheinhalde - Anrisse sind rezenter Entstehung; sie sind durch das Überlaufen von Wasserkanälchen bedingt. Seit der Einstellung der Wiesenbewässerung durch Stauung des Baches ist die Erosionstätigkeit stark zurückgegangen (siehe «Erweiterung der Gräben; Förderung von Erosion und Denudation»).

\section{a3) Kaibengraben}

Der regelmäßigste der drei Hauptgräben ist der Kaibengraben. Nördlich der Bahnlinie setzt auf $365 \mathrm{~m}$ ein langes asymmetrisches Muldentälchen mit einem Gefälle von bloß $0,7 \%$ ein. Beim Eintritt in den Wald ändert sich der Querschnitt: Er geht in eine Kastenform mit $14 \mathrm{~m}-15 \mathrm{~m}$ breiter Sohle über. Von diesem Abschnitt an nimmt das Gefälle plötzlich bedeutend $z u$; eine $V$-förmige Erosionsrinne, deren Talsohle noch $4 \mathrm{~m}-5 \mathrm{~m}$ breit ist und sich nachher weiter verschmälert, zieht gegen den Rhein zu (Fig. 8). Die Seitenwände versteilen sich stark. Das Gefälle vom

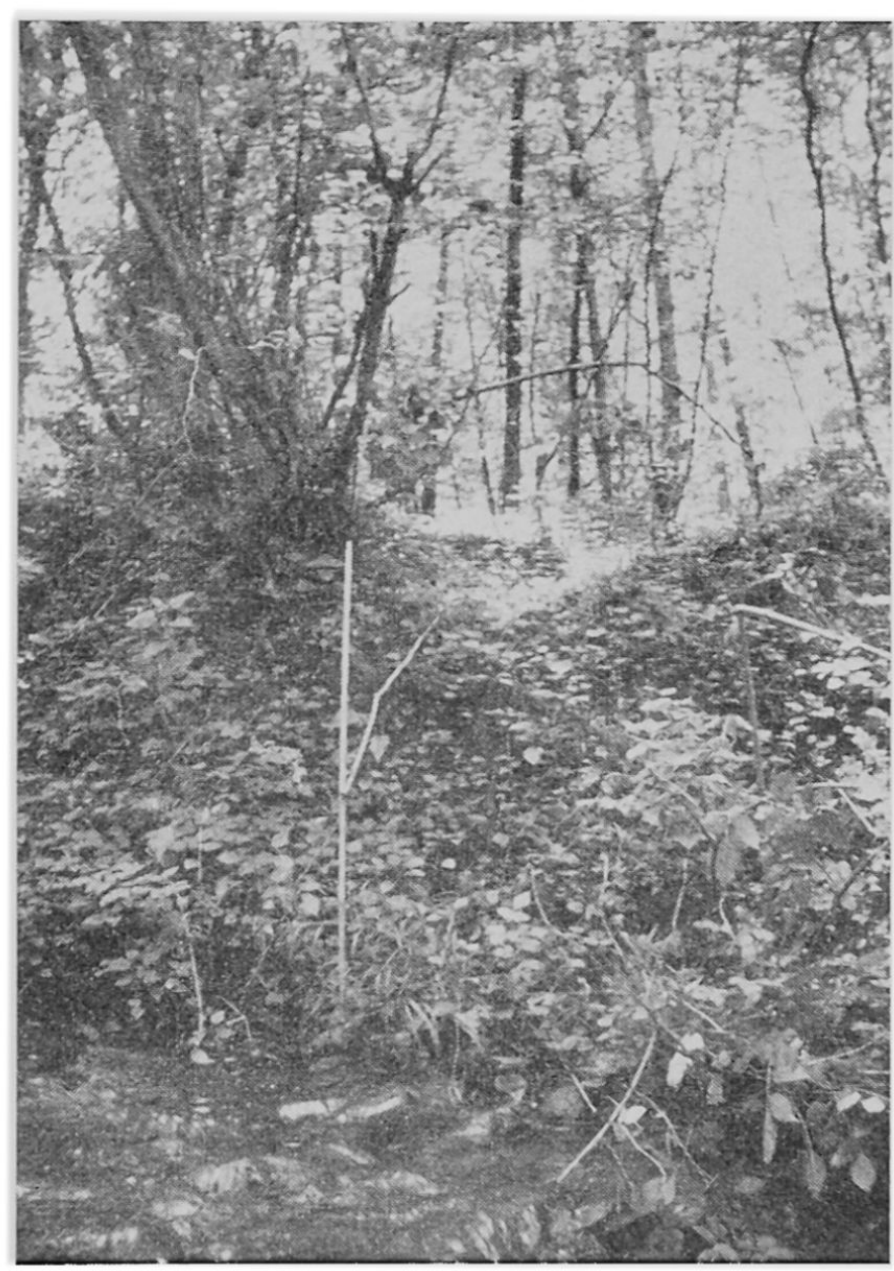

Abb. 8 Übertiefung des Sädelbaches gegenüber dem alten Bachbett. Das obere Ende des Meterstabes liegt auf der Höhe des alten Bachlaufes

Kastentalabschnitt bis zur Ausmündung beträgt auf $235 \mathrm{~m}$ Länge $27 \mathrm{~m}(=11 \%)$. Der Kaibengraben mündet auf 334 m, ca. 2 m über dem Rheinpegel; das Mündungsstück ist in der Fließrichtung des Rheins leicht verschleppt. Die Längsachse ist schwächer verbogen als bei den anderen Gräben.

Die einzelnen Versteilungen innerhalb des Längsverlaufes deuten darauf hin, daß die Erosionstätigkeit des Kaibengrabenwassers nur kürzere Zeit gedauert hat. Das Gefälle müßte sonst ausgeglichener, der Erosionsterminante genäherter erscheinen.

\section{a4) Grenzgraben}

Ein Tälchen setzt auf der Höhe der Bahnlinie an der Kantonsgrenze ein. Es ist durch einen kleinen Bach gebildet worden, der seinen Ursprung nördlich des Geländeabschnittes «Im See» genornmen hat (Dieses Gebiet ist heute drainiert; das Wasser wird in einer Röhre direkt in den Rhein geleitet. Der Bach ist auf dem Wild-Kartenblatt IX eingezeichnet.). Die Kraft des nur zu Regenzeiten fließenden Baches hat nicht ausgereicht, um eine Form in der Größenordnung der drei Hauptgräben zu schaffen; der Graben ist im Anfangsstadium stecken geblieben (Abb. 9).

Das Tälchen setzt breit ein. Nach unten verändert sich sein Querschnitt; die Kanten verlieren sich, eine scharfe Erosionskerbe fehlt. Die Terrassenkante ist durchbrochen worden. Das Tal erreicht das Rheinniveau nicht; es endet im Hang.

\section{a 5) Anriß I}

Der Anriß I setzt direkt, ohne muldenartige Eintiefung, auf $360 \mathrm{~m} \mathrm{~V}$-förmig in die Rheinhalde ein. Das Profil bietet folgendes Bild (Fig. 9): In die Terrassen- 


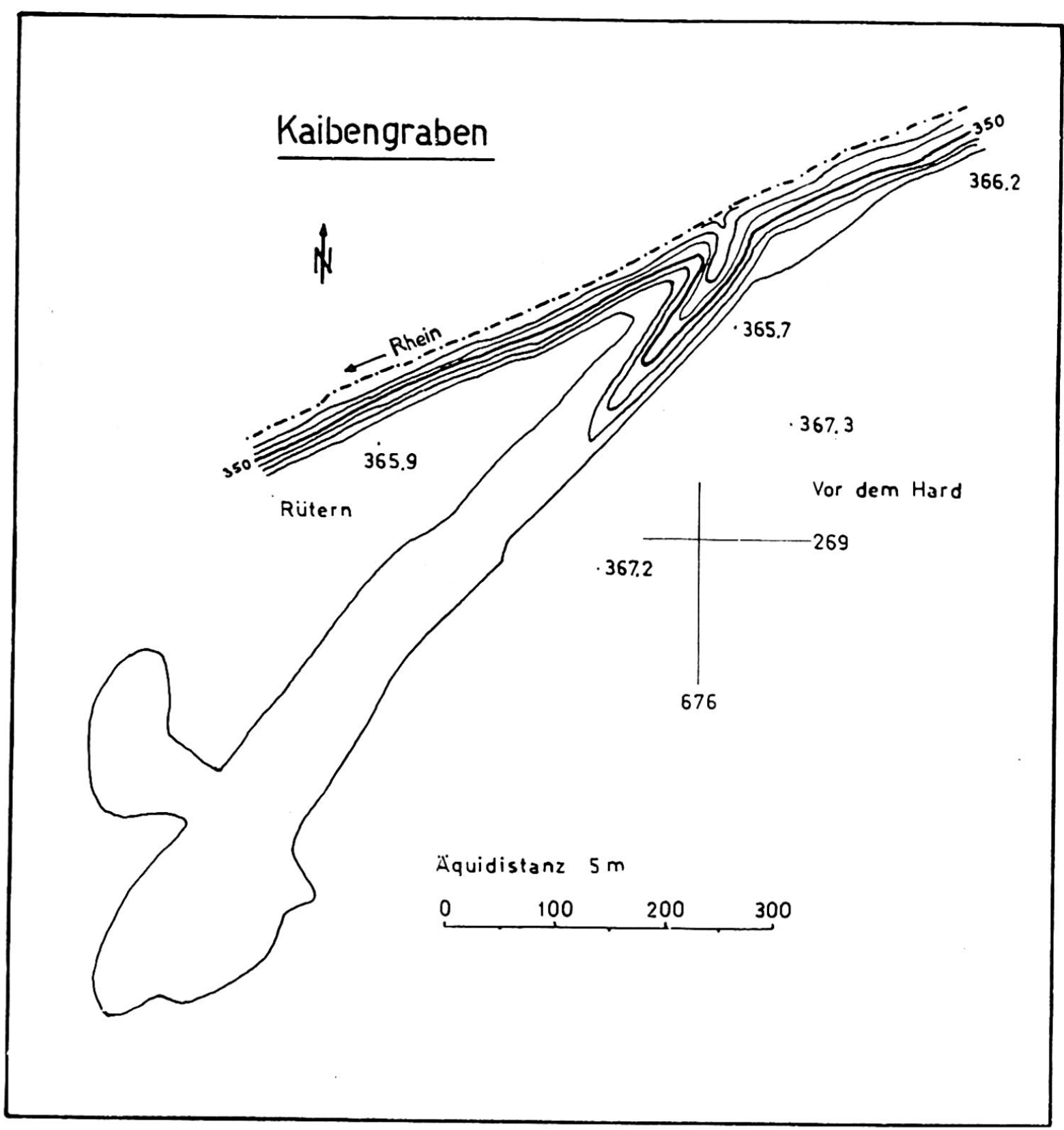

Fig. 8

fläche $\mathrm{A}$ ist der Anriß a eingeschnitten; das erodierte Material ist als Schuttkegel a auf der Terrassenfläche B zur Ablagerung gelangt.

Im Steilhang der Terrasse $\mathrm{B}$ ist der Grabenanri $\beta$ angelegt; das Ausräumungsmaterial liegt als Schuttkegel b auf der untersten Terrassenfläche C. Anriß $\beta$ und Schuttkegel b sind kleiner als die entsprechenden Formen $\alpha$ und a.

In Fig. 10 ist der Anriß I in einem Blockdiagramm schematisch dargestellt. Die Wasserkraft in diesem grabenähnlichen Gebilde ist zu schwach gewesen, um mit sämtlichem Schutt den Rhein zu erreichen; immerhin hat sie genügt, um im Terrassenhang $B$ noch eine Kerbe einzureißen.

Grabenanriß $\alpha$ und $\beta$ sind gleich alt und - aus der Schuttkegelbildung zu schließen - jünger als die Bildung der 'Terrassenfläche $C$.

\section{a6) Muldenartige Eintiefung $A^{*}$}

Diese Form ist am W-Rand des Hardwaldes gelegen und weist eine sehr geringe Eintiefung auf; sie ist weder auf der Landeskarte, noch auf dem Plan von Weiach aus dem Kurvenbild heraus ersichtlich. Die Mulde erinnert an den Beginn des Stuben- 
Abb. 9

Grenzgraben.

Blick vom

deutschen Rheinufer aus

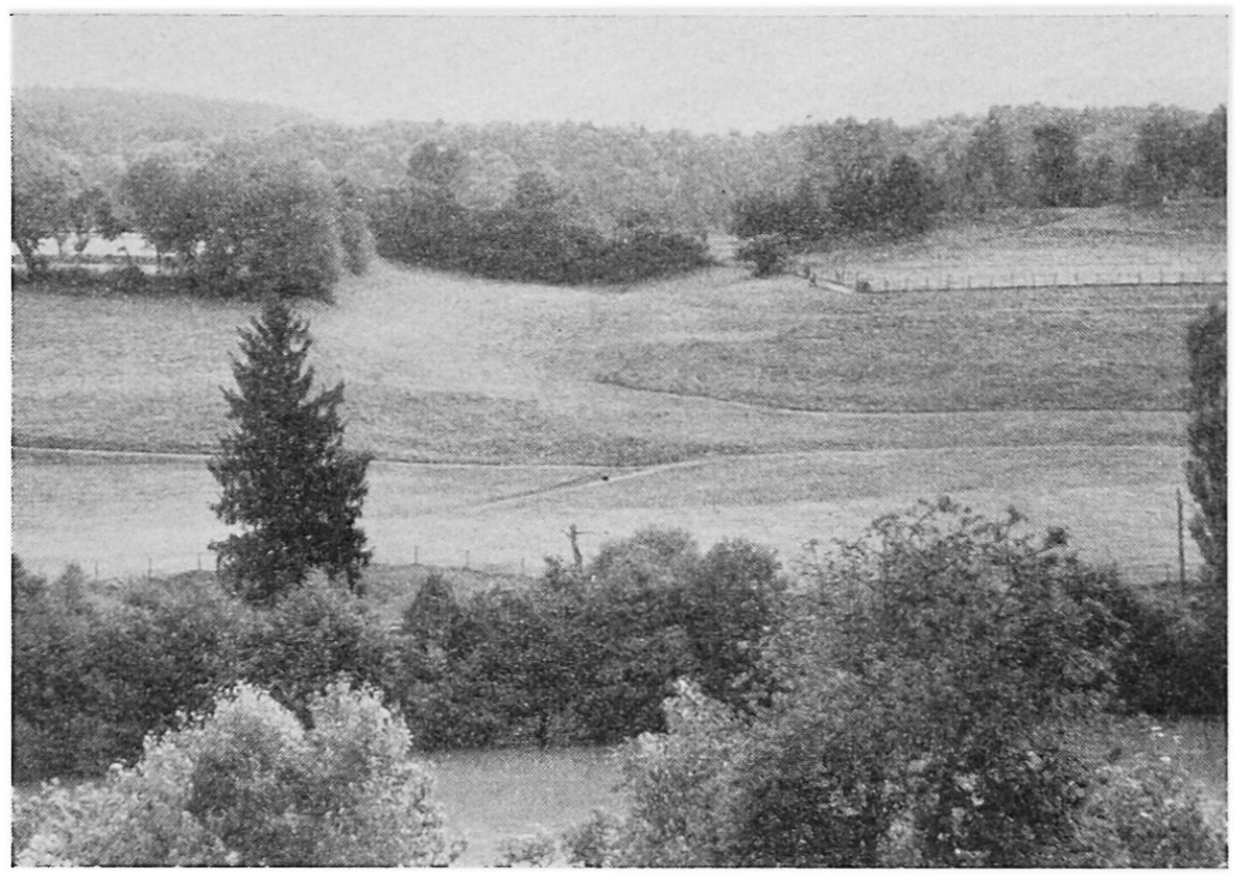

grabens. Im Gegensatz zur Kaibengrabenmulde, die eine Fortsetzung im Erosionseinschnitt findet, verliert sich die Hardmulde vor Erreichen der Steilhalde in der Ebene.

\section{a 7) Muldenartige Eintiefung $B$}

Eine weitere Mulde zieht sich nordwestlich des Hofes «Ofen» von der Straße Zweidlen-Weiach parallel zur Kaibengrabenlängsachse gegen den Hardwald hin (Im Hard ist ein Steinbeil der Rößner-Stufe, ca. 3000 v. Chr., gefunden worden; es befindet sich im Landesmuseum in Zürich.).

\section{Längsprofil Anriss I}

$\mathrm{S}$

N

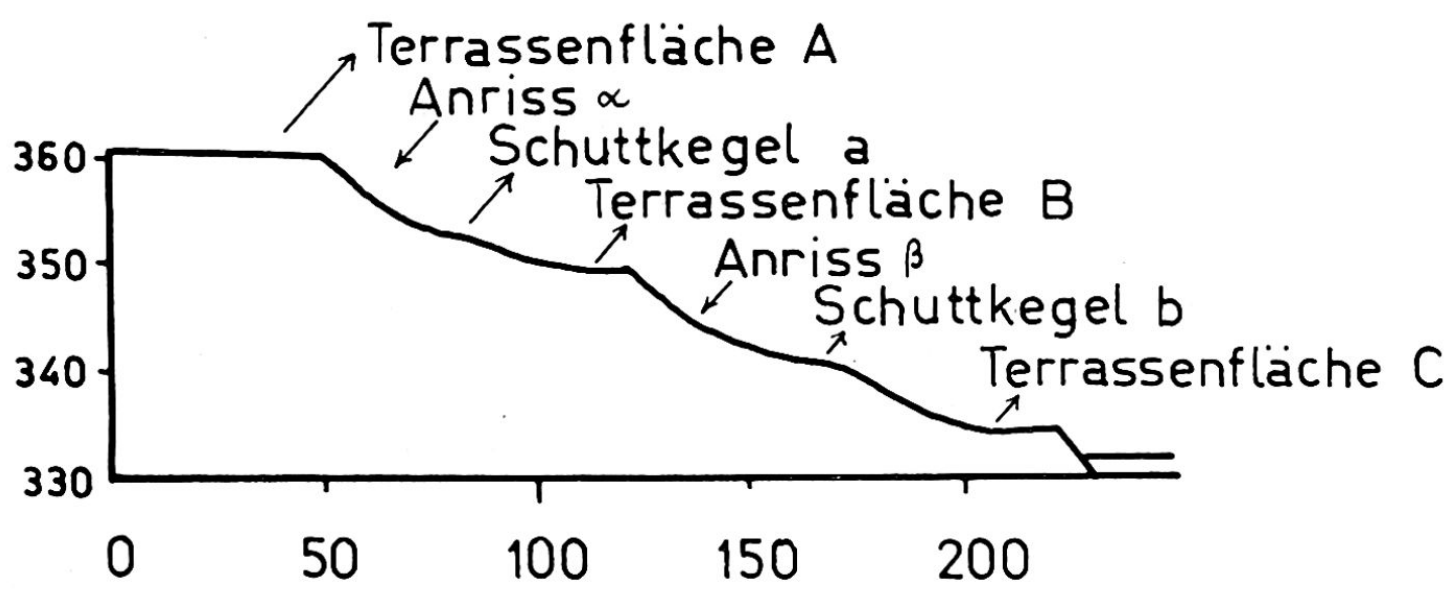

Fig. 9 


\section{Schemarisches Blockdiagramm: Anriss I}

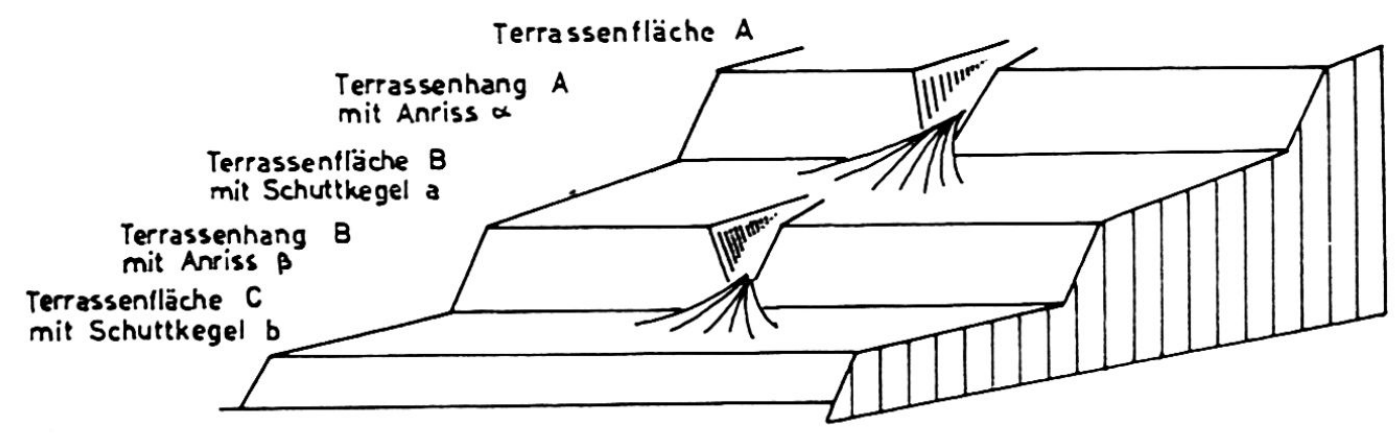

Fig. 10

\section{a 8) Muldenartige Eintiefung $C$}

Die ausgeprägteste der drei muldenartigen Eintiefungen auf der Weiacher Hauptniederterrassenfläche ist die östlichste. Die Wellung kann $100 \mathrm{~m}$ westlich des «Ofens» von der Hauptstraße aus deutlich beobachtet werden.

Über die Entwicklung der Mulden 6, 7 und 8 können nur Vermutungen ausgesprochen werden. Eine Hypothese geht dahin, daß beim Auftauen der obersten Bodenschicht Teilchen auf dem noch gefrorenen Untergrund durch Schmelzwasser abgespült worden seien. Ist einmal eine leichte Rinne vorhanden, wird diese - vor allem zur vegetationsarmen Jahreszeit - der Abspülung verstärkt unterliegen. Diese Ansicht kann gestützt werden durch die gelegentlich vorkommenden Schmelzwasserüberflutungen des Hardfeldes im Frühjahr. Eine andere Erklärungsmöglichkeit besteht darin, daß ein Bach (ungefähr in der Verlängerung des Sägebaches fließend) auf dem groBen Schotterfeld zwischen Weiach und Hardwald ein muldenartiges Tälchen zu schaffen vermocht hätte. Das Wasser müßte dann vor Erreichen der Rheinhalde versickert sein.

\section{B) Allgemeines über die unteren Gräben}

\section{boden}

$\beta 1)$ Entstehung der unteren Gräben, ausgehend von der Hypothese Dauerfrost-

Die unteren Gräben sind jünger als die Anlage der Rheinhalde; ohne den Steilhang hätten die Bäche keinen Ansatz zum Erodieren vorgefunden. Bereits vorher sind Säge- und Mühlebach geflossen. Als der Rhein beim heutigen Dorf Weiach durchpendelte, haben sich beide Bäche direkt in den Strom ergossen. Nachdem sich der Rhein aber nordwärts gewandt hatte, war es wohl möglich, daß die kleinen Seitengewässer auf die Schotterfläche ausstrahlten, ohne den Hauptfluß zu erreichen. Möglicherweise sind die muldenartigen Eintiefungen $\mathrm{A}, \mathrm{B}$ und $\mathrm{C}$ in der Gegend des Hardwaldes auf diese Art und Weise gebildet worden. Mit dem Eintiefen des Rheines im Gebiete der heutigen Rheinhalde haben die Bäche das relativ kurze Schotterzwischenstück zu überbrücken vermocht. Griesgraben und Kaibengraben haben ihre Bildung vor dem Sädel abgeschlossen; ihre Mündungsstellen liegen ca. $2 \mathrm{~m}$ über dem heutigen Rheinpegel. Der Sädel ist heute noch aktiv und dient als Wasserableiter des vereinigten Säge- und Mühlebaches. 
Eine Hypothese hat dahin gelautet, die Gräben als eiszeitlich entstanden zu erklären. Zur vegetationslosen Zeit des Dauerfrostbodens seien bedeutende Schmelzwassermengen flächenhaft vom Stadlerberg und Sanzenberg gegen die Rheinebene hinunter geflossen. Dank der Dauergefrornis sei das Wasser im Schotterfeld nicht versickert und hätte sich nur in sonnexponierte, erosionsanfällige Hänge eingefressen und so die Gräben gebildet.*

Dieser Idee liegt eine Mehrgliedrigkeit der Würmeiszeit zu Grunde, wie sie z. B. Hug (37), ERB (17) und ZINK (98) vertreten haben; denn es müßte noch ein Dauerfrostboden existiert haben, als die Rheinhalde bereits gebildet war! Zum Beleg dafür könnte man bei oberflächlicher Betrachtung eine im $380 \mathrm{~m}$ - $370 \mathrm{~m}$-Steilhang angelegte, dellenartige ausgeräumte Nische herbeiziehen. Der Schutt dieser Erdverschiebung ist auf die Weiacher Hauptniederterrassenfläche zu liegen gekommen; dies beweist, daß die Abtragungsform jünger ist als die Anlage der Hauptniederterrassenfläche. Auch im Terrassenhang beim Äußeren Haslihof hat eine Ausräumung stattgefunden, deren natürliches Ausmaß wegen Anlage einer Straße allerdings nicht genau ermessen werden kann. Das oberflächliche Erdfließen wird ebenfalls durch leichtes Hakenschlagen der obersten Schichten, erschlossen in der Kiesgrube westlich des Äußeren Hasli, bewiesen.

Die These der Mehrgliedrigkeit der vorhandenen Würmschotter kann nun aber widerlegt werden; damit fällt auch die Hypothese der Grabenbildung zur Dauerfrostbodenzeit dahin, da ja die Ausbildung der Erosionsterrassen im Spätglazial erfolgte, zu einer Zeit als der Permafrost bereits verschwunden war. Für die Unterscheidung von Akkumulations- und Erosionsterrassen ist eine neue Indizmethode angewand worden (Fig. 11, Abb. 10, 11, 23; siehe auch Boesch, 3, und Bugmans, 13). Umfaßt ein Aufschluß (in Fig. 11 mit * bezeichnet) gemeinsame Teile der Schotter der höheren Terrasse und der tieferen Fläche, liegen gute Indizien zur Beurteilung der tieferen Fläche vor.

I : Zieht eine deutlich ausgeprägte Schotterschicht der tieferen Fläche (B) unter die höhere Terrasse (a, A) hinein, können wir vermuten, daß die tiefere Fläche (B) erosiv geschaffen worden sei (man beachte die Einschränkung VI.).

II : Findet sich hingegen eine Diskordanz zwischen den Schottern unter der tieferen Fläche (D) und denjenigen, die die höhere Terrasse (c, C) unterlagern, können wir die tieferen Schotter (D) als akkumulativ eingeschachtelt denken. $\mathrm{Ob}$ die im Aufschluß vorhandene Fläche D dem Akkumulationsniveau der neuen Aufschotterung entspricht, oder ob sie bereits durch Erosion wieder tiefergelegt worden ist, müssen weitere Untersuchungen belegen (vgl. III, IV, V).

III : Das Tal in der Terrasse $\mathrm{E}$, e ist teilweise wieder aufgeschüttet worden (vgl. II). Wir denken uns die Akkumulation bis ins Niveau $F_{1}$ reichend $\left(F_{1}=\right.$ Akkumulationsniveau). Nachträglich kann die Schotterfüllung erosiv vom Niveau $F_{1}$ auf $F_{2}$ hinunter erniedrigt worden sein. $F_{2}$ müßte in diesem Falle als Erosionsfläche bezeichnet werden. Zeichnung IV soll erläutert, wie das Entstehen der tieferen Fläche ermittelt werden kann.

IV: Ist die tiefere Fläche (I) wirklich ein Erosionsniveau, können im Talverlauf oft Reste der ehemaligen Akkumulationsfläche $(\mathrm{H})$ gefunden werden. Es wäre wohl theoretisch denkbar, daß eine Rückerodierung innerhalb der genau gleichen Begrenzung wie die Aufschotterung stattgefunden hätte und dadurch sämtliche höheren Reste entfernt worden wären (vgl. Zeichnung III). In der Natur dürfte dieser Fall kaum existieren. Außerdem kann aber die Fläche I durch Seitenreosion des mäandrierenden Flusses beim Tieferschneiden so stark ausgeweitet worden sein und den Prallhang unterschnitten haben, daß nicht

* Dieser Erklärungsversuch ist um 1950 durch CARol im Zusammenhang mit den Übungen des Geographischen Institutes der Universität Zürich entwickelt worden. 

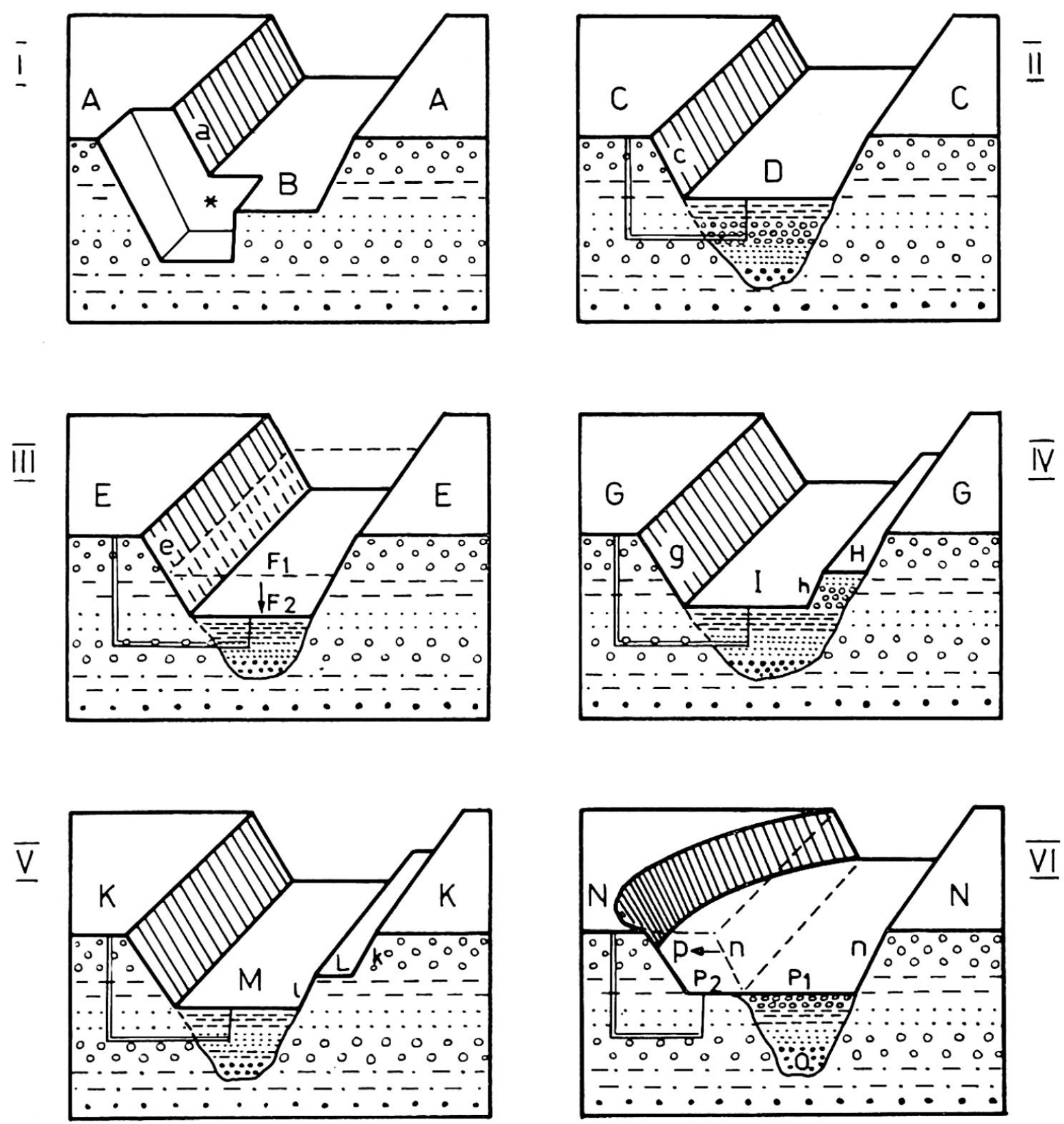

Fig. 11 Zur Beurteilung der Schotterterrassen nach der Indizmethode

nur die höheren Akkumulationsterrassenreste wegerodiert, sondern auch der Hang g angegriffen worden ist; vgl. auch Wirkung der Seitenerosion bei VI.

$\mathrm{V}$ : Zeichnung $\mathrm{V}$ ist mit Bezug auf die auftretenden Formen mit IV identisch, der Unterschied liegt in Material begründet. M erscheint als Akkumulationsfläche, da eine Schotteruntersuchung nachgewiesen hat, daß die Schotter der Terrasse 1, L mit denjenigen der Terrasse $\mathrm{k}, \mathrm{K}$ identisch sind.

VI: Finden wir einen Aufschluß im Sinne I, haben wir wohl ein starkes Indiz dafür, daß die tiefere Fläche durch Tieferschneiden des Flusses angelegt worden ist; ein Beweis hingegen ist es nicht. Zeichnung VI soll dies illustrieren: In die Schotterfläche $\mathrm{N}$ ist eine Rinne bis auf das Niveau $\mathrm{O}$ eingetieft worden. Die seitliche Begrenzung des Tales sei durch die Hänge n gekennzeichnet. Eine nachträgliche Akkumulation führt zur Aufschotterung auf das Niveau der Fläche P. $\mathrm{P}_{1}$ (im Bereiche des frisch akkumulierten Schotters gelegen) ist als Akkumulationsfläche zu bezeichnen. Eine Aufschotterung ist aber oft mit Seitenerosion verbunden (VON WISSMANN, 96), die den ehemaligen Terrassenhang 
Abb. 10

Aufschluß in der Kiesgrube östlich des Weiacher Schützenhauses $380-370$, rechts Hauptniederterrassenfläche

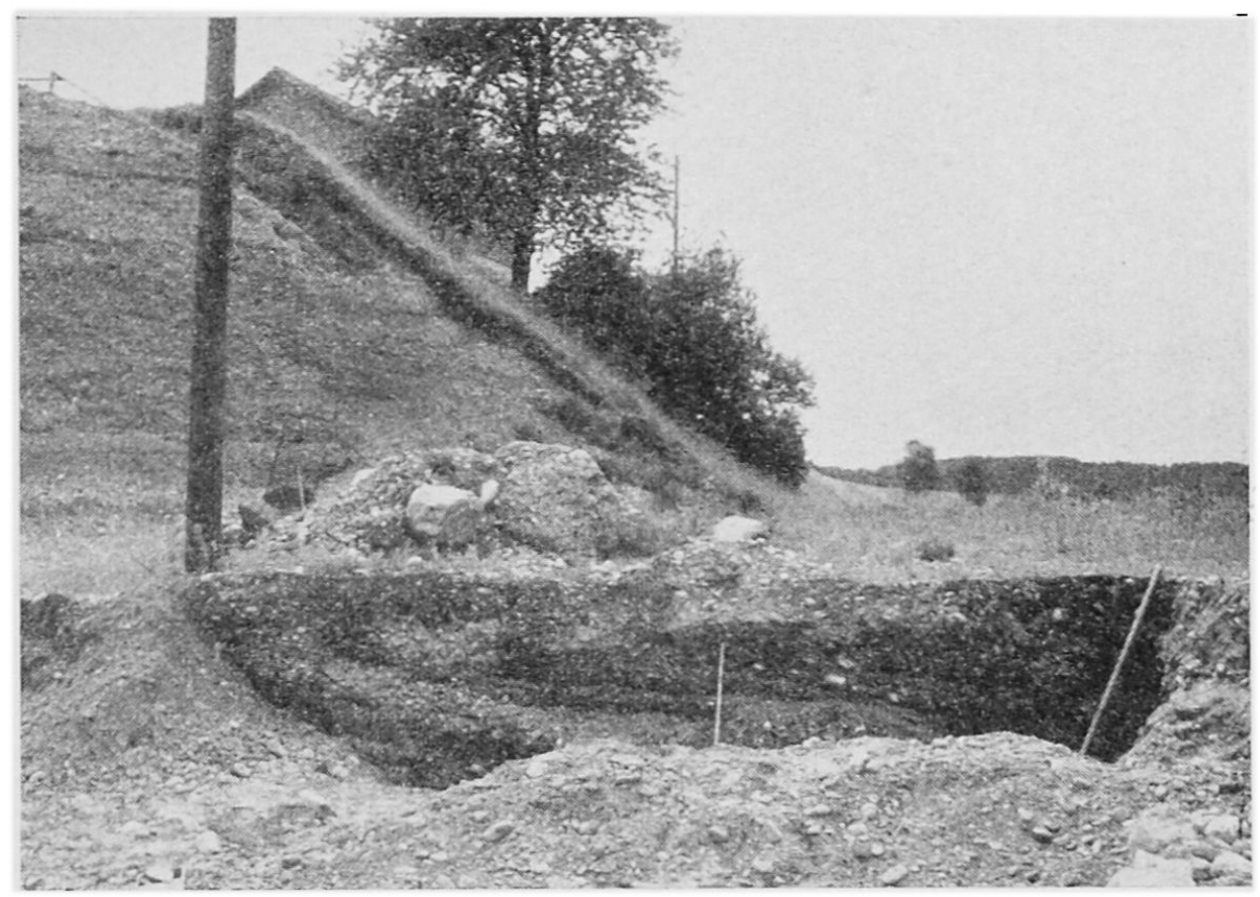

$\mathrm{n}$ nach $\mathrm{p}$ zurückzuversetzen vermag. Die Fläche $\mathrm{P}_{2}$ - eine Erosionsfläche! -, die im selben Niveau wie die Akkumulationsfläche $\mathrm{P}_{1}$ liegt, ist im gleichen Material wie die Terrasse $N$ angelegt. Der eingezeichnete Aufschluß, der nur im Bereiche des Schottermateriales der Terrasse $N$ angelegt ist und daher keine Diskordanz zeigt, könnte leicht dazu verleiten, die gesamte Fläche $\mathrm{P}_{1-}$ $\mathrm{P}_{2}$ einheitlich als Erosionsfläche zu beurteilen. Um einem solchen Fehlschluß vorzubeugen, ist es unumgänglich, die Natur der gesamten Fläche genau abzuklären. Das kann z. B. anhand von Schotteranalysen geschehen. Weist $\mathrm{P}_{1}$ einen von $\mathrm{P}_{2}$ verschiedenen Schotterbefund auf, darf auf akkumulative Einschachtelung von $\mathrm{O}$ auf $\mathrm{P}_{1}$ geschlossen werden; finden wir hingegen Materialgleichheit vor, ist die ganze tiefere Fläche wie in Zeichnung I als Erosionsfläche zu betrachten. (Oft gelingt der Nachweis der erosiven Entstehung der gesamten tie-

Abb. 11

Keine Diskordanz zwischen den

Schottern, die den Steilhang unterlagern und denjenigen der Hauptniederterrassenfläche Vergleichsmaßstab : $1 \mathrm{~m}$

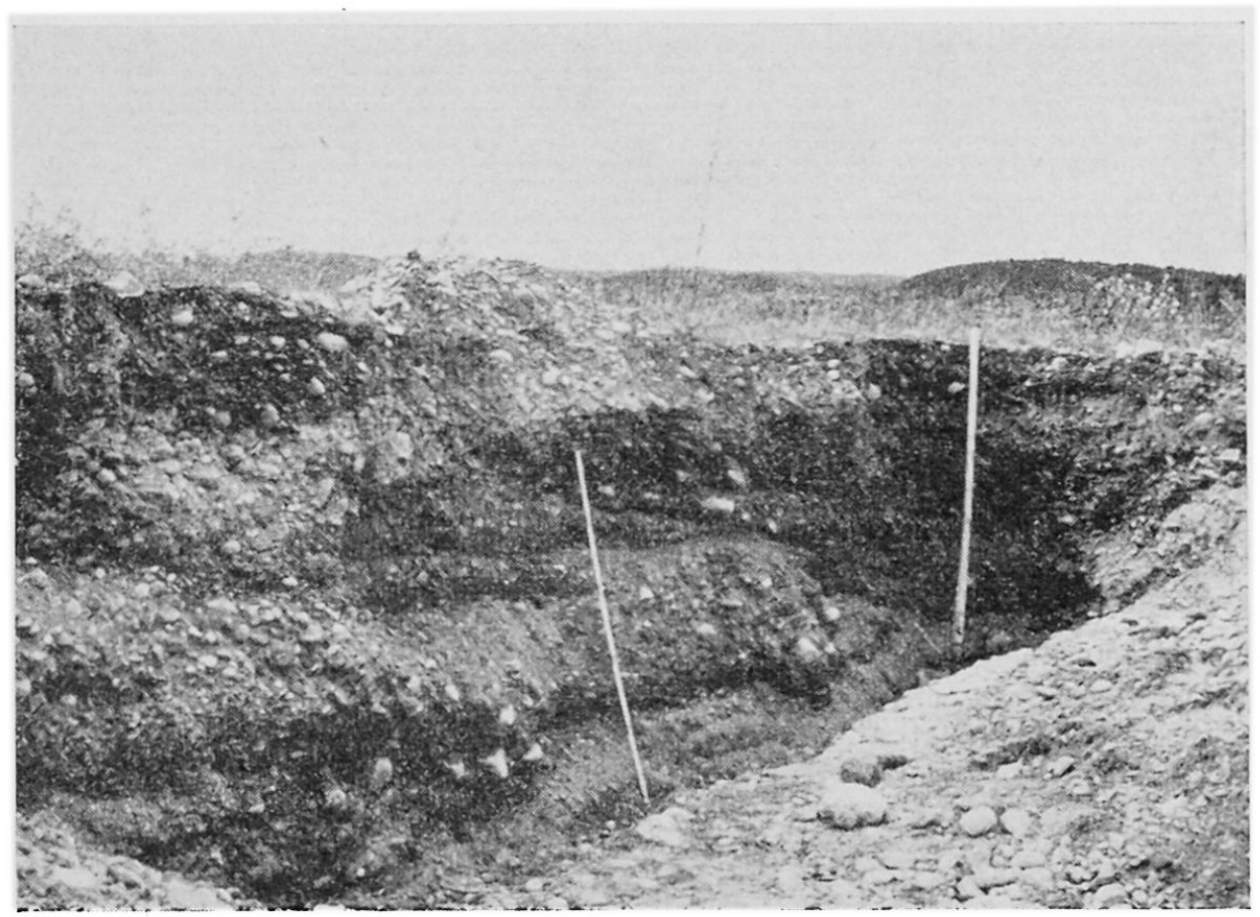




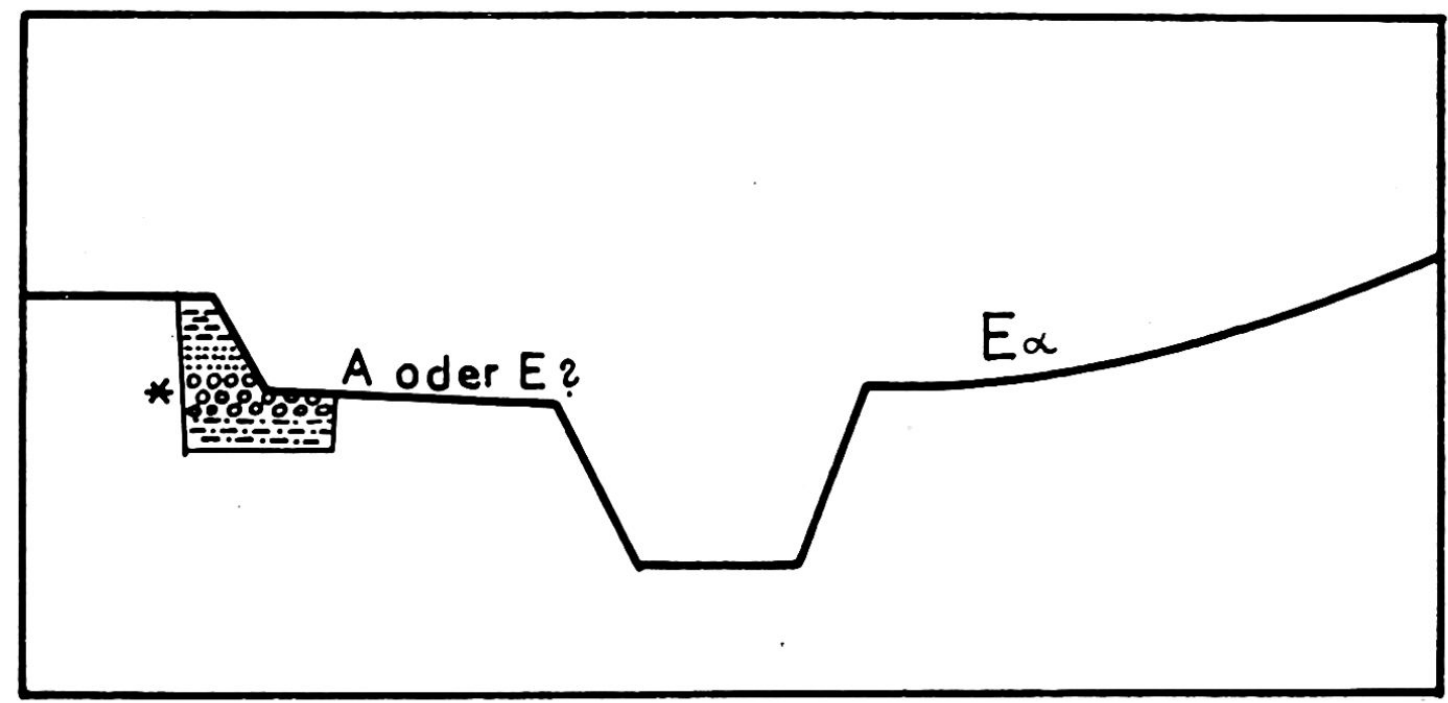

Fig. 12 Schema zur Beurteilung der erosiven oder akkumulativen Anlage der Fläche $\mathrm{A}$ oder E ?

feren Fläche auch auf einem anderen Wege; meine Erklärung zur Entstehung der Weiacher Hauptniederterrassenfläche soll dazu ein Beispiel liefern.)

Ein freigelegter Aufschluß in der Kiesgrube östlich des Weiacher Schützenhauses umfaßt Teile unter der Hauptniederterrassenfläche $(368 \mathrm{~m}-369 \mathrm{~m})$, die in der gleichen Höhe unter dem südlich anschließenden Terrassenhang durchziehen (Abb. 10). Die den 380 m-370 m-Steilhang unterlagernden Schotter sind mit denjenigen der Randteile unter der Hauptniederterrassenfläche identisch. Nirgends ist eine Diskordanz festzustellen. Auch das Hakenschlagen der obersten Steilhangschichten setzt sich unter dem inneren Terrassenhang liegenden Aufschluß nicht fort (Abb. 11).

Die Schotter der Hasliterrasse und die aufgeschlossenen Teile der Weiacher Hauptniederterrasse sind gleichaltrig. Das ist bereits ein Indiz dafür, daß die tiefere Fläche erosiv angelegt worden sein könnte. Wir haben nun nach den bei Fig. 11, VI, entwickelten Gedankengängen zu untersuchen, ob die Weiacher Hauptniederterrassenfläche in ihrer Gesamtheit als Erosionsterrassenfläche bezeichnet werden kann, oder ob es sich um eine aus verschiedenaltrigem Schottermaterial bestehende, durch kombinierte Akkumulation und Seitenerosion entstandene Oberfläche handelt. Da der Nachweis der erosiven Gestaltung der gesamten Oberfläche formmäßig gelingt, kann von einer Schotteranalyse abgesehen werden. Wie im Kapitel «Würmterrassen in den verschiedenen Abschnitten des Rheintales, Abschnitt Tössegg-Kaiserstuhl»gezeigt wird, können die bei Weiach zu untersuchenden Objekte mit anderen Flächen im Arbeitsgebiet korreliert werden. So liegt die Hasliterrasse und die Weiacher Hauptniederterrassenfläche innerhalb der Folge Gländ - Birchstud - Ober-Seglingen (nördlich der Chrüzstraß), Ghürst - Chüesetzi (südlich von Wil/Rafzerfeld), Läng Höhen-Ried (nordöstlich Hohenthengen). Diese korrelierbaren Flächen sind abgleitend. Abgleitende Flächen aber können nur während einer Erosionsphase entstanden sein. Die zu untersuchenden Weiacher Terrassen liegen innerhalb des Niveaus der erwähnten abgleitenden Folge; daher muß auch die Weiacher Hauptniederterrassenfläche erosiv entstanden sein (vgl. schematische Skizze, Fig. 12).

Der Aufschlu * $^{*}$ weist Konkordanz zwischen den Schottern der höheren Terrasse und den Randteilen unter der tieferen Terrassenfläche nach. Es soll nun entschieden werden, ob die tiefere Fläche in der Fortsetzung ebenfalls erosiver Entstehung sei oder aber wie im Falle VI eine akkumulative Oberfläche darstelle. Die Frage wird auf Grund der korrelierbaren Fläche $\mathrm{E}_{\alpha}$ beantwortet. $\mathrm{E} \alpha$ ist eine abgleitende Fläche, die nur während einer erosiven Phase entstanden sein kann; die in derselben Zeit wie $\mathrm{E}_{\alpha}$ angelegte fragliche Fläche (A oder E?) muß daher ebenfalls erosiver Entstehung sein. 
Im Falle von Weiach gilt daher folgendes:

Die Schotter der Hasliterrasse und der Weiacher Hauptniederterrasse sind gleichaltrig. Beide sind Erosionsterrassen, wobei die Form der Hauptniederterrasse jünger ist als diejenige der Hasliterrasse. Efo an. ${ }^{*}$

$\mathrm{Da}$ auch tiefere Flächen zum Teil abgleitend auftreten (z. B. Steinert-Neuhus, Niveau 5/6/7) und die erosive Entstehung der Fläche $\mathrm{D}$ nördlich Rheinheim direkt bewiesen werden kann (vgl. «Die Würmterrassen in den verschiedenen Abschnitten des Rheintales 》), erscheint die Würmaufschotterung in diesem Gebiet als eingliedrig.

Auf Grund meiner Beobachtungen kann eine Mehrphasigkeit der Würmeiszeit nicht belegt werden; mein Befund darf aber nicht als entscheidender Schluß für die Eingliedrigkeit der Würmeiszeit verstanden werden. Es ist in Betracht zu ziehen, daß wir bei dieser engen Untersuchung die eventuelle Mehrgliedrigkeit der Würmeiszeit nur nach den vorhandenen Schottern beurteilt haben. Diese Schotter erscheinen einheitlich akkumuliert. Ob der vorhandene Schotterkomplex in seiner Gesamtheit nur ein Glied der Würmunterteilung (Würm I, Würm II oder Würm III usw.) darstellt, können wir anhand dieser Beobachtungen nicht feststellen. Es sei darauf hingewiesen, daß auch bei Dangstetten die Ineinanderschachtelung der Würmschotter widerlegt werden kann (Abb. 23). Bugmann (13) stellt im untersten Aaretal ebenfalls Eingliedrigkeit der Würmaufschotterung fest.

\section{B2) Richtung und Lage der Gräben}

Vergleichen wir die Richtungen der Längsachsen der drei Hauptgräben, so können wir folgendes feststellen:

1. Die Griesgrabenlängsachse verläuft vorerst im spitzen Winkel zur Fließrichtung des Rheines; die Einmündung erfolgt ungefähr senkrecht zum Flußlauf.

2. Die Sädelachse stößt senkrecht gegen den Rhein.

3. Der Kaibengraben liegt in einem stumpfen Winkel zur Fließrichtung. Das Mündungsstück ist durch den Strom nach unten verschleppt worden.

Diese vorerst wirre Anordnung läßt sich klären, wenn wir die Längsachsen der Gräben verlängern und zum Schnitte bringen. Die Achsen schneiden sich beim Dorf Weiach, d. h. beim Zusammenfluß des Mühlebaches und des Sägebaches (Fig. 13).

Der Griesgraben findet sich in der ungefähren Verlängerung des Mühlebaches, der Kaibengraben in der Verlängerung des Sägebaches. Der Sädel liegt im Schwenkungsbereich des Unterlaufes. Die drei Gräben müssen als verschiedene Mündungsarme der vereinigten Bäche aufgefaßt werden. Die Verlagerung der Arme kann durch Intensitätsänderung in der Wasserführung sowie durch Schuttablagerung und die dadurch bedingte Abdrängung des Bachlaufes verursacht worden sein. Bei der Überfließung des flachen Schotterzwischenstückes ist ein Teil des Wassers versickert und hat dabei an bestimmten Stellen zur Versumpfung geführt.

Der heutige Bach fließt meist träge durch Wiesen und Felder. Das Gefälle ist viel zu gering, um einer bedeutenden Eintiefung zu rufen. Die Erosion setzt erst dort ein, wo der Wiesenbach in den seitlichen Arm des Sädels eingeleitet worden ist. In diesem steilen Teilstück hat sich der Bach seit 1922 stark eingefressen und rückwärts

* Jede Terrasse besteht aus zwei Flächenelementen (Terrassenfläche und Terrassenhang) und drei linearen Elementen (innerer Terrassenrand, obere Terrassenkante, untere Terrassenkante). In der Typenformel BoEschs bezeichnet der erste Großbuchstabe die Entstehungsart der Terrassenfläche, der zweite Großbuchstabe die Anlage des Terrassenhanges, wobei A für akkumulative, E für erosive Gestaltung gesetzt wird. Die Indizes 1, resp. 2, drücken die Reihenfolge in der Anlage der Flächenelemente aus. Die beigefügten Kleinbuchstaben beschreiben die Akkumulations- und Erosionsvorgänge exakter ( $\mathrm{f}=$ fluviatil; $\mathrm{d}=$ denudativ usw.). 


\section{Richtungen der Längsachsen}
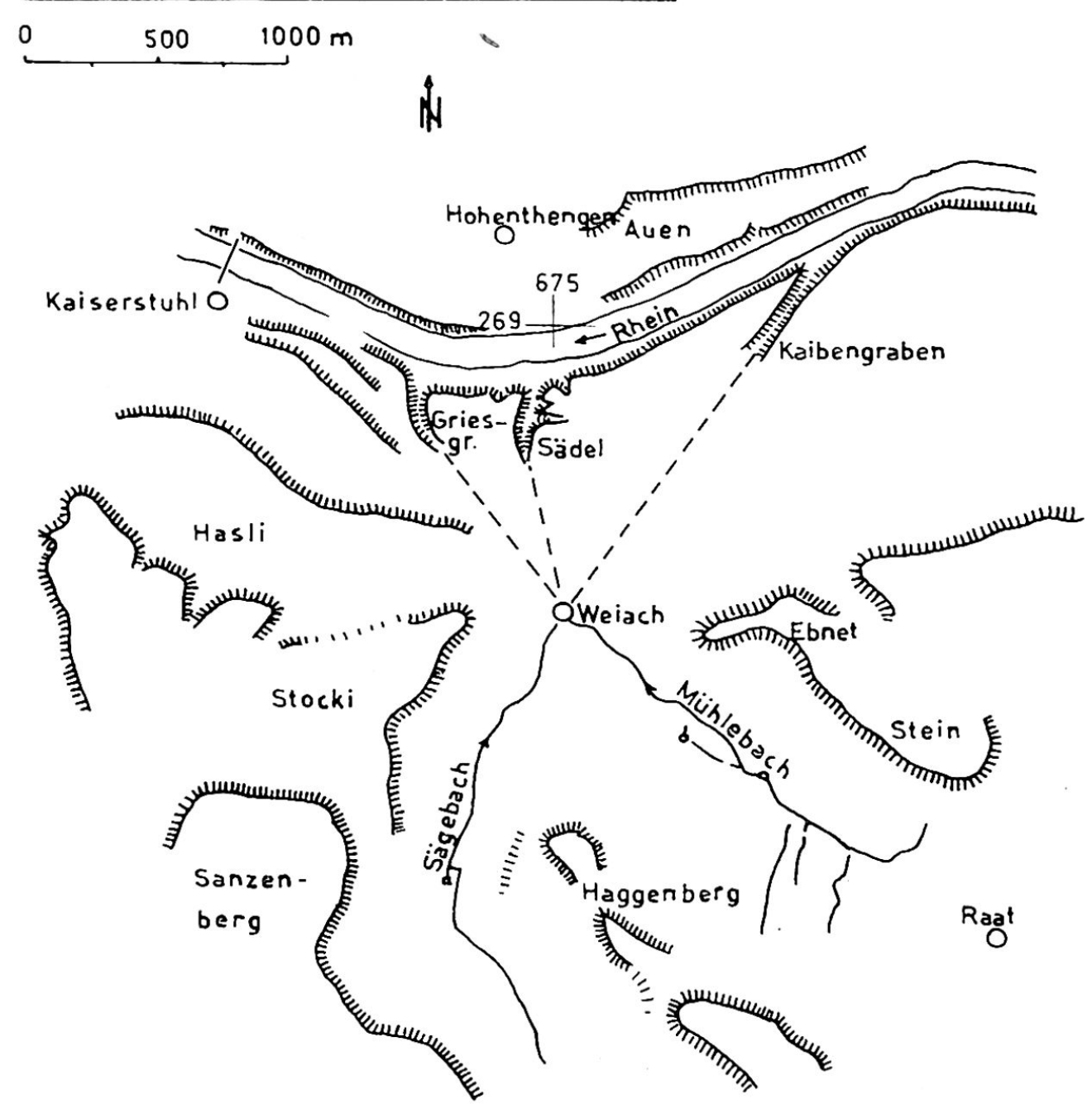

Fig. 13

erodiert. Ganz ähnlich kann man sich nun die Bäche vorstellen, die einst gegen den Griesgraben und den Kaibengraben geflossen sind: Bäche, die ihres Sickerverlustes und des geringen Gefälles wegen auf der Weiacher Ebene beinahe nicht erodiert haben. Die Erosion hat erst mit Erreichen des Rheinhalde-Steilhanges eingesetzt. Nicht irgend ein unbedeutendes, nur grundwassergespiesenes, zeitweise fließendes Bächlein hat die drei Hauptgräben geschaffen. (Das Gewässer, das seinen Anfang in der Sumpfzone «Im See» nahm, hat lediglich eine geringe Eintiefung verursacht; die Kraft zur wirksamen Einkerbung am Steilhang ist zu gering gewesen.) Ein Bach, der mindestens zeitweise bedeutende Wassermengen zu liefern imstande ist, hat die Rheinhalde-Gräben geschaffen. Dieses immerfließende, bei Unwettern bedeutend anschwellende Gewässer ist der vereinigte Säge- und Mühlebach. Der Sägebach bezieht sein Wasser «Im Moos» (Quellgebiet des Haggenberges und des Sanzenberges). Dem Mühlebach wird das Wasser aus dem großen Quellgebiet des Steins und vom Nordabhang des Haggenberges zugeführt. 


\section{B3) Erweiterung der Gräben; Förderung von Erosion und Denudation}

Bei der Ausweitung der Gräben spielen Naturereignisse wie auch anthropogene Einflüsse eine Rolle. Plötzlich erhöhte Wasserzufuhr führt zum reißenden Anschwellen kleiner Bäche: An steilen Hängen erodiert das Wasser; auf den 'Terrassenflächen gelangt das ausgespülte Material zur Akkumulation. Grabennahe durchnäßte Massen gleiten die Steilhänge hinunter und verlegen so die Grabenanrisse weiter in wertvolles Kulturland zurück. Die Erosionsanfälligkeit kann auch durch den Menschen gesteigert werden: Unvernünftige Rodungen haben ein geringeres Retentionsvermögen zur Folge; Vernachlässigung des Bachbettes ruft Überschwemmungen: Das Wasser tritt über die Ufer und vermag unter Umständen neue Rillen zu bilden. Die Anlage von Wässerkanälen birgt die Gefahr von Überschwemmungen in sich.

Diese Faktoren sind in den Weiacher Gemeinderatsprotokollen (GR) und den Gemeindeversammlungsberichten $\left(\mathrm{GV}^{\top}\right)$ aufgezeichnet $(90,91)$. Auch in den Lokalzeitungen $(99,100)$ werden einzelne Vorkommnisse festgehalten. In den Protokollen der Gemeinde Weiach sind Überschwemmungen und Hochwasserkatastrophen selten direkt erwähnt; meist erfährt man indirekt von Wassernöten, indem Gesuche um Steuererlaß gestellt werden, Straßenausbauten besprochen oder Bußen wegen fahrlässigen Verursachens von kleineren Überschwemmungen der Dorfbäche verhängt werden müssen. «Die Ergebnisse der täglichen Niederschlagsmessungen 》 (58) machen uns mit der Niederschlagsmenge von Kaiserstuhl bekannt.

Es wäre falsch, vom gefallenen Regen auf die Erosionsleistung zu schließen, ist es doch so, daß die Erosionsleistung ebenso stark von der Regenintensität abhängig ist. Beobachtungen von Waldarbeitern und eigene Feststellungen zeigen allerdings, daß auch regelmäßig fallende, größere Regenmengen zu Erosionserscheinungen in den oberen Gräben und im Sädel führen. Macht die Eintiefung auch nur einige $\mathrm{cm}$ aus, so weist sie doch darauf hin, daß diese Gräben heute noch in geringem Maße aktiv sind. Gesteigert wird die Erosionstätigkeit bei plötzlichem Wasseranschwellen, sei es nach wolkenbruchartigen Regenfällen oder noch ausgeprägter bei raschen Schneeschmelzen.

Aus folgenden Jahren werden Unwetter und anhaltende Regenfälle gemeldet, die sich auf die Erweiterung der Gräben ausgewirkt haben müssen:

1805: Ein Bergsturz und Erdrutsch aus den Reben im Solli und Bifang werden erwähnt ${ }^{*}$.

1806: Dieser Sommer zeichnet sich durch anhaltendes Regenwetter aus *2.

1835: Der Spätsommer wird als sehr naß geschildert *3.

*1 GR 17. 12. 1805: «Bedicion wegen steür aufhebung des angefürten schadens eines Bergstozes in Solli Räben und Bifang Räben genannt. Demnach der Hs. Heinrich Baumgartner genant Wirz Joglis einen muntlichen befehl von $\mathrm{Hr}$. Stathalter angst an den Gemeindraht überbracht, das der gemeindraht eine beschreibung und schazung aufnemmen solle, über den Berg Stoz so den verflossen Frühling dis Jahrs sammt den Räben hinunter geruscht und damit andere überdekt worden sind... die Erden samt den Räben circa 8 bis 9 Schu tief hinuntergeruscht... wodurch der Verlust und Schaden sich belauft Laut Pflichtmessiger und unparteyischer Schazung:

dem Jacob Schneider od. Zügere ott und meyer 1 Zelg . . . . . . . . 60.dem Hs. Heinrich Baumgartner Wirz 5 mssli . . . . . . . . . . . . 140.dem Heinrich Baumgartner, Wirz Felixen, 3 mssli . . . . . . . 85.-

*2 $G V$ 7. 8. 1806: «.... weil durch das anhaltende Regenweter circa der 4. Theil der dazumahl auf dem Feld befindenden Frucht ausgewachsen und die Ehren abgefallen seyen.»

*3 GR 14. 9. 1835: «Da durch das anhaltende Regenwetter das Besähen der Felder verspätet und man jetzt benöthigt ist dasselbe $z u$ bestellen, ohnegeachtet es sehr na $B$ ist, so hat der Gemeinderath beschlossen, sämtliche Bürger zu ermahnen, daß sie sobald als möglich ihre Felder bestellen, besonders solche welche auf Trettäcker oder auch andere Äcker müsssen, und dabey so schonend als möglich verfahren, ferner daß man die Äcker so viel möglich den Straßen nach und nicht über andere Äcker fahren solle, und endlich daß die Gräben hinter den Zelgen und neben den Straßen von den Anstößern sollen aufgethan und das Wasser abgeleitet werden.» 


\section{8: Ein starkes Gewitter vernichtet die ganze Ernte ${ }^{* 4}$.}

1876: Durch wolkenbruchartige Regen schwellen die Dorfbäche zu reißenden Flüssen an. Bei der Kirche stauen sich die Bäche und setzen das Unterdorf unter Wasser. Die Wiesen und Äcker werden durch Schutt verwüstet, die Wassergräben teils tief ausgefressen, teils zugeschüttet. Große Erdmassen gleiten in die Gräben ab; die bedeutendste Verlängerung und Ausweitung erfahren Griesgraben und Sädel. Auch der Rhein und seine Zufüsse sind gewaltig angeschwollen und verursachen Wassernot ${ }^{* 5}$.

*4 GR 25. 2. 1839: «Wurde die Vermögens- und Erwerbs und Einkommensteuer für das Jahr 1838 verlegt und einstimmig beschlossen die Erwerbssteuer für dieß Jahr gänzlich wegzulassen, in dem durch das stattgehabte Hochgewitter der Erwerb gänzlich vernichtet wurde.»

*5a) Bülach-Dielsdorfer Wochen-Zeitung vom 14. 6. 1876: «Wassernoth. Montag Abend. Am letzten Samstag bedeckte sich der Himmel mehr und mehr. Nach einigen vorhergehenden Regenschauern eröffnete Abends ein mit dem Nordwind dahintreibendes Gewitter einen nun 2 Tage andauernden durch neue Gewitter gestärkten Regen. Die Gewitter nehmen ihre Richtung mehr den Vorbergen der Alpen entlang, als über unser Hügelland. Unsere Flüsse, auch die größeren Bäche sind angeschwollen. Die Glatt ist etwas höher als letzten Winter und wird wegen ihrer beiden Seen erst morgen anschwellen. Gleichwohl hat sie viel, sehr viel Mattland unter, in Niederglatt Häuser, ins Wasser gesetzt. Der Rhein ist stark angeschwollen, einen $F u B$ höher als 1817, wenig minder als die größte bekannte Größe von 1789. Der über 2o Fuß lange Pegel unten an der Brücke in Eglisau ist zu kurz. Das Wasser erreichte um 7 Uhr abends die tieferen Enden der Brückenverschalung bis auf wenige Zoll. Im Laufe des Tages stieg das Wasser stündlich $4 \mathrm{FuB}$. Die Brücke bei Kaiserstuhl ist fortgerissen. 2 der Pappeln oberhalb dem Zollhaus sind wegen Ũnterspühlung gefallen.....»

«Eglisau 12. Juni 7 Uhr 25 abends. Der Rhein ist größer als 1817. Oberriedt, die Ufergelände und das Salzhaus sind eine Treppe hoch unter Wasser. Untere Brückenkante nur 2-3 Fuß über Niveau. Differenz von 10-15 Fuß über gewöhnlichem Wasserstand. Fallen nicht bemerkbar. 13. Juni vormittags 9 Uhr: Der Rhein ist über Nacht bis jetzt mindestens 2 Fuf gefallen. Es kommt weniger Schwemmholz. Rheingröße jetzt noch gleich 1789. Es ist dies dic höchsterlebte....»

b) Bülach-Dielsdorfer Wochen-Zeitung vom 17. 6. 1876: «Glattfelden 16. Juni. Letzten Montag begann die Glatt auch hier ihr verheerend Spiel in einem Maße wie nirgends. Am Dienstag mußte die gedeckte Staatsbrücke um dem Wasser Abzug zu verschaffen, auf Befehl des Kreisingenieurs $\mathrm{Hohl}$ mit Petroleum angezündet und verbrannt werden. Alle Brücken und Wuhrungen sind zerstört. Ihr altes Bett verlassend hat die Glatt gegenwärtig wohl die dreifache frühere Breite, nichts überflutend sondern alles vor sich herreißend. Der ganze schöne Kanal von der Spinnerei bis zur Säge ist verschwunden. Die schönsten und besten Wiesen auf der rechten Seite des Flusses in der ganzen Länge fortgeschwemmt....»

c) Aussagen von Herrn Naef, Weiach, geb. 1871 .

(Da die Gemeinderatsprotokolle Weiach aus den Jahren 1850-1889 «verschwunden》 sind und die GV nichts erwähnen, habe ich Herrn NAEF, Landwirt, ersucht, seine Erinnerungen an die Wassernot von 1876 zu schildern.)

«Das Jahr 1876 brachte der Gemeinde Weiach die größte Wassernot, die ich erlebt habe. Durch wolkenbruchartige Regengüsse schwollen die Dorfbäche zu reißenden Gewässern an. Solange die Bachbette frei waren, schoß das Wasser gerichtet gegen die Rheinhalde zu und fraß sich tief ein. Als Schutt und Holz die Bachbette verstopft hatten, trat das Wasser über die Ufer, riß die Straßen auf und überschwemmte. Der Mühlebach setzte das Unterdorf unter Wasser. Schuttmassen wurden über die Wiesen und Äcker der Langwuhr und der Lebern geführt. Weiteres wertvolles Kulturland ging durch Erdschlipfe verloren. Die größte Ausweitung erfuhr dabei der Griesgraben; viele Wagenladungen abgerutschten Drecks mußten wegtransportiert werden.»

d) Aussagen von Herrn A. Meierhofer, Weiach: MeIerhofer bestätigt die Angaben Naefs und erwähnt weiter, daß «ganze Wiesen» in den Sädel abgerutscht seien.

Viele alten Weiacher wissen aus den Schilderungen ihrer Eltern vom Schreckensjahr 1876 zu erzählen und weisen darauf hin, daß die Gemeinde Weiach keineswegs besser wegkam als die in der Bülach-Dielsdorfer Wochen-Zeitung erwähnten Ortschaften.

e) Bülach-Dielsdofer Wochen-Zeitung vom 1. 7. 1876: «Am 27. wurde das Tößbett bei Rorbas bei der Weißhaldenmühle durch einen Erdschlipf ausgefüllt. Die zirka 45o Schritt oberhalb der Imhof-Blumerschen Fabrik in das Tößtal hinunter gestürzte Fläche ist ungefähr 1 Juchart groß. Die Töß wurde in der Länge von über 200 Fuß mehrere Fuß hoch mit Erde ausgefüllt und staute sich sogleich zu einem See an. Nur der angestrengtesten Tätigkeit von 
1877: Der Frühling ist außerordentlich naß*6.

1910: Das Jahr 1910 hat der Gemeinde Weiach eine übernormale Regenmenge gebracht und bedeutende Wasserschäden verursacht; $1157 \mathrm{~mm}$ sind in Kaiserstuhl gemessen worden. (Mittlere Jahresmenge 1901-1953, mit Ausnahme der Jahre 1904-1908: 949,6 mm; Minimum: 1949 mit 593 mm; Maximum: 1940 mit $1357 \mathrm{~mm}$.) $\mathrm{Zu}$ dieser großen Regenmenge trägt bereits ein niederschlagsreicher Januar bei; am 18. 1. fallen $42,4 \mathrm{~mm}$, am 19. 1. noch $34,9 \mathrm{~mm}$. Bedeutende Niederschlagsmengen zur vegetationsarmen Zeit sind eine günstige Ausgangslage für eine intensive Erosion und Denudation ${ }^{*}{ }^{\circ}$.

Eine Woche vor der großen Überschwemmung vernichtet ein kurzes, heftiges Gewitter, begleitet von wolkenbruchartigen Regengüssen und Hagelschlag, einen Teil der Ernte. Solche intensive Niederschläge (innert ganz kurzer Zeit fallen 21,2 mm Regen) vermag der Untergrund nicht vollständig aufzusaugen. Nur ein Teil des Wassers versickert, durchfeuchtet dabei die oberste Schicht und gestaltet so den Boden rutschfreudiger. Der größere Teil des Wassers vermag oberflächlich abzufließen. Die langen Muldentälchen auf den Terrassenflächen wirken dabei als Wassersammler; sie leiten das Wasser «kanalisiert» gegen die Gräben. Bei der Versteilung des Gefälles schneidet der Bach kräftig ein. Das erodierte Material gelangt bei starker Wasserführung auf der Terrassenfläche zur Ablagerung; ist die Wasserkraft geringer, wird der weggeschwemmte Schutt bereits im sich verflachenden unteren Grabenteil abgelagert. Für Wasserschäden ist nicht nur die Menge der Niederschläge, sondern vor allem die Regenintensität maßgebend (vgl. auch Lit. 58, 1953) ${ }^{*}{ }^{\mathrm{b}}$.

ca. 100 Mann gelang es, das Tößbett bis Mittwoch wieder so flott zu machen, da $\beta$ das Wasser durch dasselbe $A b f l u B$ finden konnte. Man befürchtete indes allgemein, es werden weitere Rutschungen nachfolgen. - Letzten Sonntagabend fand in Hägelen-Bachs ein Erdschlipf statt, welcher denjenigen im Wehntal bedeutend übertreffe. 3o Jucharten besten Landes seien vernichtet.»

*6 GV 16. 5. 1877: «... in Anbetracht der anhaltend nassen Witterung... das Rindenmachen für dieses Jahr einzustellen》.

7a) Ergebnisse der täglichen Niederschlagsmessungen; 1910: «Das Jahr 1910 wird in der Witterungsgeschichte unseres Landes hinsichtlich des Regimes der Niederschläge immer denkwürdig bleiben. $Z$ u verschiedenen Malen hat es der Nordseite der Alpen ganz außerordentliche Regenfluten gebracht; so im Januar, im Juni und im November... Blieb dabei unser Land auch von einer Katastrophe im Umfange der im Seinebecken auftretenden verschont, so war doch nach den Regengüssen vom 19. 1. vielerorts Wasserschaden zu verzeichnen. Am 18. 1..... traten äußerst heftige Westwinde und starker Regen auf; letzterer hielt auch am 19. 1. noch an, an welchem Tage noch größere und im allgemeinen die größten je im Januar gefallenen Tagesmengen gemessen wurden.»

Der Wehnthaler, 21.1.191o: «Niederglatt. Die Regenmeßstation hat für den letzten 19. Januar eine Regenfallmenge von $50 \mathrm{~mm}$ zu registrieren. Diese tägliche Regenintensität übersteigt selbst die besten Regenleistungen im Regenjahr 1909. Es wird mit den Regenschauern immer bedenklicher. Seit vielen Jahren wurde die riesige Wasserfülle wie der 19. Jan. sie uns bescherte, nie mehr erreicht. Nachdem der Dez. 1909 ziemlich in Niederschlägen gemacht hatte und eine Regenmenge von total 104,2 mm spendete, hätte nun der Januar nicht nötig gehabt, derart den Wasserkübel zu schwingen....»

*7b) Der Wehnthaler, 14.6.191o: «Weiach. Freitag. den 1o. dies, gegen $7 \mathrm{Uhr}$ abends stiegen am westlichen Horizont nach schwüler Tageshitze schwere Gewitterwolken empor, die dann nach $71 / 2$ Uhr sich auch über unsere Fluren entleerten. Längere Zeit glaubte man, das Unwetter werde sich von unserer Gegend abwenden, ein leicht hörbares Tosen gegen das Wehntal ließ für die dortige Gegend schlimmes befürchten. Eine Wendung der Luftströmung, und in kurzer Zeit fielen während 20 Minuten dichte Hagelkörner von Hasel- bis Baumnußgröße mit wolkenbruchähnlichem Regen, orkanartigem Sturm und von Blitz und Donner unterbrochen; wahrlich ein schauerlicher Moment. Großen Schaden erleiden unsere schön behangenen Obstbäume, die Weinberge, die prächtigen Gartengewächse, auch die Getreidefelder, die schon unterm 22. Mai erheblich Schaden erlitten, sind diesmal wieder stark betroffen worden.... 
Die Niederschlagsmengen vom 14. 6. und 15. 6. beweisen dies deutlich: $31,9 \mathrm{~mm}$ und $11,8 \mathrm{~mm}$ werden gemessen - Zahlen, die sich bescheiden ausnehmen, verglichen mit der maximalen Tagesmenge von 76,5 mm am 25. 6. 1953 . Und trotzdem genügen die relativ geringen Mengen, um bedeutenden Überschwemmungen zu rufen. Zwei Faktoren sind dabei entscheidend:

1. Der wolkenbruchartige Charakter der Niederschläge.

2. In der übrigen Schweiz gehen über Berg und Tal beträchtliche Niederschläge nieder; Regen fällt bis $3000 \mathrm{~m}$. Somit schwellen auch die großen Ströme an und treten über die Ufer ${ }^{*}{ }^{7} \mathrm{c}$.

Es vergeht kein Monat (10.7.), bis Weiach wieder von einem kurzen, wolkenbruchartigen Regen heimgesucht wird. Obwohl die Niederschlagsmenge nur 24,2 mm ausmacht, reißen die Bäche an den steilen Hängen tiefe Gräben auf und lagern das erodierte Material in der Ebene $a b^{*}{ }^{*} \mathrm{~d}$.

1912: Der 23. Juni zeichnet sich durch die bedeutende Regenmenge von $68,0 \mathrm{~mm}$ aus. Der Regen ist durch ein heftiges Gewitter zum Ausbruch gekommen *8.

1919: Ein Hochwasser verursacht Rutschungen *9.

1929: Während eines Wärmegewitters fallen am 28. Mai 39 mm Regen. Der intensive Niederschlag bewirkt Hochwasserführung der Flüsse und Bäche *10.

1930 und 1931: Diese beiden niederschlagsreichen Jahre $(1223 \mathrm{~mm}$, resp. $1136 \mathrm{~mm})$ weisen auch große 'Tagesspitzen auf; am 2.7. 1930 fallen 61,4 mm, am 20.5. $193162,8 \mathrm{~mm}$. Vermutlich sind beides Gewitterregen. Diese bedeutenden

$\left.{ }^{*} 7 \mathrm{c}\right)$ Ergebnisse der täglicheni Nicderschlagsmessungen 1910:

«Mitte Juni gingen über einen 'Teil der Schweiz außerordentlich starke Niederschläge nieder. Diese gaben Veranlassung zu gewaltigen Hochwassern verschiedener Flüsse und damit zu wahren Katastrophen, wie wir sie seit Jahrzehnten nicht erlebt hatten.... Das war nun das Entscheidende für den katastrophalen Charakter des 14. Juni: über Berg und Tal gingen die gleichen enormen Regenmengen nieder. In den Bergen fällt Regen bis $3000 \mathrm{~m}$ und eine intensive Schneeschmelze setzt ein.»

Der Wehnthaler, 17.6.191o (siehe auch Bülach-Dielsdorfer Wochen-Zeitung vom 17. 6 . 1910) :

«Weiach. Der Rhein hat in der letzten Nacht einen Wasserstand erreicht wie seit 1876 nie mehr. Das dazumal von den Fluten weggerissene und von Schenkel wieder erstellte kleinere Wasserwerk mußte auch diesmal wieder der Gewalt weichen.»

GR 6. 7. 1910: "Das vom Hochwasser angeschwemmte Sand und Kies soll aus dem Bachbett entfernt werden. Das Sammeln von Liebesgaben für die Hochwasser-Beschädigten soll Pfarrer Kilchsperger übertragen werden.»

*7d) Der Wehnthaler, 12.7.1910 (siehe auch Bülach-Dielsdorfer Wochen-Zeitung vom 12.7. 1910) :

«Weiach. Sonntag nachts nach 1o Uhr ging über unsere Gemeinde ein Gewitter desgleichen sich wohl unsere ältesten Bürger nicht erinnern. Mehr als eine Stunde anhaltend, entleerten die Wolken ihre Wassermassen, da $\beta$ man sich bald in den jüngsten Tag versetzt glaubte. Unsere sonst ruhig dahinfließenden Dorfbäche waren bald in einen reißenden Strom verwandelt. Viele der im ersten Schlaf liegenden Bewohner mußten durch die Sturmglocken aufgeweckt werden und ein unfreiwilliges Bad nehmen, um ihre Ställe oder Keller vor dem Eindringen des Wassers zu schützen. Der Schaden an den Straßen für die Gemeinde und den Staat ist ein bedeutender, Straßenschalen sind teilweise weggespült, an den Bergstraßen hat es tiefe Furchen, Steine liegen zu vielen Fudern in den schönsten Wiesen. Fleißige Hände zu etwelcher Ausbesserung der Straßen sah man gegen Mittag überall.»

*8 Ergebnisse der täglichen Niederschlagsmessungen; 1912: «Am Abend und in der Nacht des sehr warmen 23. Juni waren am Nordfuße der Alpen heftige Gewitter zum Ausbruch gekommen, veranlaßt durch über Deutschland wegziehende Teildepression eines nordwestlichen Tiefd ruckgebietes.»

*9 GV 13. 3. 192o: «Da der Bach im Wiesenthal keinen richtigen Abfluß besitzt und derselbe letztes Jahr infolge Hochwasser einigen Wiesenbesitzern durch Rutschungen großen Schaden anrichtete, gelangten dieselben an die Baudirektion....»

*10 GR 3. 7. 1929: «... wurde beschlossen, den durch das Hochwasser demolierten Übergang beim Badeplatz am Rhein wieder erstellen zu lassen.» 
Niederschläge müssen einer Erosionswirkung gerufen haben, deren Intensität aber nicht mehr bestimmt werden kann. Vergleichsweise sei eine Beobachtung aus dem Jahre 1956 beigefügt $* 11$.

1940: Dieses ist das nasseste je gemessene Jahr. Es weist eine Niederschlagsmenge von $1357 \mathrm{~mm}$ auf, die gegenüber dem Mittel von 949,6 mm um $43 \% \mathrm{zu}$ hoch ist. An mehreren Tagen sind bedeutende Niederschläge gefallen, so am 25. 4.: $35,9 \mathrm{~mm}$; 22. 5.: $39,8 \mathrm{~mm}$; 29. $5 .: 35,6 \mathrm{~mm}$; 15. 7.: $54,2 \mathrm{~mm}$; 10. 9.: $35,4 \mathrm{~mm} ; 14$. 9.: $30,2 \mathrm{~mm}$; 23. 9.: $33,2 \mathrm{~mm}$; 7. 10.: $38,1 \mathrm{~mm} ; 6.12 .:$ $35,1 \mathrm{~mm}$. Den größten Schaden richtet das Gewitter der Julimitte an. Die respektable Menge von 54,2 mm fällt in Form von Hagel und wolkenbruchartigem Regen und vernichtet nicht nur das Getreide, sondern führt ebenso zu kleineren Überschwemmungen *12.

1944: Der November ist niederschlagsreich; am 7.11. fallen $61,6 \mathrm{~mm}$, am 8.11. immer noch $33,1 \mathrm{~mm}^{*} 13$.

1945: Im nassen Monat August werden folgende Regenmengen gemessen: 8. 8.: $48,5 \mathrm{~mm}$; 9. 8.: $10,3 \mathrm{~mm}$; 10. 8.: $36,7 \mathrm{~mm}$; 18 . 8.: $12,6 \mathrm{~mm}$; 19. 8.: $30,4 \mathrm{~mm}$; 30. $8 .: 24,7 \mathrm{~mm}^{*} 14$.

1946: Die anhaltenden Regenfälle im Juni geben zu Besorgnis Anlaß: 1. 6.: 30,9 $\mathrm{mm}$; 12. 6. : 15,4 mm; 13. 6.: 42,2 mm; 21.6.: 21,0 mm;22. 6.: 18,4 mm *15.

1950: Als ausgesprochen naß erweist sich der November: 2. 11.: 13,5 mm; 3. 11.: $22,0 \mathrm{~mm}$; 11. 11.: $18,5 \mathrm{~mm}$; 14. 11.: $18,0 \mathrm{~mm}$; 15. 11.: 12,6 mm; 16. 11.: $39,8 \mathrm{~mm}$; 24. 11.: 25,2 mm;25. 11.: 47,5 mm. Die große Niederschlagsmenge in der vegetationsarmen Zeit muß - vor allem in den oberen Gräben - zu Erosionserscheinungen geführt haben $* 16$.

1953: Das an sich niederschlagsarme Jahr $(741 \mathrm{~mm})$ zeichnet sich durch ungewöhnliche Regenmengen im Juni aus: Am 25. 6. fallen in Kaiserstuhl 76,5 mm, die maximale Tagesmenge seit Beginn der Messungen 1901. Da der Regen jedoch gleichmäßig fällt, kommt es in der Umgebung von Weiach wohl zu Erosions- und Denudationserscheinungen, aber nicht zu einer Hochwasserkatastrophe wie 1876 oder $1910 * 17$.

*11 Vergleich vom 12. 7. 1956: Am 10. 7.1956 fallen in regelmäßigem Landregen 35,o mm, am 11. 7. noch $14,2 \mathrm{~mm}$ (Angaben der Regenmeßstation Zoll Kaiserstuhl). Der gleichmäßig gefallene Regen verursacht keine Überschwemmungen. Der Saxenholzgraben, vor allem der westlichste Arm, weist Spuren frischer Erosionstätigkeit auf. Steine und Erde sind ausgeschwemmt und im breiten unteren Grabenbett akkumuliert worden.

*12 Der. Wehnthaler, 17.7.1940: «Ein furchtbares Hagelwetter ging am Montagabend nach 7 Uhr von Weiach her über die schönen und wohlgepflegten Felder des Zürcher Unterlandes. Besonders wichtig war der Hagelschlag in der Gegend um Windlach und Stadel.»

*13 Der Wehnthaler, 1o.11.1944: «Die gegenwärtigen ausgiebigen Regenfälle haben starkes Anschwellen der Bäche und Flüsse zur Folge. Die Glatt führte zum erstenmal seit etwa 2 Jahren wieder größere Wassermengen, nachdem den ganzen Sommer über ein denkbar niederer Wasserstand zu verzeichnen war. In Wiesen und Äckern bilden sich kleine Wassertümpel....»

*14 Ergebnisse der täglichen Niederschlagsmessungen 1945: «Die Niederschläge des 7. bis 10. Augusts waren verursacht durch eine Depression, die am 7. 8. über Südost-Spanien erschien und sich bis zum 10. nordostwärts nach Deutschland verlagerte.»

*15 GR 2. 7. 1946: «Der Vorsitzende und Gemeinderat Baltisser übernehmen die durch den anhaltenden Regen notwendig gewordene Kontrolle der Verbauung am Bach und der Schächte.»

*16 Ergebnisse der täglichen Niederschlagsmessungen 1950: «16. November: Niederschläge verursacht durch eine rasch wandernde Depression mit ausgesprochenem Warmsektor..... 24./25. November: in verschiedenen Gebieten der Schweiz Überschwemmungen. Die Schweiz befand sich während der ganzen Periode im Bereich der Polarfront.»

*17 Ergebnisse der täglichen Niederschlagsmessungen 1953: «Ganz ungewönlich große Niederschlagsmengen sind am 24. 6.; 25. 6. und 26. 6. gefallen... Im wesentlichen sind aber 
1956: Nach einem heißen Sommertag fallen in der Nacht vom 10.8. auf den 11.8. wolkenbruchartige Regen: 48,5 mm werden in Kaiserstuhl gemessen. Am Nachmittag des 11. 8. ist die HT-Terrassenfläche stark durchnäßt; das Wasser vermag nicht mehr zu versickern. In den muldenförmigen Eintiefungen des HTPlateaus sammelt sich das Wasser und ergießt sich auf breiter Fläche, $3 \mathrm{~cm}$ tief, gegen den Saxenholzgraben. Im mittleren Arm fließt ein Bach und erodiert, vor allem im Steilhang. Kurz vor der Vereinigung des mittleren mit dem östlichen Arm ist die Erosionsrinne $60 \mathrm{~cm}$ breit und $8 \mathrm{~cm}$ tief. Im westlichen Grabenarm sind die Erosionserscheinungen noch auffälliger: Am Grabenbeginn findet sich eine $1 \mathrm{~m}$ breite und $50 \mathrm{~cm}$ tiefe Rinne; $20 \mathrm{~m}$ weiter unten beträgt die Breite immer noch $1 \mathrm{~m}$, die Tiefe $20 \mathrm{~cm}$. Das Wasser rinnt über die gemeinsame Sohle zum Grabenausgang, ohne aber auf dem flachen Teilstück wesentlich zu erodieren. Der östliche Grabenarm führt kein Wasser. Dieser Steilhanganriß hat keine muldenförmige Fortsetzung in der H'T-Terrassenfläche; vielmehr stößt der Grabenanfang an den östlichen Muldenrand des mittleren Grabenarmes. Diese Mulde entzieht denn auch der östlichen Kerbe das anfallende Wasser. - Spuren frischer Erosion weist ebenfalls der Hasliraingraben I auf: Kurz nach dem Beginn setzt eine $40 \mathrm{~cm}$ breite und 15-20 cm tiefe Rinne ein, die sich nach unten im flacheren Gefälle verliert.

Die größte Gewalt entwickelt der Sädelbach. In seinem östlichen Teilstück tritt er aus seinem künstlich angelegten Bachbett aus, reißt den Fußweg auf und unterspült die Ufer. Griesgraben und Kaibengraben führen kein Wasser; lediglich im obersten, steilen Teilstück der Griesgrabenstraße sind einige Rillen eingerissen. Die Hohlformen der Weiacher Hauptniederterrassenfläche sind versumpft. Ein Wassertümpel $100 \mathrm{~m}$ südlich des Sädelbeginnes ist $17 \mathrm{~cm}$ tief.

1957 : Der warme, regenreiche Februar hat nicht nur der Wintersaat geschadet, sondern auch Erosionserscheinungen in den Gräben bewirkt. Am 23. 2. setzt Regen ein $(9,5 \mathrm{~mm})$, um am 24. 2. 47,9 mm zu erreichen; am 25. 2. sinkt die gefallene Menge auf 17,7 mm ab. Im Marchgraben zwischen Acker und Wiese oberhalb des Saxenholzgrabenanfanges liegt das Wasser am 27. 2. immer noch $20 \mathrm{~cm}$ tief. Das Getreidefeld ist von über $10 \mathrm{~cm}$ tiefen Rinnen durchzogen. In flacheren Teilen des Ackers finden sich deltaartige Aufschüttungen. Lange nicht alle Niederschläge sind versickert: Wasser rinnt in der Mulde gegen den mittleren Saxenholzgrabenarm zu und ergießt sich stark erodierend den Steilhang hinunter. Die Erosionserscheinungen machen sich diesmal bis an den Grabenausgang bemerkbar. Folgende Ausmaße kennzeichnen hier die neugeschaffene Eintiefung: Breite: $70 \mathrm{~cm}$; 'Tiefe: $5 \mathrm{~cm}$.

Die Erdrutsche und Erosionsleistungen, verursacht durch rasche Schneeschmelzen, können aus der Statistik nicht erfaßt werden: Wir kennen weder die Schneehöhenangaben noch den Temperaturverlauf von Kaiserstuhl. Aus den Angaben der Bauern und Waldarbeiter geht aber eindeutig hervor, daß die bedeutenden Wassermengen, die bei raschen Schneeschmelzen frei werden und auf dem noch halbwegs gefrorenen Untergrund gegen die Steilhänge zu fließen, die größten Schäden anrichten:

1940: Im Februar 1940 wird die Griesgrabenstraße durch Schmelzwasser zerstört und muß neu angelegt werden.

offenbar Umschichtungen labiler Luftmassen für die großen Niederschläge verantwortlich zu machen. Diese starken und namentlich ungewöhnlich lang anhaltenden Niederschläge haben zu verbreiteten Überschwemmungs- und Erdrutschschäden (vgl. Schmerikon) geführt.»

Der Wehnthaler, 27.6.1953: «Hochwasserschäden überall am 26. Juni. Das anhaltende Regenwetter hat auch im Unterland da und dort Schaden angerichtet. Die Glatt führt Hochwasser, so daß die Zuflüsse sich zurückstauen, demzufolge ein Teil der Kulturen im Dielsdorfer Ried unter Wasser gesetzt worden sind. An einzelnen Orten füllten sich die Keller....» 
1946: Nach plötzlicher Schneeschmelze ergießt sich ein Wasserstrom von Zweidlen her längs der Hauptstraße gegen die Kiesgrube im «Ofen» und versickert erst im Hard. Teilweise erodiert das Wasser, teilweise tritt Akkumulation ein. Auf diese Art und Weise kann die Schotterfläche gewellt werden *18.

Unachtsamkeiten der Menschen, ungeschickte Bewirtschaftung vermögen die Erosionsanfälligkeit zu erhöhen, geschickte Bachverbauungen, Anpassung der Kulturen hingegen die Erosionsgefahr zu mindern. Für dieses Kapitel spielt der Wald eine bedeutende Rolle. Wohl stockte das Holz früher auf einer viel größeren Fläche (vgl. Wild-Karte), und man könnte leicht dem Irrtum verfallen, zu glauben, daß dadurch das Retentionsvermögen auch gesteigert worden sei. Die folgenden Angaben sollen beweisen, daß aus dem Vorhandensein einer größeren Waldfläche allein noch nicht auf eine Herabsetzung der Erosionsintensität geschlossen werden darf (Die Angaben stammen aus den Gemeindeprotokollen, sowie aus den Wirtschaftsplänen über die Gemeindewaldung Weiach.). Rücksichslose Ausbeutung der Wälder, Nebennutzung durch Weide oder Streuegewinnung, Verliederlichung des Bestandes, Freigabe eines Teiles der Rheinhalde zur Holzgewinnung an Arme weisen darauf hin, daß der Wald viel weniger gepflegt worden ist als heute; auch scheint der Bestand weniger dicht gewesen zu sein. Instruktiv ist vor allem der Rechenschaftsbericht an die Regierung aus dem Jahre 1804.

1804: Im GR wird der teils verliederlichte, teils durch fremde Truppen verheerte Wald erwähnt ${ }^{* 19}$.

1841: Ende dieses Jahres ist der Weidgang in der Hardwaldung verboten worden *20.

*18 Aussagen von Waldarbeitern

über die oberen Gräben: «Bei raschen Schneeschmelzen im Frühling fließen oft bedeutende Mengen Wasser in den Gräben. Die Wege in den Grabensohlen sind dann nicht mehr benutzbar und niemand wagt sich in die Gräben hinein. Bei normalen Schneeschmelzen gelangt das im Steilhang erodierte Material in der unteren verflachten Partie zur Ablagerung. Auch das Wasser vermag gegen unten zu versickern. In Ausnahmefällen freilich vermag das reißende Wasser den Schutt bis auf die Hasli-Ebene hinauszuführen. Dreck kann dann bis gegen das Kaiserstuhler Schützenhaus geführt werden. - Nach Gewittern ist die Wasserführung seltener und schwächer.»

über die Gegend im Hard: «Wenn es in den Schnee hinein regnet, können große Wassermengen von $Z$ weidlen her gegen die Hauptstraße hinunter rinnen und sich gegen den «Ofen» und den Hard zu ergießen. 1946 versickerte das Wasser erst im Hardwald.»

über den Hungergraben (= Grenzgraben): "Fällt starker Regen auf dem Sanzenberg, führt der Hungergraben Wasser.» (Dieses Sprichwort galt allgemein vor der Drainage des Gebietes «Im See 》.)

*19 GR 16. 1. 1804: «Vor ca. 4o oder 5o Jahren ist unsere Gemeind Waldung mit bren und bauholz solcher maßen versehen gewesen, daß nicht nur vor die gemeind genug - sondern noch zum überfluB - da villes den benachbarten Orten um das gelt verkauft worden ... anno 1750 Ist zu Weyach, der gemeind und Privat Holzboden wohl besezt gewesen mit bau und anderen holz, die jungen Einschlag wahren in bester ortnung so daß weder vom geheiden, wiesen und grasen in derselben nicht bekant noch in üebung wahr. Von selbiger Zeit an bis 1770 ist solche unortnung entstanden, die dazumahligen vorgesetzten fiengen an mit Ihrem vich in den Jungen Einschlegen zu weiden und in denselben zu grasen, da ist Leicht zu begreiffen $\mathrm{da} B$ die Bürgerschaft denselben ist nachgefolg, hierauf hat sich gezeiget das ein großer Bezirk der Waldung besonders in den Jungen auf dessen große Lehre Pleze gegeben daß das vich nicht abgebissen, haben sie zertreten, und wo das vich nicht hingekommen zu weiden hat mans mit der Sichel abgeschnitten, sodaß durch dieses die Jungen Sprossen hinweggekommen, und das Holz zurük gebliben ist....» Anstelle des Holzes hat es dann «meist graß und geheid gegeben, das in Menge dergleichen Unkraut anstat Jünger Holz hervorgekommen ist.... und das Hard alwo unser kostliche Eichenholz stehet ist von Frankischen und Kaiserlichen Millitar der größte Theil verbrent, und verhert, und die andern Hölzer dergestalt veruiniert so daß in langen Jahren Ja langer Zeit kein Bau Holz zu hoffen ist.»

*20 GR 19. 12. 1841: «Da der Waidgang in unserer Hardwaldung immer noch erlaubt gewesen und noch von einigen benutzt worden, derselbe aber im gegenwärtigen $Z$ ustand nicht mehr ohne Schaden für den Nachwuchs geschieht, so hat der Gemeinderath beschlossen denselben bei 4.- gänzlich zu verbieten.» 
1845: Die Rheinhalde ist bisher für die «holzärmeren Bürger» offen gehalten gewesen. Es wird nun jedermann verboten, an dieser Halde zu holzen (Das Verbot gilt bis 18. 2. 1860) *21.

1846/1847: Ca. 720 a Hardwaldung sollen gerodet und als bleibendes Pflanzland benutzt werden $* 22$.

1852/1853: Die Weiacher stellen das Gesuch zur weiteren Rodung des Hardwaldes $* 23$.

1865: Um Geld für die Bacheinfassung zu beschaffen, wird erneut ein Gesuch zur Rodung einer Hardwaldparzelle gestellt *24.

1872: Nachdem die Gemeinde Weiach 43 Jucharten Waldung in der Fürsthalde und 6 Jucharten in der Rauhaus angekauft hat, wird ihr die Bewilligung zur Urbarisierung von 50 Jucharten Waldboden im Hard erteilt ${ }^{* 25}$.

1875: Ein Sturm entwurzelt weite Bestände *26.

1878: Es wird erneut ein Verbot erlassen, an der vorderen Rheinhalde Holz zu sammeln, da sich ein arger Mißbrauch bemerkbar gemacht hat ${ }^{* 27}$.

*21 GR 13. 1. 1845: Der Gemeinderat beschließt: ... «die Rheinhalden für jedermann und auf längere Zeit zu verbieten, damit dann das ergebende Holz gleich anderm unter sämtliche Bürger zu Vertheilen.»

*22 GR 9. 1. 1846: Auf jeden Bürger soll ca. $1 / 2$ Juchart Land als Pflanzland abgetreten werden.

GR 17. 2. 1846: «... daß cirka 2o Jucharten südwestlich von der Hardwaldung, welche in Verbindung mit dem schon bestehenden Ackerland steht, und der Zelge einen Zuwachs gibt, bis zu der Geerengrube abzutheilen und als bleibendes Pflanzland zu benutzen. Die auf dieser Abtheilung stehenden ca. 3oo Stück Eichen seien theilweise zu Bauholz anzuweißen, die übrigen dann aber zu verkaufen, und der Erlös in das zu stark in Anspruch nehmende Armengut zu thun, und demselben dadurch seine Unterstützung zukommen zu lassen.»

$G R$ 2. 12. 1846: Die Waldrodung im Hard wird von Weiach genehmigt.

GR 19. 4. 1847: Die Regierung verlangt die Aufforstung des Hardes. Weiach weigert sich, es sei besser 3-4 Jahre Pflanzland zu haben.

*23 GV 13. 9. 1852: Es wird das Gesuch gestellt, weitere Eichen- und Föhrenbestände im Hard zu fällen: «.... die Lage von No 27 kaum tausend Schritte vom Rhein den Tranzport zu Wasser, sei es nun für einen Zürcher, Waldhuter oder Waldhuter Baslerbahn sehr erleichtern ...» würde.

GV 5. 3. 1853: Die Direktion des Innern bewilligt den Abschlag von ca. 13o Eichen zu Eisenbahnschwellen.

*24 GV 3. 2. 1865: «Da voraussichtlich die Einnahmen des Gemeindegutes im laufenden Jahre die Ausgaben nicht decken werden, in dem die Vollendung der dekretierten Bacheinfassung noch bedeutende Kosten verursachen wird überhaupt noch anderweitige außerordentliche Ausgaben bevorstehen, so glaubt der Gemeinderath um dieses alles bestreiten zu können zu außerordentlichen Mitteln greifen zu müssen».... Die Gemeinde beschließt: «Es soll derselbe (d. h. der Gemeinderat) beim Titl. Oberforstamte um Bewilligung zum Schlage des ca. 100 jährigen Forrenschlages No 10 b ca. 3 Juchart groß, im Hard, nachsuchen, welches $\mathrm{Holz}$ sodann verkauft und zur Deckung der Gmdeausgaben verwendet würde.»

*25 GV 21. 1. 1872: Es wird angekauft:

«a) vom Staate, resp. dem Oberforstamt: 43 Jucharten 2273 ए' Waldung die Fürsthalde genannt für $22500 \mathrm{Fr}$.

b) von den Gebr. Baumgartner: 6 Jucharten, 2 Vrlg 1 Mäßli Waldung in der Rauhaus für 6000 Fr.»

*26 GV 27. 11. 1875: «Da durch die diesen Monat stattgefundenen Windstürme außer dem für diesen Winter bestimmten Nadelholzschlag, auf einer Fläche von noch mindestens 2 solchen Schlägen fast alle Bäume entwurzelt worden....»

*27 GV 1o. 11. 1878: «Gemäß einem früheren Gmdebeschluß dt. 18. Febr. 1860 war die vordere Rheinhalde den ärmeren Holzbedürftigen Bürgern auf deren Ansuchen hin zur Benutzung frei; es hat sich aber dieses Recht namentlich in letzter Zeit auf eine Weise geltend gemacht, daß der Gemeinderath unwillkürlich zu dem Gedanken und Schlusse kommen mußte, einem solchen Verfahren und Vergehen einzelner Bürger müßte entgegengearbeitet werden, und $\operatorname{die} \beta$ könne am richtigsten geschehen, wenn die Benutzung der vorderen Rheinhalde für Jedermann verboten werde.» (Der, Antrag wird angenommen.) 
1879: Der hintere Teil der Rheinhalde wird im Verlaufe des Winters abgeholzt ${ }^{* 28}$.

1880: Forstadjunkt FIERZ erwähnt in seinem Wirtschaftsplan die Vorteile der Reduzierung der Nebennutzung *29.

1886: In diesem Jahre wird zum letzten Mal im Hard eine landwirtschaftliche Zwischennutzung geerntet ${ }^{* 30}$.

1908: Eine Waldfäche an der ohnehin schon erosions- und denudationsgefährdeten Rheinhalde wird kahlgeschlagen $* 31$.

1914: Der Kahlschlag wird aufgehoben; es werden nicht mehr ganze Flächen der Erosion und Denudation freigegeben $* 30$.

1917/1918: Aus kriegswirtschaftlichen Gründen muß nochmals ein Kahlschlag gestattet werden $* 32$.

1945: Der 2. Weltkrieg bringt mehrere Zwangsrodungen mit sich. Erwünscht ist vor allem Ackerland auf der fruchtbaren Weiacher Ebene; weite Teile des Hardwaldes fallen dem vom Bund angeordneten Mehranbau zum Opfer*33.

Wohl ist das Waldareal gegenüber dem 18. und 19. Jahrhundert stark zurückgegangen. Die korrekte Durchforstung der übrig gebliebenen Waldflächen verhindert jedoch eine erhöhte Erosions- oder Denudationsgefahr. Kahlschläge an den ohnehin schon gefährdeten Hängen sind nicht mehr erlaubt und würden schwere Bußen nach sich ziehen. - Lokal und in geringem Maße wirkt auch die Bodenaufrauhung durch das Holzschleifen erosionsfördernd. Beobachtungen im Saxenholzgraben haben ergeben, daß vor allem die aufgerillte Bodenoberfläche erosionsanfällig ist. Mit geringer Kraft vermag das Wasser das aufgelockerte Material aus der Rille auszuschwemmen; dem nachfolgenden Wasser ist dadurch bereits ein Weg vorgezeichnet. Durch die Konzentrierung des fließenden Wassers auf diese eine Rinne wird das Einschneiden gefördert.

Weitere Überschwemmungsgefahr wird durch das Vernachlässigen des Baches hervorgerufen. In den Protokollen sind mehrere Vorkommnisse erwähnt:

*28 GV 12. 1o. 1879: «Es soll der hintere 'Theil der Rheinhalde soweit die Hardwaldung und das Akerland im Hard darangrenzt im Laufe dieses Winters abgeholzt werden.» (Wird einstimmig angenommen.)

*29 Wirtschaftsplan über die Gemeindewaldung Weyach, 1880: «Von Nebenutzungen ist die Streunutzung (Laub, Nadeln, Moos, Heide ets.) welche früher in sehr großem Maße stattfand und zur Verödung der Bestände im Hard, auf dem Schanzenberg und andernwärts wesentlich beitrug, jetzt zum Vorteil des Waldes reduzirt; immerhin zeigen sich noch sehr deutliche Spuren von gegenwärtig noch stattfindenden Streunutzungen.»

*30 Wirtschaftsplan über die Gemeindewaldung Weiach, 1926: «Die von Natur aus ohnehin empfindlichen Böden sind durch den Kahlschlagbetrieb und die landwirtschaftliche $Z_{w i-}$ schennutzung in ihrer Produktionskraft wesentlich verschlechtert worden. Ein großer Teil des Bodens ist oberflächlich verdichtet und mit der typischen rohhumusbildenden Decke aus Moos, Heidelbeere und Heide verfilzt. Diese Bodenverdichtung behindert die Wurzelatmung der Holzgewächse, und Rohhumus fördert die Auswaschung der Nährstoffe. Im Jahre 1886 wurde zum letzten Mal im Hard ldw. Zwischennutzung geerntet und seit 1914 ist der Kahlschlag aufgehoben.»

*31 GR 21. 3. 19o8: «Die Käufer von Holz in der Rheinhalden sollen zum sofortigen Abschlag desselben und zur Räumung der Schlagfläche aufgefordert werden.»

*32 Wirtschaftsplan über die Gemcindewaldung Weiach, 1948/49: «Der letzte Kahlschlag wurde 1917/18 als Kriegszwangsnutzung ausgeführt.»

*33 Siehe GR 21. 7. 1945 ; 26. 7. 1945; 16. 8. 1945; 9. 10. 1945; 3. 11. 1945 
a) Über Bäche gelagertes Holz verursacht Stauung bei Hochwasser oder Eisführung. Der Bach verläßt sein Bett und richtet Schaden am Kulturland an, sei es durch Erosion oder durch Ablagerung von Schutt*34.

b) Das Bachbett oder die Grabensohlen der Bewässerungsanlagen werden durch Akkumulation erhöht. Dadurch wird die Gefahr des Überlaufens gefördert. Nach den vielen Protokollberichten zu schließen, werden die Gräben und Bachbette nicht immer mit der nötigen Sorgfalt gereinigt $* 35$.

c) Durch Verunreinigung und Schuttablagerung werden die Wasserläufe verstopft, und das Wasser sucht sich einen neuen Weg ${ }^{*} 36$.

d) Defekte Leitungen und schlecht eingefaßte Bachbetten sind weitere Gründe, die zu Landverlusten führen. 1905 wird beschlossen, die beiden Dorfbäche teilweise in Röhren $\mathrm{zu}$ fassen *37.

e) Der Unterlauf der vereinigten Bäche (Sägebach und Mühlebach) macht den Weiachern am meisten zu schaffen. Der ursprünglich gegen die Langwuhr fließende und sich in der Längsrichtung des Sädels ergießende Bach ist 1921/ 22 in den senkrecht zur Längsachse gerichteten Arm eingeleitete worden. Der heutige Sädelbach erodiert in seinem neuen Seitenarm stark; bei der Einmündung des alten Bachbettes erreicht die Übertiefung 1,20 m. Bachtreppen müssen angelegt werden, um das Gefälle zu korrigieren. Mehrmals werden neue Verbauungen erstellt. Ausgeprägte Prallhangunterspülungen weisen auf die Erosionsintensität dieses oft stark anschwellenden kleinen Gewässers hin. Die Weiacher fragen sich heute, warum die Bacheinmündung überhaupt in den Nebenarm verlegt worden ist; durch diese Verlegung hat sich der Seitenarm des Sädels weiter vertieft und nach Osten in gutes Wiesland eingefressen. 1946 werden bereits wieder Pläne zu einer Korrektion des Dorfbaches be-

*34 $G V$ 6. 5. 183o: «Da es sich schon oft gezeigt das über die Dorfbäch gelegtes Holz im Sommer durch große Regengüß und im Winter durch starken Eisstoß Austreten derselben verursacht hat so solle vor die Zukunft alles Holz über den Bach legen gänzlich verboten sein.»

*35 GV 3o. 9. 1807: «Sollen die Dorfbäch bey 1. Fr. Buß ausgeschart werden ...» (siehe auch: GV 12. 1o. 1817 ; 27. 9. 1819 ; 8. 1o. 1821 ; 8. 1o. 1824; 8. 10. 1826; 26. 11. 1830; 23. 6. 1850; 7. 9. 1850).

$G R$ 12. 3. 1844: «Da sich die Güterbesitzer von Kaiserstuhl, im See, beim Gemeinderath dahin beschwehrt, daß die Anstößer an Seegraben ungeachtet allen auffordern und Mahnens den Graben nicht öffnen, sie den Gemeinderath Weyach ersuchen, daß dieser Graben geöffnet werde....》 (siehe auch: GR 14. 9. 1835; 19. 5. 1845; 12. 11. 1926; 17. 3. 1928).

*36 GR 15. 4. 1847: «Es sei den Gebrüdern Heinrich und Jakob Meierhofer ziegler als besizer der ziegelhütte in Weiach die anzeige zun machen, daß denselben unter Antrohung von 4 Frkn. Buße untersagt seie, von nun an Schut aus der Ziegelhütte jederart in den Dorfbach zu thun, in der Absicht, denselben wegzuschwemmen.....»

$G R$ 3o. 11. 1923: "Als Hauptgeschäft folgte die Besprechung des von Baumgartner, Gmdegutsverwalter eingereichten Anzeige gegen Edwin und Rudolf Grießer wegen Übertretung der Wasserpolizeivorschriften, da dieselben bei Übernahme des Sägeweiherausputzen unberechtigter Weise viel Schutt und Schlamm aus dem Weiher in den Dorfbach schwemmten, soda $\beta$ das Bachbett stellenweise mit Schutt und Schlamm angehäuft wurde...»

*37 GR 24. 4. 1891: «Dem Gemeindegutsverwalter wird der Auftrag erteilt im Sinne zu sorgen, damit die schlechten Stellen an beiden Dorbachbetten ausgebessert werden können.»

GR 15. 3. 1899: «Da das Dorfbachbett im Oberdorf stellenweise ganz defekt und reperaturbedürftig ist, so stellt der Gmderat z. h. der Gemeinde den Antrag: Es soll im Laufe dieses Jahres das Bachbett vom Garten des Eduard Baumgartner a. Bez. Richters bis zum Hause des Jean Baumgartner, Schneider, ca. $100 \mathrm{~m}$ lang durch große Cementröhren neu erstellt werden.»

(siehe auch GR 24. 8. 19o1; 9. 11. 19o7; 21. 3. 19o8; 24. 2. 1931; 26. 11. 1947; 14. 5.1948. GV 29. 12. 1852 ; 3. 2. 1853 ; 16. 4. 1864 ; 8. 1. 1873 ; 2. 7. 1905 ; 13. 3. 1920.) 
sprochen. Da die Bachverlegung aber in Zusammenhang mit einer Güterzusammenlegung gebracht wird, stößt sie auf großen Widerstand ${ }^{*} 38$.

f) Der bedeutendste Einfluß auf die rezente Ausweitung der unteren Gräben ist wohl auf die Anlage eines Bewässerungssystems in der Lebern und Langwuhr zurückzuführen. Wann zum ersten Mal bewässert worden ist, kann nicht festgestellt werden; der erste diesbezügliche Protokollbericht stammt aus dem Jahre 1809. Die relativ geringen Niederschläge und die rasche Versickerung des Wassers im Schotterfeld haben die Bauern dazu bewogen, das Wasser der Bäche in ein kompliziertes Kanälchensystem über einer großen Fläche aufzuteilen. Solange das Wasser regelmäßig fließt, bringt diese Anlage dem Landwirt Nutzen. Sobald aber das Wasser nach Gewittern, bei raschen Schneeschmelzen oder bei Eisstauungen anschwillt, vermögen die oft untiefen Bewässerungsrinnen das Wasser nicht mehr zu fassen; weite Teile des Schotterfeldes werden überschwemmt. Die grabennächsten Teile werden dabei so stark durchfeuchtet, daß sie nischenartig ausbrechen und in den Hauptgraben abrutschen. Im Juni 1876 sind über $100 \mathrm{~m}^{3}$ Schutt in den Sädel abgeglitten. In andern Kanälchen fließt das Wasser gerichtet gegen die Rheinhalde und vermag neue Kerben anzureißen; vor allem in der Umgebung des Sädels ist die Häufung der Grabenanrisse auffallend (Abbildung 12)*39.

*38 GR 23. 2. 1918: «Besprechung des an das Statthalteramt eingereichten Beschwerdeschreibens von Ulr. Schenkel im Oberdorf und Jean Schenkel, Wirt betreffend Schadenzufügung durch unrichtigen $A b f l u B$ des Dorfbaches auf Lebern.

Wurde beschlossen, dem Statthalteramt mitzuteilen, daß schon letztes Jahr diese Angelegenheit dem Kulturingenieur zur Erledigung resp. zur Beratung betreff. Ausführung eines richtigen Bachabflusses übertragen worden ist, bis dato noch nichts von demselben getan worden ist.»

GR 8. 7. 1944: "Die Bachverbauung auf Lebern kommt auf Eingabe des Arbeitslagers auf Fr. 800 zu stehen.» (Die Arbeiten sind durch Internierte ausgeführt worden.)

GR 19. 9. 1946: "Auf mündlichen Antrag des Vorstehers der Abteilung Wasserbau und Wasserrecht der Direktion der öffentlichen Bauten des Kts. Zürich, Hrn. Bachofner, beschließt der Gemeinderat, an die genannte Amtsstelle ein generelles Gesuch um Verlegung des Dorfbaches zu richten.»

GR 12. 1o. 1948: «Meliorations- und Vermessungsamt des Kts. Zürich: Kopie der Zuschrift vom 29. 9. 1948 an die Abteilung für Wasserbau und Wasserrecht der Kant. Baudirektion betr. das wegen der vorgesehenen Dorfbachkorrektion zu schaffende Vorprojekt für Güterzusammenlegung des nördlichen Gemeindebannes Weiach ....»

(Siehe auch GR 21. 6. 1922; 9. 4. 1932; 2.12. 1941; 18. 6. 1949; 28. 9. 1949.)

GR 11. 4. 1950: «Mit Schreiben vom 6. April 1950 erkundigt sich die Kant. Baudirektion Zürich, Abteilung Wasserbau und Wasserrecht, über den Stand der Verhandlungen in Sachen Vorschlag zur Dorfbachverlegung. Präsident Meierhofer übernimmt die Aufgabe, die sich erkundigende Amtsstelle telephonisch vom bisher größtenteils negativen Ergebnis seiner bisherigen Bemühungen mit den beteiligten Grundbesitzern Kenntnis zu geben.»

*39 GV 18. 9. 1809: «ist jeder wegen Wasser Raubung in Wisen gewahrnet der Fehlbar erfundene, nach Wasser ordnung gebüßt würde.»

GV 16. 1o. 1829: "Solle das Wässern wodurch das Akerland könnte unter Wasser gesetzt werden, behutsam geschehen, auch sollen die Abzug Gräben zwüschen Wiesen und Aeker auf gethan werden, damit durch überschwemmung niemand zu Schaden komme. Wer dieses nicht beobachten sol durch den von ihm zugefugten Schaden haften.»

(Weitere allgemeine Wässerbestimmungen:

GV 2. 7. 1828 ; 28. 3. 1831 ; 18. 2. 1860. GR 16. 6. 1836).

$G V$ 13. 3. 192o: «Da der Bach im Wiesenthal keinen richtigen $A b f l u ß$ besitzt und derselbe letztes Jahr infolge Hochwasser einigen Wiesenbesitzern durch Rutschungen großen Schaden anrichtete, gelangten dieselben an die Baudirektion und ersuchten dieselbe baldmöglichst dafür besorgt zu sein, daß diesem Übel evt. weitere Rutschungen abgeholfen werde...》

GV 27. 4. 1920: «2. Der Vorsitzende Präsident Grießer erstattet über die vom Gemeinderate gemachten Anordnungen, sowie über den Bericht der Baudirektion, in dem die Wässerwiesenbesitzer die Bachverbaungen auf ihre Kosten auszuführen hätten Bericht. 


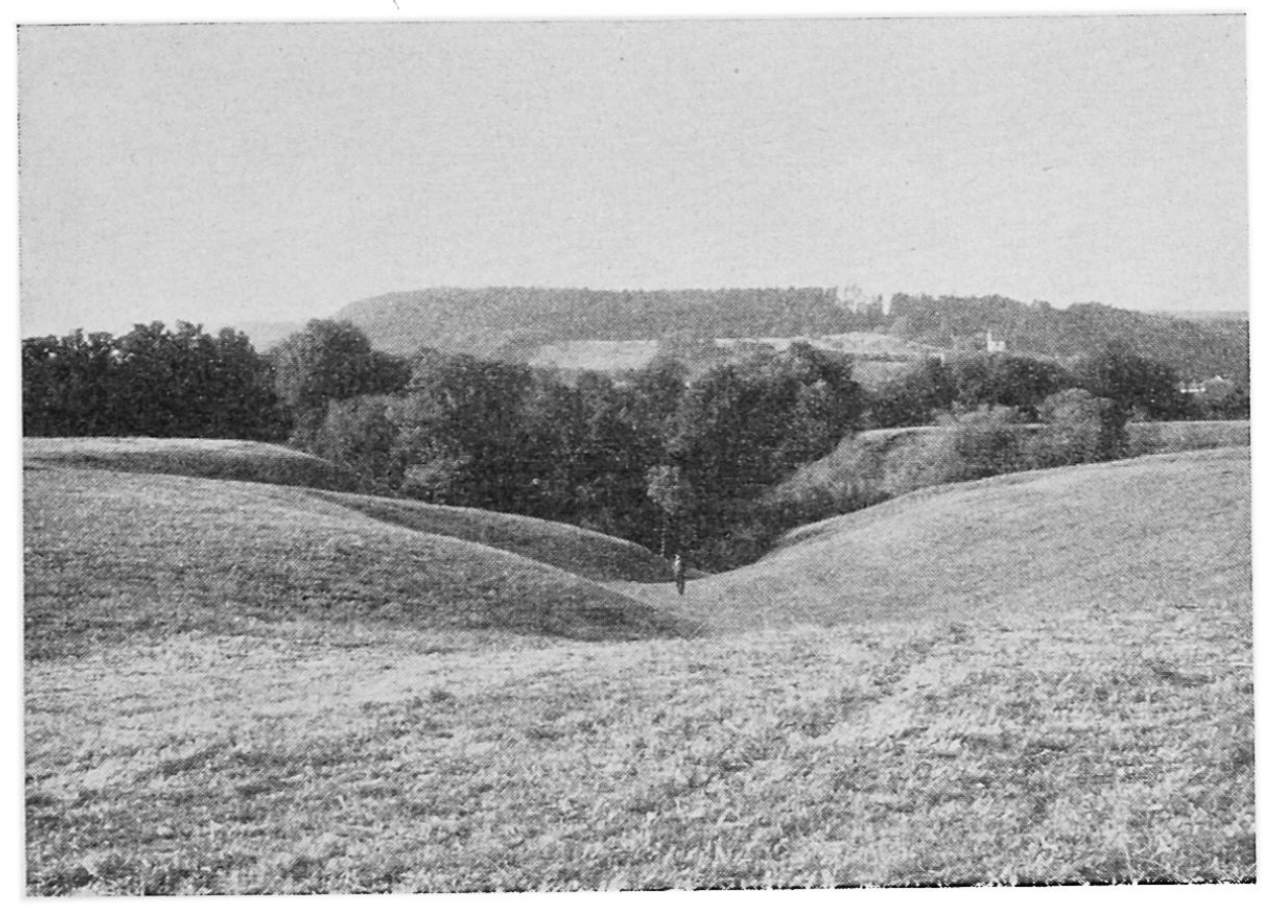

Abb. 12

Nebenanrisse des

Sädels; Zerstörung von Kulturland

Wertvolles Kulturland geht durch diese rückwärtsschreitende Erosion und Denudation verloren. Auch der Rheinhalde-Wald leidet Schaden, indem Bäume ausgeschwemmt oder den Wurzeln Erdreich entzogen wird.

3. Auf Antrag von Posthalter Meierhofer wurde beschlossen die Baudirektion zu ersuchen die Bachkorrektion auf Staatskosten vornehmen zu lassen, da der Staat über sämtliche öffentlichen Gewässer verfüge.»

$G V$ 5. 1. 1921: «2. Gestützt auf Beschluß der Baudirektion wurde denjenigen Wiesenbesitzern welche das Wässerrecht weiterhin ausüben wollen, eine Frist von 1o Tagen angesetzt, um sich zu melden, ansonst dieselben evt. nicht mehr wässerungsberechtigt werden könnten.»

$G V$ 2o. 2. 1921: «2. Berichterstattung von Hauptmann Meierhofer und Grießer Bäcker über die mündliche Verhandlung mit der Baudirektion. Nach den eingeholten Berichten soll die Verbesserung des jetzigen Ablaufes sofort auf Kosten der Wässerwiesenbesitzer und evt. der Gemeinde durchgeführt werden. Dagegen eine spätere richtige Korrektion werde auf Kosten des Staates durchgeführt werden.

3. Von Meierhofer Posthalter wurde die Anregung gemacht den Staat anzuhalten die richtige Bachkorrektion nicht auf die lange Bank hinauszuschieben.

4. Wurde beschlossen die Verbesserung des jetzigen Ablaufes nach Plan durch die Wässerwiesenbesitzer auszuführen, und das dazu nötige Holz soll von der Gemeinde unentgeltlich geliefert werden.»

$G V$ 23. 3. 1921: «1. Besprechung der von Schenkel Wirt und Schenkel Jean, Ulrichs gestellten Forderungen $400 \mathrm{Fr}$. und $450 \mathrm{Fr}$. für das zur Verbesserung des jetzigen Bachablaufes erforderliche Land.

3. Auf Antrag von Meierhofer Posthalter und Grießer Heinrich wurde die verlangte Landentschädigung von Seiten der Wiesenbesitzer verweigert.

4. Da die 2 Wiesenbesitzer trotzdem auf Ihrer Forderung beharren, kann somit die Verbauung nicht ausgeführt werden.

5. Auf Antrag von Meierhofer Posthalter wurde von 25. Anwesenden mit 24 Stimmen beschlossen die Wässerwiesenbesitzerkorporation aufzuheben.

6. Auf Antrag von Hauptmann Meierhofer hin soll den Entschädigungsfordern dieser Beschluß amtlich zugestellt werden und denselben Mitteilung gemacht werden, daß für Entstehung weiterer Schäden die Wässerwiesenbesitzer nicht aufkommen werden, da ja die Verbesserung des Bachablaufes nicht ausgeführt werden darf, resp. durch sie selber verhindert worden sei.»

GV 27. 4. 1921: «Da Graf Schmid und Willi Albert durch den jetzigen Lauf des Baches wieder geschädigt worden sind, haben dieselben bei der Baudirektion Beschwerde eingereicht, worauf durch Ingenieur Zeller von Zürich gestern nochmals ein Augenschein vorgenommen wurde. Nun erklärte Zeller in seinem Berichte, daß nun die Wiesenbesitzer die vorgeplante Bachverbauung nun einmal vornehmen sollen und über die Kosten samt Landankauf welche er auf $870 \mathrm{Fr}$. schätzte nachher einen Verleger anlegen und dann evt. Staat und Gemeinde zur 
Nachdem dieses Bewässerungsnetz mehr Schaden als Nutzen anrichtet, entschließen sich verschiedene Bauern, das Wässern aufzugeben. Die unsystematische Aufhebung hat nach Aussagen von Herrn NAEF, Weiach, wiederum Landverluste zur Folge: In den oberen Wiesen werden die abzweigenden Verteilergräben zugedeckt. Dadurch wird nun sämtliches Wasser der Bäche in die Kanäle der unteren Wiesen geleitet, die beim Anschwellen der Gewässer den vermehrten Wasseranfall nicht mehr zu fassen vermögen. Das Wasser fließt direkt gegen die Rheinhalde zu und erodiert im Steilhang. In den Jahren 1920-1922 beschließt die Wässerwiesenkorporation, dem Übel endgültig zu steuern: Mit Ausnahme von 3 Bauern verzichten alle auf ihre Wässerrechte; die Wässerwiesenkorporation wird am 23. 3. 1921 aufgehoben. Nach langwierigen Verhandlungen kommt die Bachverbauung 1921/22 endlich zustande. Die drei wässerberechtigten Landwirte nützen ihr Recht nicht mehr aus.

\section{ק4) Geologische Verhältnisse}

Die Erklärung der Grabenentstehung durch die vereinigten Dorfbäche zwingt zur Untersuchung der vom Bach durchflossenen Schotterebene, der Weiacher Hauptniederterrassenfläche: Wie kommt es, daß ein Gewässer die weite Schotterflur zu durchfließen vermag, ohne wesentliche Spuren zu hinterlassen, ohne zu erodieren?

Die genauen Untersuchungen im Gebiete von Weiach ergeben, daß die geologischen Verhältnisse komplizierter sind, als meistens angenommen wird. Die Rheinhaldeschotter täuschen folgendes einfache Profil vor, das auch im Forstprotokoll enthalten ist (Fig. 14):

Dieser Querschnitt stimmt nicht. Beim Studium alter Karten fällt einerseits die Sumpfbildung in der Langwuhr, anderseits die Lokalbezeichnung «Im See» (südlich der Hauptstraße an der Kantonsgrenze) auf. In nassen Zeiten hat sich «Im See» jeweils ein Tümpel gebildet, der längere Zeit dort liegen geblieben ist, die Wiesen versumpfend. Ein Bach nahe der Kantonsgrenze hat hier seinen Ursprung genommen. Jetzt ist dieses Gebiet drainiert. In Zeiten starker Regenfälle und heftiger Schneeschmelzen aber steigt in der Gegend der Stud auch heute noch ein nahe der Oberfläche liegender Grundwasserspiegel so stark, daß Wasser in die Keller eindringt. Das ist z. B. beim Bahnhof Weiach-Kaiserstuhl und bei der südlich davon gelegenen Garage der Fall. Welches ist nun dieser oberflächennahe Grundwasserstauer, der entweder dem Schotter eingelagert ist oder den Schotter unterteuft?

Anläßlich der Anlage eines Kanalisationsgrabens (Frühling 1956) von der Schäftefabrik südlich des Bahnhofs gegen das Dorf Weiach, habe ich die Stauschicht verfolgen und untersuchen können. Der aufgerissene Graben war 3,50 m tief, die Sohle verlief auf einem Niveau zwischen $365 \mathrm{~m}-366 \mathrm{~m}$. Die geringe Eintiefung hat - bis auf eine Ausnahme von $10 \mathrm{~m}$ Länge - genügt, um den Kontakt Schotter - wasserundurchlässige Schicht freizulegen. Nur im $10 \mathrm{~m}$ langen $Z$ wischenstück ist die Schottermächtigkeit bedeutender als $3,50 \mathrm{~m}$; im allgemeinen variiert sie zwischen $1,50 \mathrm{~m}$ und

Zahlung heranzuziehen. Gestützt auf obigen Bericht wurde beschlossen die Bachverbauung baldmöglichst vorzunehmen, und über die Verteilung der Kosten nachher Beschluß zu fassen.» GV 8. 7. 1922: «1.) Abnahme der Kostenrechnung und des Kostenverlegers über die Bachverbauung im Wiesenthal. Dieselben wurden genehmigt.

2.) Nach längerer Diskussion wurde auf Antrag von Grießer Heinrich beschlossen an die Gemeindeversammlung das Gesuch zu richten, daß die Gemeinde den Ankauf des Landes zur Bachverbauung übernehmen soll, das heißt den Betrag für den Landankauf leisten solle.»

$G V$ 23. 7. 1922: «Lag ein Gesuch vor von den Wässerwiesenbesitzer, daß die Gemeinde die Landentschädigungskosten für die Bachverbauung auf Lebern im Betrage von 234 Frk. 85 übernehmen soll da die Wiesenbesitzer immer noch die Verbauungskosten von ca. 940 Fr. zu zahlen haben. Von Baumgartner Gmdegutsverwalter wurde der Antrag gestellt die Gemeinde solle an die Verbauungskosten nur $10 \%$ was ca. 120 Frk. ausmache, bezahlen. In offener Abstimmung wurde von 61 Anwesenden mit großer Mehrheit dem Gesuche der Wässerwiesenbesitzer entsprochen.» 


\section{VORGETÄUSCHTES PROFIL KIRCHHOLZ - RHEIN}

SW
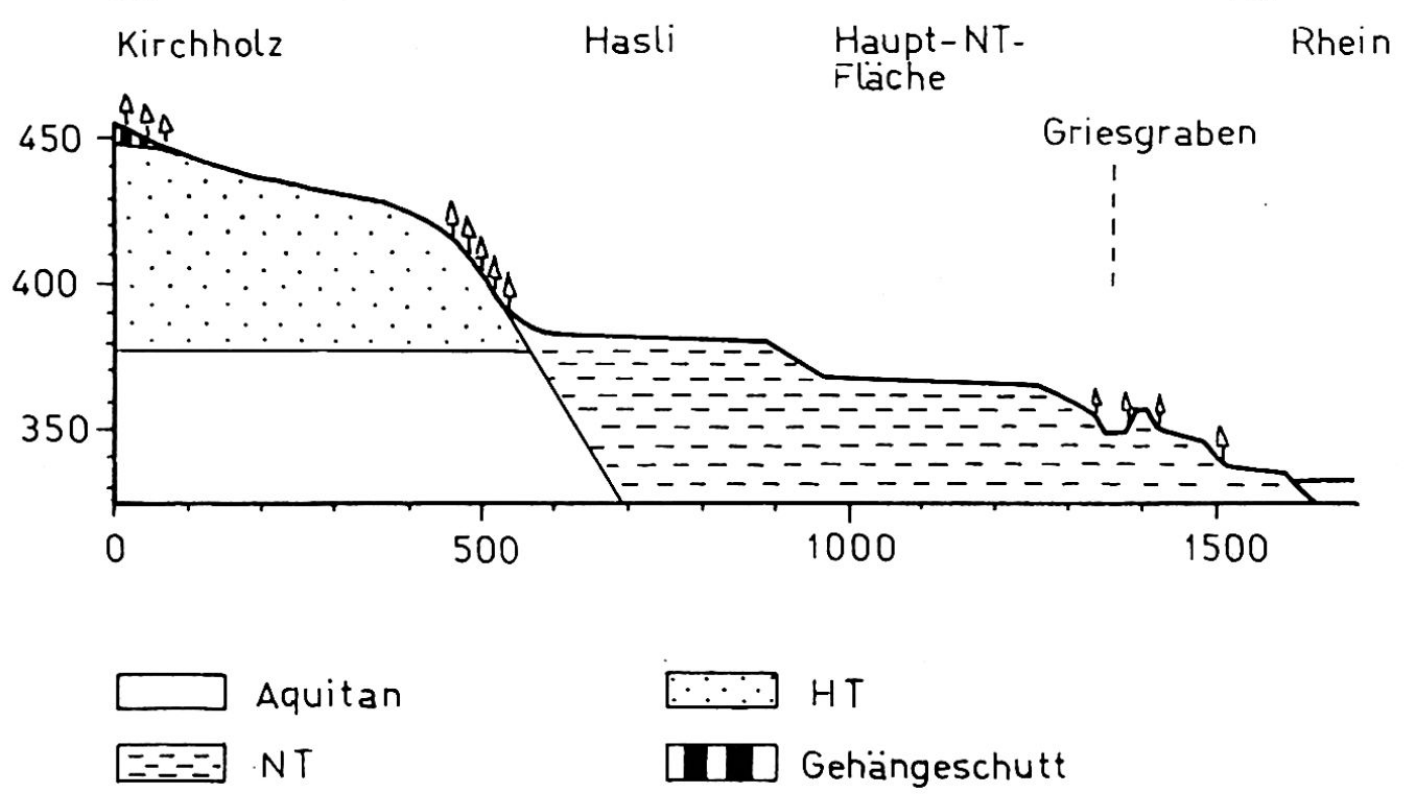

Fig. 14

2,50 m! Die Auflagerungsfläche ist recht unausgeglichen. Im Liegenden des Schotters finden sich die stauenden Schichten: Bunte Mergel, die mit graugrünen Sandsteinen wechsellagern. Die Verkittung ist sehr verschieden; bald findet sich ein lehmiger, relativ lockerer Sand, bald ist der Sandstein so hart, daß er mit dem Kompressor entfernt werden mußte. Ebenso finden sich alle $Z$ wischenstufen von Sanden und Mergeln. Die Schichten können der Molasse zugeordnet werden; sie sind gleich ausgebildet wie die aquitanen Schichten bei Eglisau (von Braun, 5; Weber, 89). Zudem weist die Höhenlage von $365 \mathrm{~m}$ auf die Zugehörigkeit zur Unteren Süßwassermolasse (Aquitan) hin (Fig. 15). Wie weit die oberflächennahe Molasseschicht durchzieht, kann nicht genau ermittelt werden. Folgende Feststellungen sollen einige Anhaltspunkte liefern:

1. Im Frühling 1957 ist bei einer Untersuchungsgrabung in der Kiesgrube beim Kleinkaliberstand Weiach-Kaiserstuhl (400 m westlich des Bahnhofes) eine Vertiefung bis in ein Niveau von $366 \mathrm{~m}-367 \mathrm{~m}$ vorgetrieben worden. Sofort füllte sich dieses Loch mit 50-60 cm Grundwasser.

2. Der Haslihof (beim $\mathrm{H}$ der Bezeichnung Außer Hasli) bezieht sein Trinkwasser aus einer Tiefe von $5 \mathrm{~m}$. Die wasserstauende Molasseschicht zieht also unter der obersten vorhandenen Niederterrassenfläche durch.

3. Die Untere Süßwassermolasse ist durch die Sumpfbildungen «Im See» und in der Langwuhr belegt. Sondierungen in $3 \mathrm{~m}$ Tiefe «Im See» haben den lehmigen Sand nachgewiesen.

4. Das Eindringen von Grundwasser in die Häuser der Umgebung des Bahnhofs ist auf diese Schicht zurückzuführen.

5. Das Fundament des Polizistenhauses zwischen Hauptstraße und Bahnlinie ist in der mergelig-sandigen Schicht angelegt. 


\section{PROFILE DURCH DIE WEIACHER EBENE}

1) $20 \mathrm{~m} W$

Strassenabzweigung

Hauptstrasse -

Dreschhausstrasse
2) Mitte der Hauptstrasse

bei Abzweigung

Dreschhausstrasse
3) $5 \mathrm{mE}$ Profil 2)
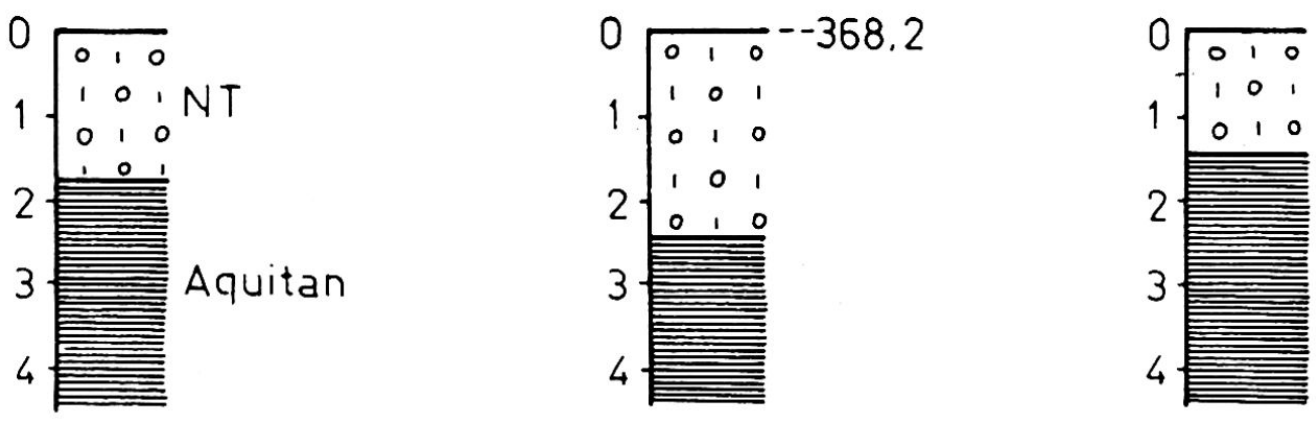

Fig. 15

6. Die Kanalisationsröhren längs der Hauptstraße (Schäftefabrik-Wiesental) liegen in der aquitanen Molasse.

7. Im Fundament des Neubaues $100 \mathrm{~m}$ westlich des Polizeipostens ist die Molasse im östlichen Teilstück in 2 m Tiefe aufgeschlossen, um dann nach NW ganz bedeutend abzusinken.

8. Nicht mehr aufgeschlossen ist die Molasseschicht an der Rheinhalde östlich des Griesgrabens.

9. Im Griesgraben ist die Molasse nach Aussage von Bauunternehmer Griesser bei einer Hangkorrektion in einer Höhe von ca. $345 \mathrm{~m}$ nachgewiesen worden.

10. Eine Bohrung für eine Quellfassung beim Hof «Ofen» ist erst in einer Tiefe von $35 \mathrm{~m}$ auf Sandstein gestoßen (Niveau: $335 \mathrm{~m}$ ).

Die unregelmäßig gewellte, $364 \mathrm{~m}-367 \mathrm{~m}$ hoch gelegene Mergel-Sandsteinschicht strebt demnach gegen Norden vor der Rheinhalde der Tiefe zu; der Molassesockel verliert vor Erreichen des «Ofens» an Höhe. (Diese Angaben mögen einen kleinen Beitrag zur Kenntnis der «Geröllunterkanten» [= Schotterauflagerungsflächen] im Rheintal liefern, über deren Höhenlage nach GRAUL, 28, p. 134, noch nirgends etwas Näheres angegeben ist. Weitere Ausführungen dazu finden sich im Kapitel: «Zur Entstehung der Würmterrassen im Rheingebiet. »)

Das Profil vom Sanzenberg nach der Rheinhalde weist demzufolge folgendes Aussehen auf (Fig. 16):

Der Mittelterrassenschotter als NT unterlagernder Rinnenschotter ist nicht eingezeichnet, da die Rheinhalde-Schotter durchwegs einheitlich erscheinen. Eine Zweiteilung konnte ich trotz eifrigen Suchens nirgends erkennen. Auffällig ist das außerordentlich starke Relief der Schotterunterlage in der Umgebung von Weiach-Kaiserstuhl: Da finden sich die Malmkalkhorste von Hohenthengen, Kaiserstuhl und Herdern. Auch der Molassesockel als Schotterträger schwankt stark in seinem Niveau. Eine Ausebnung der Schotterauflagerungsfläche wie sie Schaefer (67) beschreibt, existiert - zumindest in meinem Untersuchungsgebiet - nicht. Wir dürfen daher die 


\section{WIRKLICHES PROFIL KIRCHHOLZ - RHEIN}

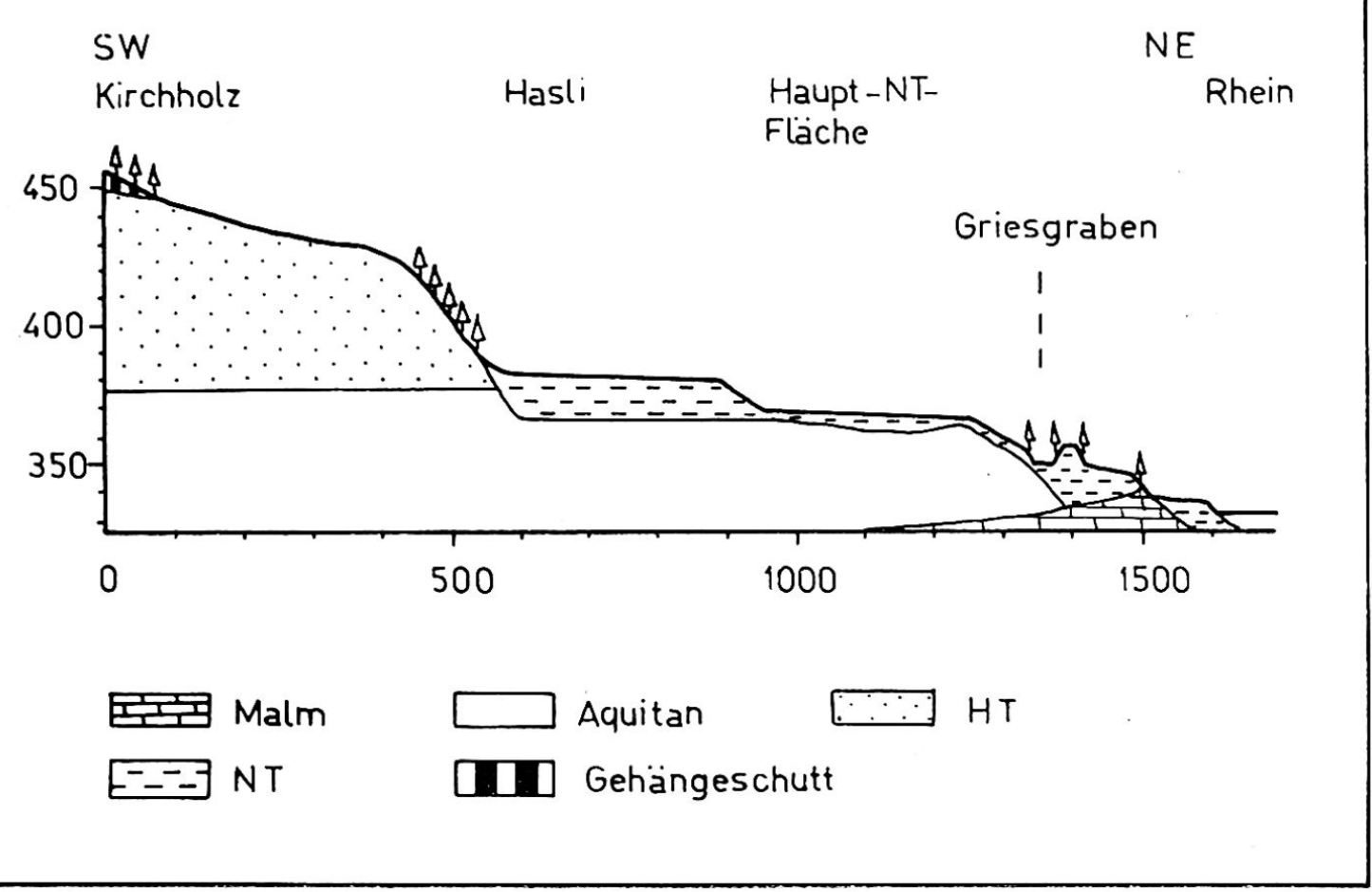

Fig. 16

verschiedenen Niveaus des Schotterträgers nicht zur Würm-Untergliederung verwenden.

Die Oberflächennähe des wasserundurchlässigen Molassesockels hat einen Einfluß auf die Grabenentstehung an der Rheinhalde. Beim Austritt des Sägebaches und des Mühlebaches aus ihrem Molasse-Oberlauf auf die NT-Schotter, können die Wasser nur wenig tief in den Untergrund eindringen und versickern nicht sofort in den tieferen Rhein-Grundwasserstrom. Weiteres Wasser steht von der HT-Molasseunterlage zur Verfügung. So ist es zur Versumpfung gewisser Schotterteile nahe der Rheinhalde gekommen (Heute sind die Sümpfe drainiert. Der Dorfbach fließt künstlich angelegt über die Schotterebene.).

\section{c) Vergleich obere Gräben - untere Gräben}

Ihrem Habitus entsprechend können Saxenholzgraben, Hasliraingraben I und II mit dem Griesgraben, Sädel und Kaibengraben verglichen werden. Die Gräben sind nicht früher als Spätwürm entstanden. Die oberen haben nach der Anlage der Haslifläche funktioniert. Das kann zu einer Zeit gewesen sein, als die Rheinhalde noch nicht ausgebildet war, Sägebach und Mühlebach noch keine Möglichkeit hatten, sich einzukerben. Die oberen Rinnen mögen in ihrer ersten Anlage also etwas älter sein als die unteren; sie sind aber noch gleichzeitig mit den tieferen Formen aktiv gewesen.

Es ist nicht so, daß die oberen Gräben als Wassersammler gedient und sich die Wasser dann über das Hasli und die Hauptniederterrassenfläche hinweg gegen die unteren Gräben ergossen hätten. Spuren eines solch gerichteten Fließens sind nirgends zu finden: Weder auf den Flächen, noch im Terrassenhang, der die Haslifläche von der Weiacher Ebene trennt, sind erosive Kerben zu finden. Die bedeutenden Schuttbewegungen und die Aufschüttung der Schuttkegel haben die Wasserkraft aufgebraucht. Auf der Ebene ist das Wasser auf den Molassesockel hinunter versickert. 
Schmelzwasser vermag stellenweise den Terrassenhang zur Hauptniederterrassenfläche überflossen haben. Darauf weisen die beiden beschriebenen Muldenformen, sowie das Hakenschlagen im Hang hin. Es muß sich dabei um eine Durchtränkung und gelegentliche Abspülung des Bodens zu Zeiten rascher Schneeschmelzen gehandelt haben. Keiner der unteren Gräben weist in seiner Längsachsenverlängerung gegen die oberen Formen.

\section{d) Andere Gräben im Rheingebiet}

\section{d1) Fisislochgraben westlich Eglisau (679 775/269 450 bis 680 250/270 275)}

Ein weiterer linksrheinischer Graben mündet $400 \mathrm{~m}$ westlich der Eisenbahnbrücke in den Rhein. Unterhalb der Straße Eglisau Rheinsfelden ist er ähnlich ausgebildet wie die drei Weiacher Hauptgräben. Durch einen bedeutenden Erdrutsch ist im mittleren Teil des unteren Grabens eine Gefällsstufe entstanden. In dieser Verebnung ist ein Bunker erstellt worden; ein Weg führt vom Rhein in die Straße vom OberSteinert gegen die Hauptstraße hinauf.

Verlängern wir die Achse des Grabens, so gelangen wir über ein flacheres $Z_{w i-}$ schenstück von $200 \mathrm{~m}$ Länge zu einer oberen Grabenfortsetzung: dem Fisisloch. Ein muldenförmiges Tälchen, auf dem wasserdurchlässigen JD-Plateau des Laubberges einsetzend, versteilt sich stark. Über eine Steilstufe wird das in Meeresmolasse angelegte Fisisloch angeschnitten. Der Erosionsbetrag ist im oberen Grabenteil des starken Gefälles und der bedeutenden Wassermenge wegen besonders groß. Das Gefälle des Hanges verflacht sich gegen die Bahnlinie zu; die erodierende Tätigkeit des flieBenden Wassers verringert sich. Aus dem tief eingefressenen Tobel ist ein kleiner Graben geworden, dessen Sohle mit Schilfgräsern bewachsen ist. Zeitweise fließt ein kleines Rinnsal; während längerer Zeit versiegt der Bach überhaupt. Heute wird das Wasser in einer Röhre unter dem Bahntrasse durchgeführt und teilweise offen fließend über den Schuttkegel geleitet. Der Schuttkegelgraben ist bloß $20 \mathrm{~cm}$ breit und $5 \mathrm{~cm}-20 \mathrm{~cm}$ tief; er steht in keinem Verhältnis zur oberen Grabenausräumung. In der Mitte der Aufschüttung läuft die Rinne aus. $5 \mathrm{~m}$ oberhalb der Straße sammelt ein $50 \mathrm{~cm}$ tiefer Schacht das oberflächlich fließende Wasser und leitet es in einer Röhre unter der Hauptstraße hindurch; dort versickert das Wasser. Der untere Graben weist keine Spuren rezenter Erosion auf.

Zwischen Bahnlinie und Hauptstraße hat der Fisisloch-Bach einen bedeutenden Schuttkegel aufgeschüttet. Das ausgeräumte obere Grabenmaterial ist hier zur Akkumulation gelangt. Beim Versuch, neben dem Bahnwärterhaus eine Zisterne anzulegen, hat man dieses Material durchbohrt und ist dabei auf Holzreste gestoßen. Kies ist nicht erreicht worden. Bei großer Schuttführung reichte die Kraft des fließenden Wassers nicht aus, das Grabenzwischenstück Hauacker zu durchtalen. Die Kraft erschöpfte sich in der Ablagerung des feuchtigkeitsdurchtränkten Schuttes. Es zeigt sich, daß der Bach vom Laubbergplateau bis zum Bahndamm bedeutende Wassermengen durch Versickern verliert. Die Feuchtigkeitsdurchtränkung der oberflächennächsten Teile macht sich in Rutschen bemerkbar; mehrere $\mathrm{m}^{3}$-große Nagelfluhblöcke sind losgerissen.

Wie gelangte nun das Wasser vom Fisisloch in die untere Grabenfortsetzung? Folgende Erklärungen sind möglich:

1. Das versickerte Wasser hat längs eines lokalen Quellhorizontes wieder aufzutauchen und sich am Steilhang in den NT-Schotter einzufressen vermocht. Einen solchen Quellhorizont kann die den Schuttkegel unterlagernde Meeresmolasse bilden.

2. Bei plötzlichen Schneeschmelzen rinnt das Wasser über den noch nicht völlig aufgetauten Boden in Richtung unterer Graben (Heute fängt der Bahndamm das Schmelzwasser auf und staut es dabei zu großen Tümpeln.). 
Der untere Graben kann altersmäßig den unteren Weiacher Hauptgräben gleichgesetzt werden. Das Alter des oberen Teiles ist schwieriger zu bestimmen. Die oberste Eintiefung mag schon nach der Erosion des JD (Bildung des Laubbergabfalles) geformt worden sein. Besonders intensiv muß die Erosion jeweils in den vegetationsarmen Tundrenzeiten gewesen sein, gekennzeichnet durch kurze, heftige Wasserführungen, deren Kraft kein Retentionsvermögen des Waldes gemildert hat. Frostböden sind zudem in aufgetautem Zustand höchst erosionsfällig (JAECKLI, 42). Die Erosionstätigkeit hat sich aber nicht allein auf die vegetationsarme Zeit beschränkt; die im Schuttkegelmaterial eingelagerten Hölzer beweisen, daß der Fisislochwald bei heftigen Unwettern der Erosion keinen eindeutigen Einhalt zu bieten vermag.

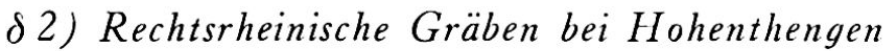

Zwischen den Dörfern Hohenthengen und Herdern finden sich drei Grabenformen, die in ihren Ausmaßen aber bedeutend hinter den Weiacher Gräben zurückstehen. Sie setzen auf einem Niveau von ungefähr $352 \mathrm{~m}$ ein.

Der östlichste Graben durchschneidet nur die oberste Kante; die Einkerbung ist durch eine Weganlage ausgeweitet worden. Im unteren Grabenteil fließt ein Gewässer in einer betonierten Rinne dem Rhein zu (675 800/269 400).

Der mittlere Graben gleicht in seiner Anlage dem Weiacher Anriß I; nur setzt die Hohenthengener Form tiefer ein. Ein oberer Terrassenhang ist angekerbt worden; auf der folgenden Terrassenfläche hat die Kraft zum Erodieren nicht mehr ausgereicht. Im untersten Steilhang ist wieder eine kleine Rinne angelegt (675 700/ $269350)$.

Der bedeutendste Graben ist der westliche. Ähnlich dem Sädel vereinigen sich drei Arme zur Hauptform. In die östliche Eintiefung wird ein Bach künstlich eingeleitet. Die Erosionskraft ist im zurückverlegten Hang sehr intensiv; die Grabenwände sind stark versteilt. Nach unten flacht die Sohle aus; der Bach versickert. Die Einmündungsstelle in den Rhein ist schilfbewachsen. Bei Hochwasser dringt der Fluß in die unterste Verflachung ein. Die Verlängerung der Grabenlängsachse führt nordwestwärts zu einer Einkerbung im oberen Terrassenhang (an der Hauptstraße Hohenthengen-Herdern). Die zwischengeschaltete Terrassenfläche ist nicht angeschnitten (675 500/269 250).

\section{Die Periglazialtälchen südlich von Wil (Rafzerfeld)}

HuBer beschreibt diese Formen in seiner Abhandlung über die Würmeiszeit (34, p. 68-69):

«Die angeschwollenen Wasser griffen das obere Rafzerfeld an, so da $\beta$ der untere Boden entstand, der durch einen Steilhang von etwa $13 \mathrm{~m}$ vom höhern Teil scharf abgegrenzt ist. Schon früher wurde darauf aufmerksam gemacht, daß in diese Halde neun tote Wasserrinnen eingeschnitten sind, deren Sohle in die tiefer liegende Ebene ausläuft. Sie könnnen aber nicht von Gletscherwasser gebildet worden sein, denn solches flo $B$ damals nicht mehr über das obere Rafzerfeld. Das beweist uns, daß beim Übergang ins Stadium 2 nicht nur die Gletscher stark zurückschmolzen, sondern gleichzeitig eine so schwere Regenzeit einsetzte, daß das atmosphärische Wasser über den Rafzerfeldschotter, der bis an die Oberfläche mit Grundwasser gefüllt wurde, abfließen mußte, während dort heute nur noch ein einziges kleines Gewässer, der Landbach, vorhanden und der Kies noch in $50 \mathrm{~m}$ Tiefe trocken ist, wie die Bohrungen auf der 389 m-Ebene beim Gasthaus Linde südwestlich Hüntwangen ergeben haben.»

Um die Schlußfolgerungen Hubers auf ihre Richtigkeit prüfen zu können, betrachten wir die Formen dieser toten Wasserrinnen genauer: Der Steilabfall der Akkumulationsterrasse des oberen Rafzerfeldes ist südlich von Wil (beginnend beim Landbüel, über P. 394 Richtung Bücken-Westrand des Stadtforrens verlaufend) durch 16 Rinnen und Mulden zerschnitten. Sechs dieser toten Tälchen laufen mit ebener Sohle auf die Terrassenfläche der Erosionsterrasse Ghürst aus; es sind dies die Eintiefungen beim Landbüel, der Landbacheinschnitt, das Tälchen nördlich von den 
Bücken, das Frauenackertälchen, die Rinne zwischen dem Frauenackertal und P. 39j, das Tälchen 395 m-399 m. Die zehn übrigen Vertiefungen münden entweder hängetalartig im Steilhang aus oder gehen in einem versteilten Gefälle -in die tiefere Terrassenfläche über. Es sind keine sicheren Schuttkegel vorhanden. Im folgenden seien die sechs Hauptformen kurz skizziert:

\section{Landbüeltälchen :}

Unterhalb des Schützenhauses Wil vereinigen sich zwei Talarme. Das Haupttälchen setzt muldenartig am südlichen Dorfende von Wil ein, währenddem die nordwestliche Mulde ihren Anfang im Molassegebiet Vor Bäl nimmt. Nach der Vereinigung wird das Talprofil asymmetrisch: Der E gelegene Hang setzt sich scharfkantig von der Fläche der Akkumulationsterrasse ab und ist gegenüber dem verschleppten W-Hang versteilt. Eine breite, nicht ganz ausgeebnete Sohle mündet auf die Erosionsterrassenfläche. Die ausgeräumte Talfüllung muß durch den Hauptfluß weggeschwemmt worden sein, denn nirgends ist ein Schuttkegel zu erblicken.

2. Landbachtälchen :

Östlich des Landbüeltälchens ist von der Akkumulationsterrasse nur noch ein kleines Reststück übrig geblieben; eine Eintiefung im Gebiete des heutigen Landbachtales hat diesen Abschnitt von der 'Terrassenfläche des Nüchemerfeldes isoliert. Die muldenartige Eintiefung setzt nordöstlich des $\mathrm{S}$ von Steinechrüz bei der Straßengabelung ein. Die Fortsetzung der Längsachse zeigt gegen die Molassehänge zwischen Bächerbuck und Hüslihof, wo Muldentäler in das Haupttal einmünden. Das Landbachtälchen geht wenig westlich der Straßenkreuzung P. 394 in die Erosionsterrassenfläche über. - Der heutige Bach erodiert in seinem zwischen Rafz und Wil künstlich angelegten, schmalen Bachbett nur sehr wenig. Erst da, wo das Gefälle durch die Überwindung der Höhenstufe zwischen Akkumulations- und Erosionsterrassenfläche größer geworden ist, vermag sich der Bach leicht einzufressen.

3. Tälchen nördlich von den Bücken:

Ein $50 \mathrm{~m}-60 \mathrm{~m}$ breites und $250 \mathrm{~m}$ langes Kastental durchbricht den Terrassenhang bei den Bücken und läuft ohne ersichtlichen Schuttkegel im Ghürst aus. Im Röggliacker setzen - wie die $405 \mathrm{~m}$ Hilfskurve schön zeigt - drei sanfte, dellenartige Einbuchtungen in der Akkumulationsterrassenfläche ein. Der nördlichste Seitenarm weist seinerseits nochmals eine in den $\mathrm{Hang}$ eingelagerte Nebenmulde auf. Nach der Vereinigung der drei Muldentälchen nimmt das Tal eine scharf profilierte Kastenform an.

4. Frauenackertälchen (am Nordrand des Stadtforrens):

Auch dieses Tälchen ist in seinem untersten Teilstück kastenartig ausgebildet; nach oben geht diese Form in eine Mulde über, die sich erst gegen den Bahnübergang (P. 409,6) in der Akkumulationsterrassenfläche verliert. Im Gegensatz zu den andern, \pm gerade verlaufenden Rinnen, mäandriert das Frauenackertälchen. Von NE mündet eine kleine Delle in das Kastental.

5. Tälchen zwischen Frauenacker und P. 395 (681 000/271 800):

Dieses Tälchen weist ein etwas steileres Gefälle auf; die Sohle ist uneben. Die Form ist in einem weniger entwickelten, früheren Zustande stecken geblieben.

6. Tal $395 \mathrm{~m}-399 \mathrm{~m}$ im Stadtforren:

Die größten Ausmaße weist Tal 6 auf: Ein muldenartiger Beginn setzt ca. $500 \mathrm{~m}$ östlich der Bahnlinie Hüntwangen-Rafz ein, während zwei weitere 


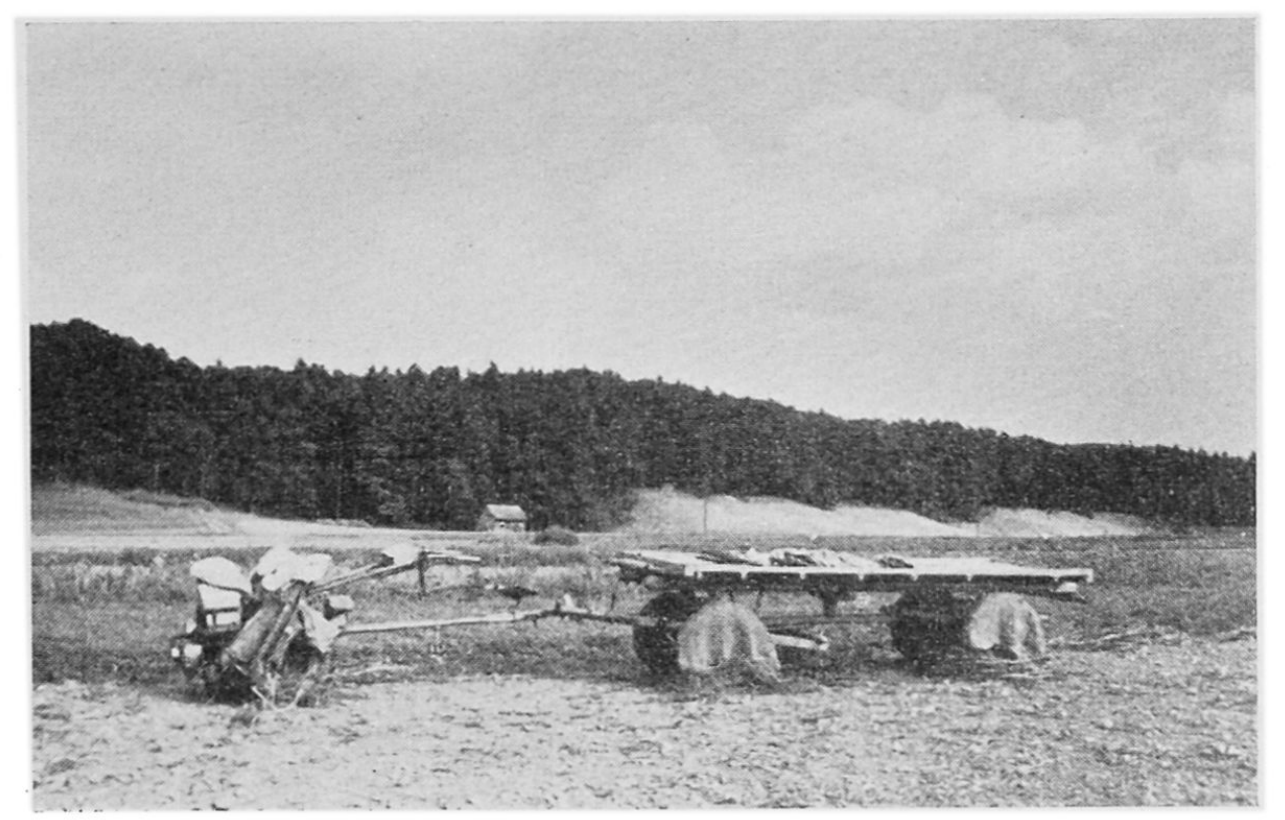

Abb. 13

Den Akkumulationsterrassenhang durchbrechende Periglazialtälchen am Westrand des Stadtforrens. Verschiedene Mündungshöhen

Seitenarme nördlich des Schienenstranges ihren Anfang nehmen. Bei der Vereinigung der Nebenarme zum Haupttälchen ist eine deutliche Erosionsrippe ausgebildet worden. Von P. 399 bis P.395 nimmt das Tal ausgeprägte Kastenform an. Eine leichte Aufwölbung, die aber nicht in der direkten Talachse verläuft, zieht in die Ebene hinaus. Der Riegel bei P. 395 kann als Verschneidung zweier Prallhänge des Rheines gedeutet werden.

In den 16 Tälern finden wir eine ganze Entwicklungsreihe vertreten (Abb. 13). Das Anfangsstadium ist durch eine hangdellenartige Mulde innerhalb des Steilhanges gekennzeichnet, wobei aber die Ausmündung die Erosionsterrassenfläche nicht erreicht.

In einem etwas weiter fortgeschrittenen Stadium hat sich von dieser Mulde her ein Tälchen rückwärts in die Akkumulationsterrassenfläche hinein zu entwickeln vermocht. Der vermehrte Wasseranfall hat die Ausmündungsstelle im Steilhang ausgeweitet und tiefer gelegt, bis schließlich die tiefere Terrassenfläche erreicht worden ist. Ein solches Tälchen ist z. B. zwischen der großen Kiesgrube und dem Sandbuck zu beobachten: Muldenartiger Beginn mit sehr geringem Gefälle, gegen den Terrassenhang zu Versteilung und Ausweitung zu einer richtigen Sohle. Das Tälchen hat dann zu funktionieren aufgehört; sein Gefälle hat sich noch nicht demjenigen der Erosionsterrassenfläche angepaßt. Die nächste Stufe in der Entwicklungsreihe stellt das Tälchen 5 zwischen Frauenacker und P. 395 dar: Eine Sohle - wenn auch noch leicht versteilt - schließt an die Ghürstfläche an. Am weitesten fortgeschritten sind diejenigen Täler, bei denen die Steilstufe immer weiter zurückverlegt worden ist und deren Kastentalsohle eben und in gleichem Niveau wie die Erosionsterrassenfläche mehrere hundert Meter in die Akkumulationsterrasse hineinzieht. Typisch ist aber auch bei diesen am stärksten zurückversetzten Tälern der dellenartige Beginn.

Die Datierung dieser 'Tälchen ist einfach: Sie sind erst nach der Akkumulation der Schotterebene entstanden und haben nach der Fertiganlage der obersten Erosionsterrassenfläche nicht mehr wesentlich funktioniert; wirkliche Schuttkegel fehlen (Kleine Unebenheiten mögen noch auf vereinzelte, schwache Schuttanlieferungen nach der Bildung der Ghürstfläche hindeuten.).

Schwieriger ist die Art der Entstehung zu deuten. HuBER hat sicher recht, wenn er schreibt, daß die Täler nicht von Gletscherwasser gebildet worden seien. Das Gletscherwasser floß damals nicht mehr über das obere Rafzerfeld ab. Nirgends lassen sich Verlängerung der Mulden in das Moränengebiet hinein feststellen. Zwischen Moränen und Tälchen schaltet sich eine mehrere Quadratkilometer mächtige, un- 
gestörte Schotterfläche ein. Muß demzufolge für die Erklärung der toten Rinnen eine schwere Regenzeit angenommen werden? Um diese Frage zu beantworten, müssen wir uns die Gestalt der Tälchen vergegenwärtigen: Sind Dellen, Muldentälchen und Kastentäler Formen, die zu Zeiten großer Niederschlagsmengen gebildet werden?

Wie ich im Abschnitt «Gräben und Dellen in der Umgebung von Weiach und ihre Beziehung zur Talgeschichte» gezeigt habe, sind die unteren und oberen Gräben auf verstärkte Erosionstätigkeit zurückzuführen. Direkte Beobachtungen lassen erkennen, wie an bestimmten Terrassenhängen zu Zeiten intensiver Regenfälle erodiert wird: Die Erosion wirkt - sobald das Gefälle groß genug ist - linear in die Tiefe; es entstehen V-förmige Tobel, nicht aber sanfte Muldentäler oder Kastenformen mit einer Sohlenbreite von $50 \mathrm{~m}-60 \mathrm{~m}$. Die Entstehung der Rafzerfelder-Periglazialtälchen muß anders erklärt werden. Die Formen lassen erkennen, daß sie noch zur Zeit des Permafrostes gebildet worden sind. An warmen Tagen kam es zu regelmäßigem Auftauen der obersten Schichten (Auftauboden). Am steilen Terrassenhang vermochte durchnäßter Schotter auf dem dauernd gefrorenen Untergrund abzugleiten. In diesen Solifluktionsformen konnte das Wasser dann bereits gesammelt abfließen. Sicher spielte bei der Entstehung dieser Tälchen auch die Korrasion mit; doch erklärt F. MüLleR, der Dauerfrostbodenformen in der Arktis untersucht hat, daß für die Umgestaltung eines Muldentälchens in eine Kastentalform vor allem folgende Faktoren verantwortlich seien:

1. die Einstrahlung der Sonne,

2. die Firnansammlung,

3. der Wärmetransport durch fließendes Wasser.

Diese Detailuntersuchungen ergeben einen wesentlich neuen Gesichtspunkt: Als sich der Rhein bereits gegen sein erstes Erosionsniveau hinunter eintiefte, fand sich im Rafzerfeld noch ein Dauerfrostboden vor. Die abgleitenden und aus den Tälchen angelieferten Schuttmassen wurden von den Fluten des an den Steilhang prallenden Rheines mitgerissen. Die ausgeräumte Masse ist nicht am Ausgang der Tälchen zur Ablagerung gelangt. Mit der Fertiganlage der Erosionsterrassenfläche verschwand der Dauerfrostboden, die Wasseranlieferung und damit die Schuttführung der Periglazialtälchen. (Es ist auch nicht einzusehen, daß beim beginnenden Rückzug der Gletscher der Dauerfrostboden mit einem Schlage hätte verschwinden sollen. Im Falle des Rafzerfeldes zog sich der Gletscher vom Maximalstand aus bis zur Anlage der ersten Erosionsterrassenfläche nur um weniger als $1 \mathrm{~km}$ ostwärts. Sölle in der Umgebung von Nack weisen das Vorhandensein großer Eismassen in noch späterer Zeit nach.)

Die Rafzerfelder Akkumulationsterrasse ist zur Zeit der Anlage der ersten Erosionsterrassenfläche stark zertalt worden. Ebenfalls an ihrem Rande angegriffen ist die Akkumulationsfläche beim Lindirain nördlich der Chrüzstraß, doch ist die ursprüngliche Form der Rinnen nicht eindeutig ersichtlich, da Straßen und Bahngeleise in diesen Lücken angelegt worden sind. Von einem Schuttkegel, wie ihn HubER (34, p. 68) beschreibt, ist nichts $\mathrm{zu}$ bemerken. Solche Zerschneidungen fehlen der Weiacher Hasliterrasse vollkommen. Ist dies ein weiterer Hinweis dafür, daß die Hasliterrasse zu einem späteren Zeitpunkt - als der Dauerfrostboden bereits verschwunden war - angelegt worden ist, d. h. bereits eine Erosionsterrasse darstellt?

\section{Periglazialtälchen, die auf das Rütifeld (nördlich Windlach) ausmünden}

In diesem Kapitel werden vor allem zwei Formen besprochen:

1. der Hasliboden,

2. die Täler zwischen Lenibuck und Chatzenstig. 


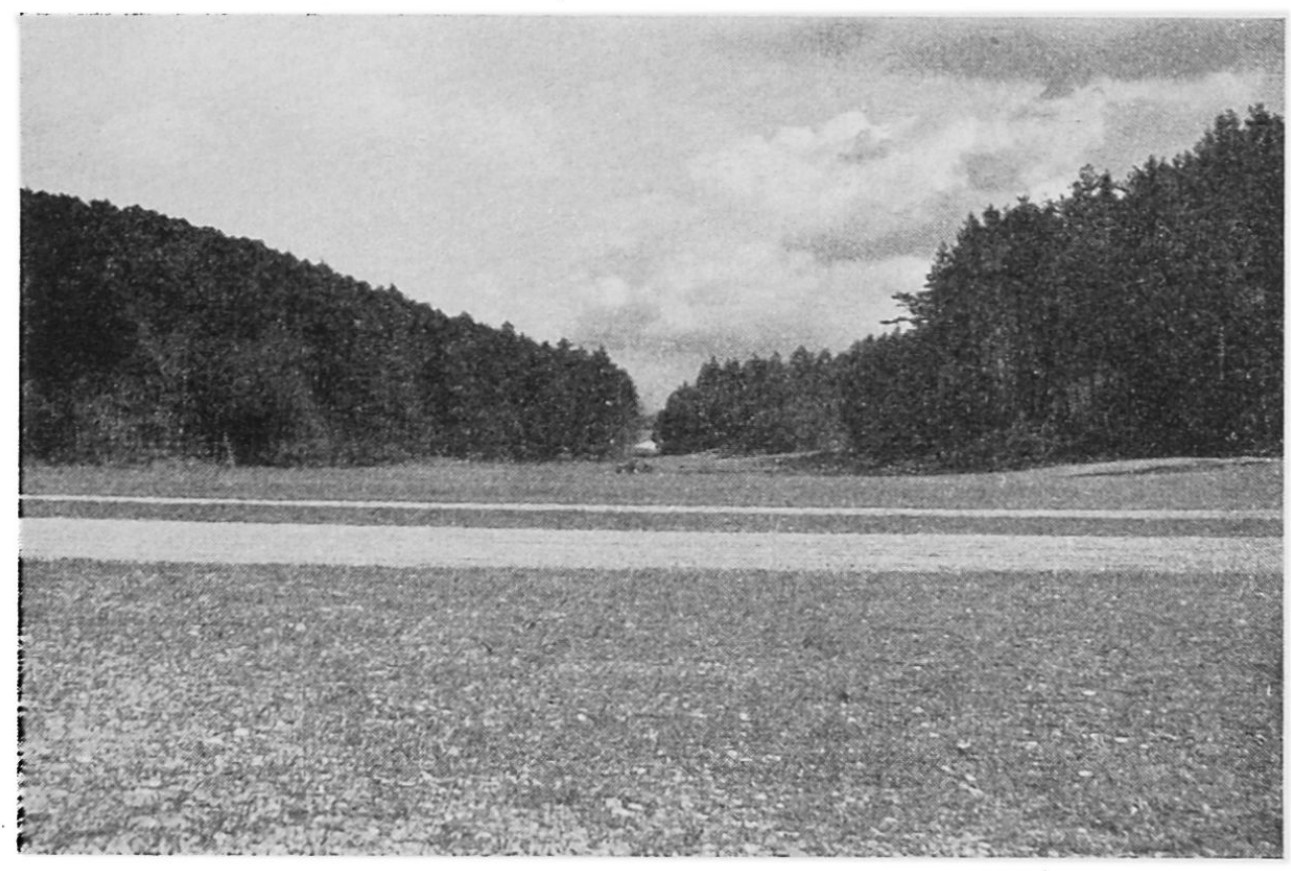

Abb. 14

Blick vom Rütifeld auf den

Hasliboden

\section{Der Hasliboden}

Das größte und am schönsten ausgebildete Periglazialtal ist wohl der zwischen dem Hasli und dem Lenibuck gelegene Hasliboden, der auf die Akkumulationsfläche des Rütifeldes ausmündet (Abb. 14).

Drei aus dem Kurvenbild deutlich ersichtliche Seitenarme ziehen vom leicht gewellten HT-Plateau des Haslis her und vereinigen sich zur Talsohle (Breite im oberen Teilstück ca. $100 \mathrm{~m}$, im untersten Abschnitt sich auf $200 \mathrm{~m}$ ausweitend). Allen Seitenarmen ist gemeinsam, daß sie muldenartig im Plateau einsetzen und weiter unten, eine breite Sohle annehmend, sich zur Kastenform entwickeln. In den Nebentälern findet sich zeitweise eine Asymmetrie der Hänge: Die W oder NW gelegenen Hänge sind versteilt. Die beiden gegen den Widisol ziehenden Seitenarme verlaufen gewunden, währenddem das Stadler Tobel in der direkten Fortsetzung der Haslibodenachse liegt und sich erst weiter östlich nach Süden wendet. Durch eine etwas länger andauernde Schuttanlieferung aus den südlichen Armen erscheint die Sohle des Haslibodens bei der Einmündung dieser Seitentälchen leicht gewellt. Ein viertes, dellenartiges Hangtal nimmt seinen Ursprung auf der Geige (175 m östlich des P. 414,2); es ist steiler als die übrigen Seitenarme und wirft einen kleinen, nicht der gesamten ausgeräumten Masse entsprechenden Schuttkegel auf den Hasliboden. Der Südabhang des Lenibuckes ist nicht zertalt. Rütifeld und Hasliboden gehen flach ineinander über. Langgestreckte, leicht erhöhte Wälle, die sich durch besonderen Steinreichtum auszeichnen, ziehen erst weit westlich im Gentner und in den Steinäckern (ungefähr längs der Hochspannungsleitung) bis zum Dorf Windlach hinauf. Da sich diese Streifen durch besondere Trockenheit und Unfruchtbarkeit auszeichnen, werden sie von den Bauern «Breustenen» (Einzahl: Breusti) = brandige Stellen genannt. Sie können nicht als Schuttkegelreste des Haslibodens gedeutet werden; eine Erklärungsmöglichkeit soll im Abschnitt «Entstehung der Würmterrassen» erwähnt werden.

Es ist nun zu prüfen, ob das Haslibodental bereits vor der Akkumulation der Würmschotter existiert habe und dann während der Vorrückungsphase der Gletscher systematisch auf das heutige Niveau aufgeschottert worden sei, oder ob das Tal seine Ausbildung erst zur Würmeiszeit erfahren habe.

Wäre die Anlage des Haslibodens älter als Würm, müßte der Hasliboden auf das Schotterauflagerungsniveau des Windlachertales - also auf $340 \mathrm{~m}-360 \mathrm{~m}$ - anstatt 


\section{HASLIBODEN - ENTSTEHUNG}

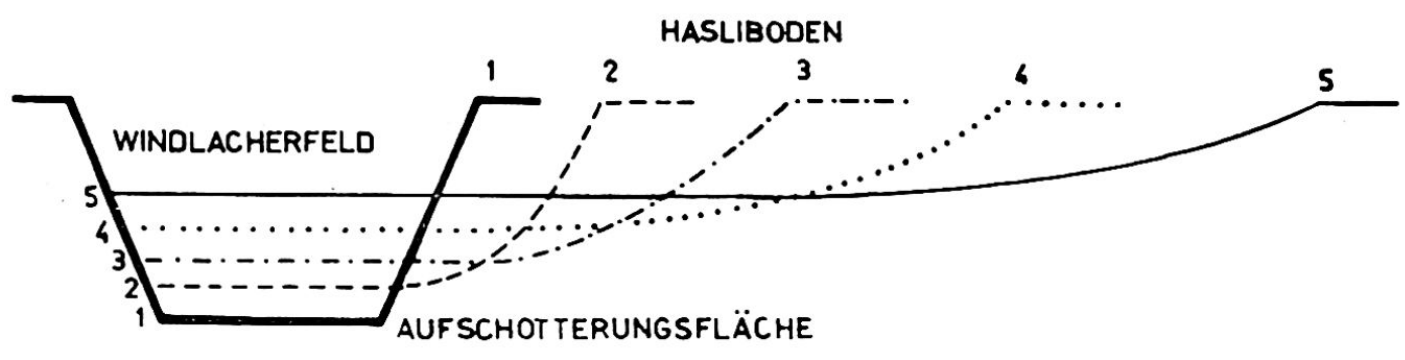

Fig. 17

auf die heutige Höhenlage von $405 \mathrm{~m}-410 \mathrm{~m}$ ausgelaufen sein. Der Oberlauf der Nebentälchen hätte sich dem gegenüber heute doppelt so großen Gefälle angepaßt und die HT-Hänge in tiefen Schluchten, nicht aber in sanften Mulden oder Kastentälchen mit breiter Sohle zerschnitten. Die Nebenarme laufen mit abnehmendem Gefälle \pm regelmäßig auf den Hasliboden aus, ein Zeichen dafür, daß sie sich der Erosionsbasis des heutigen $\mathrm{Haupttälchens} \mathrm{angeglichen} \mathrm{haben.} \mathrm{Ist} \mathrm{nun} \mathrm{lediglich} \mathrm{der} \mathrm{Hasli-}$ boden älter, die von Süden einmündenden Seitentäler hingegen erst seit Bestehen des heutigen Haslibodens angelegt worden? Der Hasliboden liegt im spitzen Winkel zur Aufschotterungsachse des Windlachertal-Flusses. Die Akkumulation auf das heutige Niveau des Haslibodens (vor allem der des südöstlichen Teilstückes) müßte durch die Schuttanlieferung der Seitentälchen erfolgt sein. Die durch Solifluktion aus den Nebenarmen angelieferte Schottermenge ist aber viel zu gering, als daß sie die Auffüllung des Haslibodentales auf das heutige Niveau hätte bwirken können.

Die Formen der Tälchen weisen auf die Entstehung während der Dauerfrostbodenzeit hin. Da das Plateau des HT-Schotters leicht gewellt ist, konnte sich das Wasser des Auftaubodens sammeln und floß konzentrierter als im Rafzerfeld. Verbunden mit dem größeren Gefällsunterschied und der längeren Zeitspanne ergibt sich als Resultat eine intensivierte Ausweitung der Haslibodentälchen. Die Ausräumung erfolgte gleichzeitig mit der Aufschotterung des Rütifeldes; die Schotter des Haupttales und des Haslibodens gehen ohne sichtbare Trennung ineinander über. In nachfolgender schematischer Skizze sei versucht, die Entwicklung des Haslibodens festzuhalten (Fig. 17) :

Das praewürmische Windlachertal war zu beiden Seiten von steilen Molasse- und HT-Hängen begrenzt. Die Sohle des Haupttales lag, wie Bohrungen zeigen (Strasser 77), zwischen $340 \mathrm{~m}-350 \mathrm{~m}$. Während der Vorstoßphase der Gletscher breitete sich der Dauerfrostboden aus. Die Aufschotterung setzte ein und erhöhte die Talsohle. Solifluktionserscheinungen legten den Steilhang zurück und verflachten ihn. Während der Auftauzeiten wurden bedeutende Wassermengen frei; im Zusammenhang mit dem Schuttfließen konnten immer weitere Wassereinzugsgebiete des Haslis erfaßt werden. Die Erosion und Denudation des Seitenhanges paßte sich dem beständig sich erhöhenden Niveau der Haupttalsohle an. Da während der Permafrostbodenzeit selbst kleinste Gefälle genügten, um den anfallenden Schutt abzutransportieren, kam es trotz der Erhöhung der Erosionsbasis noch zur Ausweitung des Haslibodens und seiner Seitentäler. Zur Zeit des maximalen Gletscherstandes mochten vielleicht Schmelzwasser einiger in der Umgebung des Rotenbrunnens und des Oberholzes auf das Hasli hinauf gepreßter Eislappen den Weg durch die Muldentälchen Richtung Hasliboden eingeschlagen haben. Ein geringes Abschmelzen der Gletscher- 
stirn genügte dann freilich, um die Wasser über den Ostabhang des Straßberges abfließen zu lassen.

Das Verschwinden des Dauerfrostbodens führte zum Absterben der Solifluktion. In den steileren Seitenarmen dauerte die Schuttführung etwas länger als auf dem flacheren Hasliboden. Kleine Schuttkegel an den Einmündungsstellen der Nebenarme in das Haupttälchen zeugen von der abklingenden Solifluktionsphase.

Eine ähnliche, allerdings weniger starke Eintalung findet sich $1 \mathrm{~km}$ westlich der Haslibodenausmündung auf der Gegenseite des Rütifeldes. Der Haberstall trennt dort das Sali vom Endberg.

\section{Die Täler zwischen Lenibuck und Chatzenstig}

Zwei Tälchen zerschneiden die Erhebung nördlich des Haslis in den südlicheren Lenibuck und den nördlicheren Chatzenstig. Die beiden Vertiefungen verlaufen in derselben Längsachse. Der Kulminationspunkt liegt $100 \mathrm{~m}$ östlich des Forsthauses Junghau-Katzenstieg, auf einer Höhe von wenig mehr als $450 \mathrm{~m}$. Hier nehmen auch die beiden Tälchen ihren Anfang: Das eine, das Chüestellihautälchen, erstreckt sich in südöstlicher Richtung gegen den Straßenpunkt 415, das andere schlägt den Weg gegen den Lochgraben ein.

Das Chüestellihautälchen ist kürzer und weniger stark entwickelt; sein Gefälle ist steiler. Die Einmündung erfolgt ohne Schuttkegelbildung in ein Muldental, das sich von der Schutzgrueb über die Straßenpunkte 428 und 415 bis westlich des Cholplatzes ausdehnt. Die Chüestellihaurinne muß gleichzeitig mit der Schutzgruebmulde funktioniert haben, d. h. zur Zeit des Dauerfrostbodens. Die durch das Auftauen des Bodens freigewordene Wassermenge ist durch Schmelzwasser von Gletschereis aus der Umgebung des Maximalstandes im Hätschgen vermehrt worden. Die $100 \mathrm{~m}$ westlich des Forsthauses aufgeschlossene, wassertragende Lehmschicht darf nicht mehr als Würm-Grundmoräne aufgefaßt werden. Die am weitesten vorgetriebenen Gletscherlappen der letzten Eiszeit sind nur wenig weit über den heutigen Waldrand des Hätschgen vorgedrungen. Der Chatzenstig-Lehm muß der Riß-Grundmoräne zugeordnet werden; die etwas weiter unten in einer Kiesgrube aufgeschlossenen Schotter stellen HT-Material dar.

Das nordwestliche Tal ist kastenförmig mit einer Sohlenbreite von 20-30 m ausgebildet. Im Mittelteil ist das Gefälle geringer als im unteren Abschnitt. Es sind keine Anzeichen rezenter Kerben zu entdecken; heute wird das wenige Wasser in künstlichen Gräben und Röhren geführt. Die Kastentalform setzt sich noch über eine sehr kurze Strecke in das Akkumulationsniveau der Würmschotter hinein fort. Ein geringes Eintiefen hat also noch nach der Aufschotterung der Rütifeldfläche stattgefunden.

Von Aarüti her zieht sich eine tiefe Kerbe, der Lochgraben, den Terrassenhang durchbrechend bis ins Rütifeld hinein. Im unteren Teilstück sehr tief eingefressen, verliert sich der Grabenanfang in zwei Armen in der Schotterfläche: Der eine zieht Richtung Chatzenstig, der andere gegen den Hasliboden; beide enden aber, bevor sie diese Seitentälchen erreichen.

Ist die Anlage des Lochgrabens darauf zurückzuführen, daß die Wasser des Chatzenstigtales und des Haslibodens gerichtet gegen den Terrassenhang geflossen sind? Diese Idee muß abgelehnt werden. Die zwischengeschaltete, ungestörte Schotterschicht - im Falle des Haslibodens immerhin $500 \mathrm{~m}$ betragend - weist darauf hin, daß der Lochgraben jüngerer Entstehung ist, eine Form für sich darstellt und unabhängig von den beiden andern Tälchen entwickelt worden ist. In seltenen Fällen, z. B. nach starken Gewitterniederschlägen oder raschen Schneeschmelzen, vermag das fließende Wasser nachträglich eine Verbindung zwischen Chatzenstigtal und Lochgraben hergestellt haben. $\mathrm{Da}$ eine regelmäßige Wasserführung gefehlt hat, beweist 
auch der Umstand, daß die Gefälle der beiden Eintiefungen nicht aufeinander abgestimmt sind.

\section{REVISION}

\section{DER WÜRM-TERRASSEN IM ERWEITERTEN ARBEITSGEBIET}

\section{Die Würm-Terrassen im Rheingebiet in der Sicht verschiedener Autoren}

\section{Allgemeines}

Kommt DU PaSQUier 1891 (60) das Verdienst zu, als erster im extramoränischen Hochrheingebiet Hoch- und Niederterrassen auseinandergehalten $\mathrm{zu}$ haben, so beschäftigen sich später in diesem Gebiete arbeitende Geomorphologen eingehend mit der Gliederung der Würmschotter. Dabei ergeben sich im wesentlichen folgende verschiedene Auffassungen:

a) Die Würmeiszeit ist einerseits durch eine Vereisung mit einheitlichem Vorstoß und anderseits durch mehrere Rückzugsstadien gekennzeichnet. Die unter dem Niveau der obersten Fläche (Akkumulationsplatte) liegenden Würmterrassenflächen sind im Sinne der PENCKschen Rückzugsschotterebenen akkumulativ geschaffen worden (d. h. während des eiszeitlichen Rückzugs Erosion, zur Zeit des Gletscherstillstandes Aufschotterung in die Erosionsrinne).

b) Die Würmeiszeit weist 2 oder mehrere Gletschervorstöße auf, die durch Interstadiale voneinander getrennt sind. Es finden sich dementsprechend 2 oder mehrere ineinandergeschachtelte Würm-Akkumulationssysteme.

c) In der Würmeiszeit hat ein Gletschervorstoß stattgefunden (geringe Oszillationen vorbehalten); als Auswirkung davon kennen wir im periglazialen Gebiet eine Akkumulationsphase: Die Aufschotterung der Akkumulationsfläche. Durch stufenweise Tieferlegung sind die unteren Terrassen, die alle Erosionsterrassen sind, entstanden.

\section{Die Interpretationen einzelner Autoren}

a) A. Penck, 1894, 1901, $1909(61,62)$ :

PENCK unterscheidet in seiner Schrift 61 einen weitesten, einheitlichen Gletschervorstoß und 5 Rückzugsstadien während der Würmeiszeit. Der Vorgang der Terrassenbildung wird folgendermaßen erklärt: Nach der Aufschüttung der Niederterrassenfläche des weitesten Vorstoßes zieht sich der Gletscher zurück. Das Gletscherende gelangt aus dem Endmoränenbereich heraus und kommt in ein tieferes Niveau zu liegen (Zungenbecken); dadurch verlegen sich auch die Betten der Abflüsse tiefer, und die Wasser sind gezwungen, den Moränengürtel zu durchbrechen. Bei Stillstand der Gletscher tritt Akkumulation ein; der Gletscherfluß schottert in der eben geschaffenen Rinne wieder auf. - In der Nachschrift zur 2. Auflage der erwähnten Schrift 61, 1901, revidiert PENCK das Bild seiner Rückzugsstadien dahin, daß während des allgemeinen Gletscherrückzuges nicht nur einzelne «Pausen» (= Stillstände) eingetreten seien, sondern auch Stadien, «während welcher das Eis neue Vorstöße von gelegentlich recht beträchtlicher Ausdehnung gemacht hat». Die Schaffhauser Terrassen sind nach PENCK keine Erosions-, sondern Akkumulationsterrassen; die Bildung einer jeden Terrasse muß man sich als eigenen Akkumulationsakt vorstellen, dem dann die Erosion gefolgt ist. Nach der Nomenklatur BoEsch (3) sind diese Terrassen als $\mathrm{Af}_{1} / \mathrm{Ef}_{2}-$ Formen $\mathrm{zu}$ bezeichnen.

PENCK unterscheidet im Gebiete um Schaffhausen folgende 6 Terrassensysteme: Maximalstand des Gletschers: Guntmadinger-Feld 


$\begin{array}{lll}\text { 1. Rückzugsschotterebene: } & \text { Breiteterrasse } \\ \text { 2. } & \gg & \text { Stokarterrasse } \\ \text { 3. } & \gg & \text { Munotterrasse } \\ \text { 4. } & \gg & \text { Feuerthaler Terrasse } \\ \text { 5. } & \gg & \text { Schaarenwaldterrasse }\end{array}$

b) J. Hug, 1909 (37; siehe auch ERb, 17 und Huber, 34)

Евв (17) faßt Hugs Darstellungen wie folgt zusammen:

«HUg zerlegt die Niederterrasse zwischen Schaffhausen und Basel in $2 \mathrm{Sy}$ steme, wovon das obere von der Äußeren Jungendmoräne ausgehen soll. Diese beiden Phasen wären durch eine kräftige Schwankung - die früher (1909) von PENCK angenommene, später (1922) aber aufgegebene Laufenschwankung getrennt. Während dieser Zeit - sagt HUG - ist in das obere Niederterrassensystem durch kräftige Erosion eine Rinne hineingefressen worden, in welche dann zur Zeit des Standes von der Inneren Jungendmoräne ein neues Schotterfeld hineingeschüttet wurde, dessen Oberfläche durchschnittlich $13 \mathrm{~m}$ unter derjenigen der oberen Niederterrasse liegt. $\mathrm{Da}$ in der petrographischen Zusammensetzung und in der Verwitterung der beiden Terrassenschotter keine wesentlichen Unterschiede zu erkennen sind, rechnet HUG nicht mit einer Teilung der Würmeiszeit in 2 getrennte Vergletscherungen, sondern nur mit 2 Phasen einer Eiszeit.»

Im Raume von Weiach-Kaiserstuhl liegt die obere Niederterrassenfläche bei 385 m (alte Höhenkote), entspricht also meiner Haslifläche (380/81 m). Die untere Niederterrasse Hugs ist mit meiner Weiacher Hauptniederterrassenfläche identisch. Hug faßt die beiden Formen als $\mathrm{Af}_{1} / \mathrm{Ef}_{2}$-Terrassen auf.

c) L. ERB, 1936 (17)

Nach ERB kann die Würmeiszeit im Hochrheingebiet in 3 Terrassensystemc zusammengefaßt werden:

Würm I : Nimmt seinen Ursprung an den Äußeren Jungendmoränen.

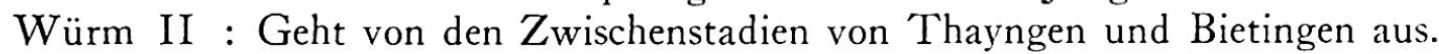
Würm III: Schließt an die Inneren Jungendmoränen an.

Alle drei Terrassensysteme sind $\mathrm{Af}_{1} / \mathrm{Ef}_{2}$-Formen. $\mathrm{Da}$ die Verwitterungstiefen der gleichgearteten Terrassenaufschüttungen ohne bemerkenswerte Unterschiede

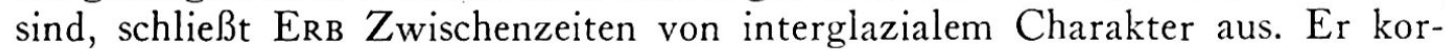
rigiert die Auffassung Hugs dahin, daß er eine dritte Würmaufschotterungsphase festlegt. Von Basel bis Lienheim stimmen die Beobachtungen der beiden Autoren überein; von Lienheim aus rheinaufwärts aber sei HUg in ein zu hohes Niveau geraten, nämlich auf die Weiacher Terrasse. Diese Terrasse sei in Wirklichkeit ein Glied zwischen der oberen und unteren Niederterrasse Hugs.

d) F. ZinK, $1940(98)$

Dieser Autor erklärt die Würmeiszeit als zweiphasig. ZINK hat versucht, ERBS Weiacherterrasse $(=$ Würm II $)$ unterhalb Lienheim weiter zu verfolgen; es sei aber morphologisch unmöglich. Deshalb betrachtet $Z_{\text {INK }}$ die Weiachterrasse als ein Teilfeld der oberen Niederterrasse, ohne dafür aber einen Beweis erbringen zu können.

Er führt folgende Möglichkeiten einer $Z$ weigliederung an:

1. Die untere Niederterrasse könne eine reine Erosionsterrasse innerhalb der oberen Niederterrasse sein.

2. Die untere Niederterrasse sei nach vorausgegangener Erosion der oberen Niederterrasse schachtelartig akkumuliert worden, wobei die vorausgegangene Erosion

a) tektonisch, 
b) klimatisch bedingt gewesen sein könne.

$Z_{\text {INK }}$ entscheidet sich auf Grund von «NT-Unterkanten- und Oberkantenaufschlüssen» in verschiedenen Niveaus bei Kaiseraugst und Schweizerhalle für den Fall 2b): Nach Ablagerung der oberen Niederterrasse sei Erosion eingetreten, die bei Augst das Rheinbett um 25 m tiefer gelegt habe, d. h. $10 \mathrm{~m}$ tiefer als die «Unterkante» der oberen Niederterrasse. Darauf sei eine erneute Aufschotterung erfolgt, diejenige der unteren Niederterrasse. Die vorausgegangene Erosion sei nicht tektonisch bedingt gewesen, da die älteren Terrassenoberkanten nicht verbogen seien; folglich müßten klimatische Bedingungen für die Erosion verantwortlich gemacht werden: ein Interstadial. Die Eisrandlage der Gletscher müsse in diesem Interstadial bedeutend weiter rückwärts gelegen haben (ev. bis hinter dem Bodensee, Laufenschwankung Pencks), um sich bei dem erneuten Vorstoß wieder bis zu den Inneren Jungendmoränen vorzuschieben.

ZiNKs Gliederung läßt sich folgendermaßen darstellen:

$$
\left.\begin{array}{ll}
\text { oberste Terrasse: } & \mathrm{Af}_{1} / \mathrm{Ef}_{2} \\
\text { Weiacher Terrasse: } & \mathrm{Ef}_{1} / \mathrm{Ef}_{2}
\end{array}\right\} \text { Würm I }
$$

e) R. Huber, 1956 (34)

Huber knüpft an die grundlegenden Arbeiten von PencK, ERB und Troll an. Wie Penck arbeitet er hauptsächlich nach der Methode der Korrelierung von Eisrandlagen mit Schottern. Seine Arbeiten basieren auf genaueren Höhenangaben als diejenigen ERBS. HuBER macht darauf aufmerksam, daß die «Rückzugs»-Stadien und -Phasen nur «sogenannte» seien. Es bestehe die Möglichkeit von kleineren und größeren Gletscherschwankungen; deshalb komme den Stadien- und Phasenbezeichnungen hie und da nicht zeitliche, sondern nur topographische Bedeutung zu (vgl. auch 61). Stadien und ihre Moränen bezeichnet HUBER mit arabischen Zahlen, die entsprechenden Schotter mit römischen. Phasen (= Unterstadien) werden mit Buchstaben angegeben.

Aus den Angaben Hubers können folgende drei Korrelations- und Vergleichstabellen aufgestellt werden (Tab. 1, 2, 3):

\begin{tabular}{|c|c|c|}
\hline Stadien und Phasen & Hauptgliederung & Entsprechende Eisrandlagen und Schotter \\
\hline 1a & Frühwürm & Guntmadinger Ablagerungen; obere Niederterrasse \\
\hline $\begin{array}{l}\text { A: } 1 b, 2,3 \\
\text { B: } 4 a, b, c \\
\text { C: } 5 a, b, c, d \\
D: 6,7\end{array}$ & Hauptwürm & $\begin{array}{l}\text { ußerste und ußere erste Eisrandlagen Neuhausen } \\
\text { Zweite Äußere Eisrandlage Schafthausen } \\
\text { Moränen und Schotter in der weiteren Umgebung von } \\
\text { Dießenhofen } \\
\text { Innere Eisrandlage Stein-Singen }\end{array}$ \\
\hline 8 & Spätivürm & Konstanz \\
\hline Postg & & \\
\hline
\end{tabular}

Korrelierung von Hubers Stadien mit Eisrandlagen und Schottern (Tab. 1) :

\begin{tabular}{|c|c|c|}
\hline & Penck & HUBER \\
\hline I & $\begin{array}{l}\text { Guntmadinger Feld }-\mathrm{NT} \\
\text { weitester Gletschervorstoß }\end{array}$ & Stadium 1 \\
\hline II & $\begin{array}{l}\text { Breiteterrasse } \\
\text { 1. Rückzugsstadium }\end{array}$ & 2 \\
\hline III & $\begin{array}{l}\text { Stokarterrasse } \\
\text { 2. Rückzugsstadium }\end{array}$ & 3 \\
\hline & $\begin{array}{l}\text { Munot-Ebnatterrasse } \\
\text { 3. Rückzugsstadium }\end{array}$ & 4 \\
\hline
\end{tabular}

Vergleich PencK - Huber (Tab. 2) : 


\begin{tabular}{|c|c|c|c|}
\hline & PENCK & HUBER & \\
\hline $\begin{array}{c}\mathrm{V} \\
\mathrm{VI}\end{array}$ & $\begin{array}{l}\text { Feuerthalerdorf und Fulachterrasse } \\
\text { 4. Rückzugsstadium } \\
\text { Schaarenwaldterrasse } \\
\text { 5. Rückzugsstadium }\end{array}$ & & 5 \\
\hline & $\cdot$ & $\begin{array}{l}\text { Gletscherstand } \\
\text { Obergailingen-Rheinklingen } \\
\text { Hemishofen-Stein a. Rhein } \\
\text { Konstanz und später }\end{array}$ & $\begin{array}{l}7 \\
8\end{array}$ \\
\hline
\end{tabular}

Vergleich ERB - Huber (Tab. 3) :

\begin{tabular}{|c|c|c|c|c|}
\hline \multicolumn{2}{|c|}{ ERB } & \multicolumn{3}{|c|}{ HUBER } \\
\hline Stadien & Würmgliederung & Stadien & & Würmgliederung \\
\hline 1 & \multirow[b]{2}{*}{ Würm I } & 1a & & Frühwürm \\
\hline $\begin{array}{l}2 \\
3\end{array}$ & & $\left.\begin{array}{l}1 \mathrm{~b} \\
2 \\
3\end{array}\right\}$ & $A$ & \multirow{3}{*}{ Hauptwürm } \\
\hline $\begin{array}{l}4 \\
5\end{array}$ & Würm II & \multirow{2}{*}{\multicolumn{2}{|c|}{ 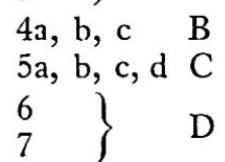 }} & \\
\hline $\begin{array}{l}6 \\
7\end{array}$ & Würm III & & & \\
\hline$\frac{8}{9 \text { (Konstanz) }}$ & & \multicolumn{2}{|c|}{8 (Konstanz) } & Spätwürm \\
\hline
\end{tabular}

\section{Die Weiacher Terrassen in der Sicht verschiedener Autoren}

Die nachstehende Tabelle faßt die verschiedenen Auffassungen über die Würmterrassen-Gliederung bei Weiach zusammen (Tab. 4):

\begin{tabular}{|c|c|c|c|c|}
\hline $\begin{array}{l}\text { HUG } \\
1909\end{array}$ & $\begin{array}{l}\text { ERB } \\
1936\end{array}$ & $\begin{array}{l}\text { ZINK } \\
1940\end{array}$ & $\begin{array}{l}\text { HUBER } \\
1956\end{array}$ & $\begin{array}{c}\text { LEEMANN } \\
1957\end{array}$ \\
\hline . & 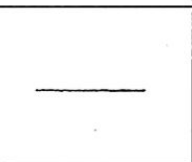 & & & $\begin{array}{l}\text { Würm-Akkumulations- } \\
\text { terrassenfläche nicht mehr } \\
\text { vorhanden } \\
{\text { Af } 1 / E f_{2}}^{-}\end{array}$ \\
\hline $\begin{array}{c}\text { obere NT } \\
\text { Af } 1 / E f_{2}\end{array}$ & $\begin{array}{l}\text { Würm I } \\
\mathrm{Af}_{1} / \mathrm{Ef}_{2}\end{array}$ & $\begin{array}{c}\text { Af } 1 / \mathrm{Ef}_{2} \\
\text { obere NT }\end{array}$ & $\begin{array}{l}\text { 1a, b d. h. Frühwürm und } \\
\text { Anfang Hauptwürmeiszeit, } \\
\text { Abschnitt A } \\
\text { Al } / \text { Ef } 2^{2}\end{array}$ & $\begin{array}{c}\text { Hasliterrasse } \\
\mathrm{Ef}_{1} / \mathrm{Ef}_{2}\end{array}$ \\
\hline $\begin{array}{c}\text { untere NT } \\
\mathrm{Af}_{1} / \mathrm{Ef}_{2}\end{array}$ & $\begin{array}{l}\text { Würm II } \\
\text { (Weiacher } \\
\text { Terrasse) } \\
\text { Af1/Ef2 }\end{array}$ & $\begin{array}{l}\text { Würm I } \\
\text { Ef1/Ef2 }\end{array}$ & $\begin{array}{l}3+4, \text { d.h. Hauptwürmeis- } \\
\text { zeit, Ende Abschnitt A } \\
\text { und Abschnitt B } \\
\text { (?) }\end{array}$ & $\begin{array}{l}\text { Weiacher Hauptniederter- } \\
\text { rasse (abgleitende Fläche) } \\
\text { Ef } / \text { Ef2 }\end{array}$ \\
\hline $\begin{array}{c}\text { tiefer als } \\
\text { untere NT } \\
\text { (nicht mehr } \\
\text { ausgeschieden) }\end{array}$ & $\begin{array}{c}\text { Würm III } \\
\mathrm{Af}_{1} / \mathrm{Ef}_{2}\end{array}$ & $\begin{array}{l}\text { Würm II } \\
\text { Af1/Ef2 } \\
\text { untere NT }\end{array}$ & $\begin{array}{l}5,6,7, \text { d. h. 'Hauptwürm- } \\
\text { eiszeit, Abschnitt C und } \\
\text { Abschnitt D } \\
\text { (?) }\end{array}$ & $\begin{array}{l}\text { untere Terassen } \\
\mathrm{Ef}_{1} / \mathrm{Ef}_{2}\end{array}$ \\
\hline
\end{tabular}

\section{Zur Entstehung der Würmterrassen im Rheingebiet}

\section{Allgemeines}

Die Detailuntersuchungen im Gebiete von Weiach-Kaiserstuhl haben mich dazu geführt, während der Würmeiszeit im extramoränischen Rheingebiet lediglich eine Akkumulationsphase anzunehmen, die das Aufschottern bis auf das Niveau der Akkumulationsfläche bewirkt hat. Die unteren Terrassen sind erosiver Entstehung. Bugmann (13) ist bei seinen Untersuchungen im untersten Aaretal zum selben Resultat gelangt. 
In den nachfolgenden Kapiteln soll der stufenweisen Tieferlegung der Würmterrassen eingehende Beachtung geschenkt und eine Lösung dieses Problems angestrebt werden. $\mathrm{Zu}$ diesem $Z$ wecke ist es nötig, daß ich meine Darstellung mit dem praewürmischen Relief des engeren Arbeitsgebietes einleite. Die daraus gewonnenen Ergebnisse müssen darauf in einen weiteren Rahmen gespannt und geprüft werden. Dies führt zur Ausdehnug meiner Untersuchungen rheinaufwärts bis nach Dießenhofen, rheinabwärts bis zur Wutach-Einmündung. Da sich bei einer Feldbegehung des Rheinabschnittes Kaiserstuhl-Waldshut wesentliche Differenzen zu Hubers Terrassendarstellungen (34) ergeben haben, war ich gezwungen, diese Gebiete selbst zu kartieren

und den Versuch einer neuen Korrelation zu wagen. Im Raume Tössegg-Kaiserstuhl ergab sich bei meinen unabhängig von jeder inneren Moränenlage durchgeführten Terrassenvergleichen eine weitgehende Übereinstimmung mit der HuBERschen Terrassenfolge (Meine Kartierungen reichen bis 1954 zurück und sind unbeeinflußt vorgenommen worden.). Bei Felduntersuchungen im Gebiete von Lottstetten - Nack Rüdlingen konnte ich Hubers Korrelation überprüfen. Ich stütze mich für Vergleiche mit dem intramoränen Raume bis Dießenhofen weitgehend auf die Terrassendaten des genannten Autors, ohne aber mit ihm in der Entstehung der Form einig zu gehen. Weitere Angaben liefern Schalch (113), Goemringer (109) und WEBER $(87,118)$.

Die Landeskarte 1:25000 läßt in den meisten Fällen die Terrassierung deutlich erkennen.

\section{Der praewürmische Verlauf des Rheines in der Gegend des Rafzerfeldes}

Wie Hug (39, p. 60) nachgewiesen hat, führt ein breiter Grundwasserstrom unter dem heutigen Rafzerfeld durch:

«Von der Thurmündung an macht unser Grundwasserstrom das Knie des Rheines bis zur Tößmündung nicht mit; er wendet sich direkt gegen Westen durch das Rafzerfeld, um erst unterhalb der Eisenbahnbrücke Eglisau wieder zum heutigen Talabschnitt zu stoßen.»

Es handelt sich nun darum, diesen westwärts gerichteten Lauf genauer zu verfolgen. Aus petrographischen Gründen (geringe Stabilität der Molassehänge) ist es unmöglich, daß sich der Rhein durch die Einschnitte zwischen den Hügeln Dietlisberg/Schneckenberg/Adenberg/Sulgerhölzli/Grafenhau gepreßt hat. In der westlichen Fortsetzung des heutigen kanalisierten Thur-Unterlaufes hingegen findet sich eine weite, offene Pforte, die den vereinigten Flüssen Rhein und Thur als Durchgang dienen mochte. Über das Gebiet beim heutigen schweizerischen Zollamt Rüdlingen ergossen sich die Wasser Richtung Eichrütenen und Hard. Der Südhang des praewürmischen Rheintales ist nicht durch die Hohenegghalde, sondern durch den Abhang eines weiter nach Norden vorgeschobenen Molassehügels (682600/271 300, südlich P. 414,5) gebildet worden (HuBER, 34, p. 11, beschreibt diese Erhebung fälschlicherweise als Moräne.).

Ein- und Austrittstelle des praewürmischen Rheines können mit geologischmorphologischen Methoden festgelegt werden; erstere liegt zwischen Grafenhau und Molassehügel südlich P. 414,5, letztere im engen Kalkschluchtenabschnitt zwischen Hohenthengen und Lienheim. Wesentlich schwieriger gestalten sich die Untersuchungen im Zwischenabschnitt.

Talformen werden weitgehend durch petrographische Verhältnisse und andere Faktoren, wie z. B. die Wasserführung, bestimmt; so schreibt HUG (39, p. 58) :

«Am Rheinfall bemißt sich die Breite des Grundwasserstromes auf kaum $100 \mathrm{~m}$. Das Tal ist nämlich in harten Jurakalk eingesenkt, welcher der Verbreiterung einen großen Widerstand entgegensetzen mußte. Ganz anders nun in der Gegend von Rheinau. Die Kiesauffüllung legt sich hier in die weichen Mergel und Sandsteine der unteren Süßwassermolasse ein, kein Wunder, wenn das Tal, resp. der Grundwasserstrom bis zu einer Breite von $800 \mathrm{~m}$ anzuschwellen vermag.» 


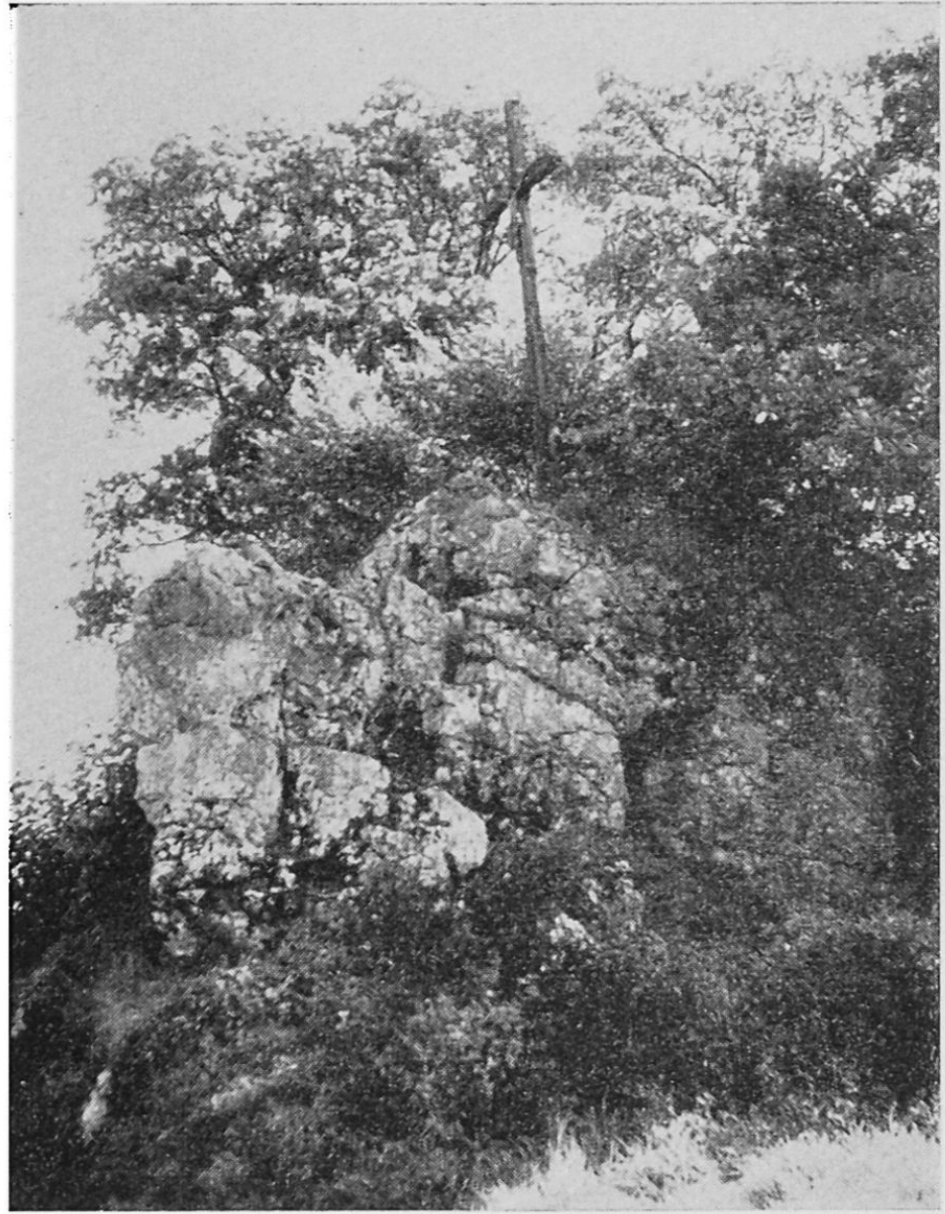

Abb. 15 Kreuz-Klotz an der Hauptstraße östlich Lienheim
Dem Untergrund muß daher die volle Aufmerksamkeit geschenkt werden. Der Talcharakter ändert, wenn ein Flußbett von Molasse auf Kalk wechselt: Weite Täler mit sanften Hängen im Molassegebiet, tiefe, enge Schluchten im Kalk. Diese Feststellung kann nicht nur anhand von Grundwasserströmen gemacht werden. Auch beim heutigen Rheinlauf finden sich solche Beispiele. Im Abschnitt Hohenthengen - Lienheim oder zwischen dem Hof Ettikon und dem Koblenzer Laufen hat sich der Rhein klusartig durch die Kalkfelsen gezwängt. Einzelne Malm-«Horste» ragen rings von Schottern umgeben über die Terrassenfläche hinaus [Schatzbühl bei Herdern, Kirchhügel Hohenthengen, Griesgraben-Kalk Weiach, Kreuz-Klotz östlich Lienheim usw. (Abb. 15)] und zeugen von der wild zerschluchteten Kalkunterlage.

Bedeutend sanfter und ruhiger, wenn auch nicht ganz ausgeglichen, sind die Eintiefungen innerhalb der Molasse; denken wir z. B. an die im Abschnitt der unteren Gräben besprochene, durch Sondierungen abgetastete aquitane Auflagerungsfläche der Weiacher Hauptniederterrassenschotter!

Nach Angaben der Geologen Schalch (113), Weber $(87,89)$ und von Braun (5) habe ich folgendes Profil quer durch das obere Rafzerfeld vom Schaffhuserhau gegen den Rinsberg gezeichnet (Fig. 18):

Aus der Konstruktion ergibt sich, daß die Auflagerungsfläche der Schotter aus zwei petrographisch ganz verschiedenen Teilen besteht: Einerseits aus Malmkalk, anderseits aus unterer Süßwassermolasse. Obwohl die Schotterakkumulation das praewürmische Relief bis über eine Höhenlage von $400 \mathrm{~m}$ zugedeckt hat, ist es doch - deduktiv geschlossen - höchst wahrscheinlich, daß sich unter der weiten Ebene eine in Malmbereich stark bewegte, mit tiefen Schluchten durchzogene Schotterauflagerungsfläche versteckt, entsprechend den direkt beobachtbaren Verhältnissen in der Umgebung von Hohenthengen. Es liegt im Aufgabenbereich des Geophysikers, den Verlauf der von mir nur schematisch eingezeichneten Kalkschluchten sowie den gesamten praewürmischen Rheinlauf bis zur Klus von Weißwasserstelz-Schwarzwasserstelz exakt festzulegen.

Wie alt ist diese Talanlage? Große Rinnenbildungen werden im allgemeinen dem Riß I/Riß II-Interglazial zugeordnet und die Rinnenfüllung als Mittelterrassenschotter bezeichnet (HUBER, 34, p. 12, 68, vertritt - ohne den Beweis dafür vorzulegen - diese Ansicht: Der bedeutendste 'Teil der Rafzerfeld-Schotter sei Riß II abgelagert worden; darauf habe während der Würmeiszeit eine lediglich geringmächtige Schotterüberstreuung stattgefunden.). Wenn dem so wäre, müßten wir einen Unter- 


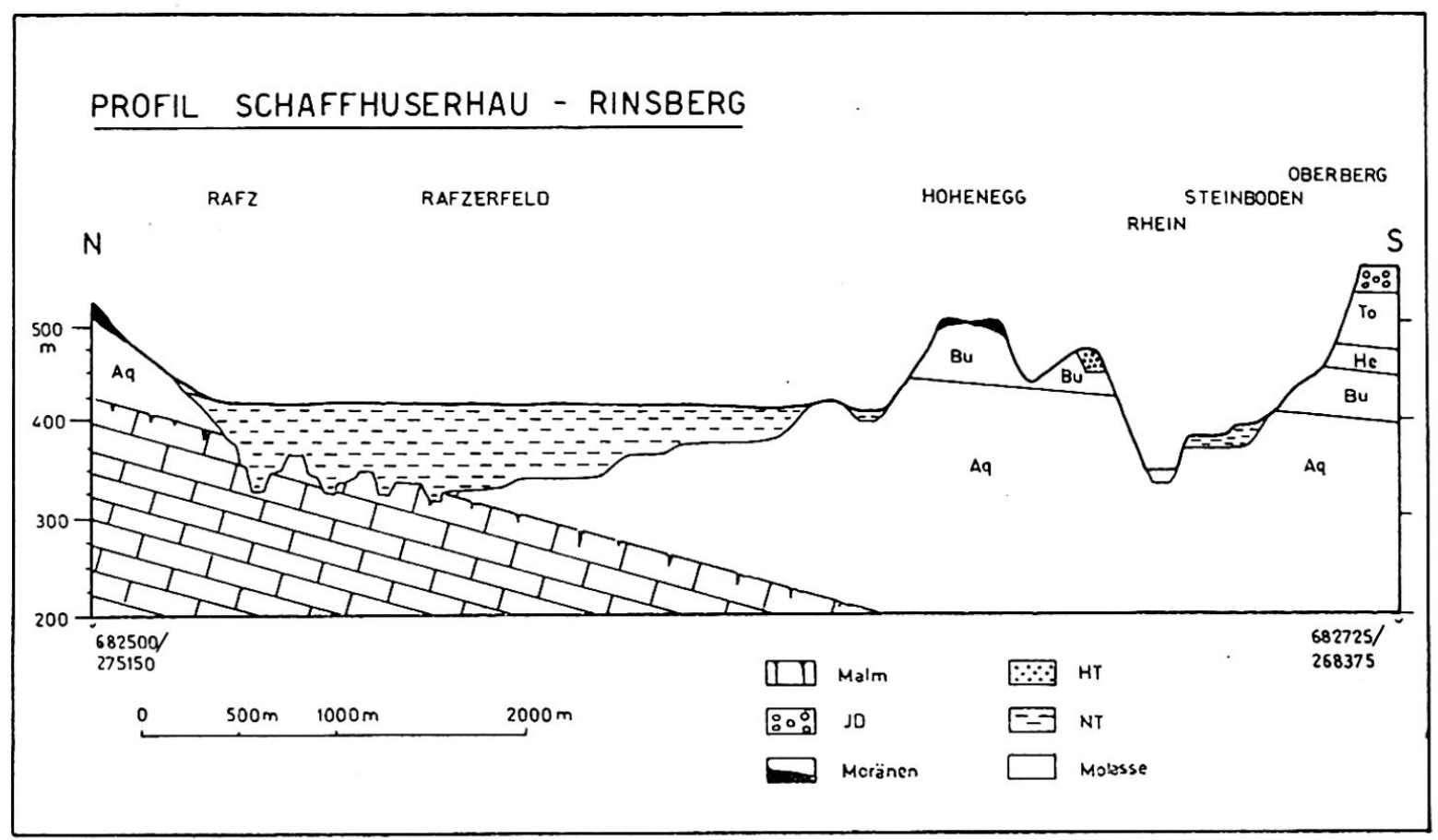

Fig. 18

schied zwischen Riß II-Ablagerungen und den Würmschottern wahrnehmen können. Die Talfüllung freilich läßt sich nicht ohne weiteres gliedern: Nirgends habe ich beispielsweise einen trennenden Verwitterungshorizont festgestellt; da auch keine anderen Unterscheidungsmerkmale sichtbar sind, geht meine Ansicht eher dahin, die Rafzerfeld-Schotter seien durchwegs der Würmeiszeit zuzuordnen. Die Frage kann allerdings nicht mit Bestimmtheit beantwortet werden; Klarheit wird erst durch eine exakte sedimentpetrographische Analyse geschaffen werden können. Für meine nachstehenden Untersuchungen ist das Problem der erwähnten Schottergliederung nicht von Belang und wird daher auch nicht eingehender untersucht.

Im Zusammenhang mit der Verfolgung der praewürmischen Rheinrinne steht das Problem der Datierung der Durchtalung zwischen Rüdlingen und der Tössegg. Hug (36, p. 60), Heim (31), Penck (vgl. Huber, 34), Weber (89, p. 139), Huber (34, p. 15) und weitere Forscher haben sich mit dieser Knacknuß beschäftigt. Ganz abgeklärt ist dieser Durchbruch immer noch nicht. Im Rahmen meiner Untersuchungen kann ich zu diesem Problem lediglich einen bescheidenen Diskussionsbeitrag liefern: Beim Betrachten des Rheinabschnittes zwischen Tössegg und Eglisau fällt das Fehlen von linksrheinischen Zuflüssen auf; von Norden her münden dagegen vier Bäche ein. Die Gestaltung dieser Gräben zeigt eine Zweigliederung: Im Oberlauf ausgeglichenere, reifere Formen; der Unterlauf hingegen tobelartig scharf ausgeprägt (Abb. 16).

Dieser Unterschied weist auf Verschiedenaltrigkeit hin; die obersten Abschnitte sind bereits praewürmisch angelegt worden, währenddem die unteren Schluchten erst mit der bedeutenden Tieferlegung der Erosionsbasis ausgestaltet worden sind. Zwischen Irchel und Buchberg mag nun praewürmisch ein ähnlicher Bach Richtung Töß geflossen sein und eine Kerbe vorgezeichnet haben (Es muß sich dabei nicht um einen Fluß in der Größenordnung der Thur gehandelt haben, wie HubER vermutet.). Im Würm-Hochglazial verlor der Rhein im Oberlauf bedeutende Wassermengen in seine vielen Seitenarme: das Klettgau, das Wangental, zwischen den Molasse-Erhebungen östlich von Rafz und im Abschnitt nördlich von Rüdlingen. Ein sekundärer Rheinarm kann den bereits vorgezeichneten Bachlauf gegen die Tössegg benutzt haben. Im Gegensatz zum Rhein mußte die Töß zu diesem Zeitpunkt eine viel bedeutendere 


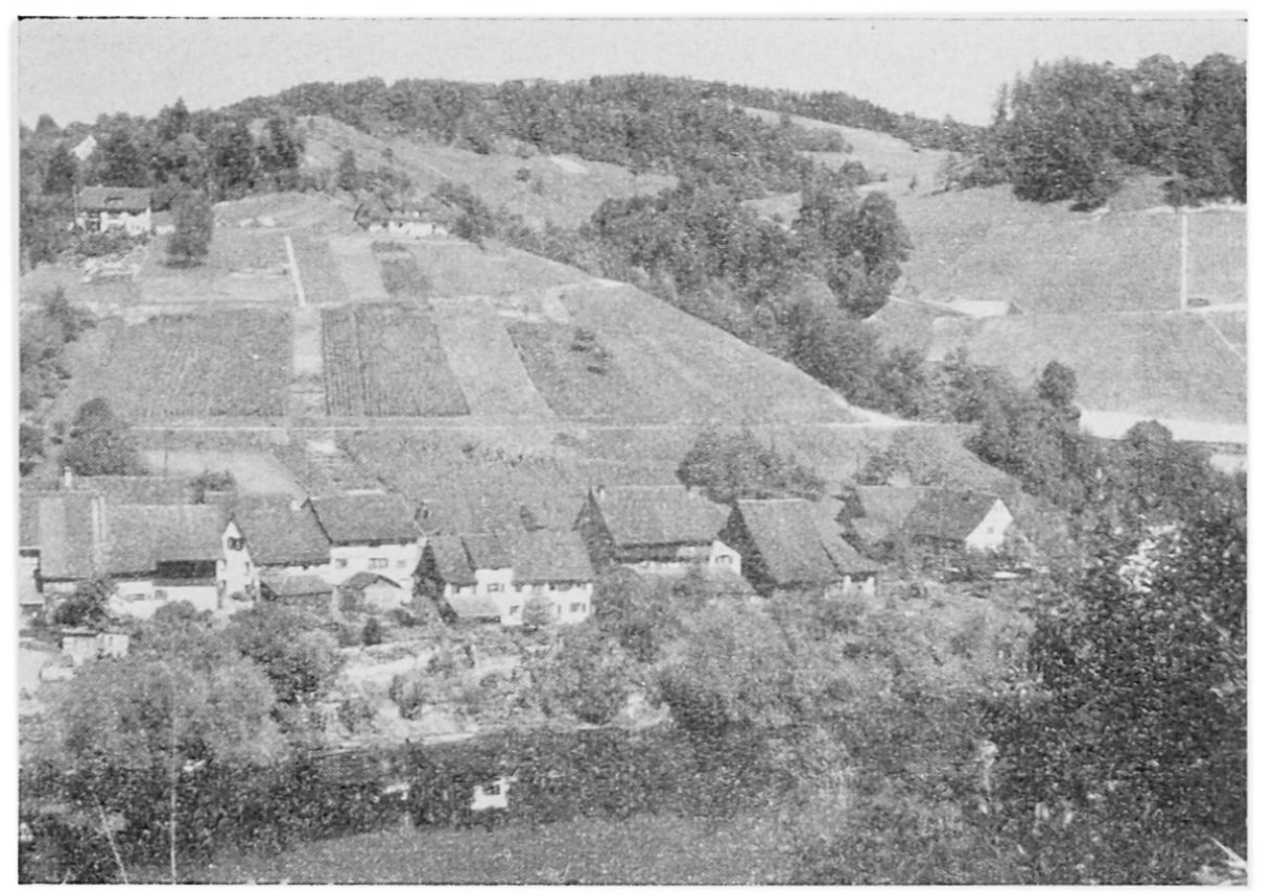

Abb. 16

Blick von Seglingen gegen Burg (Eglisau) und den Graben westlich der Risi

Wasserführung aufgewiesen haben; sie stellte in ihrem Unterlauf eine Sammelrinne dar. Thurtalgletscher (Bichelsee-Turbenthal, Aadorf-Winterthur, WiesendangenWinterthur, Hettlingen-Neftenbach), Rheintalgletscher (Rüdlingen-Tössegg) und Glattalgletscher (Illnau-Winterthur, Oberembrach-Rorbas) führten Wasser nach der Töß. Schotteranalysen vermöchten zu klären, ob die Murkatzelgschotter durch die Töß oder den Rhein aufgeschottert worden seien. Bereits zur Zeit der Anlage der ersten Erosionsfläche mußte der sekundäre Arm des Schmelzwasserrheines zwischen Irchel und Buchberg zum primären umgestaltet worden sein und die Rheincañonbildung begonnen haben. Die Vertiefung hinter den Endmoränen verhinderte beim Gletscherrückschmelzen das Abfließen des Wassers Richtung Westen. Zwischen Endmoränen und Akkumulationsterrassenhang südlich Wil sind nur die früher beschriebenen Periglazialtälchen vorhanden, die sicher nicht als Hauptableiter des Schmelzwassers gedient haben können.

Wenn diese Idee richtig ist, wäre der Rheindurchbruch erst während der Würmeiszeit entstanden; die Rafzerfeld-Rinne könnte demzufolge Riß II/Würm angelegt worden sein.

Ganz anders freilich müßte sich ein Lösungsversuch gestalten, wenn ein bedeu. tend älterer Rheinlauf Ellikon - Tössegg - Wagenbrechi (in der Lücke zwischen Rinsberg und Höhrain) nachgewiesen werden könnte.

\section{Die Akkumulation der Niederterrassenschotter.}

An die letzte Interglazialzeit anschließend trat eine allgemeine Klimaverschlechterung ein. Die sinkende Temperatur im Verband mit den bedeutenden Niederschlagsmengen bewirkte ein Anwachsen der Gletscher. Die Eismassen verließen die Alpentäler und stießen gegen das Mittelland vor. Das frei werdende Wasser mochte anfänglich noch eine korrasiv wirkende Erosion verursacht haben, aber nicht so, daß es zu einer Ausebnung der späteren Schotterauflagerungsfläche gekommen wäre. Das recht kompliziert gestaltete Auflagerungsrelief widerlegt die Ansichten ScHÄrERs (67, p. 58):

«In dieser Beziehung herrscht cinc Meinung. Ob die zahlreichen Querprofile in Penck und BRÜCKNERs A.i. E. betrachtet werden oder die in EBERLs Werk oder die in allen weiteren Spezialuntersuchungen, immer erscheint der gleiche Typ: in kastenförmig profilierten Tälern kastenartig eingelagerte fluvioglaziale Anschüttung.» 
Abb. 17

Kiesgrube westlich des Hörnlis Rüdlingen. Schotter im Liegenden, Grundmoräne im Hangenden

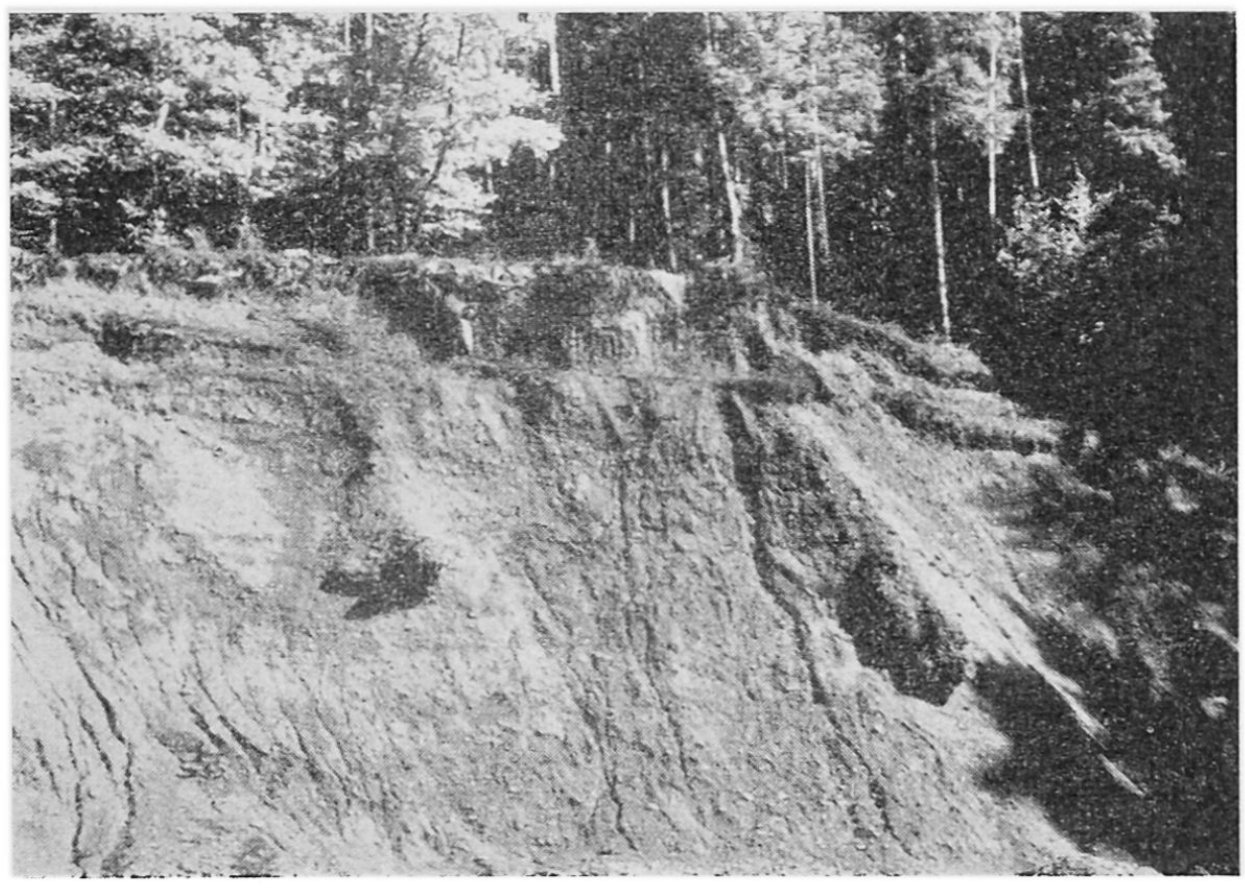

Wie auch Bugmann (13) zeigt, ist Schäfers Ansicht - zumindest in unserem Arbeitsgebiet - nicht richtig.

Das fließende Wasser wurde allmählich durch den vermehrt anfallenden Schutt überlastet, und es kam schon während der Vorstoßphase der Gletscher zur Akkumulation der Niederterrassenschotter. Der Gletscher überfuhr seine eigene Ablagerungen und überzog sie mit einer stellenweise noch heute vorhandenen Grundmoräne. Aufschlüsse solcher Art, mit Schotter im Liegenden und Grundmoräne im Hangenden; konnten im Untersuchungsgebiet beobachtet werden: Kiesgrube westlich des Hörnlis Rüdlingen, 684 100/271 650, Abb. 17, 18 (vgl. auch HUBER, 34, p. 12) und nordwestlich des Chernensees, 679 300/264 025.

Erosions- und Akkumulationsvorgänge waren nicht scharf voneinander geschieden. Wenn sich das Gleichgewicht wieder zugunsten der Wasserführung verschob, vermochten sich im frischangelegten Schotter Rinnen zu bilden, die bei einem vermehrten Schuttanfall wieder aufgefüllt worden sind (Abb. 19).

Hügelzüge führten zur Aufsplitterung des Gletschers in einzelne Arme. Huber hat diese trennenden Bergrücken eingehend untersucht; die Resultate sind in seinen

Abb. 18

Gekritzte und polierte Gerölle aus der Grundmoräne.

Kiesgrube westlich des Hörnlis Rüdlingen

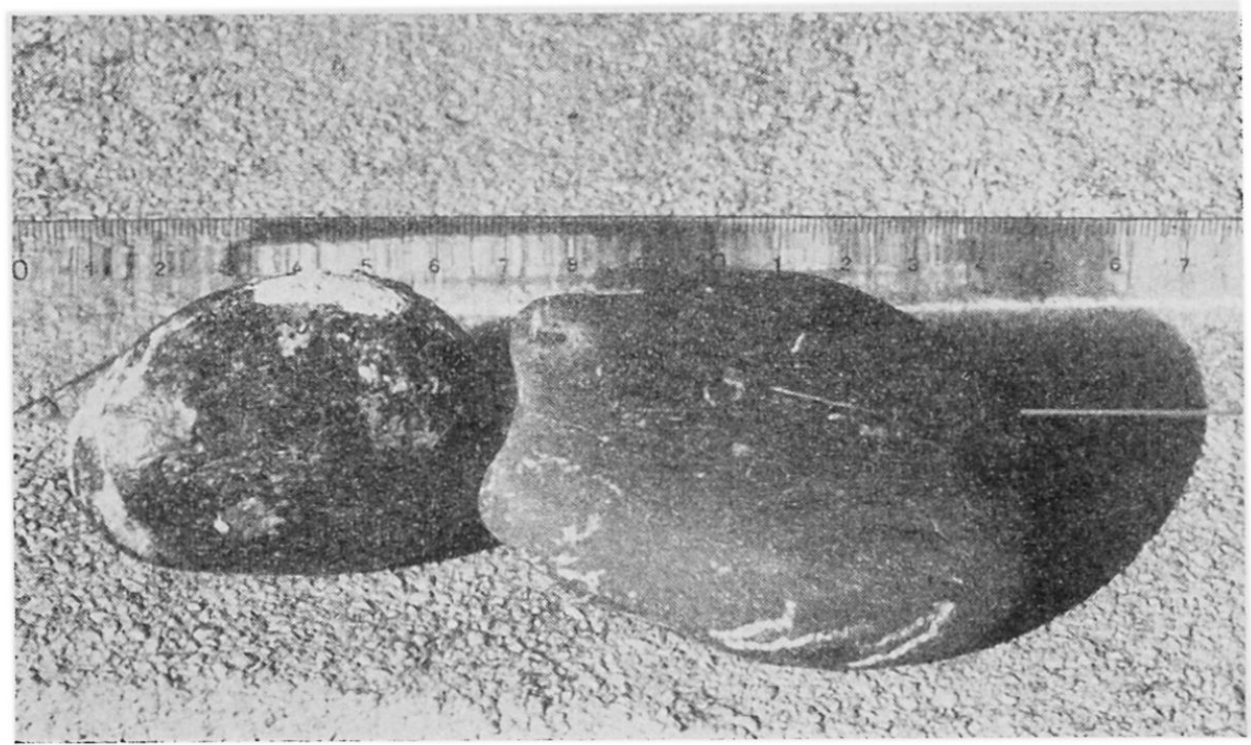




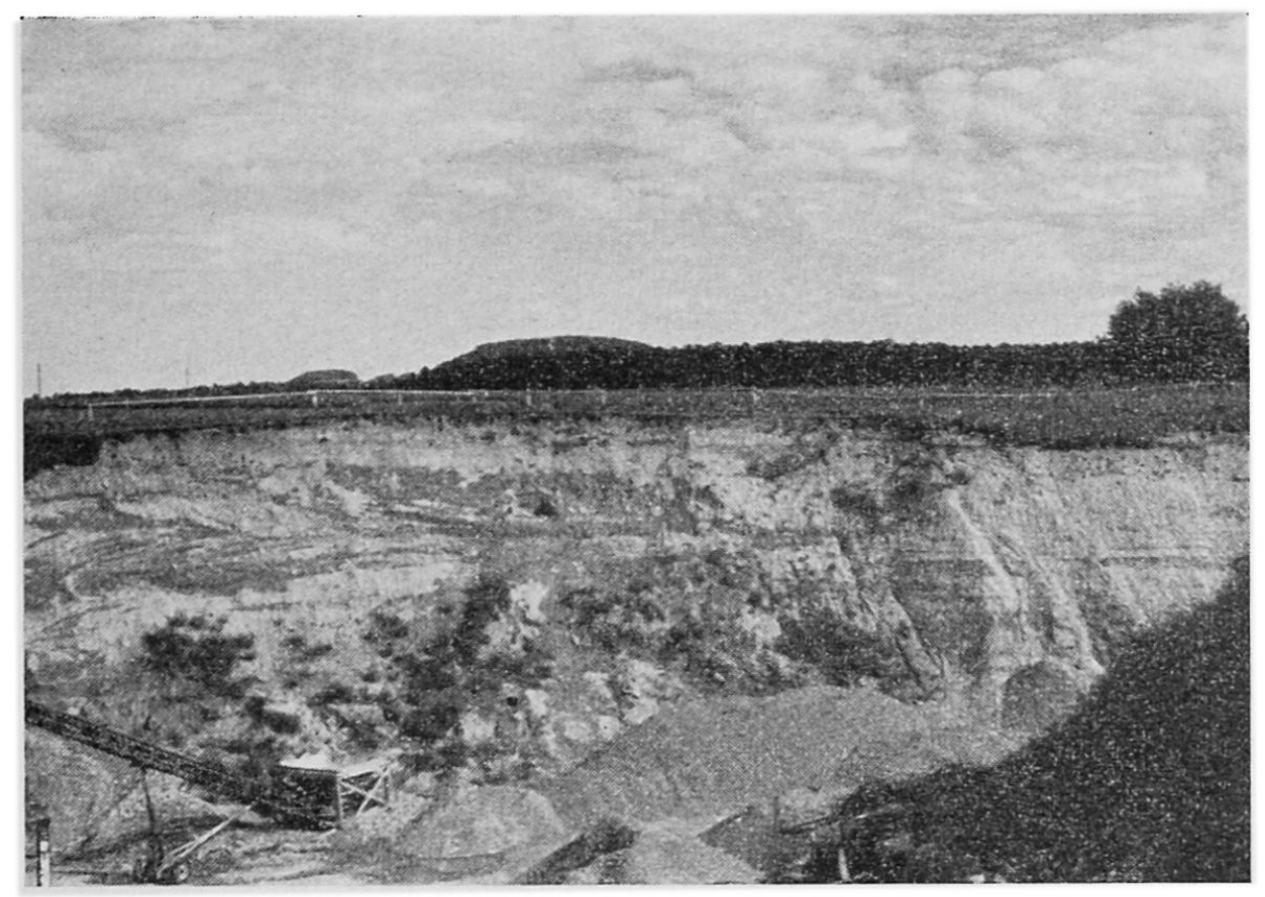

Abb. 19

Mit Sand aufgefüllter Altwasserlauf in der Sandbuckkiesgrube südlich von Wil (Rafzerfeld; $680450 / 272450)$

Eisrandlinien-Darstellungen skizziert (p. 82-88). Im Bereich des östlichen Rafzerfeldes liegt eine Molassehügelzone. Die einzelnen Gletscherzungen drängten sich durch die Mulden zwischen den Hügeln Dietlisberg/Schneckenberg/Adenberg/Sulgerhölzli/Grafenhau, wobei die Eisflanken hoch hinauf gepreßt wurden. Ob die Gletscher die einzelnen Hügel gänzlich zu überfahren vermochten, wie Hug (36, p. 53) vermutet, ist fraglich. Die vorhandenen Grundmoränenüberzüge auf den Kuppen können von einer früheren Eisbedeckung stammen (siehe auch HUBER p. 9). Eine Kiesgrube am Adenberg im Niveau $480 \mathrm{~m}-490 \mathrm{~m}$ bei denRebbergen von Solgen weist einen Verwitterungshorizont von $1 \mathrm{~m}$ Mächtigkeit auf; das Material ist lehmig-sandig, mit eckigen, kleinen Steinen durchsetzt. Nach unten schließt sich ein unregelmäßiger Schotter mit eckigen, großen Trümmern an, die zum Teil mit Gletscherschliffspuren versehen sind. Einzelne Sandschlieren bändern den Aufschluß. Die Steine liegen schlecht geordnet, wirr durcheinander. Die recht mächtige Verwitterungsschicht deutet auf eine ältere Ablagerung als Würm.

Der von Hug (36, p. 53) und Huber (34, p. 9) südlich von Nack liegende $449 \mathrm{~m}$ hohe, als «Molasse-Nunatak» bezeichnete Eisenberg weist sowohl an seinem Süd-, wie auch am Nordabhang einen leichten Schotterüberzug auf. Am Fuße des Hügels ist diese Schotterschicht später weggespült worden, und der Sandstein liegt zutage.

Der südwestlich vom Adenberg gelegene Schellbüel ist vom Gletscher nicht mehr erreicht worden.

Zur Ausbildung von bedeutenden Endmoränenwällen kam es vor allem in Bereichen, wo eine mächtige, kompakte Gletscherzunge ihre Ablagerungen frei deponieren konnte; das schönste Beispiel dafür bietet der Stadler Moränenkranz. War die Gletscherzunge hingegen in viele Arme aufgespalten, mochte sich kein Wall zu entwikkeln (Beispiel: Molassehügel östlich von Rafz; erst im freieren Raume nordwestlich Rüdlingen treten die Moränen hügelförmig auf, allerdings in bescheidenerem Ausmaße als südlich von Stadel.). Bezeichnen diese «Endmoränenhügel» wirklich den Maximalstand der Würmgletscher? Beobachtungen lassen eine andere Ansicht als möglich erscheinen. Bei meinen Untersuchungen in der Umgebung von Windlach stieß ich auf den Lebuck, $677600 / 266050$ und die Breustenen. Der Lebuck (schon von Hug, Karte 112, als Moräne eingezeichnet) liegt an der Ostflanke des Raaterberges. Der einstige Wies- und Rebhügel ragte noch vor 20 Jahren mehr als $10 \mathrm{~m}$ 
Abb. 20

Breusti im Steinacker (östlich des Schützenhauses Windlach). Eskerförmige, steinige Wälle in der Längsrichtung der Talachse

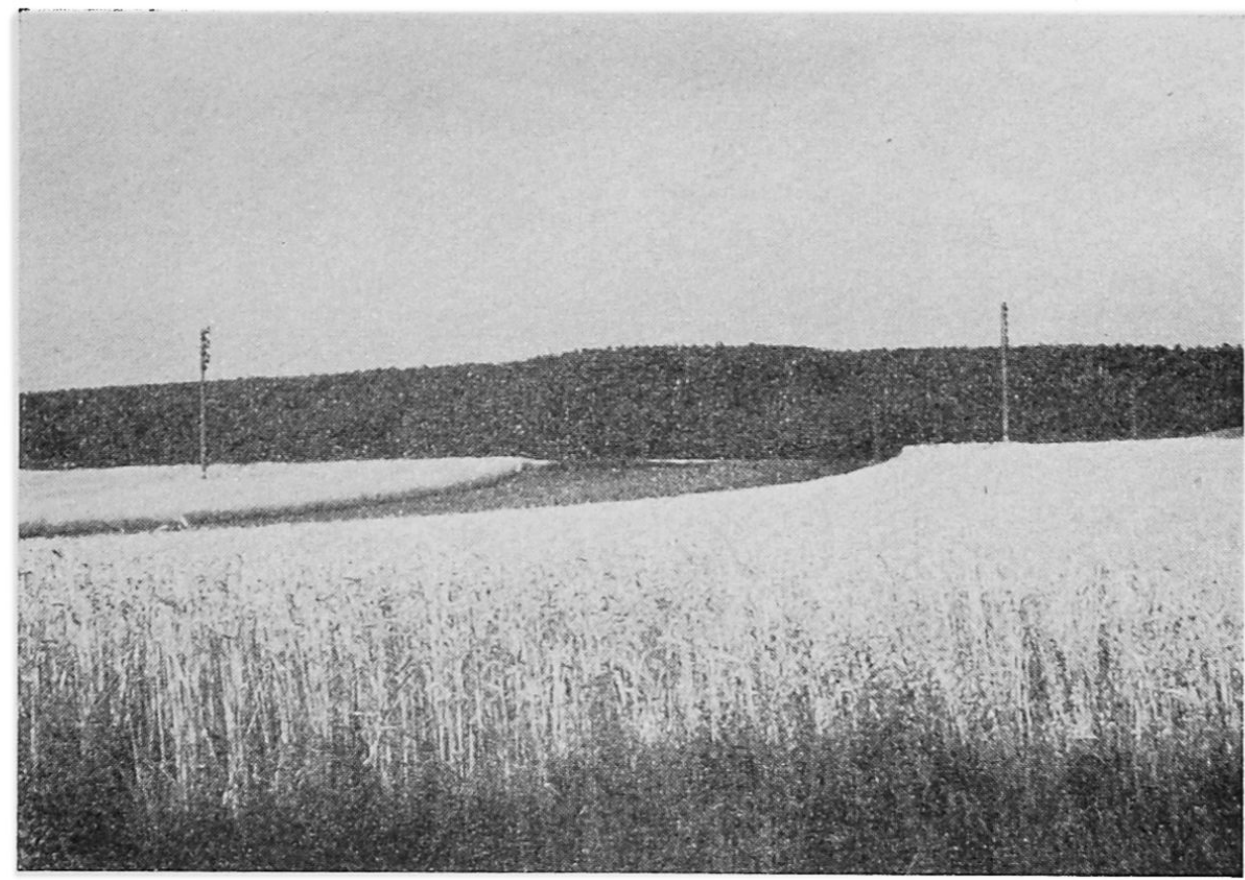

über die umliegenden Äcker hinaus. Gerne jedoch verkauften die Bauern ihr Land an diesem steinigen Buck, der ja der Steilheit wegen zur Beackerung und maschinellen Bearbeitung nicht taugte. Heute ist der Hügel durch die Geröllausbeutung weitgehend abgetragen. Die Erstellung eines Dreschhauses und die Anlage von Zufahrtsstraßen ließen den Hügel weiter erniedrigen. Auffallend in dieser Grube waren die groben, unverkitteten Gerölle, die sich deutlich von den feineren Schottern der Umgebung unterschieden. Dieser einzelne Moränenaufschluß westlich von Windlach kann noch mit dem Stadler Wall in Zusammenhang gestanden haben. Es ist denkbar, daß sich am Ostabhang des Stadlerberges ein einzelner Gletscherarm nach Norden vorgeschoben hat und längs des Raaterberges gegen den Schleumet vorgestoßen ist; der Lebuck würde in diesem Falle nichts anderes als das Produkt eines lokalen Flankenvorstoßes aus dem Gebiet der Stadler Endmoränen heraus darstellen. Infolgedessen könnte der Lebuck sehr wohl gleichzeitig mit dem Stadler Moränenwall zur Ablagerung gelangt sein, und es ist nicht notwendig - wie HUBER (p. 70) es tut - die Stadler Moränen als jünger zu erklären:

«Denn über das Rütifeld ( $410 \mathrm{~m}$ bis $399 \mathrm{~m}$ ) unterhalb Windlach, das ebenfalls Mittelterrasse ist, lief Gletscherwasser, das von den Windlacher äußersten Moränen mit dem Leebuck $(420 \mathrm{~m})$ und den großen Stadler Moränen des Stadiums 2 herkam und hiebei auf der Mittelterrasse eine Niederterrassenschotterebene anlegte.»

Er schreibt von Windlacher Moränen (Plural), gibt aber bloß eine Form bekannt. Wie ich in meiner Arbeit für das Sekundarlehrerdiplom 1953 (LeEmanN, 49) und auch im Abschnitt über «Periglaziale Tälchen, die auf das Niveau des Rütifeldes ausmünden», erwähnt habe, finden sich nördlich des Stadler Moränenwalles Breustenen, die in der Richtung der Längsachse des Tales verlaufen. Sind diese steinigen Dämme als Esker, ebenfalls bedingt durch weit über Windlach hinaus vorstoßende Eislappen, zu deuten? (Abb. 20).

Diese Frage kann durch meine lokalen Untersuchungen nicht endgültig beantwortet werden; sie bedarf einer eingehenden Bearbeitung im Zusammenhang mit den anderen schweizerischen Endmoränenständen. Es sei darauf hingewiesen, daß RINGGER bei seinen noch nicht veröffentlichten Untersuchungen im Limmattal dem bisher vermeintlichen Endwall vorgelagerte Moränen gefunden hat.

Aus den Endmoränenwällen heraus erfolgten an einigen Orten Wasserdurchbrüche, die über den bereits in der Vorstoßphase angelegten Schotter Übergangskegel zu legen vermochten, schön zu beobachten im Grafenhau nördlich von Stadel. Süd- 


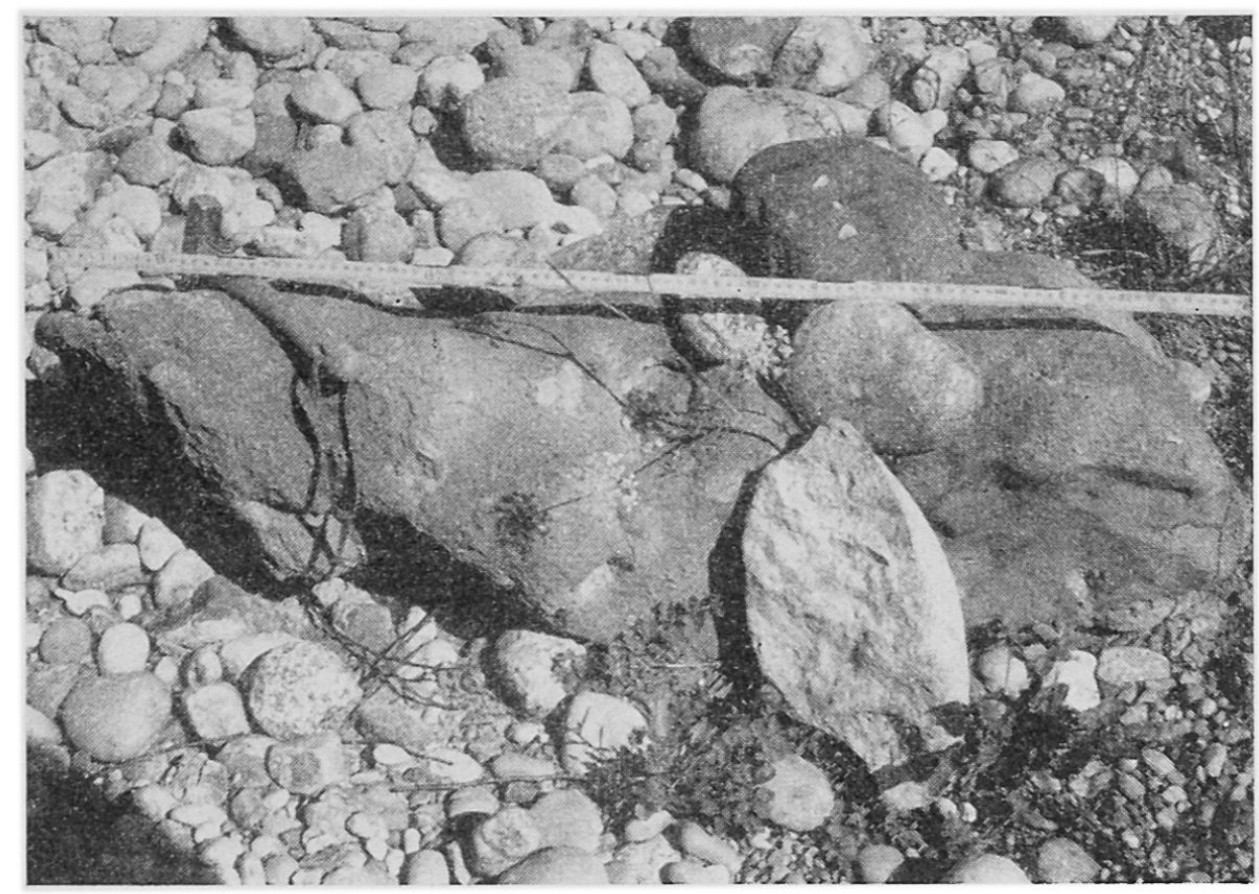

Abb. 21

Kiesgrube $683950 / 273225$.

Weiche Molasse-

Sandsteinblöcke und Schotter

westlich von Solgen, in der Kiesgrube 683 950/273 225 bei P. 432 finden sich nebst den üblichen Geröllen noch mächtige Molasse-Sandsteinblöcke in der Größenordnung $100 \times 50 \times 50 \mathrm{~cm}$ (Abb. 21), die einen längeren Wassertransport nicht ausgehalten hätten. Es muß angenommen werden, daß diese Blöcke zusammen mit Eis ausgeschwemmt worden und wenig weit unterhalb der Gletscherstirn zur Ablagerung gelangt sind.

Beim Rückzug der Gletscher in ein tieferes Niveau bildeten sich Toteisseen. Diese heute noch vorhandenen Becken sehen wir oft als Sumpftümpel; bis vor wenigen Jahren waren es noch richtige Seen, wie z. B. der Stadler- und der Chernensee. Die Wasser eines Sölles haben den Stadler Moränenwall zwischen Eselbuck und Süeßbuck durchbrochen; zuerst fließen sie parallel zum Moränenkranz nach Westen, winkeln dann im «Grund» Richtung Twärweg ab und legen eine bedeutende Vertiefung im Schotter an, die sich erst nördlich der Grundwasser-Pumpstation bei Windlach verliert.

\section{Die Terrassenentstehung}

\section{a) Versuch éiner Phasenunterteilung der Terrassenentwicklung im Rafzerfeld}

Wenn wir eine Karte des Rafzerfeldes aufschlagen und die Ablagerungen des Würmgletschers genauer untersuchen, können wir vier Phasen unterscheiden:

Phase 1: Anlage der Akkumulationsfläche.

Phase 2: Einsetzende Erosion mit weitem Pendeln des Flusses.

Phase 3: Der weitausschwingende Flußlauf legt sich allmählich gerade und schneidet sich cañonartig ein. Ausgeprägte Tiefenerosion herrscht vor.

Phase 4: Die Tiefenerosion läßt nach; eine gewisse Erstarrung tritt ein.

Zeitlich lassen sich die Phasen folgendermaßen in die klimatisch bedingte Würmgliederung Bübels einordnen:

Phase 1: Abgeschlossen im Hochglazial.

Phase 2: Einsetzend im ausgehenden Hochglazial; bis in den Beginn des Spätglazials hinein dauernd.

Phase 3: Spätglazial.

Phase 4: Eigentliches Postglazial. 


\section{SCHEMA DER EINTIEFUNGSVORGÄNGE}

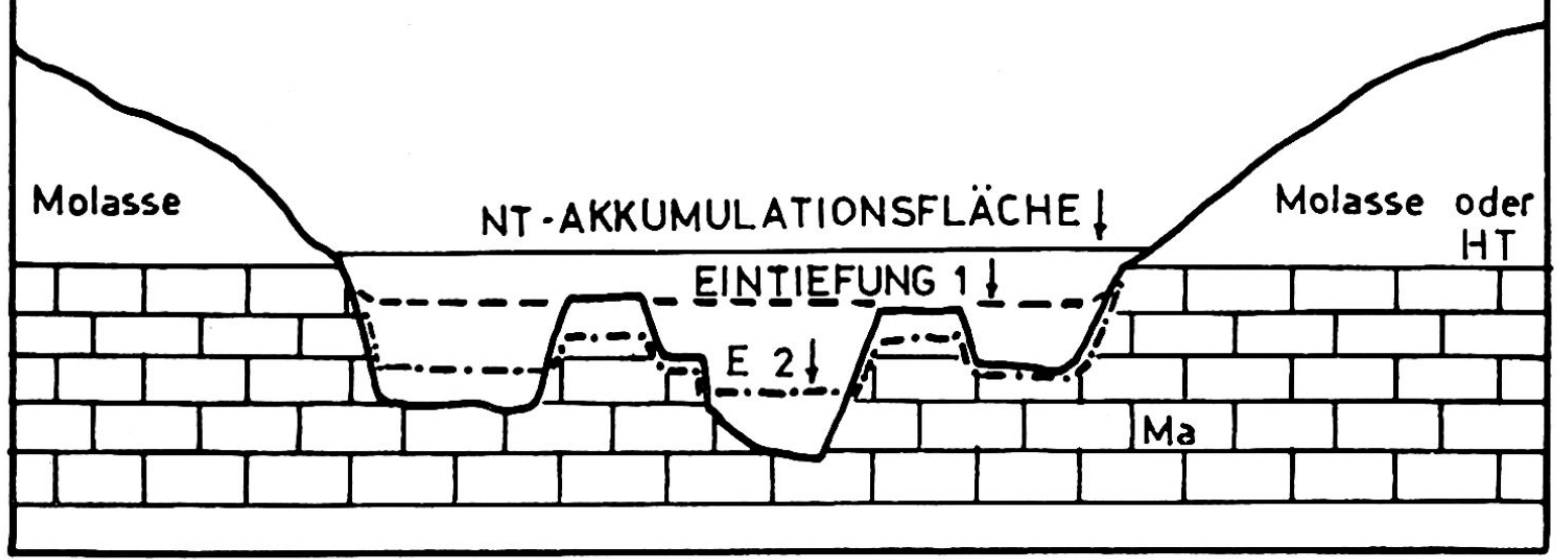

Fig. 19

Wir untersuchen nun die Phasenunterscheidung eingehender:

Phase 1: Die Aufschotterung ist (ausgenommen im Rheinabschnitt Rüdlingen-Tössegg) leicht verständlich. Der bedeutenden Schuttanlieferung durch den Gletscher waren die Flüsse auf die Dauer nicht mehr gewachsen. Die Überlastung der Flüsse führte zur Akkumulation der fluvioglazialen Schotter. Das stark geprägte Malmrelief und die Molasse-Eintiefungen sind zugedeckt worden.

Übergang von Phase $1 \mathrm{zu}$ Phase 2: Das Rückschmelzen des Eises leitete diesen Übergang ein. Dabei legten sich hinter den Endmoränenwällen Retentionsbekken frei, die als Schuttfänger wirkten. Die Wasserführung war immer noch bedeutend; abgenommen hingegen hatte die Schuttführung. Der Phasenübergang wurde von oben, d. h. von der zurückweichenden Gletscherstirn aus, dirigiert und mußte sich daher das ganze Rheintal hinunter bemerkbar machen. In anderen Tälern herrschten ähnliche Verhältnisse, da überall Retentionsbecken gebildet worden waren.

Ursache oben, Auswirkung unten.

Übergang von Phase $2 \mathrm{zu}$ Phase 3: Während der Tieferlegung in der Phase 2 kann der Fluß zufällig von seinem Schotterbett auf einen Malmklotz gelangen. Die Kalkschwelle wirkt als lokale Erosionsbasis; sie retardiert die Erosion und dirigiert das Flußgeschehen oberhalb dieser Stelle: Der Fluß pendelt weit hin und her. Wird das Bett hingegen wieder in den daneben liegenden Schotter verlagert, kommt es zu einem rascheren Einschneiden verbunden mit einem schnelleren Abfließen des Wassers; der Flußlauf wird gerader.

Im Gegensatz zum Phasenübergang $1 / 2$ ist bei $2 / 3$ die Ursache unten, die Auswirkung oben zu suchen. Der Durchbruch bei Kaiserstuhl ist petrographisch stark differenziert. Dirigiert er den Wechsel von Seiten- und Tiefenerosion (Fig. 19)? 
Eine lokale Erscheinung würde demzufolge einer lokalen Auswirkung rufen und somit eine durchgehende Terrassenkorrelation Bodensee - Oberrheinische Tiefebene in Frage stellen. Ist diese Idee richtig, finden wir in der Zeitspanne des Phasenüberganges 2/3 deutlich Unterschiede in der Terrassenentwicklung zwischen folgenden Abschnitten:

\section{Rheinfall $\longrightarrow$ Bodensee \\ II Kaiserstuhl $\rightarrow$ Rheinfall \\ III Koblenzer Laufen $\rightarrow$ Lienheim}

Um diese Frage abzuklären, ist es unumgänglich, eingehende Terrassenuntersuchungen innerhalb dieser Abschnitte vorzunehmen. Sofern ein Riegel besteht, hängt die Ausprägung der Tiefenerosion oberhalb dieser Stelle stark von den petrographischen Verhältnissen der Schwelle ab:

Ist der Riegel petrographisch differenziert, wird sich der Fluß diskontinuierlich tiefer legen und oberhalb der Schwelle auch diskontinuierlich erodieren.

Ist der Riegel hingegen petrographisch einheitlich gestaltet, tieft sich der Fluß gleichmäßig ein und bewirkt eine kontinuierliche Erosion oberhalb der Schwelle.

Schematische Darstellung zur Eigenständigkeit der Terrassenentwicklung im Spätglazial (Tab. 5):

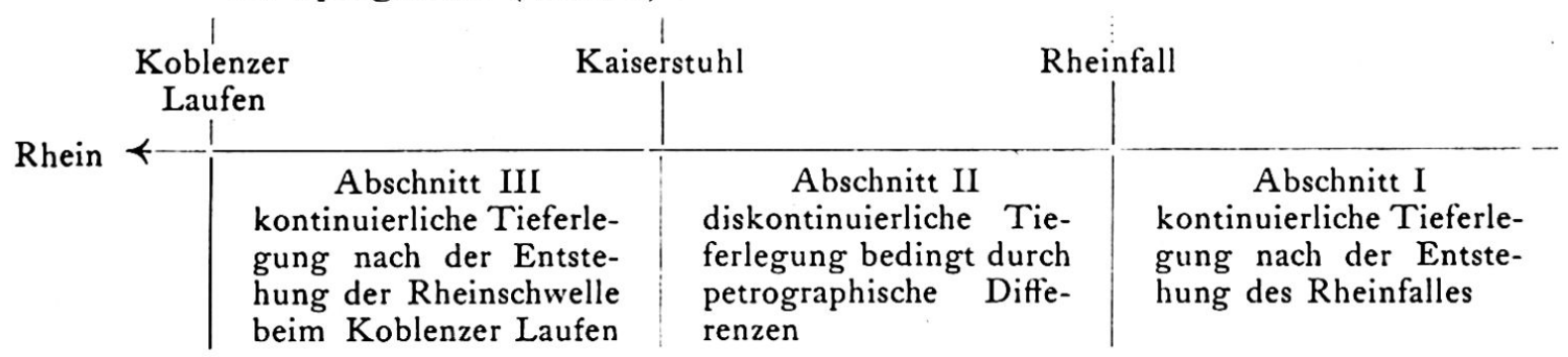

Phase 3: Diese Phase, gekennzeichnet durch den gestreckten Verlauf mit ausgeprägter Tiefenerosion, kann datiert werden. Das Blatt Eglisau der Landeskarte gibt die nötigen Auskünfte. Östlich von Herdern finden sich zwei deutlich ausgeprägte Terrassen: Die höhere Fläche auf ca. $355 \mathrm{~m}$, die tiefere, westlich des Grubenholzes, auf 350 m gelegen. Auf der ganzen Strecke Tössegg-Kaiserstuhl lassen sich innerhalb des eingetieften Rheinabschnittes keine Ausbuchtungen dieses Ausmaßes nach Norden verfolgen. Die Anlage der Herdener Terrassen ist das Resultat der Rheinabdrängung durch die Glatt. Dazumal muß die Glatt bedeutend mehr Wasser geführt haben als das heutige Flüßlein. Das ist nur zur Zeit des Gletscherstandes nördlich der Schwelle von Hombrechtikon, also vor dem PENCKschen Bühl-Stadium, möglich gewesen.

\section{b) Die Würmterrassen in den verschiedenen Abschnitten des Rheintales}

b1) Abschnitt Tössegg-Kaiserstuhl

Das Kerngebiet meiner Untersuchungen wird durch das Rafzerfeld sowie die linksrheinischen extramoränischen Gebiete zwischen Tössegg und Kaiserstuhl gebildet. Meine Darstellungen der Terrassenflächen gehen deshalb auch von diesem Abschnitt aus, umso eher als auf diese Art und Weise der Anschluß an das Akkumulationsniveau der Würmvergletscherung gewährleistet wird. Unabhängig von inneren Moränenlagen werden die tieferen Terrassenflächen erfaßt und deren Eingliederung mit der Korrelation anderer Autoren verglichen. Die Höhenangaben sind für die Gemeinde Weiach den Meßtischblättern entnommen; in den anderen Fällen habe ich mich bemüht, die Zahlen so genau als möglich aus den vorhandenen Karten (Siegfriedblätter und Landeskarte) zu ermitteln. 
Akkumulationsniveau: oberes Rafzerfeld bis südlich von Wil (405 m)

ev. Federen-Feldhof-Stelzen bei Teufen-Unterer Murkethof (410-420)

Chrüzstraß nordwärts bis Lindirain (412)

Chrüzstraß westwärts gegen Tüfächer-Schnäggen, ev. Ebni

(394)

Rütifeld nördlich von Windlach (bis 398)

1. Erosionsniveau: Unterer Murkethof (400-404)

Buechhalden-Gländ (südlich Seglingen; 396-399)

Randteile der abgleitenden Rafzerfeld-Terrassenfläche (nicht vertreten südlich des Hügels Edelmann bei Wasterkingen)

Mittlerboden (südlich Rütifeld; 388)

ev. Kalkklotz Schatzbühl Herdern $(384,5)$

Hasli Weiach (380)

Langächer (westlich Burenmüli; 375)

2. Erosionsniveau: Roggenfar Seglingen (390)

Teile der abgleitenden Rafzerfeld-Terrassenfläche

nördlich Mittlerboden

unterhalb Schulhaus Zweidlen (376)

3. Erosionsniveau: westlich Tiefert (südlich Tössegg; 390)

Tößriedern (oberhalb Dorf; 386)

Ober-Seglingen

nördlich Bahnhof Eglisau (381-384)

Teile des Rafzerfeldes (nördlich Laufenloh):

Lengg-Schuppenbaum (377)-Hasenweg-Saurütte (375)-Ried (373)

abgleitende Weiacher Hauptterrassenfläche

4. Erosionsniveau: westlich Stelzen Teufen (385)

Tößriedern (kleine Vertiefung östlich Ober-Seglingen; 380)

Murifeld (375-378)

abgleitende Weiacher Hauptterrassenfläche

(rheinhaldenächste Teile in den Rüteren)

5. Erosionsniveau: südlich Steinert Eglisau (wenig über 370)

nördlich Laufeloh (370)

unterste Teile der abgleitenden Weiacher Hauptterrassen-

fläche beim Griesgraben (um 360-365)

Blöliboden Kaiserstuhl (360)

Engelhof - Guggenmühle (um 360)

6. Erosionsniveau: Tiefert (südlich Tössegg)

Tössegg (oberhalb Wirtschaft; 368)

westlich Riedt Tößriedern (365)

Steinert westlich Bahnhof Eglisau (360; diese Terrassenfläche gleitet östlich des Neuhus in Fläche $7 \mathrm{ab}$ )

Murhalde (360)

Rheinsfelden (356-358)

Werk Rheinsfelden (356)

Herdern (355)

Auen Hohenthengen (352-353)

westlich Griesgraben Weiach (um 351-352)

unterhalb Engelhof (349) 
7. Erosionsniveau: Neuhus (östlich Rheinsfelden; 354, abgleitend von 6)

Laufeloh (352)

Grubenholz Herdern (350)

8. Erosionsniveau: Tiefert (wenig unter 360 )

Wirtschaft Tössegg (ca. 356)

Riet Tößriedern (um 355)

Murhalde Eglisau (wenig über 350)

Neuhus (350)

Beim Neuhus gleitet die Terrassenfläche 7 in die Fläche 8 ab. Nach unten lassen sich die beiden Terrassenflächen nicht mehr klar voneinander trennen; immerhin gehört die Herdener Terrassenfläche wohl eher zu 7 als zu 8.

Rheinabwärts läßt sich 7/8 weiter verfolgen über:

Rheinsfelden (westlich Kraftwerk)

Griesgraben (345-347)

Bleichi (Fisibachmündung; 343-345)

Schloßwisen (um 343)

südlich Schwarzwasserstelz (wenig über 340)

Au (Lienheim; um 339)

Noch tiefer als die oben erwähnten neun Niveaus liegen:

- kleine Verebnung südlich von Herdern wenig über 340 , die in der Höhenlage derjenigen südlich der Auen (Hohenthengen) entsprechen mag

- Bacheinmündung Herdern (332-335)

- Hohenthengen (334)

- Griesgrabenmündung (334)

Die Terrassenflächen 1-5 bilden in ihrer Gesamtheit das Rafzerfeld und die Weiacher Ebene; 4 und 5 nehmen dabei eine nur sehr geringe Fläche in der Nähe der Rheinhalde (Rüteren, südlich des Griesgrabens) in Anspruch. Da das Rafzerfeld und die Weiacher Ebene abgleitend sind, können vielerorts die Terrassen 1-5 als Formen gar nicht ausgeschieden werden; die abgleitende Fläche muß aber in der Zeit der Terrassenanlagen 1-5 entstanden sein.

Vergleich mit der Terrassenkorrelation Hubers und Webers:

Meine Gliederung der 'Terrassenfläche ist als rein regionale Darstellung zu betrachten, die nicht an ein von oben her verfolgtes Terrassensystem gebunden ist. Im Gegensatz dazu stehen die Betrachtungen Hubers, der die Korrelierung auf die einzelnen Rückzugsstadien der Gletscher ausrichtet; im extremen Falle werden Terrassen vom Bodensee her bis über Koblenz hinaus verfolgt. Webers und GöHRINGERs Gliederungen sind im Zusammenhang mit den 5 Rückzugsstadien Pencks zu verstehen. Da ich eine Terrasse als Formbegriff auffasse (nach den von BoEsch, 3, und BugmanN, 13, entwickelten Gedankengängen), habe ich keine sogenannten Teilfelder (ZINK, 98) oder Haupt- und Nebensysteme (HUBER, 34) ausgeschieden.

Huber unterscheidet im Abschnitt Tössegg - Kaiserstuhl VII Hauptsysteme, zum Teil miteinander verschmolzen; mit der Unterteilung kommt er auf 10 verfolgbare Terrassen. Weber $(87$, p. 70$)$ weist im unteren Tößtal auf 6 verfolgbare Würmsysteme hin: 1 eigentliche Niederterrasse und 5 Rückzugsterrassen. Er bringt diese in Zusammenhang mit der gleichen Gliederung im Rheintal durch Sснацсн (113), Penck (61) und Göhringer (109). Beim nachfolgenden Vergleich gehe ich von meiner Terrassenfolge aus.

Akkumulationsterrasseflächen: Huber I, Weber qn

Übereinstimmung mit HUBERs Formen im oberen Rafzer- 


\section{Erosionsniveau:}

2. Erosionsniveau:

3. Erosionsniveau:

\section{Erosionsniveau:}

5. Erosionsniveau:

6. Erosionsniveau:

7. Erosionsniveau:

8. Erosionsniveau :

feld, Chrüzstraß, Rütifeld, $Z$ weidlen. Nicht nachgewiesen ist der von HUber angenommene MT-Schotter des Rafzerfeldes, bei der Chrüzstraß und im Rütifeld.

Das Akkumulationsniveau bei Wasterkingen-Stetten läßt sich nicht sicher feststellen.

Die von HUBER «wahrscheinlich zum Akkumulationsniveau gehörende». Weiacher Hasliterrassenfläche liegt tiefer und wird von mir zum 1. Erosionsniveau gerechnet.

Teile von Webers 1 und Göhringers 1

Meine untere Murkethof-Terrassenfläche wird von Huber zu IIb gerechnet, die obere zu IIa.
Übereinstimmung in der Beurteilung der Gländ-Terrassen- fläche (Huber IIa).

$\mathrm{Da}$ ich das Rafzerfeld im großen als abgleitend auffasse, enthält sie auch Teile von HUbers II.

Teile von Webers 1 und Göhringers 1

Das Roggenfar-Niveau rechnet HUber zu IIb.

WeBer scheidet diese Terrasse nicht aus.

Übereinstimmung als Teilstück des abgleitenden Rafzerfeldes. HUBERs Bemerkung über Wasterkingen stimmt: Der Rhein hat an der Halde die höher gelegenen Schotter weggeschwemmt.

Überreste von II und IIIab können am Rutschhang zwischen Hohenthengen und Teufelsbrücke nicht ausgeschieden werden. Stimmt im großen ganzen mit Hubers IIIa überein.

WeBER: 2 (bei Murkatzelg und Ober-Seglingen)

Die Weberschen Terrassenflächen 2 sind nicht einheitlich, sondern weisen tiefere Stellen auf, z. B. Tößriedern und westlich Stelzen (Teufen), die in mein 4. Erosionsniveau gewiesen werden.

Teile von Göhringers 1 (mit Ausnahme Ried Hohenthen. gen, das GöHRINGER in sein 2 stellt)

Teile von Webers 2

Stimmt im wesentlichen mit Hubers IIIb überein. Nicht erkennbar zwischen Hohenthengen und Teufelsbrücke.

Teile von Webers 2 und GöHringers 2

Huber IV

Weber 3; Göhringer 3

HUBER V

Weber 4 (Die Ebene Riet westlich Tößriedern ist ebenfalls in dieses $4 \mathrm{zu}$ stellen, und nicht, wie WeBER schreibt, zu 5; Webers 5 südlich Stelzen auf ca. $350 \mathrm{~m}$, Riet Tößriedern ca. $355 \mathrm{~m}$ ! (Höhenangaben aus der geologischen Karte des Unteren Tößtales und Unteren Glattales von WEBER) GöHRINGER 4

HUBER VI

HUBER VII

Dieses Niveau mag, wie Huber schreibt, zum Teil aus seinem VI und VII hervorgegangen sein.

Göhringer 5 (mit tieferen Formen zusammen)

Abgesehen von den höchsten Niveaus stimmen also die Korrelationen Hubers zwischen Tössegg und Kaiserstuhl recht gut mit den meinigen überein. 


\section{b2) Abschnitt Teufelsbrücke-Koblenzer Laufen}

Um eine unvoreingenommene Parallelisierung zu gewährleisten, müssen die in diesem Abschnitt vorkommenden Terrassenflächen unabhängig von der vorhergehenden Darstellung verfolgt werden. Die einzelnen Niveaus sind - um Verwechslungen zu vermeiden - mit Großbuchstaben bezeichnet. Ein Anschluß an die erste Folge der Terrassenflächen soll am Schluß geprüft werden.

Höhere Terrassenflächen, nicht in NT einzureihen: Buck, Hard, Langforen, Längg bei Koblenz (352-360)

Niveau A: Heutal (SE Dangstetten; 360-365)

E Kirche Kadelburg (um 355)

Erlel (352)

Tüftel - Rütenen (Koblenz ; 341-345)

Niveau B: Hard (NE Rümikon; 360-365)

östlich Lienheim (über 360) ; undeutlich

ev. Rubin? (N Reckingen)

Fohrenbuck (SW Dangstetten; 351-355)

Homburg (wenig über 340)

Niveau C: ev. Verflachung bei Lienheim (348-355; unschön)

Hardt (NW Reckingen Deutschland; 342-346; z. T. abgleitend)

Rizelg (Mellikon; 348)

Chleeb (Mellikon; 347; bei Mellikon nach $\mathrm{N}$ abgleitend)

Dorf Zurzach (340-345)

Emmerich (334-335)

Niveau D: Au-Terrassenfläche (Lienheim; 340)

Rekingen Sodafabrik (Schweiz; 334-336)

Reckingen oberhalb Kirche (Deutschland ; 335-336)

Bach (W Dangstetten; 3.32)

Riedäcker (Ettikon; 325-328)

Nivnau E: südlich Mühläcker Reckingen (Deutschland; 330)

Oberfeld (W Sodafabrik Rekingen; 328; von D abgleitend)

Rheinheim (Au, Sandäcker, Altrhein ; 325-328)

Breitäcker (W Kadelburg; 324)

Laufen (Koblenz; wenig über 320)

Niveau F: Wasserächer (Rümikon; wenig über 330)

westlich Oberfeld (von E her abgleitend; 325)

Rifeld (Rietheim; 321)

Rezente Bildungen: südlich Au (Lienheim; unter 330)

Reckingen (Deutschland; um 325)

Rheininseln

Grien (NW Rietheim, mit Rhein-Altläufen)

Vergleich mit den Korrelationen Hubers:

In diesem Abschnitt zeigen sich die Unzulänglichkeiten beim Vorgehen HUBERs besonders deutlich; er preßt die Terrassenflächen in ein im Oberlauf des Flusses entwickeltes System hinein. Auf einen Irrtum in der Umgebung von Koblenz hat bereits Bugmann (13) hingewiesen. GöHringers Vergleichszahlen sind seiner Karte (109), die westwärts bis Oberhofen reicht, entnommen worden. Weber $(87, \mathrm{p}, 71)$ führt in seiner Zusammenfassung die Terrassendaten GöHRINGERs von Reckingen ebenfalls an. 


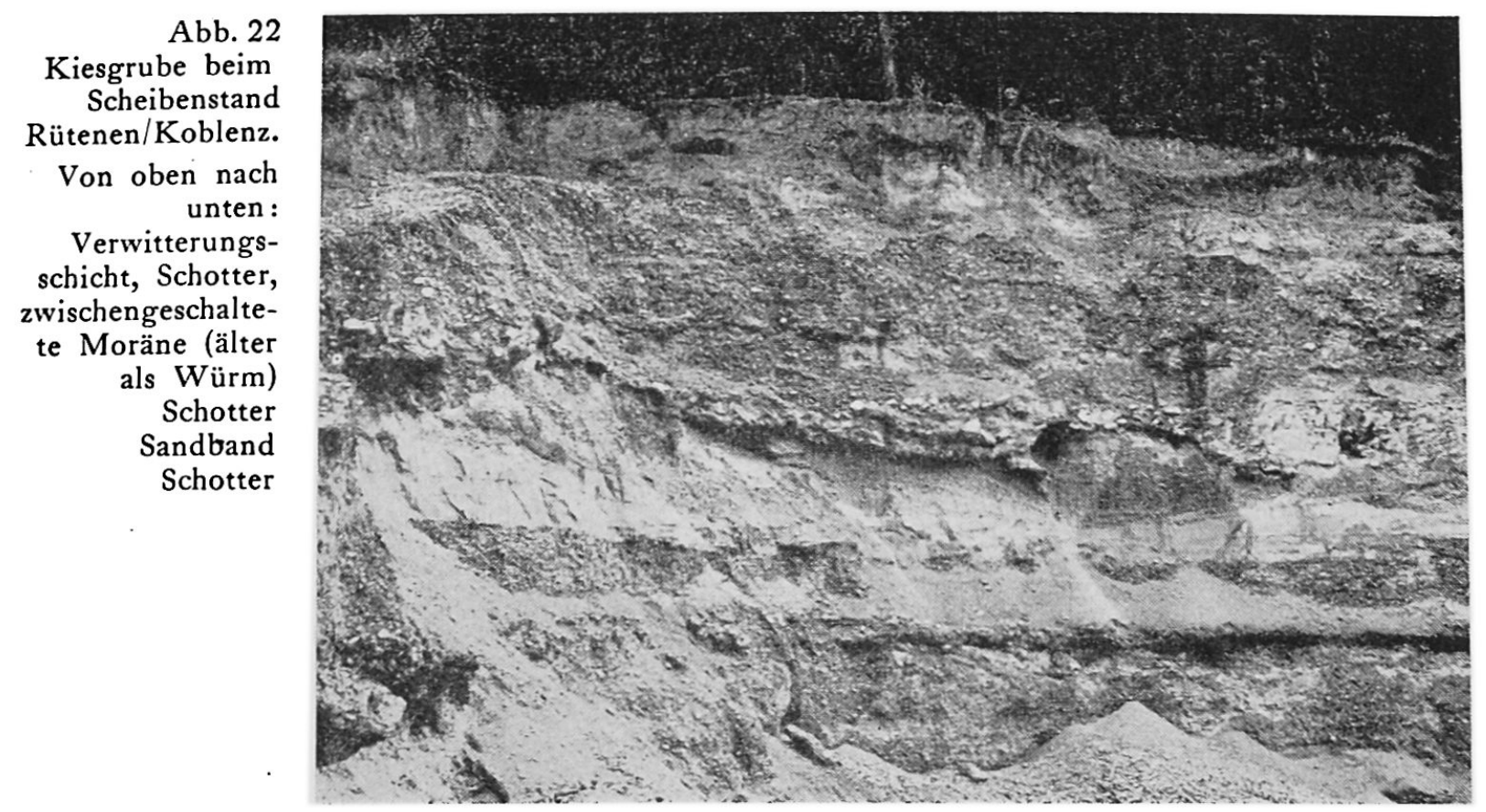

Auch unvoreingenommenen Beobachtern wird die Korrelation in diesem Abschnitt Mühe und Kopfzerbrechen verursachen. Zwei Gründe mögen dafür verantwortlich sein :

1. In den Kalkabschnitten (vgl. vor allem bei Lienheim) sind die Terrassenformen undeutlich; die Flächen sind geneigt und schwanken stark in ihrem Niveau. Dürfen solche Formen überhaupt noch als Terrassen taxiert werden, oder soll man in diesem Falle nicht eher von Versteilungen und Verflachungen sprechen?

2. Zwischen Mellikon und Koblenzer Laufen sind die linksrheinischen Terrassenflächen in den meisten Fällen abgleitend; saubere Terrassenkanten und -hänge fehlen. Wie muß nun eine solche Form gegliedert werden? Von Rekkingen bis Emmerich sind die rechtsrheinischen Terrassenflächen scharf voneinander getrennt, so daß wir für eine klare Einteilung unbedingt vom rechten Rheinufer auszugehen haben. Fehlt in diesem Abschnitt freilich eine Form, so entgeht sie uns ebenfalls in den fließenden Übergängen der linksrheinischen Terrassen.

Höhere Terrassenflächen, nicht in NT einzureihen:

Huber stellt diese Vorkommen in sein Würm 1 ab Stadium, obwohl die abgerundeten Kanten und welligen Oberflächen Indizien für Hochterrassen sind und Moränenaufschlüsse die Zugehörigkeit zur Würmeiszeit widerlegen (Abb. 22). Suter (115) und Bugmann (13) weisen diese Formen mit Recht der Hochterrasse zu.

Niveau A: Entspricht Teilstücken von HubERs II teilweise Göhringers 1

Niveau B: Teilstücke von Hubers II und III Teile von GöHringers 2

Niveau C: Im wesentlichen Hubers III. Das Hard nordöstlich Rümikon reihe ich in mein $\mathrm{B}$.

Teile von Göhringers. 3

Niveau D: Huber IV und IV/V. Die Terrassenfläche westlich der Teufelsbrücke auf ca. $360 \mathrm{~m}$ paßt nicht in dieses Niveau. Auf $3 \mathrm{~km}$ würde diese Ter- 
rassenfläche von $360 \mathrm{~m}$ auf $348 \mathrm{~m}$ in der Rizelg östlich Mellikon fallen, was einem Gefälle von 4\%o entspricht. Auch die Riedäcker nordwestlich Kadelburg sind außerhalb dieser Folge gelegen.

Teile von GöHringers 4

Niveau E: Teilstücke von Hubers $\bigvee$ und VI

Niveau F: Teilstücke von Hubers VI und VII

Rezente Bildungen: Huber VIII

Prüfung einer Korrelation Tössegg - Koblenz:

Niveau A: Diese Flächenreste entsprechen dem Akkumulationsniveau der Würmaufschotterung. Das Gefälle ist größer als bei den Erosionsterrassenflächen und erreicht außerhalb des Übergangskegels einen Wert von durchschnittlich ca. 2,5\%o (Röggliächer 409 - errechnete Höhe der Akkumulationsfläche bei Weiach 388 - Heutal 360/65 - Erlel 350/52 - Rütenen/Koblenz 341/45).

Niveau B: Hard 360/65; tiefer als: Hasli Weiach 380

Ebene W Kaiserstuhl 365,2/369

höher als: Blöliboden 359/60

Wenn eine Übereinstimmung überhaupt möglich ist, dann mit den rheinhaldenächsten Teilen der Weiacher Ebene bei den Rüteren (d. h. mit dem 4. Erosionsniveau).

Niveau C: Rizelg 348; tiefer als: Weiacher Ebene 365/70

höher als: unterhalb Engelhof 349

Eine Korrelation müßte demzufolge mit dem Blöliboden im Niveau 5 $(359 / 60)$ angestrebt werden; diese ist aber nicht gesichert, denn das Gefälle Blöliboden - Rizelg beträgt 2\%3\%, dasjenige Blöliboden Hauptstraße Mellikon sogar 3\%o, währenddem in diesem Abschnitt im allgemeinen Werte bedeutend kleiner als $2 \%$ festgestellt werden (vgl. auch ERB, 17, p. 9-12).

Niveau D: Sodafabrik Rekingen 334/36

tiefer als: Rizelg 348, demzufolge unter Weiacher Terrassenfläche wahrscheinlich tiefer als: unterhalb Engelhof 349

Eine Durchverfolgung mit 7/8 (Bleichi - Schloßwisen - westlich Schwarzwasserstelz - Au Lienheim 339 ist in Betracht zu ziehen, des geringen Gefälles wegen ( $\mathrm{Au} 339$ - Rainäcker $336=3 \mathrm{~m}$ Niveauunterschied auf $4,5 \mathrm{~km}$ ) aber fraglich; eine Verbindung mit dem 6. Erosionsniveau ergibt zwischen Guggenmühle und Sodafabrik Rekingen einen Gefällswert von fast $2 \%$. Ein Normalgefälle würde sich aus einer $Z$ wischenstufe von 6 und 7/8 ergeben.

Niveau E: südlich Mühläcker Reckingen 330

Östlich von Kaiserstuhl passen lediglich die Verebnungen südlich Herdern (wenig über 340) und südlich der Auen Hohenthengen in dieses Niveau. Da sie aber formenmäßig kaum als Terrassen angesprochen werden können und weiter oben und im $Z$ wischenstück Hohenthengen - Reckingen nicht verfolgbar sind, ist eine Einheitlichkeit dieser Terrassenfolge unwahrscheinlich.

Niveau F: Rifeld Rietheim 321/24

Von Rümikon rheinaufwärts ist dieses Niveau nicht mehr verfolgbar.

Vom Abschnitt Tössegg-Teufelsbrücke sind unterhalb Schwarzwasserstelz folgende Terrassenflächen nicht mehr erkenntlich: 
1. Erosionsniveau (Haslifläche Weiach)

2./3. Erosionsniveau; d. h. es fehlen die Hauptteile der Weiacher Terrassenfläche.

6. Erosionsniveau

7./8. Erosionsniveau

Die Korrelationen Erosionsniveau 4 mit Niveau B

5 mit Niveau C

$7 / 8$ mit Niveau D

sind nicht gesichert und eher abzulehnen.

Als neue, tiefere Flächenfolgen treten im unteren Abschnitt die Niveaus E und $\mathrm{F}$ auf.

Im Bereiche von der Endmoränenzone bis Hohenthengen überwiegen flächenmäßig die oberen Terrassen deutlich. Von Rafz-Wil südwärts ist es die Akkumulationsfläche, die dominiert, von Eglisau westwärts das fruchtbare Rafzerfeld und die Weiacher Ebene. Die Schwingungsweiten des Rheines sind in dieser Zeit beträchtlich: Vom Lindibüel bis Landbüel 4,5 km (die Südwärtsabdrängung des Rheines bei Seglingen ist durch die Wasser der einmündenden Gräben westlich von Buchberg beeinflußt worden), weiter westwärts zwischen dem Hof «Ofen» und Stetten noch 2,5 km. Zwischen Hohenthengen und Weiach wird dem Pendeln ein erster Einhalt geboten (Hohenthengen - Weiach: 1,5 km), zwischen Schloßwald und der Guggenmühle beträgt die Ausweitung sogar nur noch $500 \mathrm{~m}$. Das Abgleiten der Flächen und das weitgehende Fehlen markanter Terrassenhänge (Ausnahme: Prallhang des Haslis Weiach) lassen auf eine kontinuierliche, langsame Tieferlegung des Flußbettes während der Gestaltung der oberen Erosionsterrassen schließen (Der Steilabfall der Akkumulationsplatte südlich von Wil ist durch ein neues Flußregime, das im rechten Winkel zur Aufschotterungsachse liegt, geschaffen worden.).

Der nächste Schritt der Entwicklung ist durch ein starkes Eintiefen des Rheines markiert. Der Fluß wird gekürzt, dadurch gerader; er ist cañonartig gefangen, und die Möglichkeiten zur Ausweitung sind gering. Abdrängungen durch Nebenflüsse wie die Glatt vermögen die einzigen größeren Terrassen zu bewirken. Es ist nicht erstaunlich, daß Hug (37) bei der Zweiteilung der Niederterrasse diese unteren Formen gar nicht mehr berücksichtigt hat, treten sie flächenmäßig doch nur wenig in Erscheinung. Der Schwingungsbereich des Rheines ist fast durchwegs auf weniger als $500 \mathrm{~m}$ zusammengeschrumpft (Ausnahme: durch Glatt bedingte Herdener Terrassen); der heutige Rhein ist noch enger eingefangen.

Vergleichen wir nun die Entwicklung des Rafzerfeldes mit derjenigen des Abschnittes unterhalb des Kalkdurchbruches Lienheim-Rümikon. Die Talweite ist gegenüber dem oberen Abschnitt geringer; sie überschreitet selten eine Breite von $2 \mathrm{~km}$. Von den obersten Terrassen sind nur noch geringe Reststücke vorhanden; wir müssen annehmen, daß eine flächenhaft wirkende Erosion die Ablagerungen größtenteils weggeräumt hat. Auch die Terrassenfolge B weist innerhalb des Abschnittes nur eine sichere, größere Fläche (bei Dangstetten) auf. Ein recht kräftiges Gewässer, der Hinterbach, hat den pendelnden Lauf des Rheines nach Süden und Südwesten abgedrängt und auf diese Art und Weise zur Erhaltung des isolierten Terrassenstückes beigetragen. Die Hardterrasse ist noch innerhalb des Kalkdurchbruches gelegen. Eine große Kiesgrube nordöstlich des Friedhofes Rheinheim umfaßt den Terrassenhang B des Fohrenbuckes und die Terrassenfläche $\mathrm{D}$ des Friedhofes. Die Kiesbänder unter der Ebene $D$ ziehen ungestört unter dem Steilhang $B$ durch und weisen so auf die erosive Entstehung der Terrassenfläche D hin (Abb. 23; vgl. auch Kap. "Gräben und Dellen in der Umgebung von Weiach und ihre Beziehung zur Talgeschichte»).

Bei der Eintiefung in die Terrassenfläche Emmerich gleitet der Rheinlauf vom Schotter (Niveau B) auf den Muschelkalk nordwestlich des Hofes Ettikon, der die Erosion oberhalb dieser Stelle wesentlich retardiert. Gleichzeitig schneiden sich aber 


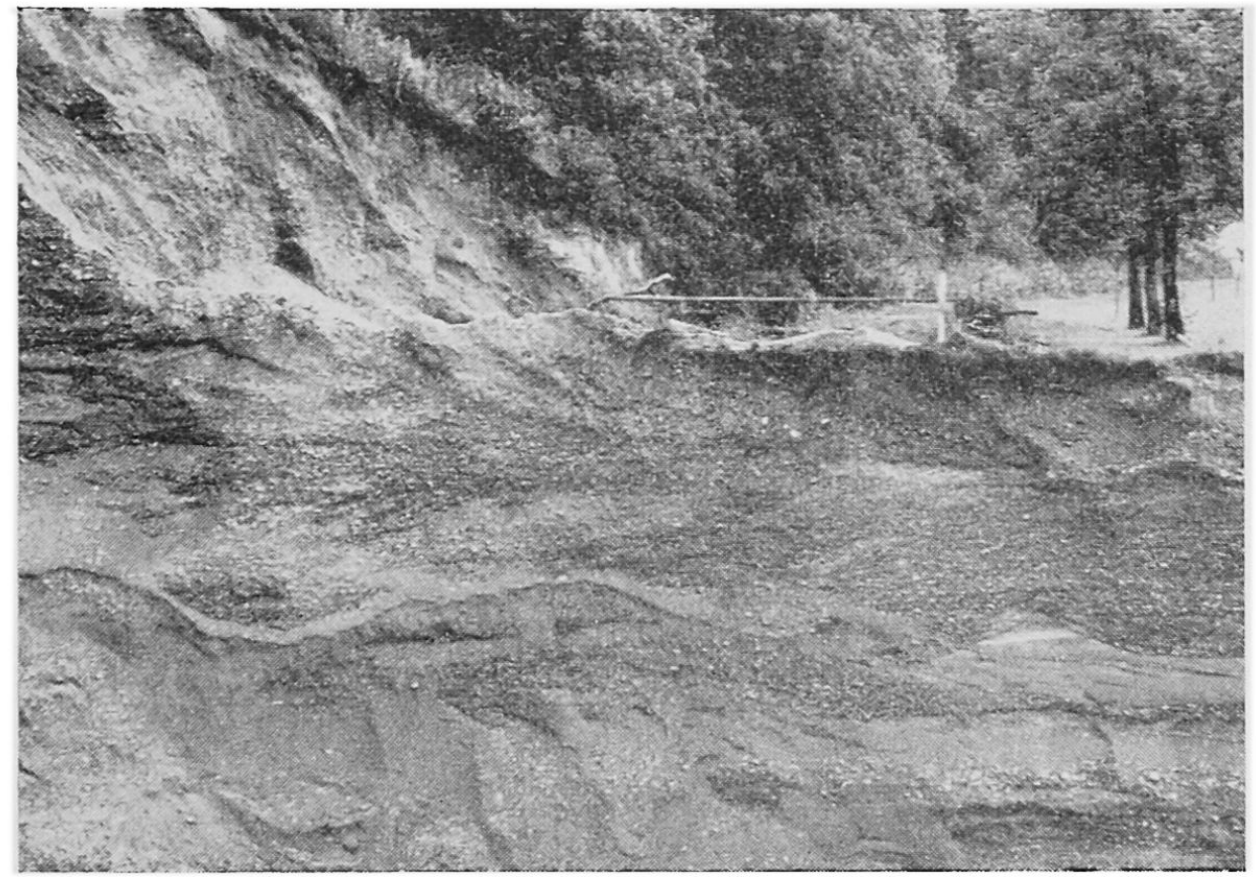

Abb. 23

Kiesgrube NE

Friedhof Rhein-

heim. Die Kiesbänder unter der

Terrassenfläche D ziehen ungestört unter die Terrasse B

die Wasser des Rheines zusammen mit denjenigen der Schlücht und der Wutach unterhalb der Muschelkalk-Barriere weiterhin im Schotter ein, so da $\beta$ es vorerst zur Ausbildung einer Stromschnelle und hierauf eines Wasserfalles kommt. Der Stau Albbruck-Dogern deckt heute diese Schwelle zu. HuBER (34, p. 73) beschreibt die Entwicklung folgendermaßen:

«In dieser Gegend war also der Abfluß des sich nur langsam in die nachfolgende Kalkbarriere einschleifenden Rheines so stark gehindert, daß in den Stadien 4, 5, 6, 7 und 8 nordwestlich Rheinheim und Rietheim bis Ettikon eine $4 \mathrm{~km}$ lange und stellenweise $2 \mathrm{~km}$ breite Erosionsfläche entstehen konnte, die im Westen bis an den Fuß der $13 \mathrm{~m}$ hohen Halde reicht, welche den Talabschlu $\beta$ bildet.»

Wie Huber zeigt, übt diese Barriere rheinaufwärts einen Einfluß auf die Talgestaltung aus; Seitenerosion herrscht vor. Die linksrheinischen Terrassenflächen sind abgleitend und lassen sich kaum trennen; am rechten Ufer finden sich Prallhänge mit klar ausgebildeten Terrassenhängen bis $\mathrm{D} / \mathrm{E}$. Die unteren Terrassenflächen $\mathrm{E}, \mathrm{F}$ und rezent sind auch rechtsrheinisch nicht mehr durch Steilhänge getrennt. Der Rhein fließt nicht gerade, in einem Cañon eingefangen wie oberhalb Kaiserstuhl. Im Grien westlich Rietheim lassen sich noch deutlich alte Rheinarme erkennen (siehe auch Landeskarte, Blatt Zurzach, 1050), die auf ein rezentes Pendeln des Flusses aufmerksam machen.

In den beiden Abschnitten pendelt der Rhein vorerst auf dem Akkumulationsschotterfeld und legt die erste Erosionsfläche frei. Oberhalb Kaiserstuhl stößt er dabei schon bald auf einzelne Kalkklötze (Schatzbühl Herdern 384,5 m, Kirchhügel Hohenthengen $370 \mathrm{~m}-378 \mathrm{~m}$ ), die flußaufwärts retardierend auf die Erosion einwirken und die Anlage der abgleitenden Terrassenfläche bedingen. Darauf fällt der Rhein in die schottergefüllten Kalkschluchten ab, die Tiefenerosion begünstigen; von Herdern bis Guggenmühle finden sich tiefe Schotterstränge. Der Fluß verfängt sich innerhalb einer solchen Rinne, und die Terrassenbildung wird erschwert. In diesen Punkt unterscheidet sich der untere vom oberen Abschnitt. Während wir im Übergang von der Akkumulationsphase zur ersten Erosionsphase noch die gleichen Bedingungen, dirigiert durch die zurückschmelzende Gletscherstirn, antreffen, weichen sie im folgenden stark voneinander ab. Die Kalkbarriere beim Koblenzer Laufen liegt tiefer; der Rhein schneidet sich länger in Schotter ein, und es ist wahrscheinlich, daß zu diesem Zeitpunkt die Talweitung geringer war. Erst später (B/C) gerät der Rhein in den Muschelkalk, fließt aber bis heute über diese Kalkschwelle. Deshalb finden wir 
hier im Gegensatz zum oberen Abschnitt in der jüngsten Zeit noch die Seitenerosion vorherrschend, die alte Terrassenreste abzuschleifen und in den tiefen Lagen breite Flächen anzulegen imstande ist.

\section{b3) Abschnitt Rheinfall-Buchberg}

Bei den Terrassenvergleichen im intramoränen Bereiche stütze ich mich weitgehend auf die Höhenvergleiche Hubers; dies ist umso eher möglich, als unsere Korrelationen von der Tössegg bis nach Kaiserstuhl von meinem 3. Erosionsniveau an im wesentlichen übereinstimmen und höhere Flächen intramorän eine geringe Rolle spielen. Den Abschnitt Rüdlingen - Balm kenne ich von eingehenden Felduntersuchungen. In meiner Arbeit gebe ich lediglich einen Überblick über HuBERs Durchverfolgung der Terrassenflächen und verweise für die detaillierteren Angaben auf die Daten und Karten Hubers (34), ohne zu seinen genetischen Erklärungen im einzelnen Stellung zu nehmen.

HUBER II :

Breiteterrasse zweiteilig

HUBER III : Stokarterrasse

HUBER IV: Munotterrasse dreiteilig

HUBER V: FulachSchaarenwaldterrasse vierteilig

HUBER VI : Obere Singener Terrassen dreiteilig

HUBER VII: Untere Singener Terrassen vierteilig

HUBER VIII: rezent mehrteilige Breiteterrasse Schaffhausen

Lehmgrube Durstgraben (444-447)

Jestetten $433-440$

zweiteilige Stokarterrasse Schaffhausen

a: W Bahnstation Altenburg (428-432)

b: E Chlaffental gegen Landesgrenze

ab: die zusammenhängend auftretende, große Lottstetter Ebene gegen Rüdlingen $(400-416)$

a: Weitenfeld SE Dachsen (425-430)

unterhalb Station Altenburg (420)

b: Lauferfeld (405-410)

Riethof (2 km E Altenburg: 412-415)

ev. Chachberg (395)

c: Grund W Nohl (410-415)

a: SE Dachsen (405-410)

Altenburg NW Wall (400-405)

NE-Teil des Rinauer Feldes (397-400)

Naßenweg (395-399)

Sewerben (398)

b: E Wall Altenburg (wenig unter 400)

Neurheinau (393)

Teile des Rinauer-Feldes

c: Härdli S Dachsen (387-390)

Neurheinau Solboden (388)

Rinauerfeld (387)

cd: $N$ des Schwabens (N Rheinau; 390)

d: Teile des Schwabens

Ebene W Chorb Rheinau (388)

gegen Tugstein, Häuli und Eichelhag (380)

Radhof (380)

Steinboden Dachsen (384-390)

E-Rand des Schwabens $(380-390)$

Balm und Zil $(380-385)$

Ölberg (375)

Radholz - Weierchot (374)

Junkerenbuck - Fosenacker (370)

Dammboden (W-Teil des Schwabens; 370-380)

Au Rheinau (365-372)

Spitzäcker S Balm (um 370)

Winzlerboden (Niderholz; um 365)

E Schulhaus Ellikon (364)

einzelne hohe Reste im Hardt (Nacker Mühle; über 360)

Ischleg (Gemeinde Buchberg; um 360)

niedrige Teile des Hardt

Ellikon (350-355)

Thurtalboden

Woog und Unterfeld Rüdlingen 


\section{b4) Abschnitt Dießenhofen-Schaffhausen}

HUBER III:

HUBER IV:

SW Gloggenguet Herblingen

Herblingertal Ebnat (437)

Herblingen $(437-440)$

a: Feuerthalen (440)

h: Feuerthalen (425)

c: Feuerthalen (430)

HUBER V:

Fulachtal

bedeutendste Ausbildung im Schaarenwald: Ratihart - Schaaren -

Weieracker - Paradis - Langwiesen - Station Feuerthalen (400-415)

Lätten S Dießenhofen (um 410)

Diese Terrassenflächen sind abgleitend.

HUBER VI:

Schupferzälg E Dießenhofen (410-415)

Das Fehlen höchster Schotterfelder ist nicht erstaunlich, durchschneiden doch die Schmelzwasser nach dem Zurückweichen der Gletscher in der nun Nord-Süd gerichteten Entwässerungsachse Schaffhausen - Rüdlingen die Ablagerungen weitgehend. In der gleichen Erosionsphase, die das weite Rafzerfeld geprägt hat (HUBER IIIab, LEEMANN 3,4), ist auch hinter dem Endmoränengürtel eine weite Fläche freigelegt worden: die Lottstettener Ebene. Mehrere prächtige Söllbecken lassen sie vom extramoränischen Bereich deutlich unterscheiden; sie weisen auch darauf hin, daß sich die Gletscherstirn seit dem Maximalstand erst um 1-3 km zurückgezogen hat. Währenddem der Rhein sich von der Tössegg bis Kaiserstuhl nun kräftig eintieft und dadurch die Terrassenentwicklung stark gehindert wird, bildet sich im Abschnitt nördlich Rüdlingen eine verwirrende Fülle von Terrassen aus. Die verschiedenartige Gestaltung ist durch die Lage bestimmt. Im intramoränischen Bereiche gestalten sich die Verhältnisse sehr kompliziert. Kleine Eisrandschwankungen machen sich in der unmittelbaren Umgebung der Gletscherstirn sofort bemerkbar, sei es durch Ablagerung von ausgeschwemmtem Material, sei es durch die Ausbildung neuer Rinnen; es wäre sinnlos, solche Lokalbildungen im ganzen Rheinlauf durchzuverfolgen. Eine weitere Komplizierung bringt die Trennung des zurückweichenden Gletschers in die zwei Arme Rheintalgletscher und Thurtalgletscher mit sich. HUBER (p. 66/67) weist auf die Möglichkeit einer Retardierung der Tiefenerosion während seines Stadium 5 durch eine teilweise Sperrung des Rheincañons unterhalb Rüdlingen hin; nach dieser Ansicht könnte der Gletscher im untersten Thurtal den Abfluß des Wassers gehemmt haben ( $\mathrm{Ob}$ ein Gletschervorstoß dieses Ausmaßes stattgefunden hat, ist allerdings fraglich.). Eine weitere Möglichkeit der Ausweitung sieht HuBER wohl mit Recht im Zurückweichen des Thurgletschers:

«Mit dem periodischen Zurückweichen des Thurtalgletschereises wurde die dem Fluß zur Verfügung stehende Talfläche immer breiter, und die beim zeitweisen starken Abschmelzen des Rheingletschers entstehenden Hochwasser konnten immer neue, deutlich abgesetzte und tiefer liegende Flußschlingen bilden.»

Die Wasser der weit mäandrierenden Flußläufe werden durch die enge Schlucht unterhalb Rüdlingen aufgefangen und fließen konzentriert in die tiefe Rinne des unteren Abschnittes. Je weiter sich der Gletscher zurückzieht, umso mehr Raum steht für die Terrassenentwicklung im Abschnitt Rüdlingen - Rheinau zur Verfügung; so ist es begreiflich, daß die unteren Terrassen vorwiegen. Ganz anders im extramoränischen Bereich des Rafzerfeldes: Je tiefer sich der Rhein im Schotter einfrißt und sich dadurch in vorgezeichneten Schluchten verfängt, umso mehr wird seine Schwingungsweite eingeengt. Die oberen Terrassen sind hier dominierend.

Interessant ist die Terrassengestaltung in der Umgebung von Schaffhausen. Während wir eine deutliche Ausprägung der höheren Terrassen vorfinden (vgl. Breiti, Stokargut, Munot und Feuerthalen), sind die tieferen abgleitend (vgl. Schaarenwald gegen Schaarenwis) und nicht mehr trennbar. Der Rhein pendelt; in einem weiten Bogen holt er gegen die Verebnung des Dorfes Büsingen aus und umfließt dadurch den Schaaren. Diese Verhältnisse erinnern an das Rifeld bei Rietheim. Die folgen- 
den Untersuchungen sollen zeigen, daß gleiche Ursachen ähnliche Formen bewirkt haben.

Beim Eintiefen in den Schotter verfangen sich die Rheinwasser in den Malmschluchten der Auflagerungsfläche. Der Laufener Kalkfelsen weist eine Höhe von $411 \mathrm{~m}$ auf, muß also zur Zeit der Anlage des Lauferfeldes bereits aus dem Schotter aufgetaucht sein. Wie Huber schreibt, ist aber die noch tiefer im Schotter stekkende Jurakalkwand erst in der Folge abgedeckt worden, so da $\beta$ der Katarakt mit der heutigen Fallhöhe von $380 \mathrm{~m}-360 \mathrm{~m}$ zu Beginn des Gletscherstadiums 5 noch nicht bestanden hat. HUBER zieht nun die richtigen Konsequenzen und anerkennt für den Rheinabschnitt oberhalb Schaffhausen (wie auch oberhalb des Koblenzer Laufens) die formdirigierende Wirkung der Kalkschwelle (p. 63):

«Daß Terrassen VI und VII im Rheintal zwischen Dießenhofen und Neuhausen nirgends sicher erkennbar sind, hängt mit den sich nur langsam vertiefenden Kalksteinschwellen beim Lächen Schaffhausen und oberhalb des Rheinfalles zusammen. Erst unterhalb von Laufen konnten sich wieder leichter ausgeprägte Schotterflächen bilden.»

Dieses Eingeständnis bedeutet aber nichts anderes, als daß lokale Erosionsbasen die durchgehende Terrassenverfolgung in Frage stellen.

\section{c) Zusammenfassende Darstellung über die Würmterrassen im Rheintal}

Bei den einleitenden Bemcrkungen zum Versuch einer Unterteilung der Terrassenentwicklung in Phasen habe ich drei Abschnitte ausgeschieden: I) Rheinfall - Dießenhofen, II) Kaiserstuhl - Rheinfall, III) Koblenzer Laufen - Kaiserstuhl. Diese Dreiteilung ist auf Grund regulierender Schwellen vorgenommen worden; sie ist beeinflußt durch Beobachtungen im extramoränischen Bereiche. Nähere Untersuchungen zwingen, intramorän einen weiteren Abschnitt auszuscheiden: Rüdlingen - Rheinfall; Veränderungen der Eisrandlagen wirken hier entscheidend auf die Terrassengestaltung ein.

Zusammenfassend läßt sich die Terrassenentwicklung in den vier Abschnitten wie folgt darstellen (Tab. 6) :

Die Korrelationen zeigen, daß eine durchgehende Terrassenverfolgung (Terrasse immer als Formgebriff im Sinne Boeschs, 3, und Bugmanns, 13, verstanden) nicht möglich ist. Denken wir z. B. an die verwirrende Fülle der Terrassen in der Umgebung von Rheinau (HuBer Va, b, c, d; VIa, b, b'; VIIa, a', b; VIIIa, b, b')! Diese Formen können nach unten und oben nicht mehr einzeln ausgeschieden werden; zur Zeit der Anlage dieser mannigfaltigen Terrassen zwischen Rheinfall und Rüdlingen finden wir nur spärliche Reststücke zwischen Tössegg und Kaiserstuhl; oberhalb Schaffhausen treten abgleitende Flächen auf. Ausgeprägt ist der Formenverlust im Abschnitt Kaiserstuhl - Koblenzer Laufen. IV/V und VI/VII werden von Huber (p. 72 ) als «Doppelterrassen» zusammengefaßt, wobei wie oben gezeigt, jede dieser Formen ihrerseits wieder aus mehreren Teilformen hervorgegangen sei. $\mathrm{Da} \beta$ das Gefälle flußabwärts geringer wird, die Terrassenflächen nach unten deshalb durch geringere Niveauunterschiede voneinander getrennt sind und sogar ineinander übergehen können, ist an und für sich durchaus normal. Würden aber nur Gletscherschwankungen (durch das Klima bedingt) allein die Terrassenbildung beeinflussen, müßte sich der Terrassenreichtum systematisch von oben nach unten verringern. Dem ist aber nicht so (vgl. dazu z. B. Huber VI, VII oberhalb und unterhalb des Rheinfalles). Wie der Korrelierungsversuch Tössegg-Koblenzer Laufen zudem erweist, ist eine durchgehende Terrassenverbindung mit normalen Gefällsverhältnissen nicht möglich; wir müssen der Entwicklung in den einzelnen Abschnitten eine weitgehende Eigenständigkeit zugestehen. Wie sind andere Autoren zu einer durchgehenden Terrassenkorrelierung im Rheintal gelangt? Nach meinem Dafürhalten sind folgende Gründe dafür verantwortlich: 
Tabelle zur Terassenent.wicklung im Rheintal zwischen Dießenhofen und Koblenzer Laufen (Tab. 6)

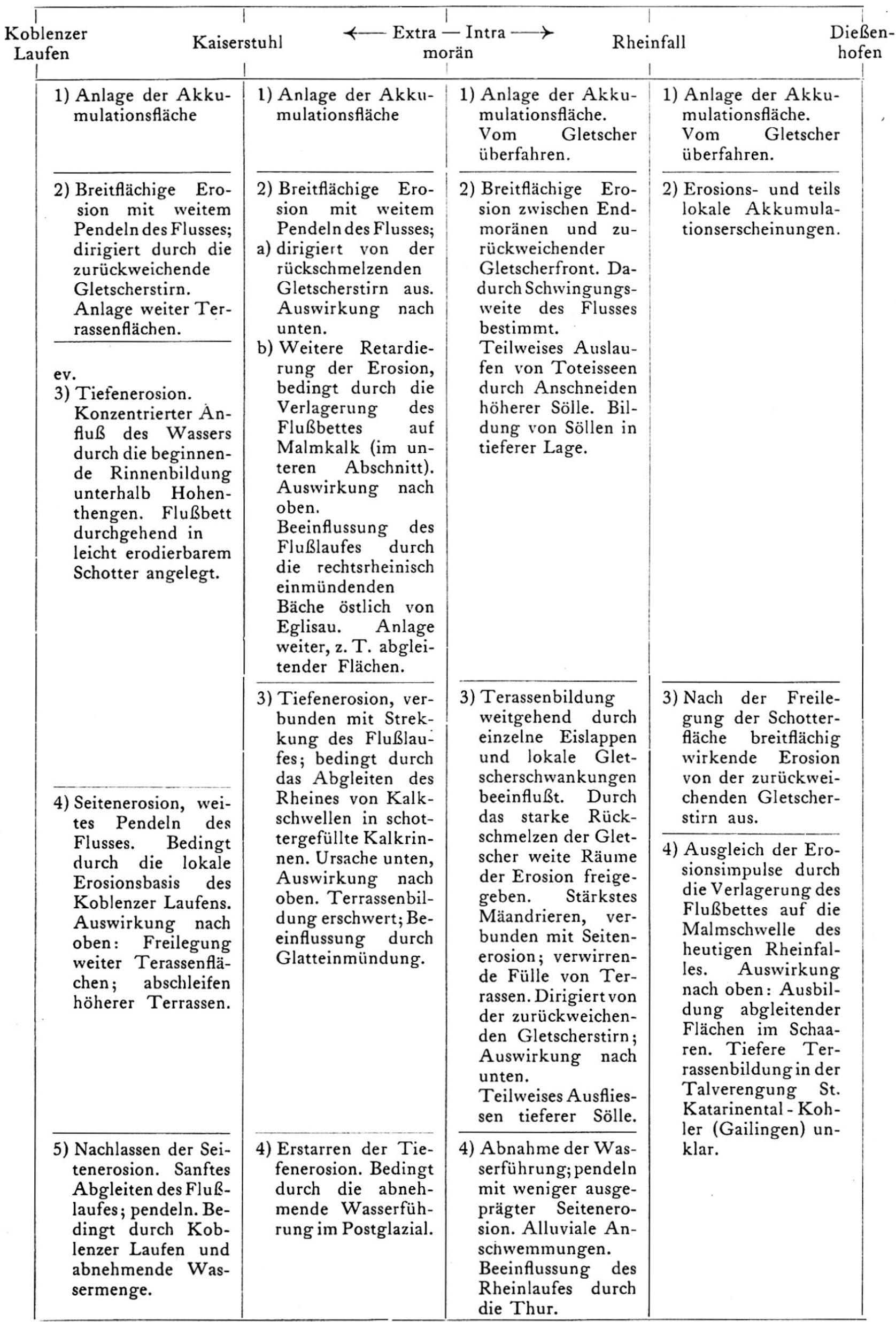


a) Der Terrassenbegriff ist oft unklar.

b) Die Terrassengliederung beruht auf der Idee einer akkumulativen Ineinanderschachtelung zweier oder mehrerer Würmschotter von verschiedenen Moränenständen aus. Theoretisch müssen sich diese Akkumulationsfelder durchverfolgen lassen, genau so wie wir eine erste durchgehende Aufschotterungsebene angenommen haben.

Diese Hypothese beherrscht die Terrassengliederung. Größere, nicht in das System passende Formen werden als Teilfelder bezeichnet, andere für die Gliederung ganz vernachlässigt. Die verschiedene Zahl der aufgeführten Terrassen ist daher nicht verwunderlich: HUG und $Z_{\text {INK }}$ scheiden nur 2, ERB 3 Terrassen aus; Penck, Göhringer, Weber und weitere führen 1 oberste Akkumulationsfläche und 5 Rückzugsschotterebenen an. In größere Schwierigkeiten gerät HUBER, der alle Terrassen zu berücksichtigen versucht und diese Fülle nur durch komplizierte Klimaänderungen und den damit verbundenen Gletscherschwankungen erklären kann (HuBER, 34, p. 81!).

Wie meine Untersuchungen gezeigt haben, kann die Ineinanderschachtelung mehrerer Würmschotter widerlegt werden. Im extramoränischen Bereich findet sich lediglich eine Akkumulationsfläche; die tieferen Terrassen sind erosiver Entstehung. Es ist nun zu überlegen, ob Akkumulation und Erosion die gleichen Formen schaffen. Dies ist aus theoretischen Erwägungen nicht möglich. Eine Schotterakkumulation ist in erster Linie von der Anlieferung des Schuttes durch den vorrückenden Gletscher abhängig. Die Auflagerungsfläche spielt keine Rolle: Ob Kalk oder Molasse, der Schotter deckt das bewegte praeglaziale Relief zu und bildet eine weitgehend ausgeebnete Fläche. Anders liegen die Verhältnisse bei der Erosion. Für die Erosionswirkung sind nicht nur klimatische Verhältnisse, verbunden mit Gletscherschwankungen, entscheidend; Untergrund, Wassermenge, Einmündung von Nebenflüssen, Gefälle, vorgezeichnete Schluchten sind weitere Faktoren, die die Terrassengestaltung beeinflussen. In meinem petrographisch stark differenzierten Untersuchungsgebiet dürfen wir daher keine durchgehende, gleichmäßige Terrassierung erwarten. Der verschiedene Grad der Erosionsfälligkeit des Untergrundes verhindert eine regelmäßige Ausbildung. Die Detailuntersuchungen im Gelände mit Einbeziehung aller Terrassenflächen bestätigen uns diese Ansicht. In petrographisch einheitlichen Gebieten müssen sich die klimatischen Auswirkungen auch einheitlicher bemerkbar gemacht haben und erscheinen dominierend. Eine Kalkschwelle im Schottergebiet aber vermag der Erosion, bedingt durch einen erhöhten Wasseranfall während einer Klimabesserung, entgegenzuwirken und dirigiert die Formenbildung. Wo Nebenflüsse einmünden, können lokale Terrassen gebildet werden, die mit dem System des Hauptflusses in keiner direkten Beziehung stehen. Enge Durchbruchsstellen erschweren die Terrassenentstehung.

Die Terrassenbildung ist auf eine Wechselwirkung verschiedenster Faktoren zurückzuführen; je nach Abschnitt überwiegt der eine oder andere. Eine durchgehende Korrelation in unserem Gebiet wird daher immer wieder zu Fehlern führen müssen, da die formbestimmenden Faktoren wechseln.

Ein Vergleich, durchgeführt mit Hilfe der normalen Gefällsverhältnisse, liefert uns dennoch Hinweise: Es wird uns nämlich offenbar, welche Faktoren zu einer bestimmten Zeitspanne in den verschiedenen Abschnitten formbestimmend gewesen sind. Wir werden auf die bedeutenden, in den einzelnen Abschnitten verschieden gestalteten Erosionsleistungen während des Spätglazials aufmerksam gemacht und sehen, daß die postglaziale Ausräumung nur noch bescheidene Ausmaße aufweist. Auf Grund der Untersuchungen ergibt sich eine teilweise Übereinstimmung mit BUGManNs Ergebnissen: 
Frühglazial: Vorerst Erosion; mit zunehmender Schotterüberlastung Einsetzen der Akkumulation.

Hochglazial: Abflauen der Akkumulation. Noch während des Hochglazials einsetzende Erosion.

Spätglazial: Ausgeprägte Erosionserscheinungen.

Postglazial: Starkes Abflauen der Erosionsintensität.

Wie ich gezeigt habe, ist die Differenzierung von Breiten- und Tiefenerosion nicht durchwegs an klimatische Faktoren gebunden.

(BUGManN, 13: «Die bereits angeführte, im Hochglazial einsetzende, breitflächige fluvioglaziale Erosion geht im Laufe des Spätglazials über in die linear wirkende interglaziale Tiefenerosion.»)

Lokale Erosionsbasen können auch im Spätglazial eine breitflächige Erosion bedingen. Eine stark ausgeprägte, postglaziale Tiefenerosion ist für das Rheintal abzulehnen.

\section{ZUSAMMENFASSUNG}

In der vorliegenden Arbeit werden gewisse Probleme der Würmablagerungen im schweizerisch-deutschen Hochrheingebiet unter besonderer Berücksichtigung periglazialer Erscheinungen behandelt. Eingehende Beachtung wird der Terrassenentstehung geschenkt. Die Untersuchungen sind im Rahmen weiterer quartärmorphologischer Arbeiten des Geographischen Institutes der Universität Zürich durchgeführt worden, so vor allem im Zusammenhang mit der Dissertation Bugmanns über die Eiszeitformen im benachbarten nordöstlichen Aargau (13). Im Gegensatz zu früheren großräumigen Untersuchungen basiert meine Arbeit auf Detailstudien, die auf Grund neuer Erkenntnisse der Periglazialforschung ausgewertet worden sind. In einem erweiterten Arbeitsgebiet (Dießenhofen-Koblenz) sind die gewonnenen Ergebnisse angewandt und die bestehenden Interpretationen der Würmterrassen in Rheintal kritisch gesichtet worden.

Kap. BI:

Im zürcherisch-aargauischen Grenzgebiet des Rheines (Weiach-Kaiserstuhl) sind Gräben und Dellen untersucht worden. Bei den höher gelegenen Gräben und Dellen ist deutlich zwischen dauerfrostbodenbeeinflußten Dellen und Tälchen einerseits und den im Spätglazial-Holozän gebildeten Gräben anderseits zu unterscheiden. Die älteren Formen haben die Hauptmasse des ausgeräumten Materials früh-hochglazial auf die in Bildung begriffene oder bereits gebildete Akkumulationsterrassenfläche abgegeben, währenddem die jüngeren Gräben mächtige Schuttkegel auf die Erosionsterrassenfläche Hasli aufgeschüttet haben.

Die tiefer gelegenen Gräben sind nach der Dauerfrostbodenzeit angelegt worden; ihre Ausbildung und Lage ist durch die oberflächennahe, wasserundurchlässige Schotterauflagerungsfläche (aquitane Mergel und Sandsteine) und die bei Unwettern stark anschwellenden Weiacher Dorfbäche bedingt. Anthropogene Einflüsse wie Rodungen, Anlage von Wässerwiesen haben Abtragungserscheinungen gefördert.

Für die Unterscheidung von Akkumulations- und Erosionsterrassen ist eine neue Indizmethode angewandt worden: Umfaßt ein Aufschluß sowohl Teile der höheren Terrasse wie auch Schotter unter der tieferen Terrassenfläche, liefert der Schichtenverlauf gute Indizien zur Beurteilung der Entstehung der tieferen Terrassenfläche. Zieht eine deutlich ausgeprägte Schotterschicht der tieferen Terrassenfläche ungestört unter der höheren Terrasse durch, vermuten wir erosive Entstehung der tieferen Terrassenfläche. Findet sich hingegen eine Diskordanz zwischen den Schottern der tieferen Terrassenfläche und denjenigen unter der höheren Terrasse, können wir die tiefere Schotterterrassenfläche als akkumulativ eingeschachtelt denken (vgl. die ein- 
gehenden Ausführungen p. 111-114; siehe auch Bugmann, 13). Die Terrassen werden nach der Nomenklatur Boesch (3) klassifiziert.

Alle bei Weiach in NT-Schottern angelegten Terrassen sind Erosionsterrassen $\left(\mathrm{Ef}_{1} / \mathrm{E} \mathrm{f}_{2}-\mathrm{Formen}\right)$; die Akkumulationsfläche ist erodiert worden. Eine Ineinanderschachtelung verschiedener Würmschotter kann widerlegt werden. Nach den vorhandenen Schottern beurteilt, erscheint die Würmeiszeit als eingliedrig (siehe auch p. 115). Auch eine Zweiteilung in Riß II- und Würmmaterial ist nicht ersichtlich.

Die Schotterauflagerungsfläche ist unausgeglichen und schwankt stark in ihrem Niveau; tiefe Schluchten durchziehen den Kalk.

Kap. BII:

Es wird nachgewiesen, daß die in die Akkumulationsterrasse eingetieften und auf die erste Erosionsterrassenfläche ausmündenden Tälchen südlich von Wil (Rafzerfeld) zur Zeit des Dauerfrostbodens geschaffen worden sind. Als sich der Rhein bereits gegen sein erstes Erosionsniveau hinunter eintiefte, fand sich im Rafzerfeld noch ein Dauerfrostboden vor. Der Permafrostboden ist nicht schlagartig mit dem einsetzenden Gletscherrückzug verschwunden.

Kap. B III:

Als weitere Periglazialformen, die aber noch in den H'T-Schotter oder in die Molasse hineinreichen, werden die auf das Rütifeld nördlich Windlach (Bez. Dielsdorf) ausmündenden Tälchen erkannt und erklärt.

Kap. CI:

Im ersten Kapitel des Abschnittes $C$ wird eine kurze Zusammenfassung über die Terrasseninterpretationen verschiedener Autoren (PENCK, HUG, ERB, ZINK und HUBER) gegeben.

Kap. C II:

Das zweite Kapitel des Abschnittes C ist der Morphogenese gewidmet. Der praewürmische Rhein ist in der Fortsetzung des heutigen Thurunterlaufes zwischen Grafenhau und dem Molassehügel südlich P. 414,5 in das Rafzerfeld eingedrungen; der Kalkschluchtenabschnitt westlich Hohenthengen bildet die Austrittsstelle. Die Schotterauflagerungsfläche des Rafzerfeldes muß aus deduktiven Überlegungen ähnlich gestaltet sein, wie das praewürmische Relief bei Weiach, d. h. unausgeglichen und im Kalkabschnitt schluchtendurchsetzt. Die Aufschotterung ist in der Vorstoßphase der Gletscher erfolgt; der Gletscher überfuhr seine eigenen fluvioglazialen Schotter. Abb. 17 (Kiesgrube westlich des Hörnlis Rüdlingen) zeigt einen Aufschluß mit Schotter im Liegenden und einwandtrei nachgewiesener Grundmoräne mit gekritzten und polierten Geschieben im Hangenden. Erosions- und Akkumulationsvorgänge sind nicht scharf getrennt gewesen. Ein Aufschluß bei Wil (Rafzerfeld, Abb. 19) läßt einen mit Sand aufgefüllten Altwasserlauf erkennen.

Ob der Endmoränenwall bei Stadel wirklich den Maximalvorstoß des Würmgletschers markiert, wird angezweifelt. Dem Stadler Moränenwall vorgelagerte, in der Längsrichtung des Tales gelegene Steinwälle (Breustenen) lassen einen weiteren Gletschervorstoß als möglich erscheinen.

Da die Terrassenbildung auf eine Wechselwirkung verschiedenster Faktoren zurückzuführen ist, sind für die Terrassenentstehung nicht nur Gletscherschwankungen maßgebend. Die Aufmerksamkeit ist ebenso auf den Untergrund, die Wassermenge, die Einmündung von Nebenflüssen, das Gefälle und vorgezeichnete Schluchten zu richten. Auf Grund der Verhältnisse im Rafzerfeld sind für die Würmterrassenentstehung in diesem Gebiet vier Phasen ausgeschieden und datiert worden:

Phase 1: Anlage der Akkumulationsfläche, abgeschlossen im Hochglazial. 
Phase 2: Einsetzende Erosion mit weitem Pendeln des Flusses, beginnend im ausgehenden Hochglazial, abgeschlossen im Anfangsstadium des Spätglazials.

Phase 3: Ausgeprägte Tiefenerosion; cañonartiges Einsenken des Flußlaufes im Spätglazial.

Phase 4: Nachlassende Tiefenerosion im Postglazial.

Der Phasenübergang 1-2 ist auf die Bildung von Retentionsbecken im Oberlauf des Flusses zurückzuführen (Ursache oben, Auswirkung unten). Der Phasenübergang 2-3 wird bestimmt durch das Abgleiten des Flußbettes von Kalk in schottergefüllte Schluchten (Ursache unten, Auswirkung oben).

Meine Untersuchungen haben ergeben, daß eine durchgehende Korrelierung DieBenhofen - Koblenz unmöglich ist. Die Differenzierung von Breiten- und Tiefenerosion ist nicht durchwegs an klimatische Faktoren gebunden; lokale Erosionsbasen können auch im Spätglazial eine breitflächige Erosion bedingen. Das Untersuchungsgebiet ist in vier in sich einheitliche Abschnitte gegliedert worden:

I Rheinfall $\longrightarrow$ Bodensee: Beeinflussung durch die Malmschwelle des Rheinfalles.

II Endmoränen Rafzerfeld $\longrightarrow$ Rheinfall: Beeinflussung der Terrassenbildung durch die Gletscherrandlage.

III Kaiserstuhl $\longrightarrow$ Endmoränen Rafzerfeld: Diskontinuierliches Einschneiden des Rheines, bedingt durch petrographische Differenzen bei Hohenthengen - Kaiserstuhl.

IV Koblenzer Laufen $\rightarrow$ Lienheim: Kontinuierliches Tieferlegen nach Freilegung der Muschelkalkschwelle des Koblenzer Laufens.

Die weitgehende Eigenständigkeit der 'Terrassengestaltung in den verschiedenen Rheinabschnitten wird auf die in den einzelnen Abschnitten andersgearteten formbestimmenden Faktoren zurückgeführt. Die zusammenfassende Tab. 6 veranschaulicht die Ursachen und ihre Auswirkungen.

\section{E. LITERATURVERZEICHNIS}

1 Baulig H.: Vocabulaire Franco-Anglo-Allemand de Géomorphologie. Publications de l'Université de Strasbourg, fasc. 130, 1956.

2 Birot P.: Les méthodes de la morphologie. Paris 1955.

3 Boesch H.: Bemerkungen zum Terrassen-Begriff. Tijdschrift van het Koninklijk Nederlandsch Aardrijkskundig Genootschap; LXXIV/3, Juli 1957.

4 Bonté A.: Introduction à la lecture des cartes géologiques. Paris 1953.

5 von Braun E.: Geologische und sedimentpetrographische Untersuchungen im Hochrheingebiet zwischen Zurzach und Eglisau. Ecl. Geol. Helv. 46/2, 1953.

6 BÜdel J.: Die morphologischen Wirkungen des Eiszeitklimas im gletscherfreien Gebiet. Geol. Rundschau, 34, 1944.

7 Büdel J.: Die klima-morphologischen Zonen der Polarländer. Erdkunde, II/1948.

8 BÜDEL J.: Neue Wege der Eiszeitforschung. Erdkunde, III/1949.

9 Büdel J.: Die räumliche und zeitliche Gliederung des Eiszeitklimas. Naturwissenschaften, 36/1949.

10 BÜdel J.: Die Klimazonen des Eiszeitalters. Eiszeitalter und Gegenwart, 1/1951.

11 BODEL J.: Die «periglazial»-morphologischen Wirkungen des Eiszeitklimas auf der ganzen Erde. Erdkunde, 4/1953.

12 Bugmann E.: Geomorphologische und Wirtschaftsgeographische Untersuchungen im untersten Aaretal. Diplomarbeit Uni Zürich, 1954; Manuskript.

13 Bugmann E.: Eiszeitformen im nordöstlichen Aargau. Diss. Uni Zürich 1956.

14 Cailleux A. \& Romanovsky V.: La glace et les glaciers. Que sais-je, 562, 1953.

15 Dylik J.: Premières notions sur les formations de couverture dans la Pologne Centrale. Bulletin de la Société des Sciences et des Lettres de Lòdz, III/18, 1952.

16 Dylikowa A.: De la méthode structurale dans la morphologie glaciaire. Bulletin de la Société des Sciences et des Lettres de Lòdz, III/18, 1952.

17 ERB L.: Zur Stratigraphie des mittleren und jüngeren Diluviums in Südwestdeutschland und dem schweizerischen Grenzgebiet. Mitt. Bad. Geol. Landesanstalt Freiburg, 11/6, 1936. 
18 FEZER F.: Schuttmaßen, Blockdecken und Talformen im nördlichen Schwarzwald. Göttinger Geogr. Abh. 14/1953.

19 Flohn H.: Studien über die athmosphärische Zirkulation in der letzten Eiszeit. Erdkunde 4/1953.

20 FreI R.: Monographie des Deckenschotters. Beitr. zur Geol. Karte der Schweiz, 1912.

21 Furrer G.: Solifluktionsformen im schweizerischen Nationalpark. Diss. Uni Zürich 1954.

22 Furrer G.: Frostbodenformen in ehemals nicht vergletscherten Gebieten der Schweiz. Geogr. Helv. X/3, 1955.

23 Furrer G.: Die Strukturbodenformen der Alpen. Geogr. Helv. X/4, 1955.

24 Furrer G.: "Steingärtchen» in den Alpen. Leben und Umwelt, 4/1955.

25 Furrer G.: Bodenformen aus dem subnivalen Bereich. Die Alpen, 6/1955.

26 Gallwitz H.: Eiskeile und glaziale Sedimentation. Geologica, 2/1949, Berlin.

27 Göhringer A.: Erläuterungen zu Blatt Lienheim (169) der geol. Spezialkarte des Großherzogtums Baden. Bad. Geol. Landesanstalt, 1915.

28 Graul H.: Bemerkungen zur Würmstratigraphie im Alpenvorland. Geol. Bavarica, 14/1952.

29 Graul H.: Bemerkungen zu einer geologischen Übersichtskarte des Iller-Riß-Gebietes. Deutsche Geol. Ges., 105/1953.

30 Graul H.: Tagung zum Studium schweizerischer Quartärfragen in Aarau. Eiszeitalter und Gegenwart, 1954.

31 Heim A.: Geologie der Schweiz, Leipzig, 1916-1919.

32 Hennig E.: Zur Entwicklung des schweizerischen Flußnetzes. Geogr. Helv. 1949.

33 Hövermann J.: Die Periglazialerscheinungen im Harz. Göttinger Geogr. Abh., 14/1953.

34 Huber R.: Ablagerungen aus der Würmeiszeit im Rheintal zwischen Bodensee und Aare. Vierteljahresschrift der Natf. Ges. in Zürich, CI/1956.

35 Hübscher J.: Klettgau-Randen. Geol. Exk. in der Umgebung von Zürich, Exk. 23. Geol. Ges. Zürich 1946.

36 Hug J.: Die letzte Eiszeit im nördlichen Teil des Kantons Zürich und den angrenzenden Gebieten. Diss. ETH, 1907; Beitr. zur geol. Karte der Schweiz, XV. Lfg.

37 Hug J.: Die Zweiteilung der Niederterrasse im Rheintal zwischen Schaffhausen und Basel. Zeitschr. f. Gletscherkunde, III/1909, Berlin.

38 Hug J.: Die. letzte Eiszeit in der Umgebung von Zürich. Vierteljahresschrift der Natf. Ges. in Zürich, 1917.

39 Hug J.: Die Grundwasservorkommnisse der Schweiz. Annalen der Schweiz. Landeshydrographie, 1918.

40 Hug J.: Die Schweiz im Eiszeitalter. Zürich 1919.

41 Hug J.: Die wichtigsten Typen der ausnützbaren Grundwassergebiete der Schweiz. Monatsbull. des Schweiz. Vereins f. Gas- und Wasserfachmänner, 1928.

42 JäCKL.I H.: Talgeschichtliche Probleme im aargauischen Reusstal. Geogr. Helv., 1/1956.

43 Jayet A.: Le problème du Fluvio-Glaciaire. Geogr. Helv., 3/1955.

44 Knauer J.: Widerlegung der Einwendungen K. Trolls gegen die Vorrückungsphase der Würmeiszeit. Mitt. Geogr. Ges. München, 1937.

45 Knauer J.: Zur Theorie der “überfahrenen» Würm-Endmoränen. Mitt. Reichsst. f. Bodenforschung, München, 1941.

46 KNauer J.: Gedanken über die Bildung der fluvioglazialen Täler im Alpenvorland und die Ursachen für ihre Zuschüttung. Geol. Bavarica, 1953.

47 Knauer J.: Die Zweiteilung der Würmeiszeit im nördlichen Alpenvorlande. Petermanns Mitt., $4 / 1953$.

48 KNauer J.: Über die zeitliche Einordnung der Moränen "Zürich-Phase» im Reußgletschergebiet. Geogr. Helv., 2/1954.

49 LeEmann A.: Zwei Bauernhöfe in Windlach. Sekundarlehrer-Schlußarbeit, Manuskript; Uni Zürich 1953.

50 Louls H.: Albrecht Penck; der bahnbrechende Eiszeitforscher. Forscher und Wissenschaftler im heutigen Europa. Weltall und Erde. Oldenburg 1955.

51 LƠDI W.: Waldgeschichte und Klimaveränderungen im schweizerischen Mittellande während der jüngeren Postglazialzeit. Vierteljahresschrift der Natf. Ges. in Zürich, LXXX, 1935.

52 Lüdi W.: Lößablagerungen auf den Deckenschottern Nordzürichs? Veröff. Geobot. Inst. Rübel; Zürich 1941.

53 Macar P.: Principes de géomorphologie normale. (Etude des Formes du Terrain des Régions à Climat humide.) Liège 1946.

54 Maснатsснек F.: Diluviale Hebung und eiszeitliche Schneegrenzendepression. Geol. Rundschau, 7/8, 1944.

55 Маснатsснек F.: Geomorphologie. Leipzig 1950.

56 Maull O.: Geomorphologie. Wien 1938.

57 Menschning H.: Die periglaziale Formung der Landschaft des unteren Werratales. Göttinger Geogr. Abh., 14/1953.

58 Meteorologische Zentralanstalt: Ergebnisse der täglichen Niederschlagsmessungen auf den Meteorologischen- und Regenmeß-Stationen in der Schweiz. 1901-1953. 
59 Moser S.: Entwurf zu einer geomorphologischen- Übersichtskarte 1:200 000 für das Gebiet des Mittellandes und des Juras. Geogr. Helv., 2/1955.

60 DU Pasquier L.: Die fluvioglacialen Ablagerungen der Nordschweiz. Beitr. zur Geol. Karte der Schweiz, Lfg. 31, 1891.

61 Penck A.: Die Glacialbildungen um Schaffhausen; 1894 und 1901. Auszug aus der Denkschrift der Schweiz. Natf. Ges. XXXV, 1901.

62 Penck A. \& Brückner E.: Die Alpen im Eiszeitalter. Leipzig 1909.

63 Peyer B.: Kohlfirst. Geol. Exk. in der Umgebung von Zürich; Exk. 22. Geol. Ges. Zürich 1946.

64 Poser H.: Boden- und Klimaverhältnisse in Mitteleuropa während der Würmeiszeit. Erdkunde $1 / 3,1948$.

65 PoSER H.: Zur Rekonstruktion der spätglazialen Luftdruckverhältnisse in Mittel- und Westeuropa auf Grund der vorzeitlichen Dünen. Erdkunde, 1/2, 1950,

66 Pouquet J.: L'érosion. Que sais-je, 491, 1951.

67 SChäFER I.: Die diluviale Erosion und Akkumulation. Forschungen zur Deutschen Landeskunde. Landshut 1950.

68 SCHÄFER I.: Über methodische Fragen der Eiszeitforschung im Alpenvorland. Zeitschr. Deutsche Geol. Ges. 102/II, 1951.

69 Schäfer I. Das Quartär. Erlaße zur Geol. Karte von Bayern, 1953.

70 Schäfer I. \& Graul H.: Zur Gliederung der Würmeiszeit im Illergebiet. Geol. Bavarica, 18/1953.

71 Scheidig A.: Der Löß und seine geotechnischen Eigenschaften. Dresden und Leipzig 1934.

72 Schenk E.: Die Mechanik der periglazialen Strukturböden. Abh. des Hessischen Landesamtes für Bodenforschung, Wiesbaden 1955.

73 Schui.z H.: Der Geschiebedecksand als spätglaziale Wanderschuttdecke im Brandenburgischen Alt- und Jungmoränengebiet. Petermanns Mitt, 1/1956.

74 Steeger A.: Diluviale Frostbodenerscheinungen am Niederrhein. Geol. Rundschau, 1944.

75 Streffen M.: Zur Morphologie des südlichen Randgebietes der Luxemburger Ardennen. Diss. Uni Zürich 1951.

76 STEIN M.: Morphologie des Glattales. Diss. Uni Zürich 1948.

77 STrasser E.: Grundwasserprospektierung der Gemeinde Stadel. Vorbericht 1953, Schlußbericht 1954. Gemeindearchiv Windlach.

78 SUTER H.: Geologie von Zürich einschließlich seines Exkuısionsgebietes. Zürich 1939.

79 Suter H.: Glazialgeologische Studien im Gebiet zwischen Limmat, Glatt und Rhein. Ecl. Geol. Helv. XXXVII/1, 1944.

80 Suter H.: Lägern. Geol. Exk. in der Umgebung von Zürich; Exk. 19. Geol. Ges. Zürich 1946.

81 SuTER H.: Wehntal-Kaiserstuhl. Geol. Exk. in der Umgebung von Zürich; Exk. 20. Geol. Ges. Zürich 1946.

82 Thornbury W.D.: Principles of Geomorphology. New York und London 1954.

83 Troll C: Diluvialgeologie und Klima. Geol. Rundschau, 1944.

84 Troll C.: Strukturböden, Solifluktion und Frostklimate der Erde Geol. Rundschau, 1944.

85 Troll C.: Der subnivale Bereich oder periglaziale Zyklus der Denudation. Erdkunde 1/3, 1948.

86 WaGNER G : Einführung in die Erd- und Landschaftsgeschichte. Öhringen 1931.

87 Weber A.: Glazialgeologie des Tößtales und ihre Beziehung zur Diluvialgeschichte der Nordschweiz. Diss. ETH Zürich 1928.

88 Weber A.: Zur Glazialgeologie des Glattales. Ecl. Geol. Helv. XXVII/1, 1934.

89 Weber A.: Seebach - Glattbrugg - Kloten - Bülach - Eglisau - Rüdlingen - Irchel Winterthur. Geol. Exk. in der Umgebung von Zürich; Exk. 21. Geol. Ges. Zürich 1946.

90 WEIACH: Protokolle des Gemeinderates Weiach, 1803-1807, 1816-1850, 1889-1894, 18961904, 1907-1955. Gemeinderatskanzlei Weiach.

91 Weiach: Protokolle der Gemeindeversammlungen Weiach. 1803-1833, 1850-4.2. 1956. Gemeinderatskanzlei Weiach.

92 WeiaCh: Wirtschaftspläne über die Gemeindewaldung Weiach. 1880: W. Fierz; 1900: A. von Orelli: 1926: F. Heer, 1936: F. Heer; 1948/49: W. Fischer, E. Wegmann.

93 Weidenbach F.: Gedanken zur Lößfrage. Eiszeitalter und Gegenwart, 1952.

94 Weinberger L.: Frostspalten und Froststrukturen in Schottern bei Leipzig. Geol. Rundschau, 1944.

95 Wiegner \& Pallmann: Anleitung zum quantitativen agrikulturchemischen Praktikum. Berlin, 1938.

96 von Wissmann H.: Über seitliche Erosion. Colloquium Geographicum, Bd. I; Geogr. Inst. der Universität Bonn 1951.

97 Woldstedt P.: Das Eiszeitalter. Grundlinien einer Geologie des Quartärs, Bd. 1. Stuttgart 1954.

98 ZiNk F.: Zur diluvialen Geschichte des Hochrheins und zur Altersstellung der paläolithischen Station «Murg». Mitt. Reichsstelle für Bodenforschung, Freiburg i. Br. 1940.

99 Zeitungen : "Bülach-Regensberger Wochen-Zeitung»; später unter dem Namen « Bülach-Dielsdorfer Wochen-Zeitung" erscheinend.

100 Zeitungen: "Der Wehnthaler»; heute unter dem Namen "Der Zürichbieter» herausgegeben. 


\section{KARTEN UND PLÄNE}

a) Topographische Karten:

101 Gyger-Karte: Blatt Kaiserstuhl; 1667.

102 Landeskarte der Schweiz, 1:25 000: 1031 Neunkirch, 1032 Dießenhofen, 1050 Zurzach, 1051 Eglisau, 1071 Bülach.

103 Topographischer Atlas der Schweiz: 12 Merishausen, 14 Hemmenthal, 15 Neunkirch, 16 Schaffhausen, 21 Koblenz, 21 bis Lauchringen, 23 Zurzach, 24 Hüntwangen, 25 Rheinau, 26 Kaiserstuhl, 27 Eglisau, 40 Steinmaur, 41 Bülach, 44 Opfertshofen, 45 Thayngen, 46 Ramsen, 47 Dießenhofen, 48 Stein am Rhein, 52 Andelfingen, 53 Stammheim, 54 Hettlingen.

104 WILD-KarTE: Blatt IX, Weiach.

b) Pläne:

105 Messtischblätter: Eglisau, 1:5000, Weiach, 1:5000.

106 Übersichtspläne: Eglisau, 1:10 000, Rafz, 1:5000, Wil, 1:5000.

c) Geologische Karten:

107 von Braun E.: Geologische Karte des Klettgaues und der nördlichen Teile der Kantone Aargau und Zürich, 1:50 000. Ecl. Geol. Helv., 2/46, 1953.

108 Bugmann E.: Geol. Karte des untersten Aaretales, 1:25 000. Diplomarbeit, 1954, Uni Zürich.

109 Göhringer A.: Lienheim, 1:25 000. Geol. Spez. Karte des Großherzogtums Baden, 169, 1915.

110 Hug J.: Andelfingen, 1:25 000. Beitr. zur Geol. der Schweiz, 34, 1905.

111 Hug J.: Rheinfall, 1:25 000. Beitr. zur Geol. der Schweiz, 35, 1905.

112 Hug J.: Kaiserstuhl, 1:25 000. Beitr. zur Geol. der Schweiı, 36, 1905.

113 Schalch F. \& Göhringer A.: Jestetten — Schaffhausen, 1:25 000. Geol. Spez. Karte, $158,1921$.

114 Stein M.: Geologische Karte des Glattales. Diss. Uni Zürich 1948.

115 Suter H.: Geologische Karte des Kantons Zürich und der Nachbargebiete, 1:150 000. Beilage zur Geol. von Zürich und Exkursionsgebiet, 1939.

116 Suter H.: Glaziale Schotter zwischen Limmat, Glatt und Rhein, 1:75 000. Glazialgeol. Stud. zw. dem unt. Glattal, dem Wehntal und dem Rhein. Ecl. Geol. Helv. 1/37, 1944.

117 Suter H.: Geol. Übersichtskarte des Gebietes zw. dem unt. Glattal, dem Wehntal und dem Rhein. Geol. Exk. in der Umgeb. von Zürich, 1946.

118 Weber A.: Geologische Karte des unt. Tößtales und des unt. Glattales zw. Dättlikon, Bülach und Eglisau, 1:25 000. Diss. ETH Zürich 1928.

\section{REVISION OF THE WÜRM TERRACES IN THE RHINE VALLEY BETWEEN DIESSENHOFEN AND KOBLENZ}

Certain problems of the Würm deposits in the Rhine Valley on the Swiss-German border are treated in this study with special reference to the development of terraces. In contrast to the earlier extensive investigations, my work consisted of detailed research in a limited field from which I worked outwards (as far as Dießenhofen - Koblenz); at the same time comparison is made with earlier studies.

Based on the conditions of the Rafzerfeld we can distinguish four phases of Würm terrace development :

Phase 1: Building of the accumulation plain, completed in the Hochwürm.

Phase 2: Commencement of erosion by the wide swings of the river; beginning in the late Hochwürm and finishing in the early Spätwürm.

Phase 3: Intensive down-cutting by the river in the Spätwürm.

Phase 4: Moderated incision during postglacial times.

The transition from $1-2$ is based on retention basins in the upper course; the cause is above and the effect below. The transition from $2-3$ is due to the river sliding from the limestone to old gravel-filled gorges (cause below, effect above).

The results of my research show that a correlation of terraces from Dießenhofen to Koblenz is impossible. The differentiation between lateral erosion and incision is not only based on climatic factors, but local base-levels of erosion may cause lateral erosion in the Spätwürm, too.

The region of my study is divided into four individual parts:

I Rheinfall $\longrightarrow$ Bodensee: Controlled by the Malm escarpment of the Rheinfall.

II Terminal morains of the Rafzerfeld $\longrightarrow$ Rheinfall: Development of terraces influenced by the movement of the ice-front.

III Kaiserstuhl $\longrightarrow$ terminal morains of the Rafzerfeld: Discontinuous erosion by the Rhine due to petrographic differences at Hohenthengen - Kaiserstuhl.

IV Koblenzer Laufen $\longrightarrow$ Lienheim: Continuous gradual downcutting, since the river flows over the Muschelkalk at the Koblenzer Laufen. 